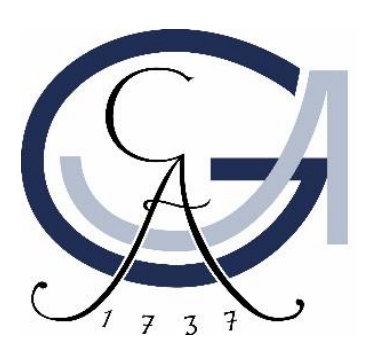

\title{
Transport of Tail-anchored Proteins
}

\section{to the Inner Nuclear Membrane}

\author{
Dissertation for the award of the degree \\ "Doctor rerum naturalium" \\ of the Georg-August-Universität, Göttingen
}

within the doctoral program "Molecular Biology of Cells" of the Georg-August University School of Science (GAUSS)

\author{
submitted by \\ Janine Pfaff \\ from Bad Hersfeld
}

Göttingen, 2016 
Thesis Committee/ Examination Board:

Prof. Dr. Ralph H. Kehlenbach ( $1^{\text {st }}$ referee)

Department of Molecular Biology

Faculty of Medicine

Georg-August-University, Göttingen

Prof. Dr. Blanche Schwappach-Pignataro (2 ${ }^{\text {nd }}$ referee)

Department for Molecular Biology

Faculty of Medicine

Georg-August-University, Göttingen

Max-Planck-Institute for Biophysical Chemistry, Göttingen

Prof. Dr. Mikael Simons

Department of Neurology

Max-Planck-Institute for Experimental Medicine, Göttingen

Institute of Neuronal Cell Biology

TU Munich and German Center for Neurodegenerative Diseases Munich

Further Members of the Examination Board:

Prof. Dr. Hans Dieter Schmitt

Department of Neurobiology

Max-Planck-Institute for Biophysical Chemistry, Göttingen

Dr. Nuno Raimundo

Department of Cellular Biochemistry

Faculty of Medicine

Georg-August-University, Göttingen

Prof. Dr. Michael Thumm

Department of Cellular Biochemistry

Faculty of Medicine

Georg-August-University, Göttingen

Date of the oral examination: November 9th, 2016 


\section{Statutory declaration}

I hereby declare that I have written this PhD thesis independently with no other sources and aids than clearly stated.

This thesis was not submitted in the same or in a substantially similar version to any other authority to achieve an academic grading and was not published elsewhere.

Janine Pfaff 


\section{Contents}

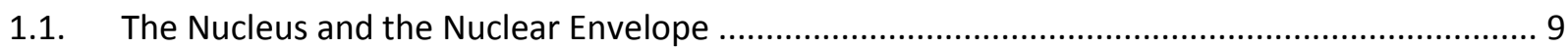

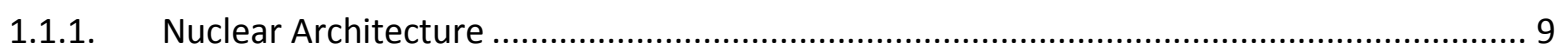

1.1.2. Nuclear pore complexes and their role in nucleocytoplasmic transport ........................... 10

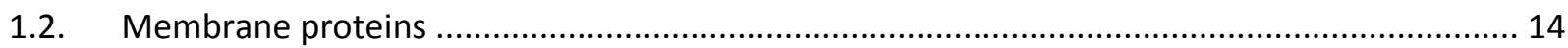

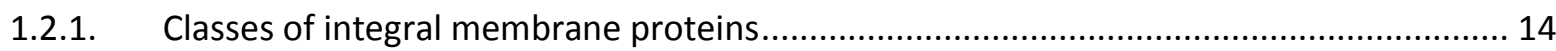

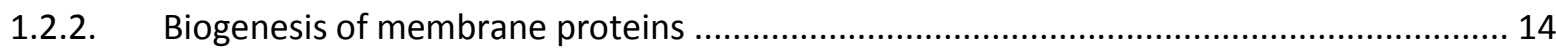

1.2.2.1. Co-translational membrane protein insertion at the ER ......................................... 14

1.2.2.2. Post-translational membrane insertion in mammals.............................................. 15

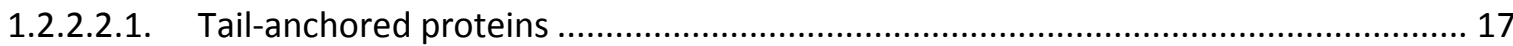

1.2.3. Proteins of the inner nuclear membrane ................................................................... 18

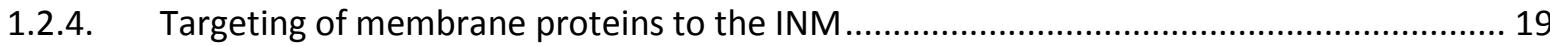

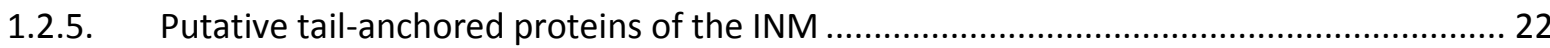

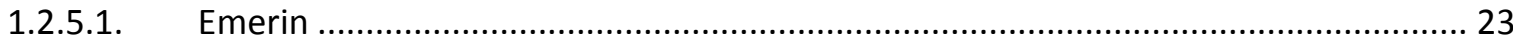

1.2.5.2. LAP2

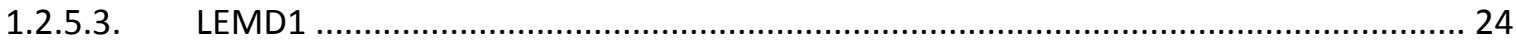

1.2.5.4. PTP1B

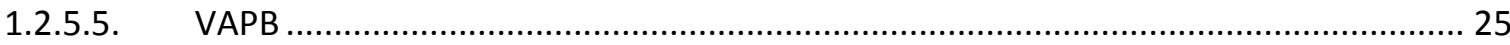

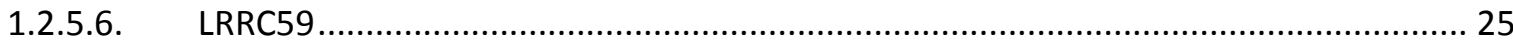

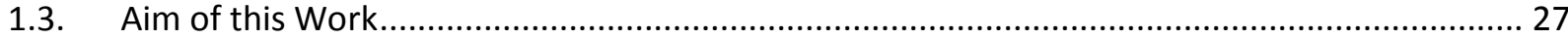

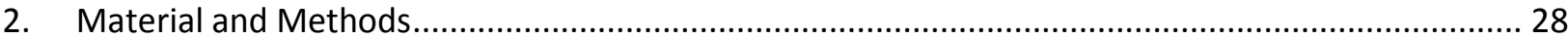

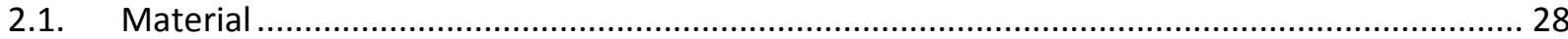

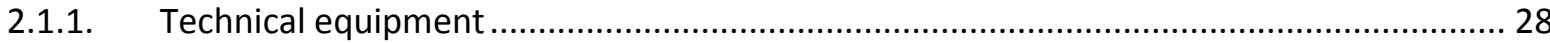

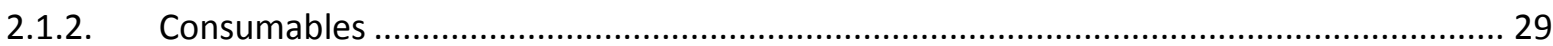

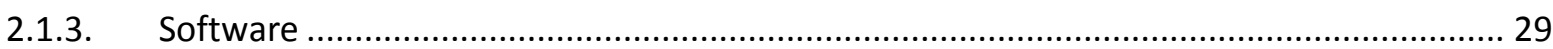

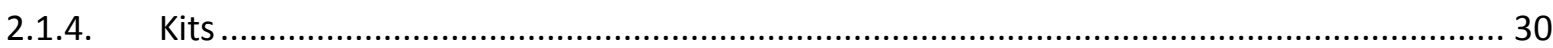

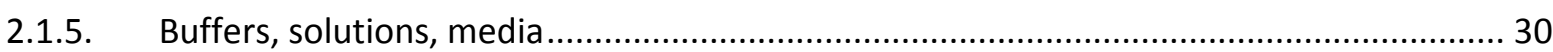

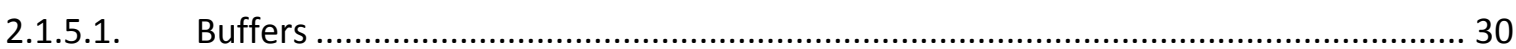

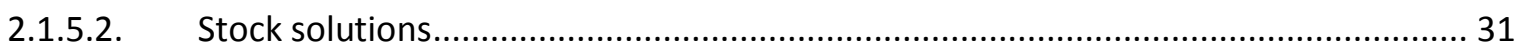

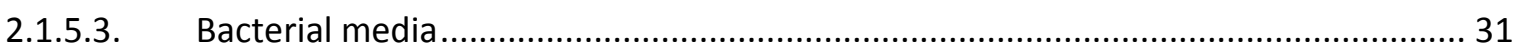

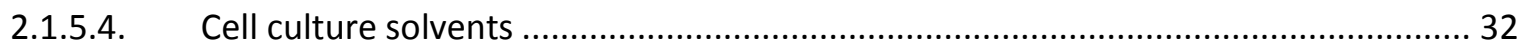

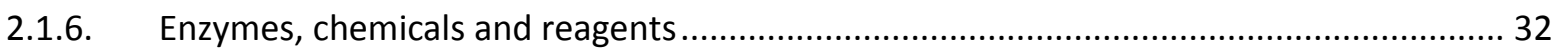

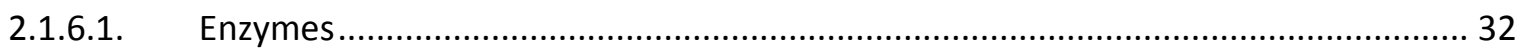

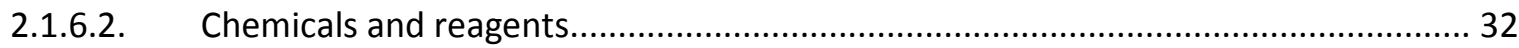

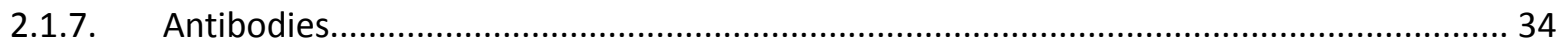

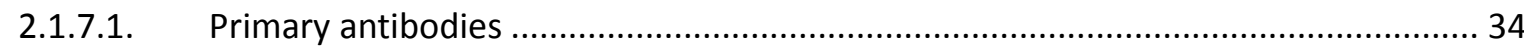




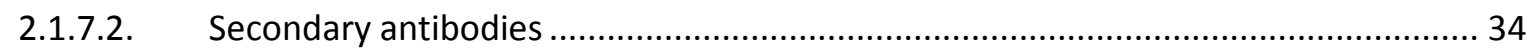

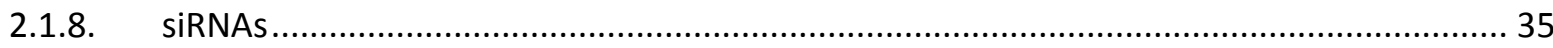

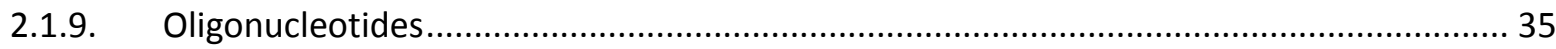

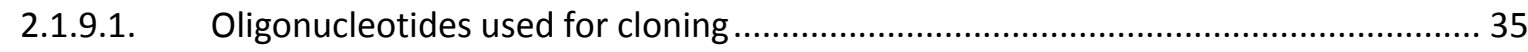

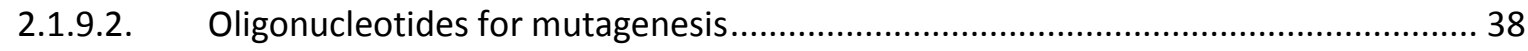

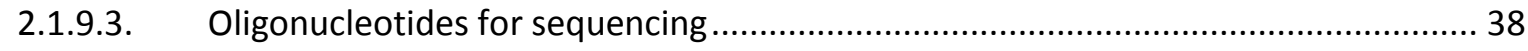

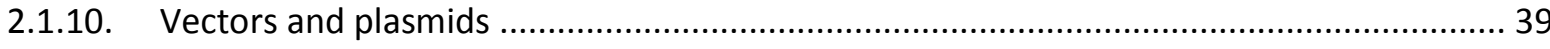

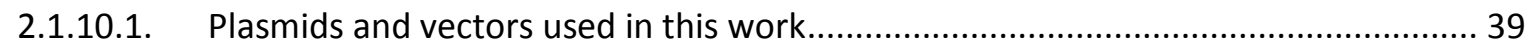

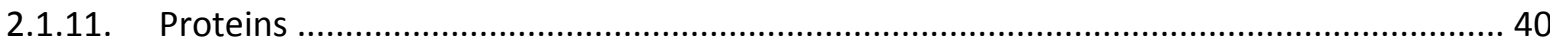

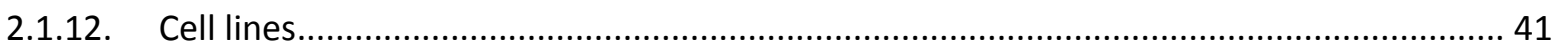

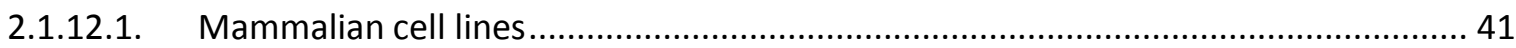

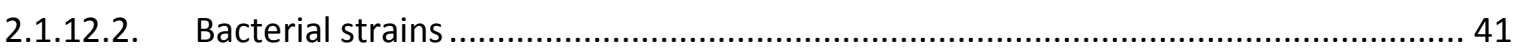

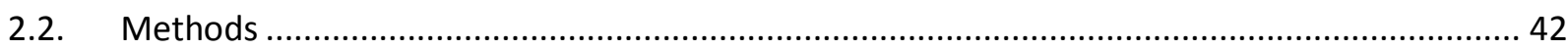

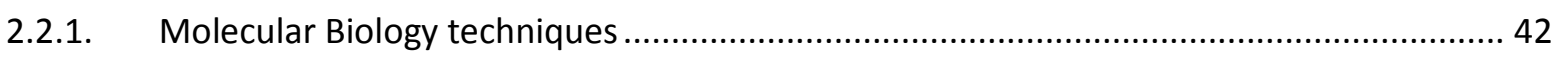

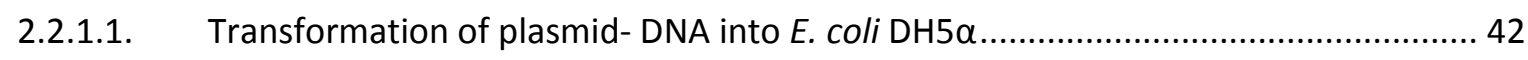

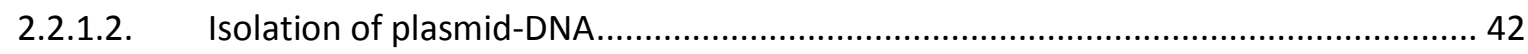

2.2.1.3. Polymerase chain reaction ..................................................................... 42

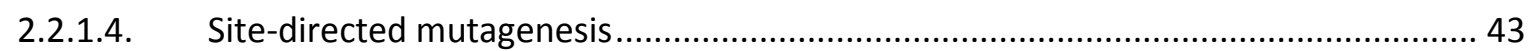

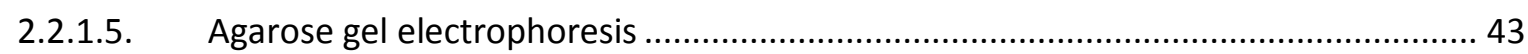

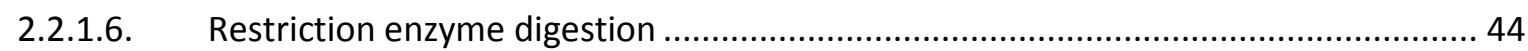

2.2.1.7. Dephosphorylation of vectors ............................................................... 44

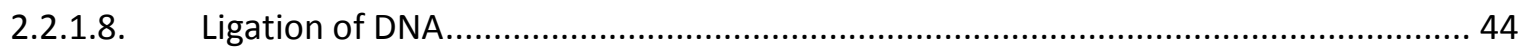

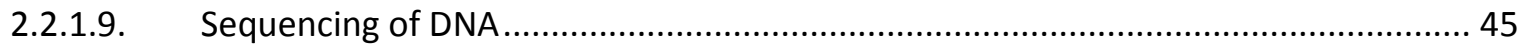

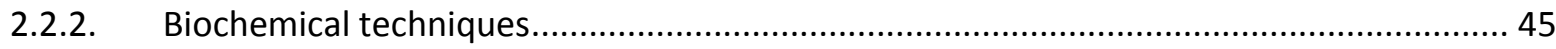

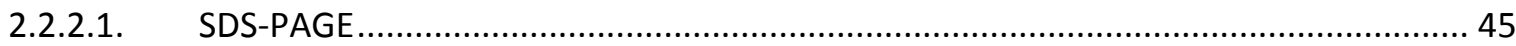

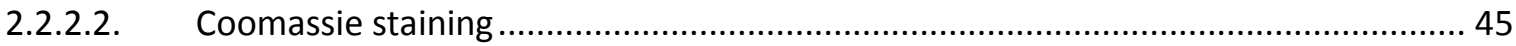

2.2.2.3. Western Blotting and detection of proteins ................................................ 45

2.2.2.4. Expression and purification of tail-anchored proteins ........................................ 46

2.2.2.5. In vitro transcription and translation system ............................................... 47

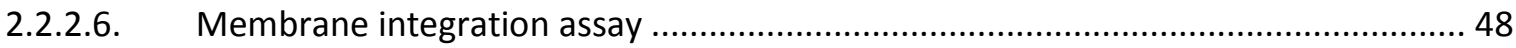

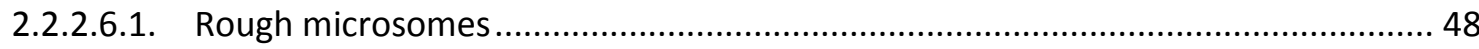

2.2.2.6.2. Semi-permeabilized cells.................................................................... 49

2.2.2.6.2.1. Fractionation of cellular membranes by using a carbonate buffer................ 50

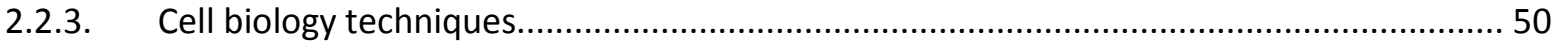

2.2.3.1. Cultivation of adherent cells ...................................................................... 50

2.2.3.2. Coating coverslips with Poly-L-lysine ...................................................... 50

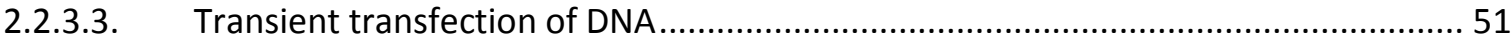




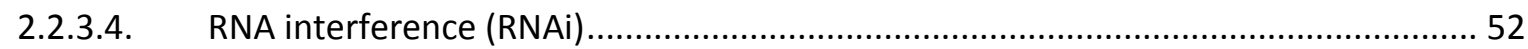

2.2.3.4.1. Transfection of siRNAs with calcium phosphate method .................................... 52

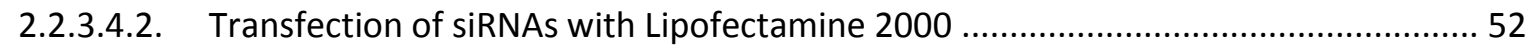

2.2.3.5. Indirect Immunofluorescence for protein detection ..................................... 52

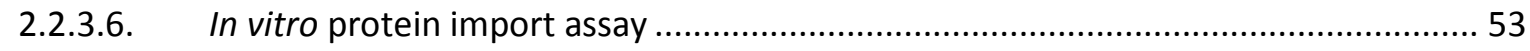

2.2.3.7. Development of a stable cell line expressing the FKBP12-reporter protein ............. 53

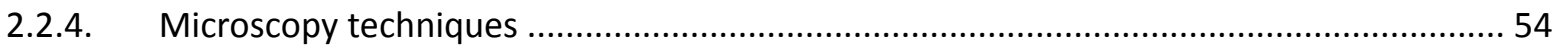

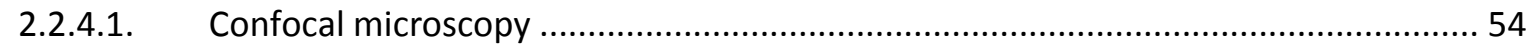

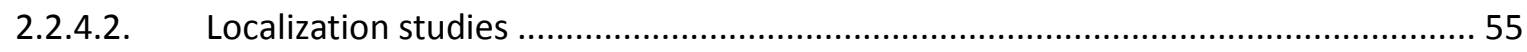

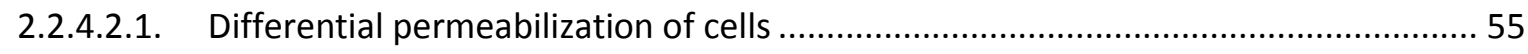

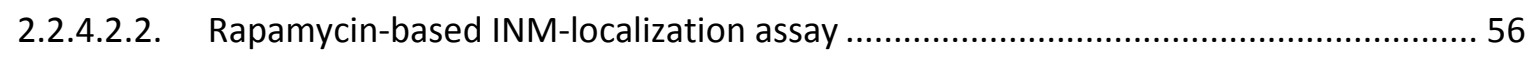

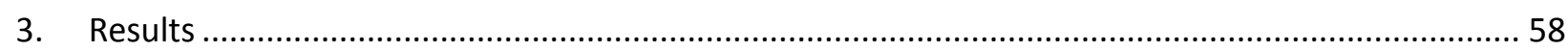

3.1. Post-translational membrane insertion of putative tail-anchored proteins............................58

3.1.1. Verification of the membrane localization of putative INM-proteins.............................59

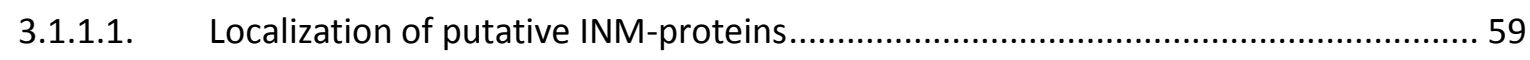

3.1.2. Membrane insertion mechanisms of putative INM-proteins ........................................62 62

3.1.2.1. In vitro translated putative TA-INM-proteins integrated into rough microsomal

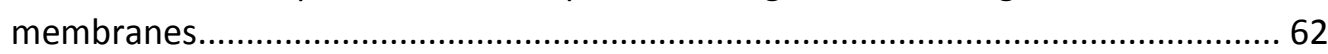

3.1.2.2. Characterization of membrane insertion of emerin utilizing the TRC40-pathway for membrane insertion at the ER as a tail-anchored protein....

3.1.2.2.1. Membrane integration of bacterially expressed and purified emerin into RM and semi-permeabilized cells 66

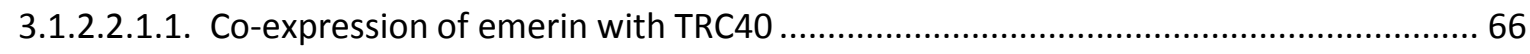

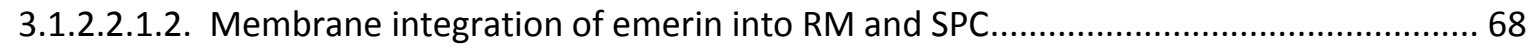

3.1.2.3. Membrane insertion of in vitro translated HZZ-emerin-op is affected by TRC40-

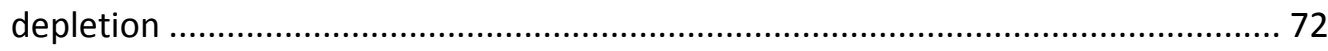

3.1.3. Investigation of INM-protein transport using an in vitro import assay......................... 72

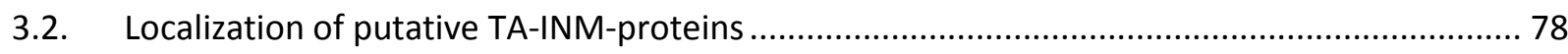

3.2.1. Differential permeabilization approaches revealed emerin, LAP $2 \beta$ and LRRC59 to localize at the INM in contrast to the ER-membrane receptor WRB.

3.2.2. Discrimination between ONM and INM localization using a rapamycin-based localization assay......

3.2.2.1. Establishing a rapamycin-based INM-targeting assay.......................................... 81

3.2.2.2. Analysis of INM-localization of emerin, LAP2, PTP1B, LRRC59, VAPB and LEMD1 using

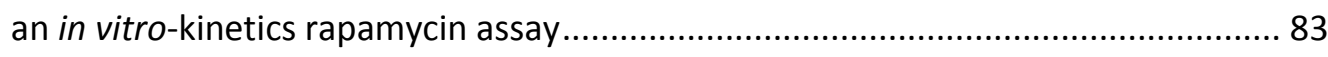

3.2.2.2.1. Confirmation of INM localization of emerin using the in vitro rapamycin assay ....... 87

3.2.2.2.1. Alternative FKBP12 reporters can be used to determine the localization of a protein

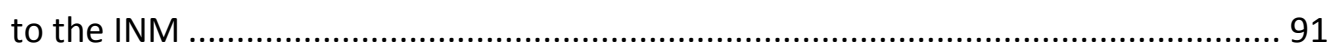

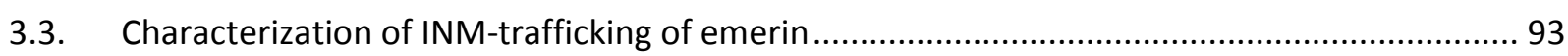


3.3.1. Depletion of TRC40 and WRB reduces the levels of emerin at the NE .........................93

3.3.2. Emerin interacts with TRC40 in an in situ approach ............................................ 96

3.3.3. Investigation of effect of changes in the C-terminal portion of emerin on targeting to the

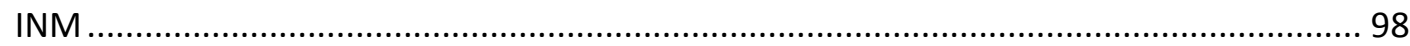

3.3.3.1. Characteristics of the selected emerin mutant variants ...................................... 98

3.3.3.2. TRC40-dependent membrane insertion of emerin mutants............................... 100

3.3.3.2.1. Purification of emerin mutants in a complex with TRC40................................. 100

3.3.3.2.2. Membrane integration of emerin mutants in RM............................................ 100

3.3.3.3. Targeting of emerin mutants to the NE ................................................... 102

3.3.3.3.1. Morphology and localization of emerin mutants within cells............................ 102

3.3.3.3.2. Mutations of emerin affect targeting to the INM ........................................ 104

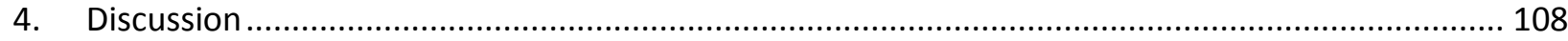

4.1. Membrane insertion mechanisms of putative INM-proteins.......................................... 108

4.2. Verification of localization of proteins to the inner nuclear membrane protein using a

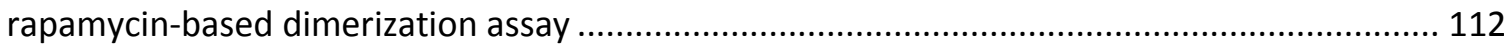

4.2.1. Applications of a newly developed rapamycin-induced dimerization assay ................. 112

4.2.2. Localization of emerin, LAP2 $\beta$, VAPB, PTP1B, LEMD1 and LRRC59 at the INM ............. 113

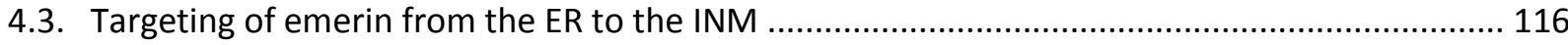

4.4. Disease-related emerin mutants exhibit decreased targeting efficiency to the inner nuclear membrane

4.5. Outlook

REFERENCES

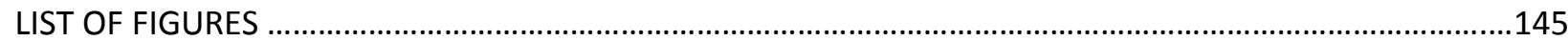

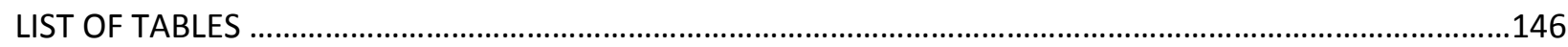

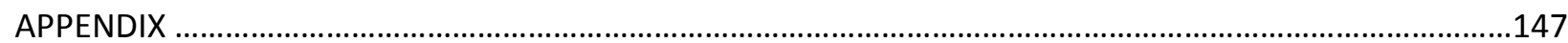




\section{Abstract}

In contrast to the well-studied process of nucleocytoplasmic transport of soluble macromolecules, little is known about the targeting of integral membrane proteins to the inner nuclear membrane (INM), therefore the targeting of INM-proteins was studied in this work.

Two major models haven been proposed for INM-protein transport, the diffusion-retention model, which assumes passive diffusion of proteins from the ER membrane, across the nuclear pore complex (NPC) to the INM and the transport factor-mediated model, where membrane proteins are believed to translocate across the NPC into the nucleus upon binding to nuclear import receptors.

In this work, the targeting of proteins to the INM was studied for several tail-anchored (TA)proteins, which contain only a single C-terminal transmembrane domain (TMD). As a model protein, the well-established INM-protein emerin was used. With the help of membrane insertion assays, we showed that emerin, expressed in bacteria or a cell-free lysate, can be posttranslationally integrated into ER membranes by the TRC40-pathway.

The involvement of the TRC40-system was shown by use of inhibitory fragments of the ERmembrane receptors $W R B$ and CAML in the membrane insertion reaction. An interaction between emerin and TRC40 could further be confirmed by proximity ligation assays. Additionally, TRC40 knockdown experiments demonstrated a reduction of emerin localized at the nuclear envelope.

An important objective of this work was to verify correct targeting of emerin and other integral membrane proteins to the INM.

To accomplish this, we performed differential permeabilization experiments, and established a rapamycin-based dimerization assay. These experiments allowed us to confirm the localization of emerin at the INM in a microscopy based approach.

In addition to wild type emerin, we also analyzed mutants. Mutations in the emerin gene in the TMD or in the C-terminal part lead to the neuromuscular disease Emery-Dreifuss muscular dystrophy. As the TMD of emerin is crucial for anchoring of emerin in a membrane, several Cterminal emerin mutations were selected and studied for their post-translational membrane insertion and localization at the INM. Several of these mutants showed severely disturbed TRC40binding, membrane integration and INM-targeting.

The efficiency of targeting to the INM might therefore rely on properties within the TMD or at least the C-terminal region of emerin. The disease could therefore be a consequence of an impaired transport process or a reduced retention at the INM.

Apart from emerin, other putative tail-anchored INM-proteins like LAP2 $\beta$, LEMD1, PTP1B, VAPB and LRRC59 were confirmed to localize to the INM using the rapamycin assay. Furthermore, some of them were shown to use a post-translational membrane insertion mechanism at the ER. 


\subsection{The Nucleus and the Nuclear Envelope}

\subsubsection{Nuclear Architecture}

The nucleus contains most of the genetic information of a cell and is one of the most important organelles in eukaryotic cells. It is enclosed by a double phospholipid bilayer. The nuclear interior is defined as nucleoplasm. Inside the nucleoplasm, a specialized substructure for ribosome biogenesis, the nucleolus, is located (Cooper, 2000).

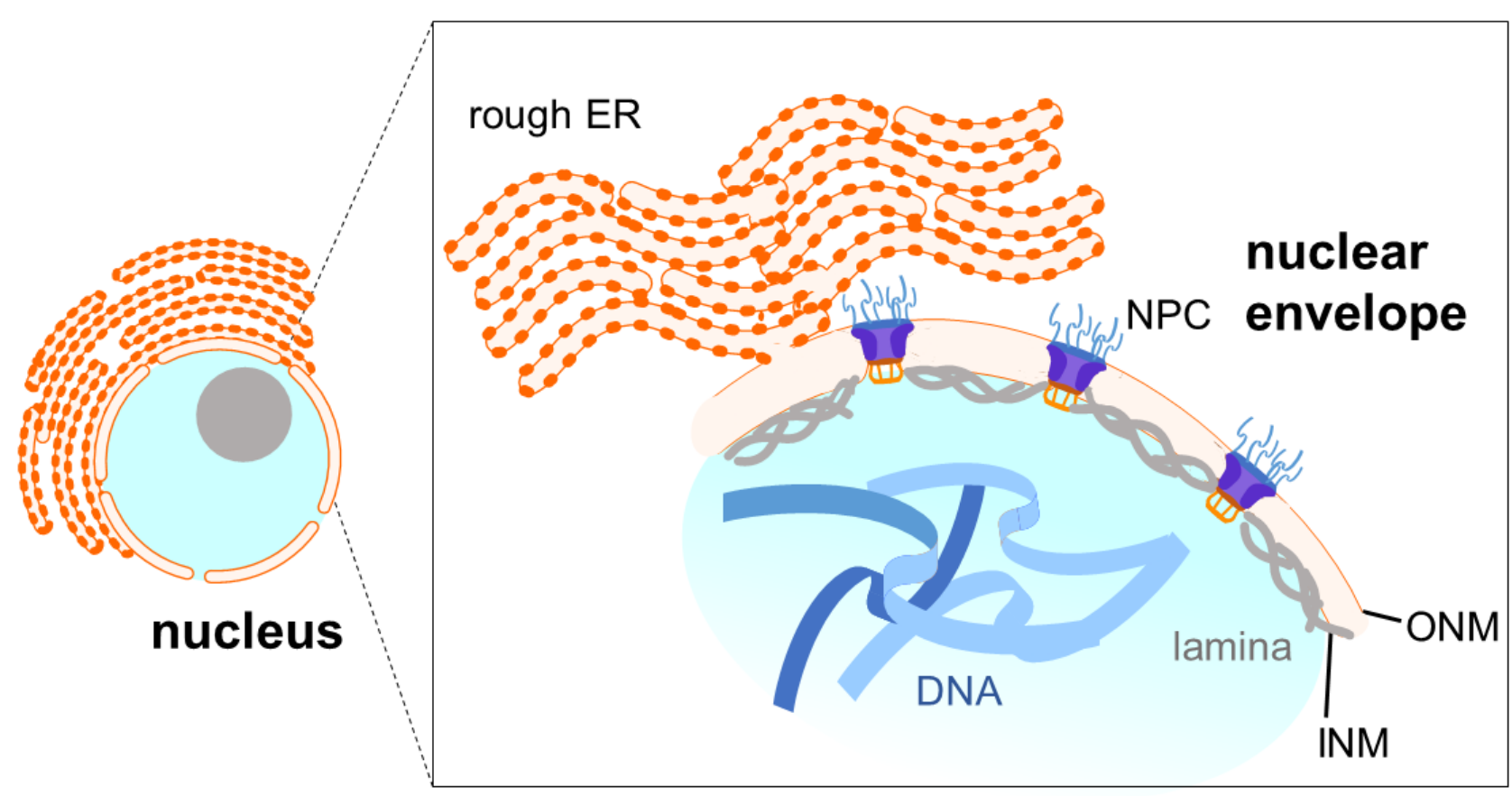

Figure 1: The nucleus and the nuclear envelope composition. The nucleus of a cell is surrounded by a double membrane system (inner and outer nuclear membrane (INM, ONM)), in which the nuclear pore complexes (NPCs) are embedded. This entity is referred to as the nuclear envelope (NE) (box, zoom in). The endoplasmic reticulum (ER) itself is shown to be continuously connected with the ONM. From the inside, the nucleus is wrapped by the nuclear lamina meshwork (grey), which interacts with proteins of the INM and chromatin (shown as DNA).

In contrast to prokaryotic cells, which do not possess a nuclear compartment, in eukaryotic cells, the nucleus as an entity provides spatially segregation and protection of the genetic material from influences in the cytoplasm. Furthermore, this segregation enables a highly regulated gene expression, transport of molecules e.g. transcripts or proteins and controlled signal transduction (Cho et al., 2016).

The nuclear envelope (NE) (Figure 1) comprises the following structural components. The outer nuclear membrane (ONM), the inner nuclear membrane (INM) and many nuclear pore complexes (NPCs), which are embedded in these membranes. Depending on the cell type, about 2000 NPCs can be found in vertebrate cells (Beck et al., 2011; Maul and Deaven, 1977). These huge, 125 MDa (Reichelt et al., 1990) multimeric protein complexes are spanning both membranes and present a natural barrier for molecule diffusion and protein trafficking.

In between the ONM and INM, a 30 to $50 \mathrm{~nm}$ region is referred to as perinuclear space (PNS) (Zwerger et al., 2010). 
Underlying the INM, the nuclear lamina (NL) faces the nucleoplasmic side. The filamentous lamina network is intertwining with the proteins of the INM and provides structural robustness to the nucleus against mechanical forces. This meshwork consists of two major components, the A- and B-type lamins, which are members of the intermediate filament family (Gerace and Burke, 1988; Gerace et al., 1978). Additionally, roles of the lamina in organization and anchoring of chromatin and an influence on the cytoskeleton via the LINC complex have been reported (Crisp et al., 2006; Haque et al., 2006; Burke and Stewart, 2013).

The ONM is continuously connected with the membrane of the endoplasmic reticulum (ER). Therefore, the ONM-protein composition is similar to that of the ER and can be studded with ribosomes. On the contrary, the INM is decorated by unique membrane proteins (Dreger et al., 2001; Schirmer et al., 2003; Schirmer and Gerace, 2005; Senior and Gerace, 1988). Linkage points of the outer and inner nuclear membrane are represented by regions, where NPCs span the membranes.

\subsubsection{Nuclear pore complexes and their role in nucleocytoplasmic transport}

Transport and exchange of molecules between the cytoplasm to the nucleus is restricted by the nuclear envelope. The NE is perforated by a huge number of nuclear pore complexes. These macromolecular complexes are comprised of about thirty distinct proteins termed nucleoporins (Nups), occurring in multiple copies per NPC (Cronshaw et al., 2002).

NPCs function as a selective barrier in terms of nucleocytoplasmic trafficking of soluble cargo molecules like proteins, RNA and ribonucleoprotein (RNP) particles (Johnson et al., 2002; Köhler and Hurt, 2007; Daneholt, 2001). Due to the association of NPCs with chromatin, they are further reported to serve as platforms for gene expression regulation (Ptak et al., 2014). With regard to transport of different kinds of cargo (e.g. histones, RNA) through the NPCs, nuclear transport was characterized to be a bidirectional process (Feldherr et al., 1984).

Vertebrate NPCs are arranged in an eight-fold-symmetrical ring (Hinshaw et al., 1992; Akey and Radermacher, 1993). In general, the composition of the NPC is based on the discrimination of three different "layers" of Nups (Figure 2), whose main components are conserved in eukaryotes (Neumann et al., 2010). Between a thin "nucleoplasmic ring" and a "cytoplasmic ring", the channel forming "spoke ring" is located (Alber et al., 2007).

Nucleocytoplasmic transport through the NPCs can happen in a diffusion-driven or active manner. The size of the cargo was described to be a limiting factor for nuclear transport. Molecules smaller than 40 kDa were reported to diffuse through the NPC (Paine et al., 1975), but larger molecules instead, like proteins or RNAs need to be transported actively (Kutay et al., 1998). With respect to the size of cargoes transported through the NPC, it was found that molecules with a $39 \mathrm{~nm}$ diameter can be transported through NPCs in vertebrate cells (Pante and Kann, 2002). The inside of the central channel is lined with nucleoporins (Nups) and is characterized by intrinsically disordered phenylalanine-glycine repeats, which contribute to the selectivity barrier of the NPC (Kabachinski and Schwartz, 2015). 


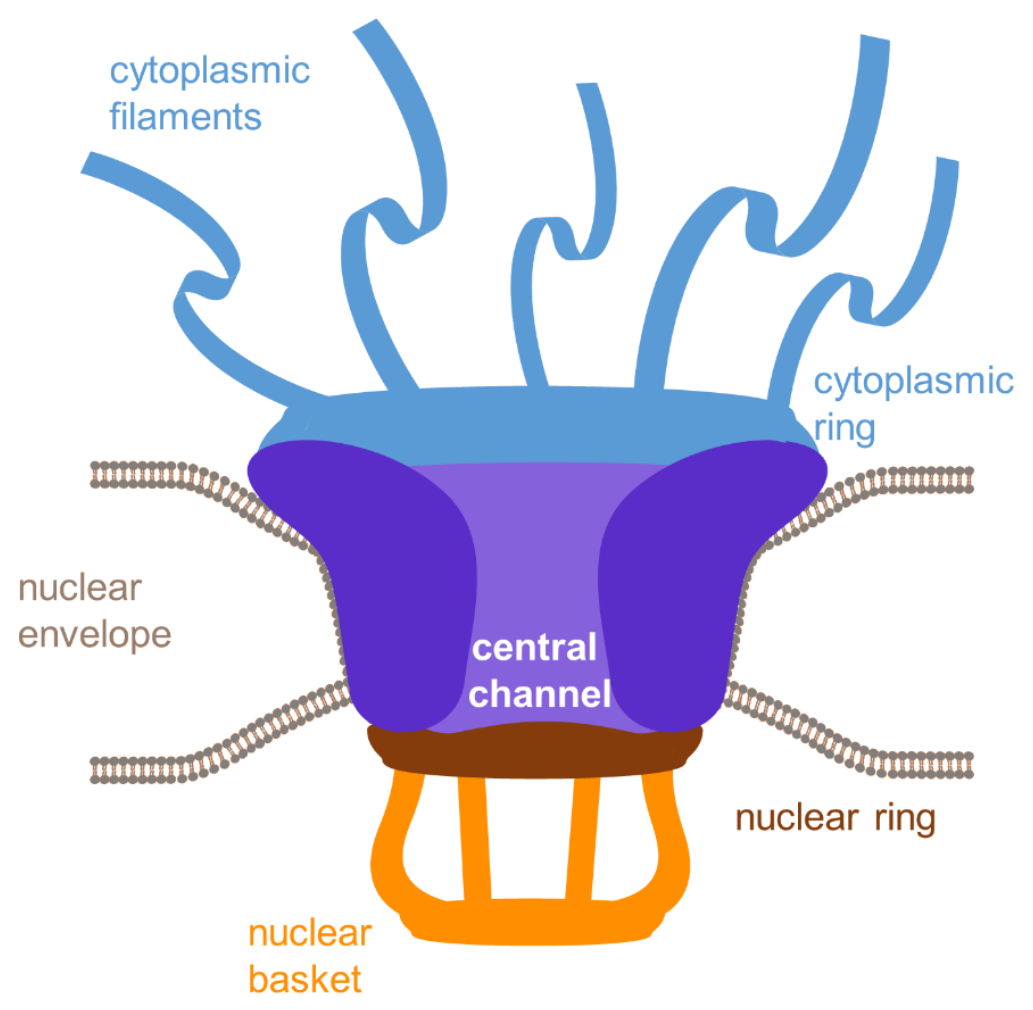

Figure 2: Schematic view on the nuclear pore complex architecture. A scheme of the different units of the NPC as a vertical section within the nuclear envelope (grey) is shown. The nucleoporins of the "cytoplasmic ring" and filaments are shown in light blue, the Nups of the "spoke ring" forming a central transport channel in dark blue and purple (central channel). Nucleoporins of the "nuclear ring" and the nuclear basket facing the interior are depicted in brown and orange.

For classical nucleocytoplasmic-transport in addition to NPCs, soluble nuclear transport receptors (NTRs) are essential (Pemberton and Paschal, 2005). The major transport processes are performed by NTRs belonging to the karyopherin $\beta$ superfamily, like importin $\beta 1$ (Görlich et al., 1995; Radu et al., 1995; Chi et al., 1995; Imamoto et al., 1995) or transportin 1 (Pollard et al., 1996). These transport receptors are divided in those performing only import (importins) and export (exportins). Only few NTRs were shown to be involved in bidirectional transport as for example importin 13 (Mingot et al., 2001). Whether a cargo is an import or export substrate is determined by a nuclear targeting sequence. There are two types of classical nuclear localization signal (NLS) bound by importin $\alpha / \beta$. They can be divided into mono- and bipartite NLSs (Lange et al., 2007). The first consists of a single cluster of basic amino acids (lysine/arginine) and the latter of two clusters separated by a linker of 10-12 amino acids (aa). In addition to NLSs recognized by the importin $\beta$ transport receptors, other non-classical nuclear localization sequences like the 38 aa signal, termed M9, exist and can be recognized by transportin (Pollard et al., 1996).

Besides the possibility of diffusion for molecules below the exclusion size of the NPC, for instance even small molecules like histones were shown to be actively imported by different transport receptors like importin $\beta /$ importin 7 via the recognition of an NLS with comparatively few basic amino acids (Baake et al., 2001; Muhlhausser et al., 2001; Bauerle et al., 2002).

Export of proteins from the nuclear compartment to the cytoplasm relies on the recognition of a leucine-rich nuclear export signal (NES), which contains four to five hydrophobic residues within a stretch of 10 aa (La Cour et al., 2003), of the cargo by an exportin such as CRM1 (Fornerod et 
al., 1997). In both nuclear import and export, the transport receptor-cargo complex interacts with the FG-repeats of the Nups in the center of the NPC. As mentioned above, for molecules larger than 40-50 kDa an active transport through the NPC is required. The NTRs bind cargo, interact with NPCs and circulate between both compartments. For import as well as export, the Ran-GTP cycle (Melchior et al., 1993) plays an important role. The small GTPase Ran (25 kDa) can cycle between a GDP- and a GTP-bound form (Görlich et al., 1996). A Ran-GTP gradient across the nuclear envelope exists and controls the binding and release of cargo in the respective compartment. In the cytoplasm, the Ran-GTPase activating protein (RanGAP) and inside the nucleus the protein Ran guanine nucleotide exchange factor (RanGEF), as well as nuclear transport factor 2 (NTF2) are responsible for establishing a Ran-GTP gradient. In this, the cytoplasm displays lower cytoplasmic and higher nuclear concentrations of Ran-GTP and can be recognized by the Ran-GTP-binding domains of the NTRs.

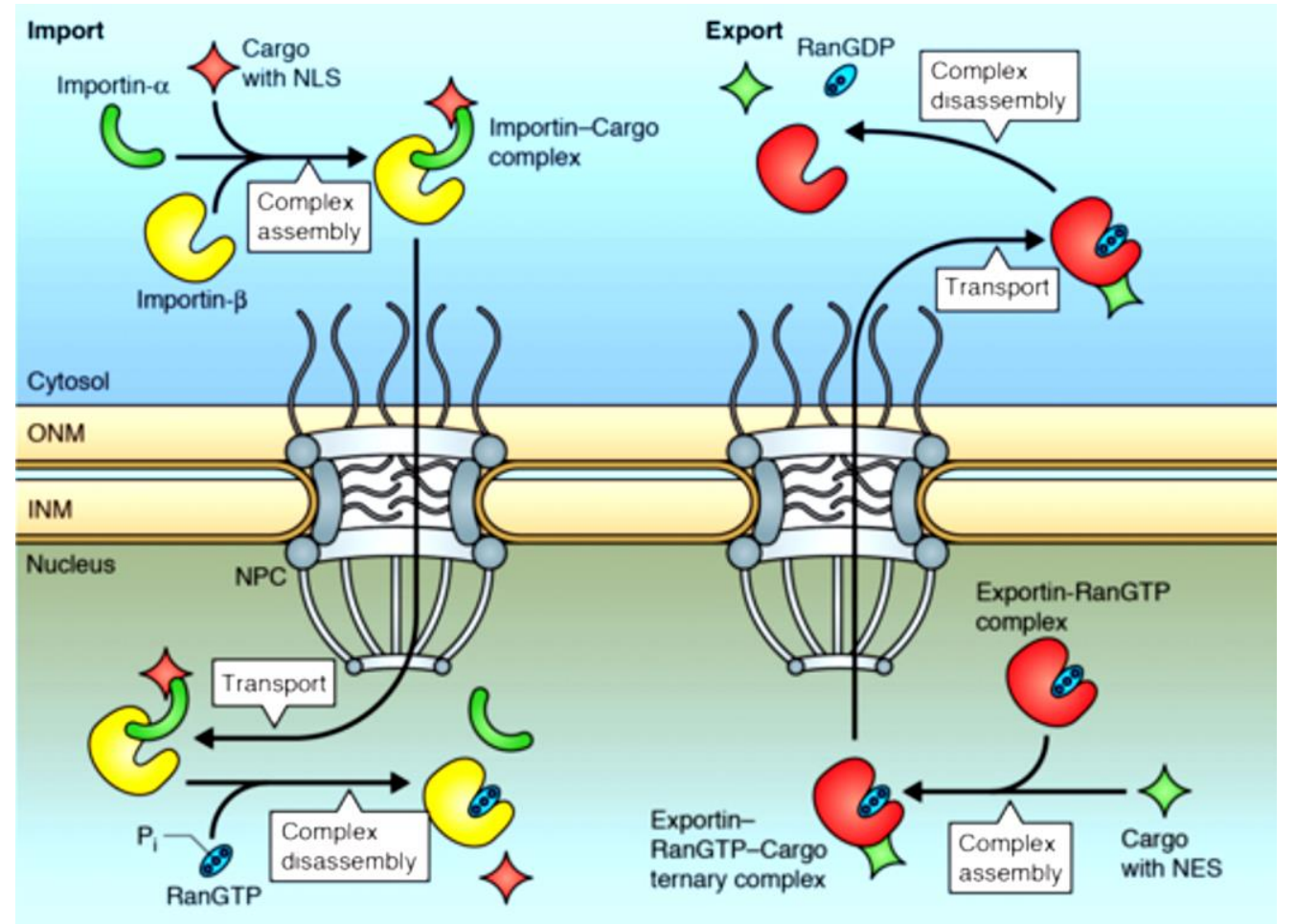

Figure 3: Nucleocytoplasmic transport. Left: Import of soluble cargoes into the nucleus is carried out via the recognition of a nuclear localization sequence (NLS) by the transport receptors importin $\alpha / \beta$ (green/yellow). Importin $\alpha / \beta$-cargo complex passes the NPC via FG-Nup (black filaments) interactions and is disassembled due to RanGTP (blue) binding in the nucleus. Right: Nuclear export of soluble proteins requires the binding of a nuclear export sequence (NES) to an exportin-RanGTP complex (red/blue). After translocation through the NPC RanGTP hydrolysis occurs and removes the NES-cargo (light green) from the transport receptor. Both nuclear transport receptors are recycled back to either cyto- or nucleoplasm, whereas the specific cargoes accumulate at their destination (modified from Kabachinski and Schwartz (2015)).

In the case of nuclear import, after translocation through the NPC, importin $\beta$ binds to Ran-GTP. Due to a conformational change, the cargo protein can be released into the nucleoplasm. Then importin bound to RanGTP exits the nucleus and bound GTP is hydrolysed, the import receptor is available for a new transport process. 
Nuclear export of proteins is carried with the help of this gradient as well. The exportin-cargo complex passes the NPC and in the cytoplasm, GTP hydrolysis occurs and the complex of Ran, export cargo and exportin disassembles. Free Ran-GDP can be imported back to the nucleus via NTF2 and a re-charging of Ran with GTP by RanGEF takes place (Cho et al., 2016; Bischoff and Ponstingl, 1991).

Currently, there are different models available trying to explain how FG-Nups and transport receptors are involved in mediating translocation of cargoes through the NPC: The "virtual gating model" (Rout et al., 2000; Rout et al., 2003; Yamada et al., 2010), the "selective phase model" (Ribbeck and Görlich, 2001) and the "oily-spaghetti model" (Macara, 2001).

The "virtual gating model" (Rout et al., 2003) is based on unstructured non-cohesive FG-repeat filaments, which fill the NPC. Inert macromolecules, which are not bound by nuclear transport receptors, are excluded by "non-interacting"-FG-filaments, also termed FG-bristles. The interaction of NTRs with these FG-brushes would allow the macromolecule (bound to the NTR) to overcome the virtual entropic barrier and speed up transit through the NPC. Therefore, noncohesive FG-domains would be adequate to provide the selectivity characteristics of the NPC (Weis, 2007; Schmidt and Görlich, 2016).

In the "selective-phase or hydrogel" model, the permeability of the NPC is proposed to be limited by FG-Nups, which form a sieve-like hydrogel due to their interaction with each another. Transport receptors can bind to the hydrophobic FG-repeats and transiently and locally interact with this meshwork and become a part of it. By doing this, they are capable of passing the NPC (Ribbeck and Görlich, 2001; Hülsmann et al., 2012; Ribbeck and Görlich, 2002, 2002).

In the last model, the "oily spaghetti-model" (Macara, 2001), the Nups with its FG-repeat regions reaching into the central channel of the NPC not like a meshwork described in the other model, but instead more loosely separated. It is proposed that NTRs interact with the FG-repeats and pass the central channel of the NPC by binding and "jumping" from FG to FG repeat. All of these models try to explain the biophysical properties of the NPC as a barrier for nucleocytoplasmic transport of soluble macromolecules. In the field, it is still a highly discussed topic (Kabachinski and Schwartz, 2015; Schmidt and Görlich, 2016). 


\subsection{Membrane proteins}

Contrary to the well-studied process of nuclear transport of soluble proteins, the transport of membrane proteins to the inner nuclear membrane is not as well understood (Zuleger et al., 2012; Laba et al., 2014). Therefore, this chapter deals with integral membrane proteins, especially inner nuclear membrane proteins, their biogenesis and a detailed view on tailanchored proteins.

\subsubsection{Classes of integral membrane proteins}

Integral membrane proteins can be discriminated into different classes based on their structural features (Ott and Lingappa, 2002). Generally, monotopic proteins with only one transmembrane domain (TMD) can be distinguished from polytopic proteins, which are multi-spanning proteins. The first group can be divided into several protein types with respect to their topology, the specific orientation inside a lipid bilayer with regard to their TMD (van Geest and Lolkema, 2000). Proteins, which have their C-terminus oriented to the cytoplasm belong to the type I integral membrane proteins. Type II proteins instead have their amino-terminus facing the cytoplasmic side and their C-terminus directed away from the cytoplasm (e.g. a protein at the ER would have the C-terminus facing the ER-lumen). A specialized version of type II proteins is termed signalanchor Type II proteins, which use their N-terminal TMD as both a signal sequence and a stop transfer sequence.

The last class of monotopic proteins are called C-terminal anchor or tail-anchored (TA) proteins, because the TMD is found to be very close to the carboxy-terminus of the protein.

According to their structural characteristics, the biogenesis of transmembrane proteins can occur in different ways. Either a co- or post-translational membrane insertion depending on the protein type is possible (see 1.2.2). The first entry site of the protein being properly integrated into a membrane is not necessarily the membrane of its final destination. Commonly the ER provides such a place, because many proteins might undergo modifications in the ER or Golgi-network. There, integral membrane proteins can exhibit specific localization signals as for instance ERretention, NLS or Golgi-retrieval signals (Laba et al., 2014).

\subsubsection{Biogenesis of membrane proteins}

\subsubsection{Co-translational membrane protein insertion at the ER}

Poly- as well as monotopic (type I, II and signal-anchor type II) membrane proteins can be inserted into the ER membrane via a co-translational pathway, also termed as SRP-Sec61-pathway (Görlich and Rapoport, 1993; Wickner and Schekman, 2005). However, soluble and secretory proteins can as well use a signal recognition particle (SRP)-dependent or an Sec62-mediated pathway (Park and Rapoport, 2012; Jadhav et al., 2015). Generally, three stages of this mechanism can be distinguished: The recognition of the substrate, the association with the target membrane (ER membrane) and the integration of the protein (Keenan et al., 2001; Shao and Hegde, 2011).

When an integral membrane protein is synthesized, the nascent polypeptide chain emerges from the ribosome and immediately a component of the SRP-Sec61-pathway needs to recognize the substrate. This step is performed by the signal recognition particle (SRP) (Walter and Blobel, 1980; Walter and Blobel, 1982). Either a hydrophobic TMD or a signal sequence can be displayed 
by the protein and is bound by SRP. After binding of SRP to the polypeptide chain a short arrest in elongation occurs, then the SRP-protein-ribosome complex is targeted to the ER membrane. At the membrane, the SRP receptor can interact with SRP and transfer the protein in a GTPasedependent manner (Keenan et al., 2001). Subsequently, the SRP is released from the complex in its GDP-bound state. The SRP-receptor transfers the polypeptide chain-ribosome complex to the Sec61 translocon. While translation finishes, the polypeptide chain is released from the ribosome directly into the channel of the translocon. The fact that protein translation is directly coupled to the translocon minimizes the possibilities of misfolding of a TMD-protein in the cytosolic environment. Finally, the mature protein is integrated from the Sec61 channel into the lipid bilayer of the ER through a lateral opening.

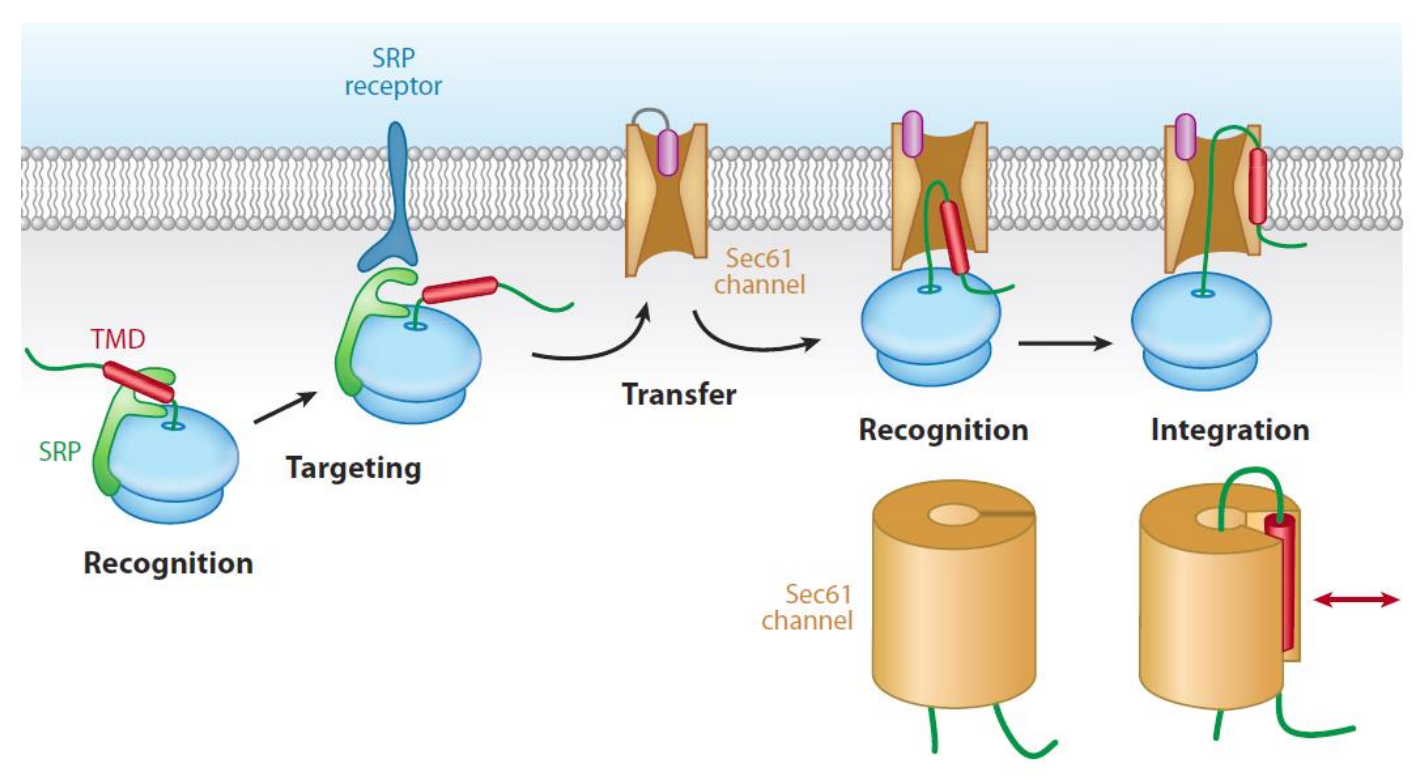

Figure 4: Scheme of co-translational membrane protein insertion. An integral membrane protein (depicted here: monotopic protein (dark green), its TMD (red)) is recognized via the SRP (green) emerging from the ribosome (light blue). Targeted to the ER membrane, the SRP receptor (dark blue) binds to SRP under GTP hydrolysis. The SRP receptor transfers the ribosome-protein complex to the Sec61 translocon (beige). After translation termination, a lateral integration of the mature membrane protein is performed at the Sec61 channel (modified from (Shao and Hegde, 2011)).

\subsubsection{Post-translational membrane insertion in mammals}

Especially the group of C-terminal or tail-anchored (TA) proteins requires a post-translational mechanism for insertion, but also very small monotopic proteins were reported to use this way of insertion (Shao and Hegde, 2011). By virtue of the position of their transmembrane domain (TMD) in TA-proteins, a mechanism other than the co-translational membrane insertion system is needed. Because TA-proteins do not possess a signal-peptide in their $\mathrm{N}$-terminal half and their very $\mathrm{C}$-terminal, hydrophobic transmembrane segment does not emerge out of the ribosomal tunnel until translation is terminated, the targeting and insertion into the ER membrane needs to occur after their synthesis is completed. 
The SRP binds only signal peptides and signal anchors as long as they are part of the nascent polypeptide chain, therefore, this class of proteins cannot be recognized via the SRP and insert into the ER via the common Sec61-pathway (Borgese et al., 2003).

Post-translational integration of membrane proteins into the ER has been described to occur via different pathways, which can be divided into assisted and unassisted mechanisms (Borgese and Fasana, 2010).

One of the assisted pathways is the TRC40 (or ASNA1)-mediated insertion (GET3-pathway in yeast) (Figure 5) (Favaloro et al., 2010). There are three main components of this pathway. The arsenical pump-driving ATPase protein (ASNA1) was identified playing a role in TA-protein delivery and therefore renamed as Transmembrane Recognition Complex subunit of $40 \mathrm{kDa}$ (TRC40) (Stefanovic and Hegde, 2007; Favaloro et al., 2008).

As soon as the translation of a TA-protein is terminated, a three-component pre-targeting complex, consisting of Bag6, TRC35 and Ubl4A in mammals facilitates capturing of the TA-protein from the ribosome via the TMD and hand-off to TRC40 (Mariappan et al., 2010). After binding the substrate, the ATPase TRC40 can be found in its ATP-bound state and the pre-targeting complex disassembles from TRC40. This complex of TRC40 (Appen et al., 2015) and TA-protein is delivered to the ER.

At the ER membrane, the proteins WRB (tryptophan-rich basic protein) and CAML (calciummodulating cyclophilin ligand) function as receptors for TA-protein integration (Yamamoto and Sakisaka, 2012; Vilardi et al., 2011). For proper insertion of proteins into the ER membrane, the binding of WRB to the transmembrane segments of CAML was reported to be crucial (Vilardi et al., 2014).

There, TRC40 docks onto the WRB-CAML complex and releases the protein under ATP hydrolysis. The membrane integration is synergistically performed by the receptors WRB and CAML, but not studied in detail so far. After binding to the receptors, TRC40 exists in its nucleotide free form and can be recycled for a novel round of substrate binding. The Get3 (guided entry of tailanchored proteins 3; yeast homologue of TRC40) structural features of an open or closed conformation of its complex have been investigated and a crystal structure of the complex consisting of a homodimer binding the TA-protein as its substrate, was analyzed (Hu et al., 2009; Mateja et al., 2009; Yamagata et al., 2009; Appen et al., 2015; Mateja et al., 2015).

Recently it has been reported that the membrane receptors WRB and CAML could influence each other's expression, which makes the regulation of the TRC40-pathway an even more complex process (Colombo et al., 2016). Furthermore, the core component TRC40 functions not only in membrane integration but also in quality control mechanisms. In case translation results in a misfolded protein, the TRC40-complex can also bind this protein and distribute it for ubiquitination and degradation processes (Hessa et al., 2011). In connection to this, Get3 was found at places of deposition for protein aggregates under conditions where membrane targeting was blocked (Powis et al., 2013), as well a chaperone function under oxidative stress conditions has been reported (Voth et al., 2014).

Another assisted option for post-translational membrane insertion is a chaperone-mediated pathway involving heat-shock proteins (Abell et al., 2007). Here, Hsp40/Hsc70 bind to a TAprotein released from the ribosome in a ATP-dependent manner and shield their hydrophobic TMD. The insertion into the membrane could happen unassisted or via a so far unknown receptor at the ER. Perhaps the function of $\mathrm{Hsp} 40 / \mathrm{Hsc70}$ is only to keep them in an insertion-competent 
state (Rabu et al., 2009). It was shown that proteins with a low hydrophobicity favor this pathway (Rabu et al., 2008).

A further mode describes membrane integration to happen in an unassisted manner. In this case, substrates with a TMD of low hydrophobicity can spontaneously integrate into the lipid bilayers such as the TA-proteins cytochrome b5 and PTP1B (Brambillasca et al., 2006; Colombo et al., 2009).

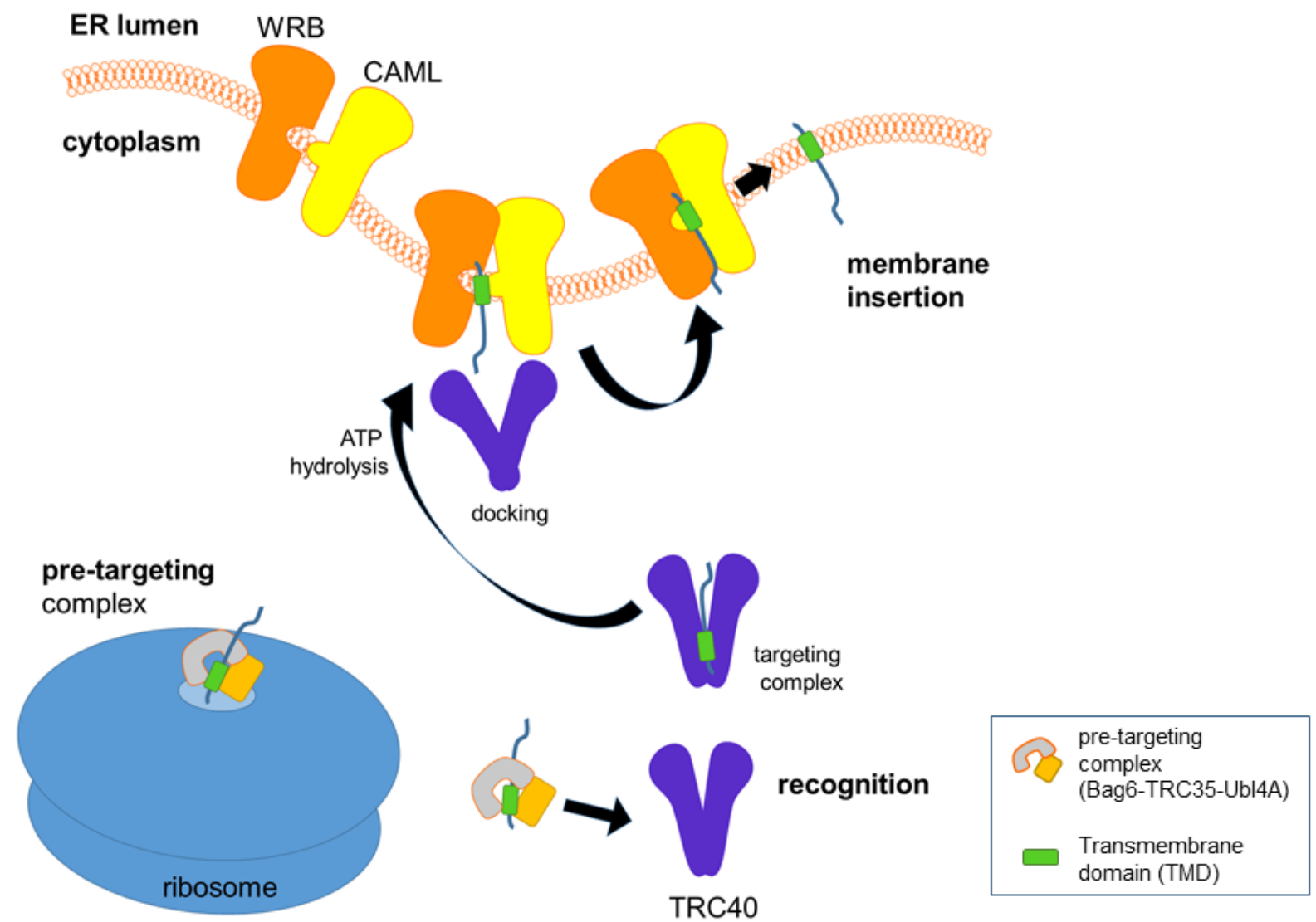

Figure 5: Post-translational membrane insertion of TA-proteins via the TRC40-pathway. The TA-protein (blue with TMD in green) emerges from the ribosome and can be bound immediately via its TMD by a pretargeting complex (Bag6-TRC35-Ubl4A). The pre-targeting complex binds to TRC40 (dark blue) in an ATPbound conformation. After dissociation from the pre-targeting complex, TRC40 mediates delivery to the ER membrane. The membrane receptors WRB (orange) and CAML (yellow) bind to the substrate under ATP hydrolysis. Via a synergistic mode, the WRB-CAML complex integrates the TA-protein into the membrane such that the small C-terminal stretch is facing the ER lumen. TRC40 is available in its open, nucleotide unbound form and cycles back into the cytosol to be available for a new delivery processes.

\subsection{Tail-anchored proteins}

This work focuses on the special type of integral membrane proteins called tail-anchored (TA) proteins or C-terminal anchor proteins. In a bioinformatics approach applied to the human genome, about 400 TA-proteins derived from about 300 genes have been identified and in this study the group of SNARE-TA-proteins were found to share a distinctive composition of their transmembrane segment (Kalbfleisch et al., 2007). Furthermore, in yeast about 55 TA-proteins 
have been reported (Beilharz et al., 2003). Generally, TA-proteins can be found as well throughout plants and bacteria (Kriechbaumer et al., 2009; Borgese and Righi, 2010).

They have been first described as a class of proteins having a single C-terminal membrane anchor, which at the same time acts as some kind of targeting signal (Figure 5). The single transmembrane domain is characterized to consist of a stretch of 20 hydrophobic amino acids very close to the C-terminal end (Kutay et al., 1993). It has been shown that this group can be characterized biochemically with respect to their ER membrane insertion mechanism in vitro (Favaloro et al., 2010; Vilardi et al., 2011). Due to the fact that they have only one TMD, their topology is easier to predict compared to other type II or even polytopic proteins located the ER and their larger $\mathrm{N}$-terminal region is always oriented to the cytosolic side.

This class of proteins was shown to be involved in various cellular processes like vesicle fusion and transport (SNARE proteins) and apoptosis (Bcl-2 proteins). In eukaryotes, TA-proteins can be found at nearly every compartmental membrane of the cell including mitochondria or peroxisomes (Chen et al., 2014a). For a few TA-proteins a dual localization to ER and mitochondrial outer membrane was observed and it was supposed that generally, a competition between diverse compartments for TA-protein integration exists (Borgese et al., 2003). As explained above, different routes of membrane insertion can be taken by TA-proteins (Leznicki et al., 2011; Borgese and Fasana, 2010). A main route is the post-translational insertion via the TRC40-pathway (or GET pathway in yeast) (see 1.2.2.2) (Stefanovic and Hegde, 2007). Another could be a chaperone-dependent route (e.g. via Hsc70 and Hsp40) (Abell et al., 2007; Rabu et al., 2008) or an insertion in an unassisted manner (shown for cytochrome b5) (Leznicki et al., 2011; Brambillasca et al., 2006; Colombo et al., 2009). Furthermore, the strength of hydrophobicity of the TMD might have an impact on the mode of membrane insertion as it is seen and compared for the proteins VAMP2, RAMP4 and cytochrome b5 (Rabu et al., 2009). A study by Ott et al. (2011) indeed revealed that for proper post-translational insertion a minimal length of 15 aa of the TMD was required for the Herpes virus TA-protein pUL34.

\subsubsection{Proteins of the inner nuclear membrane}

The inner nuclear membrane, as a part of the NE, plays an important role in maintenance of the nuclear structure due to its linkage to chromatin and the nuclear lamina. It provides a connection to the cytoskeleton and can regulate and influence gene expression as well as cell signaling (Haque et al., 2006; Gomez-Cavazos and Hetzer, 2012).

Early on, the INM was reported to be a part of the NE characterized by its distinct set of proteins when compared to the ER and the outer nuclear membrane (Senior and Gerace, 1988). Several proteomics approaches have been performed to elucidate the composition of the nuclear envelope and the inner nuclear membrane in particular (Dreger et al., 2001; Schirmer et al., 2003; Schirmer and Gerace, 2005; Malik et al., 2010; Wilkie et al., 2011).

Furthermore, the NE proteome was found to vary between different tissues (Korfali et al., 2012; de Las Heras, Jose I et al., 2013), which might be interesting in the context that INM-proteins were linked to human diseases and can lead to tissue-specific phenotypes (Mejat and Misteli, 2010; Dauer and Worman, 2009).

In the above-mentioned proteomics screens for identification of new nuclear envelope proteins, well-studied and typical INM-proteins like the lamin B receptor (LBR) with multiple transmembrane domains and monotopic INM-proteins like emerin and LAP2 $\beta$ were identified 
(Figure 6). LBR itself is one of the best studied proteins of the INM, having eight TMDs (Worman et al., 1990). It is involved in tethering the nuclear lamina and chromatin to the NE. As for other INM-proteins, mutations in the LBR gene can lead to specific diseases and abnormal membrane morphology (Zwerger et al., 2010) as mentioned in the beginning of this chapter.

Over 200 proteins of the INM were identified for the human genome, among them several tailanchored membrane proteins. With regard to this, potential TA-proteins of the INM should be investigated in this work for their membrane insertion and localization.

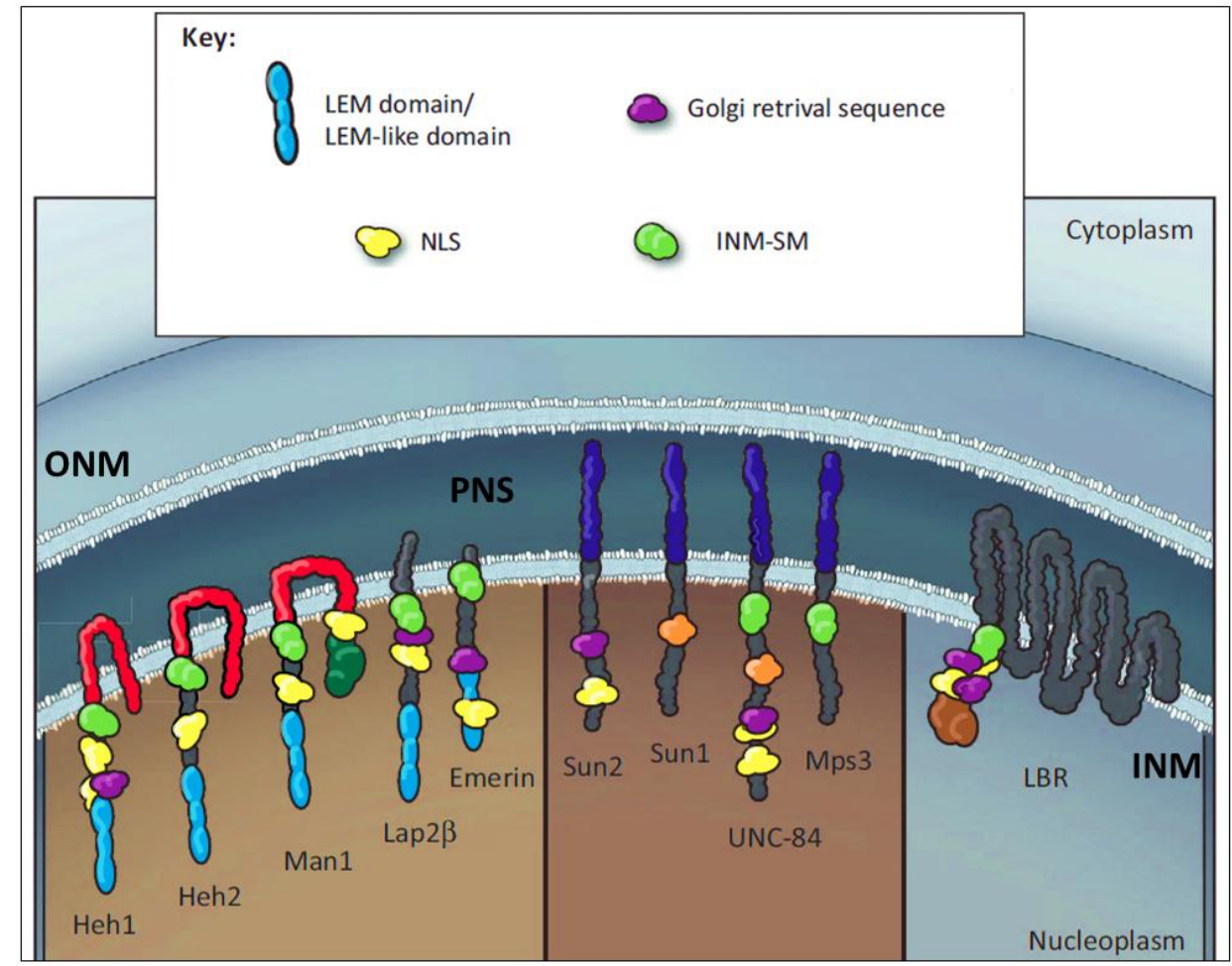

Figure 6: Schematic view of prominent INM-proteins and their unique features. Human, yeast and C. elegans inner nuclear membrane proteins are depicted and arranged via similarities in their structural features and sorting motifs as well as orientation at the INM (illustrated specific features are explained in the white box) (modified from (Katta et al., 2014)).

\subsubsection{Targeting of membrane proteins to the INM}

So far, it is not fully understood, how proteins are able to enrich at the INM compared to the ER or ONM. In this context, two essential mechanisms of INM targeting can be envisioned for cells in open mitosis and interphase cells (Antonin et al., 2011).

Since studies of integral membrane proteins during mitosis are available, INM-proteins were reported to be distributed throughout the mitotic ER serving as an intermediate place of storage after NE breakdown (Yang et al., 1997; Ellenberg et al., 1997). In telophase, the NE-material was reported to be found surrounding the condensing chromosomes and it was shown that INMproteins can interact with chromosome surfaces and therefore allow diffusion from the mitotic ER to the reforming nuclear envelope (Yang et al., 1997; Ellenberg et al., 1997; Antonin et al., 2011). The lamin B receptor (LBR), MAN1, LAP2 as well as the nucleoporin Ndc1, POM121 were shown to direct ER membranes to the reassembling NE based on their binding to chromatin 
(Haraguchi et al., 2000; Haraguchi et al., 2001; Anderson and Hetzer, 2008; Anderson et al., 2009).

During interphase instead, the ER and the ONM are continuously connected and NPCS are the linkage points of both INM and ONM, thus an alternative mechanism for INM-protein targeting is required to exist. Depending on the integral membrane protein, different models for INM targeting (Katta et al., 2014; Laba et al., 2014; Burns and Wente, 2012; Gonzalez and Andres, 2011; Antonin et al., 2011) have been proposed for interphase cells (Figure 7).

Early on, transport to the INM has been observed to be an energy- and temperature-dependent process (Ohba et al., 2004) speaking against a pure diffusion process from the inner to the outer nuclear membrane. Along these lines, based on the transport mechanisms known for soluble proteins, a transport-factor-mediated model (Figure 7, B) has been proposed, because for the yeast INM-proteins Heh1 and Heh2, an import receptor-dependent, NLS-based transport to the INM as well as an involvement of nucleoporins was shown (King et al., 2006; Laba et al., 2015; Turgay et al., 2010). In this model, INM-proteins containing an NLS are proposed to interact with classical import receptors of the karyopherin family. At this point, the protein is already bound to the ER membrane and shuttles together in a complex with the importin to the NPCs. At NPCs, the importin-INM-protein complex could either pass through the central channel via a very long linker (Meinema et al., 2011) or use one of the small, peripheral channels of the pore though with assistance of a membrane-associated import receptor version (Saksena et al., 2006).

Similar to the transport-factor dependent model, a sorting-motif-based model (not illustrated) also includes the recognition of a small and specifically charged domain (Figure 6) within the INMprotein by a shortened version of importin $\alpha$ directly after protein synthesis at the ER membrane (Saksena et al., 2006). This complex could then be directed along the membrane and through a peripheral channel of the NPCs. An interaction with Nup50/Nup2 could facilitate the cargo release inside the nucleus. Braunagel et al. (2007) showed that the INM-sorting-motif of LBR can be bound by short importin $\alpha-16$, when LBR is integrated at the ER membrane adjacent to the Sec61 translocon.

The other major diffusion-retention model (Figure 7, A), was proposed very early and suggested to apply for lamin- and chromatin- binding INM-proteins (Powell and Burke, 1990; Smith and Blobel, 1993; Soullam and Worman, 1993; Torrisi et al., 1987). With this path, proteins are supposed to passively diffuse from the ER membrane, where they are inserted via a co- or posttranslational insertion mode (section 1.2.2), to the ONM. There, translocation from the ONM to INM can occur through peripheral channels of the NPC. These $10 \mathrm{~nm}$ channels have been found for NPCs of humans and the amoeba Dictyostelium (Maimon et al., 2012; Beck et al., 2007). Proteins transported via this model should not exceed a limit $60 \mathrm{kDa}$ (Terry and Wente, 2009). At the INM, the proteins are proposed to be retained via interaction partners (e.g. lamins, chromatin) (Holaska et al., 2002; Lee et al., 2001; Foisner and Gerace, 1993; Dechat et al., 2000). The observation of differences in the INM-protein mobility in the ER and INM supports this model (Zuleger et al., 2011). Quite recently, this model has been strongly supported by two studies investigating the transport of the INM-proteins LBR, LAP2 $\beta$ and SUN2 with the help of targeting assays considering real-time measurements and kinetics of this process (Boni et al., 2015; Ungricht et al., 2015). 


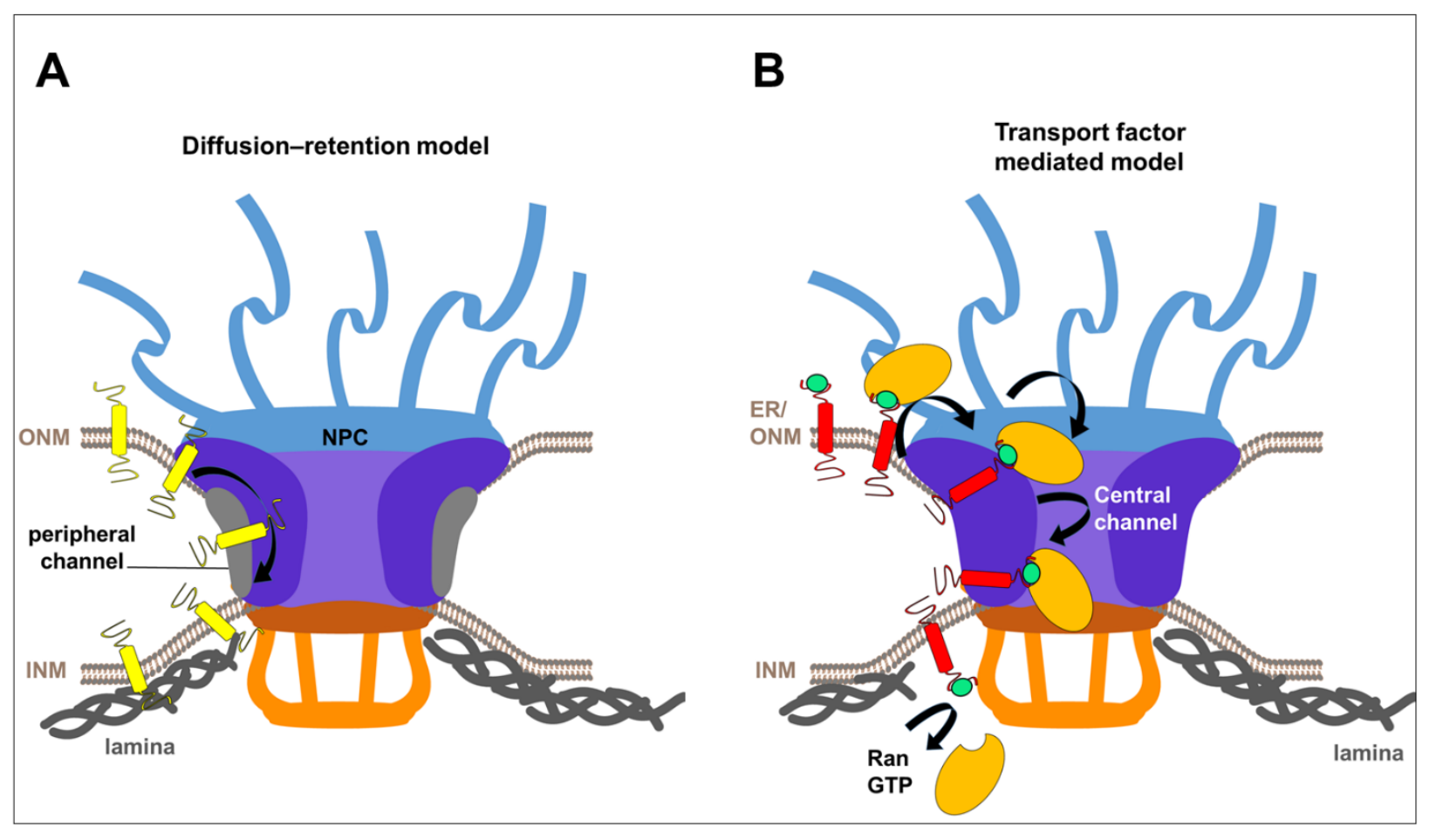

Figure 7: Major models of membrane protein trafficking to the INM. Integral membrane proteins are coor post-translationally inserted into the ER membrane and believed to be transported to the INM via two main models. (A) The passive diffusion-retention mechanism. The cargo protein (yellow) diffuses from the ER membrane via a peripheral channel of the NPC to the INM and is sequestered there by interactions with e.g. lamins (grey) (B) The active transport receptor mediated model is based on the recognition of an NLS (green) by a nuclear transport receptor (orange). The translocation occurs as an active process through the central channel of the NPC, the cargo protein (red) -transport receptor complex disassembles.

Finally, a vesicle-mediated mechanism (not illustrated) has been suggested. Vesicles budding from the ONM to the perinuclear space and might dock and fuse with the INM, there the INMprotein can diffuse into the INM without any involvement of NPCs. Speese et al. (2012) could show that at least for the export of RNP complexes such a pathway is possible.

Besides the main models explained, studies also showed that other properties of INM-proteins can have an influence on the route of transport. Wu et al. (2002) showed for the LEM-domain protein MAN1 (Lin et al., 2000) that also the size of the N-terminal portion of proteins influence transport to the INM. In yeast, NE transmembrane proteins (NETS) having internal FG-motifs, which interact with Nup35 in the peripheral channel, could mediate passage through the NPC and transport to the INM by themselves (Zuleger et al., 2011).

Taken together, to date no uniform or standard mode of INM-trafficking has been found. Depending on the structural features as well as possible interaction partners of individual INMproteins, they may utilize one out of several possible pathways along or through the NPC. 


\subsubsection{Putative tail-anchored proteins of the INM}

As delineated in section 1.2.2.2.1, over 400 human TA-proteins have been identified for several compartments like ER, mitochondria and peroxisomes but among them, also proteins localizing to the NE and particularly to the INM (Kalbfleisch et al., 2007). The following paragraph describes the depicted putative TA-proteins of the INM (Table 1), which were characterized in this work.

Table 1 Integral membrane proteins studied throughout this work including properties of their transmembrane domain (TMD).

\begin{tabular}{|c|c|c|c|c|c|}
\hline $\begin{array}{c}\text { Protein } \\
\text { (total length) }\end{array}$ & Species & $\begin{array}{l}\text { Position of TMD } \\
\quad \text { (length) }\end{array}$ & $\begin{array}{l}\text { Distance to } \\
\text { C-Terminus } \\
\text { (aa) }\end{array}$ & TMD - aa sequence & $\begin{array}{l}\text { Predicted } \\
\Delta \mathrm{G}^{*} \\
{[\mathrm{kcal} / \mathrm{mol}]}\end{array}$ \\
\hline Emerin (254 aa) & human & $223-243(20)$ & 11 & $\begin{array}{c}\text { VPLWGQLLLFLVFVIVL } \\
\text { FFIY }\end{array}$ & -4.3 \\
\hline LAP2 $\beta$ (452 aа) & rat & $410-430(20)$ & 22 & $\begin{array}{c}\text { VPMWIKMLLFALVAG } \\
\text { FLFLVY }\end{array}$ & -2.1 \\
\hline VAPB (243 аa) & human & $223-243(20)$ & - & $\begin{array}{l}\text { RLLALVVLFFIVGVIIGK } \\
\text { IAL }\end{array}$ & -3.0 \\
\hline PTP1B (435 aа) & human & 400-435 (35) & - & $\begin{array}{c}\text { HALSYWKPFLVNMCV } \\
\text { ATVLTAGAYLCYRFLF } \\
\text { NSNT }\end{array}$ & -0.3 \\
\hline LEMD1 (181 aa) & human & $152-172(20)$ & 9 & $\begin{array}{c}\text { FPVGLKLAVLGIFIIVVF } \\
\text { VYL }\end{array}$ & -2.7 \\
\hline LRRC59 (307 aa) & human & $245-265$ (20) & 42 & $\begin{array}{l}\text { WAVLKLLLLLLLFGVA } \\
\text { GGLVA }\end{array}$ & -2.9 \\
\hline RAMP4 $^{\diamond}$ (66 aа) & human & $39-59(20)$ & 7 & $\begin{array}{c}\text { GPWLLALFIFVVCGSAI } \\
\text { FQ॥I }\end{array}$ & -1.5 \\
\hline $\begin{array}{l}\text { Cytochrome b5 }{ }^{\ddagger} \\
(134 \text { aa) }\end{array}$ & human & $109-131(32)$ & 3 & $\begin{array}{c}\text { WWTNWVIPAISAVAV } \\
\text { ALMYRLYM }\end{array}$ & -0.24 \\
\hline \multicolumn{6}{|c|}{$\begin{array}{l}\text { *Calculations were obtained by Membrane Protein Explorer (MPEX) (Snider et al., 2009) based on Uniprot database } \\
\text { entries (window size: 19, Wilmey-White Scale: interfacial, water to bilayer). Predicted } \triangle G \text { provides an alternative } \\
\text { indication of biological hydrophobicity (Hessa et al., 2007). The more negative the value, the more hydrophobic the } \\
\text { TMD shown. } \\
\text { } \\
\text { (Faverence protein; confirmed TA-protein using the TRC40-pathway for membrane insertion at the ER } \\
\text { ₹ reference protein; confirmed TA-protein using an unassisted mode of membrane insertion at the ER } \\
\text { (Brambillasca et al., 2006). }\end{array}$} \\
\hline
\end{tabular}




\subsubsection{Emerin}

In this project, emerin is focused on as the model protein, because it is a well-studied protein of the INM, which was proposed to be a TA-protein (Laba et al., 2014). It has a size of $29 \mathrm{kDa}$ and is encoded by the STA gene. Its gene was identified by genetic mapping (in context of the recessive X-linked form of Emery-Dreifuss muscular dystrophy (EDMD) (Emery and Dreifuss, 1966; Emery, 1989), a neuromuscular disease associated with muscle weakness and cardiomyopathy (Vohanka et al., 2001). The disease is inherited either as an autosomal-dominant or an X-linked recessive form. In the latter, Emerin is either absent or defective in EDMD patients as a result of mutations in the gene (Manilal, 1999; Nagano et al., 1996).

Shortly after a link to the responsible gene was made, emerin was found to be a protein of the nuclear envelope, more precisely the INM (Manilal, 1996; Nagano et al., 1996). Besides the ubiquitous expression, it is present in the heart as well as in skeletal muscles at very high amounts, speaking for the strong effect seen in EDMD. Emerin contains a single stretch of 23 hydrophobic amino acids (Table 1 ) at its very C-terminal end, which indicates emerin to potentially be a TA-protein. Furthermore, it belongs to the family of LEM- domain proteins, whose name originates from the INM-proteins LAP2, emerin, MAN1 (LEM). Most of the present known members are anchored to the INM via one TMD. For LEM-domain proteins, as it is the case for emerin, an interaction with barrier-to -autointegration factor (BAF) (Haraguchi et al., 2001; Furukawa, 1999; Zheng et al., 2000; Shumaker et al., 2001), a DNA-binding factor, and the nuclear lamina was reported (Berk et al., 2013b; Barton et al., 2015). In this context, lamin interactions were shown to function as an INM retention signal (Vaughan et al., 2001; Östlund et al., 2006; Wu et al., 2002) for emerin or MAN1. Moreover, $\mathrm{N}$ - and C-terminal regions of homology between emerin with the family of thymopoetins like LAP $2 \beta$, which is described below, were identified (Manilal et al., 1996).

Based on the many interaction partners at the INM and the behavior of emerin in a mobility study (Östlund et al., 1999)), it is proposed to use a diffusion-retention mode for trafficking to the INM (different models of INM-targeting are described in section 1.2.4).

Many diverse functions have been shown for emerin, ranging from contributing to nuclear architecture, influencing gene regulation, mRNA splicing, mechanotransduction and to regulating signaling pathways (Markiewicz et al., 2006; Holaska and Wilson, 2007). Beyond this, emerin itself is a highly post-translationally regulated protein. Due to its serine/threonine-, tyrosine-rich sequence, it can be easily phosphorylated and is regulated e.g. during the cell cycle (Foisner and Gerace, 1993). In interphase cells, emerin localizes to the INM, but can be found mainly at the ER membranes at the end of mitosis. Haraguchi et al. (2001) observed that for the re-assembly of the $N E$, the chromatin-binding protein $B A F$ is required. Other studies showed that emerinlaminA/C interactions are important for proper localization of emerin at the NE (Vaughan et al., 2001; Sakaki et al., 2001).

Even though the major fraction of emerin is found at the INM, there are reports about a pool at the ONM. There, emerin contributes to controlling spacing between nucleus and the centrosome (Salpingidou et al., 2007). Especially in the heart, emerin has a unique localization to desmosomes and fasciae adherens of the intercalated discs (Cartegni et al., 1997). Recently, the self-assembly ability of emerin was studied and it turned out to be crucial for proper function of emerin. As a consequence, emerin mutations interfering with this self-assembly, were reported to cause EDMD (Herrada et al., 2015). The multi-functional INM-protein emerin and several mutant 
variants related to EDMD are explicitly analyzed in this study with respect to membrane insertion and targeting to the INM.

\subsubsection{2. $\quad \operatorname{LAP} 2 \beta$}

Lamina-associated polypeptide 2 (LAP2) exists in six alternatively spliced forms in mammalian cells. In this study, the protein LAP2 $\beta$ is analyzed, because it contains a single, C-terminal transmembrane domain (Table 1), rendering it a potential TA-protein (Foisner and Gerace, 1993) and because it was shown to localize to the nuclear envelope (Furukawa et al., 1995). With a size of $51 \mathrm{kDa}$ it is larger than emerin. Recent studies provided evidence for a diffusion-retention based mode of INM-transport (Ungricht and Kutay, 2015; Boni et al., 2015). As a member of the LEM-domain family, it can bind to the lamina, whereby the region coincides with the 76 aa region needed for stable INM targeting (Furukawa et al., 1998; Furukawa, 1999). The N-terminal part was shown to be directly involved in chromatin association (Furukawa et al., 1997) and as reported for emerin also the chromatin-binding factor BAF was reported to mediate this interaction (Furukawa, 1999; Shumaker et al., 2001). Not much about the function of Lap2 $\beta$ is known, but a role of LAP2 in regulation of the lamina growth has been implicated and it therefore could contribute to NE reassembly and nuclear growth (Yang et al., 1997; Gant et al., 1999). Additionally, in Drosophila LAP2 $\beta$ was observed to mediate transcriptional repression (Nili et al., 2001). Even though LAP2 is a ubiquitously expressed protein, it was found to be highly expressed in digestive tract cancers (Kim et al., 2012) and lately, it was even discussed as a marker for breast cancer (Marrero-Rodriguez et al., 2015).

\subsubsection{LEMD1}

LEM domain-containing 1 (LEMD1) is about $20 \mathrm{kDa}$ in size and belongs to the group of LEMdomain proteins of the INM. Due to its very C-terminal TMD (Table 1) it is seen as a potential TAprotein. However, not much is known about this protein so far. There are six alternatively spliced forms of LEMD1 transcripts found and it is predominantly expressed in testis and reported to play a role in different kinds of cancer (Yuki et al., 2004; Sasahira et al., 2016; Ghafouri-Fard et al., 2010). Further, a co-localization with the DNA binding factor BAF was reported like for other LEM-domain inner nuclear membrane proteins (Yuki et al., 2004).

\subsubsection{PTP1B}

Protein tyrosine phosphatase 1B (PTP1B), originally isolated from human placenta (Tonks et al., 1988b, 1988a), belongs to the protein tyrosine phosphatase family. Besides a catalytic domain, it has one moderately hydrophobic TMD (Table 1 ) close to its C-terminal end compared to the more hydrophobic TA-protein VAMP2 (Synaptobrevin 2) (Chen et al., 2011). Because of its TMD, it belongs to the receptor-like membrane bound subgroup of protein tyrosine phosphatases (Walton and Dixon, 1993) and is able to insert into the ER membrane unassisted like cytochrome b5 (Brambillasca et al., 2006). In another in vitro approach however, it was observed that addition of Hsc40/Hsp70 could promote the membrane insertion of PTP1B into ER-derived membranes (Rabu et al., 2008). Further, full-length endogenous or recombinant PTP1B was shown to localize at the ER depending on its 35 aa C-terminal region, since C-terminal truncations resulted in a 
cyto- or nucleoplasmic localization. An important finding was made by Kuchay et al. (2007), when PTP1B was observed to be cleaved by the protease calpain, which cuts off the hydrophobic tail of PTP1B and releases a soluble, more active form of the enzyme.

PTP1B has a size of about $50 \mathrm{kDa}$ and does not contain any organellar targeting motif (Frangioni et al., 1992). With respect to a possible function of the protein, an in vitro interaction with the cell cycle protein p34cdc2 has been observed (Morla et al., 1989; Flint et al., 1993) and a role in nerve growth factor signaling has been reported (Brobeil et al., 2015). Interestingly, for the Drosophila orthologue PTP61F two variants with identical catalytic domains exist. The variants are shown to be differentially targeted to either the ER or nucleus accompanied by differences in their ability to regulate signaling pathways (Buszard et al., 2013). Yip et al. (2012) found PTP1B localized to the INM and there, it was shown to regulate the tyrosine phosphorylation of the model protein of this work, emerin.

\subsubsection{VAPB}

The human VAMP-associated protein B (VAPB) has a molecular weight of about $28 \mathrm{kDa}$. Characteristic for this protein is an N-terminal MSP (Major Sperm Protein) domain followed by a coiled-coil domain and a C-terminal membrane anchor. As sites of localization inside the cell the ER, Golgi, ERGIC, endosomes and the plasma membrane have been demonstrated (Skehel et al., 2000; Soussan et al., 1999).

Via the MSP domain, interactions with FFAT-motif (two phenylalanines (FF) in an Acidic Tract) containing proteins are possible e.g. oxysterol-binding proteins (Baron et al., 2014). Concomitantly, it was shown that VAPB can bind an FFAT-like motif of TRC40 (ASNA1) via its MSP domain, but not with the C-terminal TMD of VAPB (even though it is a TA-protein). In the same study, a perinuclear distribution of overexpressed TRC40 together with endogenous VAPB was observed, indicating another possible function of the TRC40-VAPB complex than membrane insertion. Regarding the known functions of VAPB, it was shown to be involved as an adaptor protein in regulation of lipid transport, membrane trafficking, release of neurotransmitters and the unfolded protein response (Lev et al., 2008).

Defects in the STA gene encoding for emerin may result in the neuromuscular disease EDMD, likewise a mutation in the $V A P B$ gene can cause the neurodegenerative disease amyotrophic lateral sclerosis (ALS8) (Nishimura et al., 2004). A VAPB disease mutant was investigated for its membrane insertion capacity, but no effect on membrane insertion compared to the wild type was found for defective VAPB. Nevertheless, Fasana et al. (2010) showed evidence for VAPB using an assisted post-translational insertion mode. Interestingly, as seen for the protein PTP1B a link between the proteins VAPB and emerin can be made. VAPB was described to have an influence on the transport of NE components like emerin and Nups and these proteins were shown to be accumulated in the ER-Golgi intermediate compartment (ERGIC) (Tran et al., 2012).

\subsubsection{LRRC59}

Leucine rich repeat-containing protein 59 (LRRC59) was first identified as ribosome-bindingprotein 34 (p34) (Ohsumi et al., 1993). According to its name, it contains four leucine rich repeats, a coiled-coil and a C-terminal transmembrane segment. It was shown to be integrated into ERderived membranes (Ohsumi et al., 1993) and could be found localized to the ER membrane and 
the nuclear envelope in an osteosarcoma cell line (Skjerpen et al., 2002; Zhen et al., 2012). Early on, LRRC59 has been implicated in the binding of ribosomes to microsomal membranes and was reported to be present in close proximity to the protein translocation site for secretory proteins (Ichimura et al., 1993). Furthermore, LRRC59 seems to be involved in the transport of the fibroblast growth factor FGF1 and cancerous inhibitor of PP2A (CIP2A) to the nucleus and the regulation of toll-like-receptor trafficking (Zhen et al., 2012; Tatematsu et al., 2015; Pallai et al., 2015). 


\subsection{Aim of this Work}

The transport of soluble proteins from the cytoplasm to the nucleus across NPCs is a well-studied process. However, little is known about the targeting of integral membrane proteins upon their synthesis in the cytoplasm to the INM. Therefore, a central aim of this thesis was to characterize the targeting of proteins to the INM. For a better understanding of this process, emerin is used a model protein, as it is one of the best characterized INM proteins.

Emerin is proposed to belong to the group of tail-anchored proteins and therefore a posttranslational insertion mechanism into the ER membrane as a first site of membrane integration can be envisioned. Following membrane insertion emerin and other INM proteins need to be targeted to the INM. However, standard fluorescence microscopy does not allow for a clear differentiation between an INM and ONM localization, as the two membranes are only separated by a distance of 30-50 $\mathrm{nm}$ (Franke et al., 1981).

Therefore, a simple and robust assay was developed, which confirms a correct localization of a protein of interest to the INM. The established method of differential permeabilization is limited due to the prerequisite of available and reliable antibodies. A possible approach could be the use of the rapamycin-dimerization mechanism (Chiu et al., 1994; Stan et al., 1994; Choi et al., 1996). Using these assays, emerin and other putative TA-proteins could be tested for their localization to the INM as well as their post-translational insertion into ER membranes.

To get a better understanding of the targeting process of emerin to the INM, emerin mutants associated with Emery-Dreifuss muscular dystrophy which are reported to have mutations within or close to their TMD, could be analyzed in more detail by means of the developed assay.

Overall, these experiments should provide valuable insights on the transport of specific proteins to the INM. 


\section{Material and Methods}

\subsection{Material}

\subsubsection{Technical equipment}

\begin{tabular}{|c|c|}
\hline Equipment & Company \\
\hline Agarose gel documentation GelSTICK touch & INTAS Science Imaging Instruments \\
\hline Agarose gel running chamber & Home-made, Workshop, UMG \\
\hline Autoclave DX-200 & Systec \\
\hline BioPhotometer & Eppendorf \\
\hline Cell culture hood Herasafe ${ }^{\mathrm{TM}} \mathrm{KS}$ & ThermoScientific \\
\hline Cell culture incubator Heracell ${ }^{\mathrm{TM}} 150 \mathrm{i}$ & ThermoScientific \\
\hline Cell culture incubator Cytoperm 2 & Heraeus Instruments \\
\hline Centrifuge 5415R & Eppendorf \\
\hline Centrifuge 5424 & Eppendorf \\
\hline Centrifuge Sigma & Sigma \\
\hline $\begin{array}{l}\text { Centrifuge Allegra }{ }^{\circledR} \text { X-15R with rotor } \\
\text { SX4750 }\end{array}$ & Beckman Coulter \\
\hline Centrifuge Allegra ${ }^{\circledR}$ X 22 with rotor SX4250 & Beckman Coulter \\
\hline $\begin{array}{l}\text { Centrifuge Avanti }{ }^{\mathrm{TM}} \mathrm{J}-30 \mathrm{I} \text { with rotor } \\
\text { JA30.50Ti }\end{array}$ & Beckman Coulter \\
\hline Centrifuge J6-MI with rotor JS 4.2 & Beckman Coulter \\
\hline $\begin{array}{l}\text { Centrifuge Optima MAX-XP with rotor TLA } \\
120.1\end{array}$ & Beckman Coulter \\
\hline Confocal microscope LSM 510 meta & Zeiss \\
\hline Decon FS-100 ultrasonic bath & Decon Laboratories \\
\hline Developer machine CURIX60 & Agfa \\
\hline Dual Gel Caster for Mini Vertical Units & Hoefer \\
\hline EmulsiFlex-C3 & Avestin \\
\hline FACSAria $^{\mathrm{TM}}$ II (Cell Sorting Facility/UMG) & BD Bioscience \\
\hline FACSCanto $^{\mathrm{TM}}$ II & BD Bioscience \\
\hline Fluorescence microscope Axioskop 2 & Zeiss \\
\hline Incubator Heraeus function line & Heraeus \\
\hline Incubator Shaker INNOVA 4430 & New Brunswick Scientific \\
\hline $\begin{array}{l}\text { Incubation/Inactivation Water Bath Model } \\
1003\end{array}$ & GFL \\
\hline Mini Trans-Blot ${ }^{\circledR}$ Cell & Bio-Rad \\
\hline Odyssey ${ }^{\circledR}$ Sa Infrared Imaging System & LI-COR \\
\hline Olympus CK40 Culture Microscope & Olympus \\
\hline $\begin{array}{l}\text { SE250 Mighty Small II Mini Vertical } \\
\text { Electrophoresis Unit }\end{array}$ & Hoefer \\
\hline SDS-gel documentation LAS-3000 & Fujifilm \\
\hline Spectrophotometer NanoDrop 2000c & ThermoScientific \\
\hline Thermocycler FlexCycler2 & Analytik Jena AG \\
\hline Thermocycler PTC-200 DNA Engine & MJ Research \\
\hline Thermocycler Tprofessional & Biometra \\
\hline Thermomixer comfort & Eppendorf \\
\hline Thermomixer compact & Eppendorf \\
\hline
\end{tabular}


Equipment

UV transilluminator

Vortexer MS2 Minishaker

Western blot incubation boxes

XCell SureLock ${ }^{\circledR}$ Mini-Cell
Company

Biometra

Uvitec

IKA

LI-COR

life technologies

\subsubsection{Consumables}

Consumable

$5 \mathrm{ml}$ Polystyrene Round-Bottom Tubes

Amersham Hybond ECL Nitrocellulose

Blotting Membrane

Amersham Hyperfilm ${ }^{\mathrm{TM}} \mathrm{ECL}$

Amersham Protran $0.45 \mu \mathrm{m}$ NC

Nitrocellulose Blotting Membrane

Cell culture consumables

Cell culture plastic ware

Centrifuge Bottle Assembly, Polycarbonate

$50 \mathrm{ml}$

Centrifuge tube, thickwall, Polycarbonate $500 \mu \mathrm{l}$

Casy cups with lids

Medix XBU medical x-ray film

Microscope cover slips $(10 \mathrm{~mm}, 12 \mathrm{~mm} \emptyset)$

Microscope slides (76×26 mm)

Microscope slides

Minisart RC 15, single use syringe filters

(0.45 $\mu \mathrm{m}, 0.20 \mu \mathrm{m})$

Minisart single use filter units $(0.45 \mu \mathrm{m})$

NuPAGE ${ }^{\circledR}$ Novex ${ }^{\circledR}$ 4-12\% Bis-Tris Protein

Gels

Parafilm "M"

pH indicator strips

Reaction tubes $(1.5,2 \mathrm{ml})$

Syringes and needles

Whatman gel blotting paper
Company

BD Biosciences

GE Healthcare

GE Healthcare

GE Healthcare

Sarstedt, Greiner bio-one

Sarstedt, Greiner bio-one, Nalge Nunc

International

Beckman Coulter

Beckman Coulter

Roche Diagnostics (Fisher Scientific)

FOMA Bohemia

Marienfeld

Glaswarenfabrik Karl Hecht GmbH \& Co KG

ThermoScientific

Sartorius Stedim Biotech

Sartorius Stedim Biotech

life technologies

Bemis Company, Inc.

Macherey-Nagel

Sarstedt, greiner bio-one

B. Braun, Servoprax

GE Healthcare

\subsubsection{Software}

Software

Company

Adobe Illustrator CS6

Adobe

Citavi 5

Swiss Academic Software

FACS Diva 6.1.1

BD Biosciences

GraphPad Prism 5.01

Genome Compiler

GraphPad Software Inc.

Image Reader LAS-3000

Genome Compiler Corporation

ImageJ

Fujifilm

$\mathrm{NIH}$ 


\begin{tabular}{ll} 
Software & Company \\
\hline \hline ImageStudio/ ImageStudio Lite 4.0.21 & LI-COR \\
\hline Lasergene 10.1.1 (3) & DNASTAR \\
\hline LSM 510 Release Version 4.0 SP2 & Zeiss \\
\hline LSM Image Browser & Zeiss \\
\hline Microsoft Office Home and Student 2016 & Microsoft \\
\hline MPEX-Membrane Protein Explorer 3.2.15 & Snider et al., 2009 \\
NanoDrop 2000 Software & ThermoScientific \\
\hline SnapGene Viewer 3.1.4 & GSL Biotech LLC \\
PPT Drawing Toolkits & Motifolio Inc. \\
\hline
\end{tabular}

2.1.4. Kits

\begin{tabular}{|c|c|}
\hline Kit & Company \\
\hline CloneJET PCR Cloning Kit & ThermoScientific \\
\hline NucleoBond ${ }^{T M}$ Xtra Midi & Macherey-Nagel \\
\hline NucleoSpin ${ }^{\circledR}$ Gel and PCR Clean-up & Macherey-Nagel \\
\hline NucleoSpin ${ }^{\circledR}$ Plasmid & Macherey-Nagel \\
\hline $\begin{array}{l}\text { TnT }^{\circledR} \text { Quick Coupled } \\
\text { Transcription/Translation System }\end{array}$ & Promega \\
\hline
\end{tabular}

\subsubsection{Buffers, solutions, media}

\subsubsection{Buffers}

\begin{tabular}{|c|c|}
\hline Buffers & Composition \\
\hline Carbonate buffer & $0.2 \mathrm{M} \mathrm{Na}_{2} \mathrm{CO}_{3} \mathrm{pH} 11.0,4 \mathrm{mM}$ EDTA, $0.5 \mathrm{mM}$ \\
\hline $\begin{array}{l}\text { (membrane insertion) } \\
\text { Coomassie fixing solution }\end{array}$ & $\begin{array}{l}\text { PMSF } \\
40 \% \text { ethanol, } 10 \% \text { acetic acid }\end{array}$ \\
\hline Coomassie staining & $\begin{array}{l}5 \% \text { aluminum sulfate-(14-18)-hydrate, } 10 \% \\
\text { ethanol, } 2 \% \text { ortho-phosphoric acid, } 0.02 \% \text { CBB- } \\
\text { G250 }\end{array}$ \\
\hline DNA loading buffer $(6 x)$ & $\begin{array}{l}0.2 \% \text { bromophenol blue, } 0.2 \% \text { xylene cyanole, } \\
60 \% \text { glycerol, } 60 \text { mM EDTA }\end{array}$ \\
\hline Glycoprotein Denaturing buffer (10x) & $5 \%$ SDS, 0.4 M DTT \\
\hline G5 Reaction Buffer (10x) & $0.5 \mathrm{M}$ Sodium Citrate, $\mathrm{pH} 5.5$ at $25^{\circ} \mathrm{C}$ \\
\hline G7 Reaction Buffer (10x) & $0.5 \mathrm{M}$ Sodium Phosphate, $\mathrm{pH} 7.5$ at $25^{\circ} \mathrm{C}$ \\
\hline TA-protein high salt (HS) buffer & $\begin{array}{l}50 \mathrm{mM} \text { HEPES, } 500 \mathrm{mM} \text { KOAc, } 5 \mathrm{mM} \mathrm{Mg}(\mathrm{OAc})_{2,} \\
10 \% \text { glycerol, } 1 \mathrm{mM} \text { PMSF, } 1 \mathrm{mM} \text { DTT, pH } 7.0 \\
\text { freshly added: } 20 \mathrm{mM} \text { imidazole }\end{array}$ \\
\hline Laemmli running buffer (10x) & $250 \mathrm{mM}$ Tris, $1.92 \mathrm{M}$ glycine, 0.5\% SDS \\
\hline TA-protein low salt (LS) buffer & $\begin{array}{l}50 \mathrm{mM} \text { HEPES, } 150 \mathrm{mM} \mathrm{KOAc,} 5 \mathrm{mM} \mathrm{Mg}(\mathrm{OAc})_{2}, \\
\text { 10\% glycerol, } 1 \mathrm{mM} \text { PMSF, } 1 \mathrm{mM} \text { DTT, } \mathrm{pH} 7.0 \\
\text { freshly added: } 20 \mathrm{mM} \text { imidazole }\end{array}$ \\
\hline PBS (10x) & $\begin{array}{l}1.37 \mathrm{M} \mathrm{NaCl}_{2} 27 \mathrm{mM} \mathrm{KCl}, 100 \mathrm{mM} \mathrm{Na}_{2} \mathrm{HPO}_{4} \text {, } \\
18 \mathrm{mM} \mathrm{KH}_{2} \mathrm{PO}_{4}, \mathrm{pH} 7.5\end{array}$ \\
\hline PBST & $1 \times$ PBS $+0.1 \%$ Tween-20 \\
\hline PonceauS staining solution & $0.5 \%$ PonceauS in $1 \%$ acetic acid \\
\hline
\end{tabular}




\begin{tabular}{ll} 
Buffers & Composition \\
\hline \hline SDS sample buffer (4x) & $125 \mathrm{mM}$ Tris pH 6.8, 4\% SDS, 0.02\% \\
& Bromophenol blue, 10\% glycerol \\
\hline TAE buffer (50x) & 2 M Tris, 0.05 M EDTA, 5.71\% acetic acid \\
Transport buffer (10x) & $200 \mathrm{mM} \mathrm{HEPES,} \mathrm{1.1} \mathrm{M} \mathrm{KOAc,} \mathrm{20} \mathrm{mM} \mathrm{Mg(OAc)}$, \\
& $10 \mathrm{mM} \mathrm{EGTA,} \mathrm{pH} \mathrm{7.3}$ \\
Western blot transfer buffer (10x) & $250 \mathrm{mM}$ Tris, 1.93 M glycine, 0.2\% SDS \\
HK buffer (microsome assay) & $50 \mathrm{mM}$ HEPES, 50 mM KOAc
\end{tabular}

\subsubsection{Stock solutions}

Solution

1,4-Dithiothreitol (DTT)

Ammonium persulfate (APS)

Ampicillin

Aprotinin

Adenosine triphosphate (ATP)

Creatine phosphokinase

Creatine Phosphate

Digitonin

Hoechst 33258

Isopropyl b-D-1-thiogalactopyranoside

(IPTG)

Kanamycin

Leupeptin/Pepstatin

Phenylmethylsulfonyl fluoride (PMSF)

Puromycin

Tetracyclin (DH5 $\alpha$ BL21A1)

WGA (wheat germ agglutinine/lectin)

\section{Composition}

$1 \mathrm{M}$ in $\mathrm{H}_{2} \mathrm{O}$

$10 \%$ APS (Sigma) in $\mathrm{H}_{2} \mathrm{O}$

$100 \mathrm{mg} / \mathrm{ml}$ in $\mathrm{H}_{2} \mathrm{O}$

$1 \mathrm{mg} / \mathrm{ml}$ in $20 \mathrm{mM}$ HEPES $\mathrm{pH} 7.4$

$100 \mathrm{mM}$ ATP in $100 \mathrm{mM} \mathrm{Mg}(\mathrm{OAc})_{2}, 20 \mathrm{mM}$

HEPES (pH 7.4)

$0.5 \mathrm{M}$ ATP in TA-protein LS buffer

(protein purification)

$2000 \mathrm{U} / \mathrm{ml}$ in 50\% glycerol, $20 \mathrm{mM}$ HEPES $\mathrm{pH}$

7.4

$80 \mathrm{mg} / \mathrm{ml}$ in $\mathrm{H}_{2} \mathrm{O}$

$10 \%(\mathrm{w} / \mathrm{v})$ in DMSO

$10 \mathrm{mg} / \mathrm{ml}$ in $\mathrm{H}_{2} \mathrm{O}$

$1 \mathrm{M}$ in $\mathrm{H}_{2} \mathrm{O}$

$60 \mathrm{mg} / \mathrm{ml}$ in $\mathrm{H}_{2} \mathrm{O}$

$1 \mathrm{mg} / \mathrm{ml}$ each, in DMSO

$100 \mathrm{mM}$ in 2-propanol

$10 \mathrm{mg} / \mathrm{ml}$ in $\mathrm{H}_{2} \mathrm{O}$

$12.5 \mu \mathrm{g} / \mathrm{ml}$

$2 \mathrm{mg} / \mathrm{ml}$ in TPB

\subsubsection{Bacterial media}

\begin{tabular}{|c|c|}
\hline Medium & Composition \\
\hline LB & $\begin{array}{l}1 \%(\mathrm{w} / \mathrm{v}) \text { bacto-tryptone, } 0.5 \%(\mathrm{w} / \mathrm{v}) \text { yeast } \\
\text { extract, } 1 \%(\mathrm{w} / \mathrm{v}) \mathrm{NaCl}, \mathrm{pH} 7.0\end{array}$ \\
\hline LB agar plates & LB supplemented with $1.5 \%(\mathrm{w} / \mathrm{v})$ bacto-agar \\
\hline SOC & $\begin{array}{l}2 \%(\mathrm{w} / \mathrm{v}) \text { tryptone, } 0.5 \%(\mathrm{w} / \mathrm{v} \text { ) yeast extract, } \\
10 \mathrm{mM} \mathrm{NaCl}, 2.5 \mathrm{mM} \mathrm{KaCl} 10 \mathrm{mM} \\
\mathrm{MgCl}_{2}, 10 \mathrm{mM} \mathrm{MgSO}_{4}, 0.36 \%(\mathrm{w} / \mathrm{v}) \text { glucose, } \\
\mathrm{pH} 7.0\end{array}$ \\
\hline
\end{tabular}




\subsubsection{Cell culture solvents}

\begin{tabular}{|c|c|}
\hline Solvent/Medium & Company/ source \\
\hline Cytosol (9 mg/ml) & $\begin{array}{l}\text { prepared as described in Kehlenbach et al., } \\
1998\end{array}$ \\
\hline Calcium chloride buffer & $250 \mathrm{mM} \mathrm{CaCl}_{2}$ \\
\hline FBS Superior (fetal bovine serum) & Biochrom \\
\hline Gentamycin (G418) & $1 \mathrm{mg} / \mathrm{ml}$ in HEPES \\
\hline Gibco $^{\circledR}$ DMEM (1x) & life technologies \\
\hline Gibco $^{\circledR}$ Opti-MEM ${ }^{\circledR}(1 x)$ & life technologies \\
\hline $\begin{array}{l}\text { Gibco }^{\circledR} \text { Penicillin Streptomycin } \\
\text { (Pen Strep) }\end{array}$ & life technologies \\
\hline HEPES buffer $(2 x)$ & $\begin{array}{l}50 \mathrm{mM} \mathrm{HEPES} 250 \mathrm{mM} \mathrm{NaCl}, 1.5 \mathrm{mM} \\
\mathrm{Na}_{2} \mathrm{HPO}_{4}, \mathrm{pH} 6.98\end{array}$ \\
\hline L-Glutamine $200 \mathrm{mM}$ & Gibco (life technologies) \\
\hline PBS (10x) & Gibco (life technologies) \\
\hline
\end{tabular}

2.1.6. Enzymes, chemicals and reagents

\subsubsection{Enzymes}

\begin{tabular}{ll} 
Enzyme & Company \\
\hline \hline Creatine phosphokinase, Rabbit Skeletal & Calbiochem \\
Muscle & \\
DNAsel & Roth \\
Endoglycosidase H (EndoH) & NEB \\
\hline Fast alkaline phosphatase (FastAP) & Thermo Scientific \\
\hline Pfu Ultra II polymerase & Agilent \\
\hline Phusion High-Fidelity DNA Polymerase & Thermo Scientific \\
\hline Restriction enzymes (various) & Thermo Scientific \\
\hline T4 DNA ligase & Thermo Scientific \\
\hline Gibco ${ }^{\circledR}$ Trypsin/ EDTA 0.25\% (1x) & life technologies \\
Peptide -N-Glycosidase F (PNGaseF) & NEB \\
\hline
\end{tabular}

\subsubsection{Chemicals and reagents}

\section{Reagent}

B-Mercaptoethanol

Acrylamide 4K Solution (30\%)

Adenosine 5'-triphosphate disodium salt hydrate (A3377)

Advanced protein assay reagent 5x

Amylose Resin High Flow

\section{Company}

Roth

AppliChem

Sigma-Aldrich

Cytoskeleton Inc.

New England BioLabs 


\begin{tabular}{|c|c|}
\hline Reagent & Company \\
\hline $\begin{array}{l}\text { Bio-Rad Protein Assay dye reagent } \\
\text { concentrate }\end{array}$ & Bio-Rad Laboratories GmbH \\
\hline Bovine Serum Albumin (BSA) $(20 \mathrm{mg} / \mathrm{ml})$ & Thermo Scientific \\
\hline BSA, fraction $V$ & AppliChem \\
\hline D-Maltose & Serva Electrophoresis GmbH \\
\hline Dako Fluorescent Mounting Medium & Dako \\
\hline DAPI (D9542) & Sigma-Aldrich \\
\hline dNTP Set, $100 \mathrm{mM}$ solutions & Thermo Scientific \\
\hline Ethanol (analytical grade) & Roth \\
\hline Formaldehyde solution $\min .37 \%$ & Millipore \\
\hline G418 disulfate salt (A1720) & Sigma-Aldrich \\
\hline Gelatin from cold water fish & Sigma-Aldrich \\
\hline GeneRuler 100bp DNA Ladder & Thermo Scientific \\
\hline GeneRuler 1kb DNA Ladder & Thermo Scientific \\
\hline Imidazole & Roth \\
\hline $\begin{array}{l}\text { Immobilon }{ }^{\mathrm{TM}} \text { Western Chemiluminescent } \\
\text { HRP Substrate }\end{array}$ & Millipore \\
\hline IPTG & Thermo Scientific \\
\hline L-Arabinose & Roth \\
\hline Lipofectamine ${ }^{\circledR} 2000$ & life technologies \\
\hline Methanol (technical grade) & Roth \\
\hline MOWIOL ${ }^{\circledR} 4-88$ & Calbiochem \\
\hline Ni-NTA Agarose & Qiagen \\
\hline NP-40 & $10 \%$ solution \\
\hline NuPAGE ${ }^{\circledR}$ MES SDS Running Buffer (20x) & life technologies \\
\hline NuPAGE ${ }^{\circledR}$ MOPS SDS Running Buffer (20x) & life technologies \\
\hline Oligofectamine ${ }^{\mathrm{TM}}$ Reagent & life technologies \\
\hline Oligonucleotides & Sigma-Aldrich \\
\hline ortho-Phosphoric acid $85 \%$ p.A. & AppliChem \\
\hline PageRuler Prestained Protein Ladder & Thermo Scientific \\
\hline PageRuler Unstained Protein Ladder & Thermo Scientific \\
\hline Poly-L-lysine solution $0.1 \%$ (w/v) & Sigma-Aldrich \\
\hline Powdered milk & Roth \\
\hline $\begin{array}{l}\text { Puromycin dihydrochloride } \\
\text { from Streptomyces alboniger (P8833) }\end{array}$ & Sigma-Aldrich \\
\hline $\begin{array}{l}\text { Rapamycin Ready Made Solution, } \\
2.5 \mathrm{mg} / \mathrm{ml} \text { in DMSO ( } 2.74 \mathrm{mM}) \text {, } \\
\text { from Streptomyces hygroscopicus }\end{array}$ & Sigma-Aldrich \\
\hline SafeView $^{\mathrm{TM}}$ Classic (DNA stain) & Applied Biological Materials Inc. \\
\hline Trypan blue solution $0.4 \%$ & Sigma-Aldrich \\
\hline Tris (buffer grade) & AppliChem \\
\hline
\end{tabular}




\subsubsection{Antibodies}

\subsubsection{Primary antibodies}

\begin{tabular}{|c|c|c|c|c|c|}
\hline Name & Species & Origin & Application & Dilution & Number \\
\hline$\alpha$-Calnexin & rabbit & Enzo & WB & $1: 1000$ & Ab220 \\
\hline$\alpha$-Emerin & rabbit & Proteintech & IF/WB & $1: 300-1: 1000$ & $\mathrm{Ab083}$ \\
\hline$\alpha$-Emerin & rabbit & Genosphere & IF/WB & $1: 500$ & Ab209 \\
\hline$\alpha$-Emerin & mouse & Santa Cruz & IF/WB & $1: 200-1: 1000$ & Ab301 \\
\hline$\alpha$-GAPDH & rabbit & Proteintech & WB & 1:1000 & Ab080 \\
\hline$\alpha$-GFP & rat & Chromotek & IF/WB & $1: 500$ & Ab015 \\
\hline$\alpha-H A$ & mouse & Convance & IF/WB & 1:1000 & Ab186 \\
\hline$\alpha-H A$ & rabbit & Sigma & IF & $1: 500$ & Ab134 \\
\hline$\alpha-H s c 70$ & rat & Stressgen & WB & 1:1000 & --- \\
\hline$\alpha-\operatorname{Lamin} A / C$ & mouse & Abcam & IF/WB & $1: 200$ & Ab095 \\
\hline$\alpha$-LAP2 $\beta$ & rabbit & Millipore & IF & $1: 100$ & Ab199 \\
\hline$\alpha$-LBR & rabbit & Proteintech & IF/WB & $1: 300-1: 500$ & Ab085 \\
\hline$\alpha$-LRRC59 & rabbit & Sigma & IF/WB & $1: 200$ & Ab090 \\
\hline$\alpha-m y c$ & mouse & Santa Cruz & IF & $1: 200$ & Ab191 \\
\hline$\alpha$-opsin & mouse & $\begin{array}{l}\text { (Adamus et al., } \\
\text { 1991) }\end{array}$ & IF/WB & $1: 500$ & Ab092 \\
\hline$\alpha$-RFP & rat & Chromotek & IF/WB & 1:1000 & $\mathrm{Ab060}$ \\
\hline$\alpha-\operatorname{Sec} 61 \beta$ & rabbit & $\begin{array}{l}\text { Bernhard } \\
\text { Dobberstein, } \\
\text { Heidelberg }\end{array}$ & IF & $1: 1000$ & --- \\
\hline$\alpha-$ STT3B & rabbit & $\begin{array}{l}\text { Stephen High, } \\
\text { Manchester }\end{array}$ & IF & $1: 200$ & --- \\
\hline$\alpha-\operatorname{TRC} 40$ & mouse & Sigma & IF & $1: 200$ & Ab222 \\
\hline$\alpha-$ TRC40 & rabbit & $\begin{array}{l}\text { (Favaloro et al., } \\
\text { 2010) }\end{array}$ & WB & $1: 1000$ & --- \\
\hline $\begin{array}{l}\alpha \text {-alpha } \\
\text { Tubulin }\end{array}$ & rabbit & Proteintech & WB & 1:1000 & Ab081 \\
\hline$\alpha-V A P B$ & rabbit & Proteintech & IF & $1: 200$ & Ab221 \\
\hline $\begin{array}{l}\alpha \text {-WRB } \\
\text { (SYSY7676) }\end{array}$ & rabbit & $\begin{array}{l}\text { Synaptic } \\
\text { Systems }\end{array}$ & WB & $1: 200$ & --- \\
\hline
\end{tabular}

2.1.7.2. Secondary antibodies

\begin{tabular}{lllll} 
Name & Species & Origin & Application & Dilution \\
\hline \hline a-mouse HRP & goat & Jackson ImmunoResearch & WB & $1: 10000$ \\
\hline a-rabbit HRP & goat & Jackson ImmunoResearch & WB & $1: 10000$ \\
\hline a-mouse 680 & donkey & LI-COR & WB & $1: 10000$ \\
a-mouse 800 & donkey & LI-COR & WB & $1: 10000$ \\
a-rabbit 680 & donkey & LI-COR & WB & $1: 10000$ \\
a-rabbit 800 & donkey & LI-COR & WB & $1: 10000$
\end{tabular}




\begin{tabular}{|c|c|c|c|c|}
\hline Name & Species & Origin & Application & Dilution \\
\hline $\begin{array}{l}\text { a-mouse AlexaFluor }{ }^{\circledast} \\
488 \text { conjugated }\end{array}$ & donkey & Molecular Probes & IF & $1: 1000$ \\
\hline $\begin{array}{l}\text { a-mouse AlexaFluor }{ }^{\circledR} \\
594 \text { conjugated }\end{array}$ & donkey & Molecular Probes & IF & 1:1000 \\
\hline $\begin{array}{l}\text { a-mouse AlexaFluor }{ }^{\circledR} \\
633 \text { conjugated }\end{array}$ & goat & Molecular Probes & IF & $1: 1000$ \\
\hline $\begin{array}{l}\text { a-rabbit AlexaFluor }{ }^{\circledR} \\
488 \text { conjugated }\end{array}$ & donkey & Molecular Probes & IF & $1: 1000$ \\
\hline $\begin{array}{l}\text { a-rabbit AlexaFluor }{ }^{\circledast} \\
594 \text { conjugated }\end{array}$ & donkey & Molecular Probes & IF & $1: 1000$ \\
\hline $\begin{array}{l}\text { a-rabbit AlexaFluor }{ }^{\circledR} \\
647 \text { conjugated }\end{array}$ & donkey & Molecular Probes & IF & $1: 1000$ \\
\hline $\begin{array}{l}\text { a-rat AlexaFluor }{ }^{\circledR} 488 \\
\text { conjugated }\end{array}$ & goat & Molecular Probes & IF & $1: 1000$ \\
\hline
\end{tabular}

2.1.8. SiRNAs

\begin{tabular}{|c|c|c|c|}
\hline Name & siRNA sequence $5^{\prime} \rightarrow 3^{\prime}$ & Target & Company \\
\hline siRNA ASNA1_75 & GCCCUUUCAUCUCACAGAUTT & ASNA1/TRC40 & Ambion \\
\hline siRNA ASNA1_77 & CAACAUCUCAGAUGCUUUUTT & ASNA1/TRC40 & Ambion \\
\hline SIRNA CAMLG & $\begin{array}{l}\text { UAAUGAACGAGUCCAAUUUGUCUCC } \\
\text { (Yamamoto and Sakisaka, 2012) }\end{array}$ & CAMLG & Ambion \\
\hline siRNA emerin & GAAGAAGAUCUUCGAGUAC & emerin & $\begin{array}{l}\text { Eurofins } \\
\text { MWG Operon }\end{array}$ \\
\hline siRNA Lamin A/C & GGUGGUGACGAUCUGGGCU & LaminA/C & $\begin{array}{l}\text { Thermo } \\
\text { Scientific }\end{array}$ \\
\hline $\begin{array}{l}\text { siRNA non- } \\
\text { targeting (nt) }\end{array}$ & $\begin{array}{l}\text { Silencer Negative Control\#1 siRNA } \\
\text { (Cat. \# AM4635) }\end{array}$ & $\begin{array}{l}\text { scrambled } \\
\text { sequence }\end{array}$ & Ambion \\
\hline SIRNA WRB & $\begin{array}{l}\text { AAAUCCAACAGGUAAUUCCAACACC } \\
\text { (Yamamoto and Sakisaka, 2012) }\end{array}$ & WRB & Ambion \\
\hline
\end{tabular}

\subsubsection{Oligonucleotides}

All oligonucleotides used in this work were ordered either in a lyophilized state or in a ready-touse $100 \mu \mathrm{M}$ solution (purification grade: desalted) from Sigma-Aldrich and used in a $10 \mu \mathrm{M}$ working solution.

\subsubsection{Oligonucleotides used for cloning}

\begin{tabular}{lll} 
Number & Name & Sequence $\mathbf{5}^{\prime} \rightarrow \mathbf{3}^{\prime}$ \\
\hline \hline $\mathbf{G 9 0 1}$ & $\begin{array}{l}\text { Emerin Xhol } \\
\text { forward }\end{array}$ & TTTCTCGAGCTACCATGGACAACTACGCAGATCT \\
$\mathbf{G 9 0 2}$ & $\begin{array}{l}\text { Emerin BamHI - } \\
\text { stop rev }\end{array}$ & TTTGGATCCCGGAAGGGGTTGCCTTCTTCAG \\
$\mathbf{G 9 0 3}$ & $\begin{array}{l}\text { Emerin BamHI } \\
\text { +stop rev }\end{array}$ & TTTGGATCCCTAGAAGGGGTTGCCTTCTTCAG \\
$\mathbf{G 9 1 2}$ & $\begin{array}{l}\text { Emerin Kpnl } \\
\text { forward }\end{array}$ & TTTGGTACCACCATGGACAACTACGCAGATCTT \\
&
\end{tabular}




\begin{tabular}{|c|c|c|}
\hline Number & Name & Sequence $5^{\prime} \rightarrow 3^{\prime}$ \\
\hline \multirow[t]{2}{*}{ G913 } & Emerin Opsin & CAAGCTTTATCAGCCCGTCTTGTTGGAGAAAGGCACGTAGAA \\
\hline & HindIII reverse & GTTTGGGCCGAAGGGGTTGCCTTCTTCAG \\
\hline G914 & $\begin{array}{l}\text { LAP2 Nhel } \\
\text { forward }\end{array}$ & TTTGCTAGCACCATGCCGGAGTTCCTAGAG \\
\hline G915 & $\begin{array}{l}\text { LAP2 BamHI } \\
\text { minus stop rev }\end{array}$ & TTTGGATCCCGGTTGGATATTTTAGTATCTTG \\
\hline G916 & $\begin{array}{l}\text { LAP2 Kpnl } \\
\text { forward }\end{array}$ & TTTGGTACCATGCCGGAGTTCCTAGAG \\
\hline G917 & $\begin{array}{l}\text { LAP2 BamHI } \\
\text { +stop rev }\end{array}$ & TTTGGATCCCTAGTTGGATATTTTAGTATCTTG \\
\hline \multirow[t]{2}{*}{ G918 } & LAP2 Opsin & CGGATCCTATCAGCCCGTCTTGTTGGAGAAAGGCACGTAGAA \\
\hline & BamH1 reverse & GTTTGGGCCGTTGGATATTTTAGTATCTTGAAG \\
\hline G1061 & Emerin_r_Spel & AAAACTAGTTCAGAAGGGGTTGCCTTCTTCAGC \\
\hline G1062 & LAP2_f_Ncol & AAAACCATGGTTATGCCGGAGTTCCTAGAG \\
\hline G1063 & LAP2_r_Spel & AAAACTAGTTCAGTTGGATATTTTAGTATCTTGAAGA \\
\hline G1058 & $\begin{array}{l}\text { pQE_fwd } \\
\left(2333 \_2356\right)\end{array}$ & GATAGATCCAGTAATGACCTCAGA \\
\hline G1059 & $\begin{array}{l}\text { pQE_rev } \\
\text { (2447_2465) }\end{array}$ & TCCATTTTAGCTTCCTTAG \\
\hline G1060 & Emerin_f_Ncol & AAAACCATGGTTATGGACAACTACGCAGATCTTTCG \\
\hline G1061 & Emerin_r_Spel & AAAACTAGTTCAGAAGGGGTTGCCTTCTTCAGC \\
\hline G1062 & LAP2_f_Ncol & AAAACCATGGTTATGCCGGAGTTCCTAGAG \\
\hline G1063 & LAP2_r_Spel & AAAACTAGTTCAGTTGGATATTTTAGTATCTTGAAGA \\
\hline G1214 & $\begin{array}{l}\text { Oligo_cNLS_297_ } \\
402 \mathrm{fwd}\end{array}$ & AGCTTCGAATTCAGGCCCAAAGAAAAAGAGGAAAGTTGGGG \\
\hline G1215 & $\begin{array}{l}\text { Oligo_cNLS_297_- } \\
402 \text { reverse }\end{array}$ & TCGACCCCAACTTTCCTCTTTTTCTTTTGGGCCTGAATTCGA \\
\hline G1261 & FRB Kpnl fwd & TTTGGTACCGAGATCTGGCATGAAGGC \\
\hline G1262 & FRB Xhol rev & TTTCTCGAGCTGCTTTGAGATTCGTCG \\
\hline G1263 & LAP2 Xhol fwd & TTTCTCGAGCCGGAGTTCCTAGAGGAC \\
\hline G1268 & $\begin{array}{l}\text { LAP2_Kpnl_A_ } \\
\text { fwd }\end{array}$ & TTTGGTACCACCGGAGTTCCTAGAG \\
\hline G1269 & FRB fwd Spel & TTTACTAGTGAGATGTGGCATGAAGGC \\
\hline G1270 & $\begin{array}{l}\text { Emerin Forward } \\
\text { Xhol (FRB) }\end{array}$ & TTTCTCGAGATGGACAACTACGCAGATCT \\
\hline G1271 & $\begin{array}{l}\text { Emerin minus } \\
\text { start fwd Xhol }\end{array}$ & TTTCTCGAGGACAACTACGCAGATCTTTCG \\
\hline G1314 & $\begin{array}{l}\text { Emerin mut } \mathrm{C}_{-} \mathrm{H} \\
\text { BamHI + stop rev }\end{array}$ & TTTGGATCCCTAGCCTGCATGAAGTGGTAAATG \\
\hline G1315 & $\begin{array}{l}\text { Emerin mut D } \\
\text { BamHI + stop rev }\end{array}$ & TTTGGATCCCTAGAGCGGGACCTGGCGATCCTG \\
\hline G1316 & $\begin{array}{l}\text { Emerin mut E } \\
\text { BamHI + stop rev }\end{array}$ & TTTGGATCCCTAGCCCCAGAGCGGGACCTGGCG \\
\hline G1363 & $\begin{array}{l}\text { LEMD1 minus } \\
\text { start fwd Xhol }\end{array}$ & TTTCTCGAGGTGGATGTGAAGTGTCTGAGT \\
\hline
\end{tabular}




\begin{tabular}{|c|c|c|}
\hline Number & Name & Sequence $5^{\prime} \rightarrow 3^{\prime}$ \\
\hline$\overline{\text { G1364 }}$ & $\begin{array}{l}\text { LEMD1 BamHI } \\
\text { stop rev }\end{array}$ & TTTGGATCCTTAACCAAACAGCGACTTATTTTC \\
\hline G1379 & $\begin{array}{l}\text { LRRC59 Forward } \\
\text { Xhol }\end{array}$ & TTTCTCGAGATGACCAAGGCCGGTAGC \\
\hline G1382 & $\begin{array}{l}\text { FRB_BamH1_Mo } \\
\text { d }\end{array}$ & TTTGGATCCGGCTGCTTTGAGATTCGTCGGAA \\
\hline G1385 & $\begin{array}{l}\text { VAPB Forward } \\
\text { (Kpnl) }\end{array}$ & TTTGGTACCGCGAAGGTGGAGCAG \\
\hline G1386 & $\begin{array}{l}\text { VAPB Reverse } \\
\text { (BamHI) }\end{array}$ & GGATGGATCCCTACAAGGCAATCTTCCCAAT \\
\hline G1390 & $\begin{array}{l}\text { VAPB fwd Kpnl } \\
\text { corr }\end{array}$ & TTTGGTACCAGCGAAGGTGGAGCAGGTC \\
\hline G1394 & $\begin{array}{l}\text { VAPB_op BamHI } \\
\text { rev pET }\end{array}$ & $\begin{array}{l}\text { TTTGGATCCTCAGCCCGTCTTGTTGGAGAAAGGCACG } \\
\text { TAGAAGTTTGGGCCCAAGGCAATCTTCCCAATAAT }\end{array}$ \\
\hline G1395 & PTP1B Kpnl fwd & TTTGGTACCCATGGAGATGGAAAAGGAGTTC \\
\hline G1396 & $\begin{array}{l}\text { PTP1B } \\
\text { BamHI_stop rev }\end{array}$ & TTTGGATCCCTATGTGTTGCTGTTGAACAG \\
\hline G1397 & $\begin{array}{l}\text { PTP1B fwd Kpnl } \\
\text { pET }\end{array}$ & TTTGGTACCATGGAGATGGAAAAGGAGTTC \\
\hline G1398 & $\begin{array}{l}\text { PTP1B_op_BamHI } \\
\text { rev pET }\end{array}$ & $\begin{array}{l}\text { TTTGGATCCTCAGCCCGTCTTGTTGGAGAAAGGCACGTAGAA } \\
\text { GTTTGGGCCTGTGTTGCTGTTGAACAGGAACCT }\end{array}$ \\
\hline G1424 & LBR fwd Xhol & TTTCTCGAGTTATGCCAAGTAGGAAATTTGCC \\
\hline G1425 & $\begin{array}{l}\text { LBR rev BamHI } \\
\text { stop }\end{array}$ & TTTGGATCCCTAGTAGATGTATGGAAATATACG \\
\hline G1452 & LRRC59 forw Xhol & TTTCTCGAGCTACCATGACCAAGGCCGGTAGC \\
\hline G1453 & LRRC59 rev EcoRI & TTTGAATTCTCACTGCTGAGAGTCGGTC \\
\hline G1454 & $\begin{array}{l}\text { LEMD1 fwd Kpnl } \\
\text { pET }\end{array}$ & TTTGGTACCATGGTGGATGTGAAGTGTCTG \\
\hline G1455 & $\begin{array}{l}\text { LEMD1_op_Bam } \\
\text { HI rev pET }\end{array}$ & $\begin{array}{l}\text { TTTGGATCCTCAGCCCGTCTTGTTGGAGAAAGGCACGTAGAA } \\
\text { GTTTGGGCCACCAAACAGCGACTTATTTTC }\end{array}$ \\
\hline G1471 & $\begin{array}{l}\text { FKBP12 BspEl } \\
\text { (Kpn2I) fwd }\end{array}$ & TTTTCCGGAATGGGAGTGCAGGTGGAGACT \\
\hline G1472 & FKBP12 Bglll rev & TTTAGATCTTTCCAGTTTTAGAAGCTCCAC \\
\hline G1473 & FRB Ncol fwd & TTTCCATGGAAGAGATGTGGCATGAAGGC \\
\hline G1474 & FRB EcoRI rev & TTTGAATTCTGCTTTGAGATTCGTCGGAA \\
\hline G1475 & $\begin{array}{l}\text { Emerin Xhol fwd } \\
(p E F)\end{array}$ & TTTCTCGAGAATGGACAACTACGCAGATCTT \\
\hline G1476 & $\begin{array}{l}\text { Emerin Spel stop } \\
\text { rev }\end{array}$ & TTTACTAGTCTAGAAGGGGTTGCCTTCTTC \\
\hline G1477 & LBR Xhol_fwd & TTTCTCGAGATGCCAAGTAGGAAATTTGCC \\
\hline G1502 & $\begin{array}{l}\text { Histone1 Hindlll } \\
\text { fwd }\end{array}$ & TTTAAGCTTAATGACCGAGAATTCCACGTCC \\
\hline G1503 & $\begin{array}{l}\text { Histone1 BamHI } \\
\text { rev }\end{array}$ & TTTGGATCCTTCTTCTTCTTGCCGGCCCTCTT \\
\hline G1504 & FKBP12 Nhel fwd & TTTGCTAGCAAATGGGAGTGCAGGTGGAGACC \\
\hline
\end{tabular}




\begin{tabular}{|c|c|c|}
\hline Number & Name & Sequence $5^{\prime} \rightarrow 3^{\prime}$ \\
\hline G1505 & $\begin{array}{l}\text { FKBP12 HindIII } \\
\text { rev }\end{array}$ & "TTTAAGCTTAATTCCAGTTTTAAGAAGCTC \\
\hline G1506 & $\begin{array}{l}\text { Emerin Clal } \\
\text { (Bsu15I) fwd } \\
\text { (pEF) }\end{array}$ & TTTATCGATAATGGACAACTACGCAGATCTT \\
\hline G1507 & $\begin{array}{l}\text { LEMD1 Clal } \\
\text { (Bsu15I) fwd } \\
\text { (pEF) }\end{array}$ & TTTATCGATAATGGTGGATGTGAAGTGTCTG \\
\hline G1508 & $\begin{array}{l}\text { LEMD1 Spel stop } \\
\text { rev }\end{array}$ & TTTACTAGTCTAACCAAACAGCGACTTATT \\
\hline G1509 & $\begin{array}{l}\text { PTP1B Clal } \\
\text { (Bsu15I) fwd } \\
\text { (pEF) }\end{array}$ & TTTATCGATAATGGAGATGGAAAAGGAGTTC \\
\hline G1510 & $\begin{array}{l}\text { PTP1B Spel stop } \\
\text { rev }\end{array}$ & TTTACTAGTCTATGTGTTGCTGTTGAACAG \\
\hline G1511 & $\begin{array}{l}\text { VAPB Spel stop } \\
\text { rev }\end{array}$ & TTTACTAGTCTACAAGGCAATCTTCCCAAT \\
\hline G1512 & $\begin{array}{l}\text { VAPB EcoRI fwd } \\
\text { (pEF) }\end{array}$ & TTTGAATTCAATGGCGAAGGTGGAGCAGGTC \\
\hline G1514 & FKBP12 Bglll fwd & TTTAGATCTATGGGAGTGCAGGTGGAGACC \\
\hline G1518 & FRB Kpnl fwd & TTTGGTACCAGAGATGTGGCATGAAGGC \\
\hline G1519 & FRB BamHI rev & TTTGGATCCTGCTTTGAGATTCGTCGGAA \\
\hline G1522 & $\begin{array}{l}\text { LAP2b Clal } \\
\text { (Bsu15I) fwd pEF }\end{array}$ & TTTATCGATACCGGAGTTCCTAGAGGAC \\
\hline G1523 & $\begin{array}{l}\text { LAP2b Spel stop } \\
\text { rev }\end{array}$ & TTTACTAGTCTAGTTGGATATTTTTAGTATC \\
\hline G1540 & M9 EcoRI fwd & TTTGAATTCAGGGAATTACAACAATCAGTCT \\
\hline G1541 & M9 Sall rev & TTTGTCGACATAGCCACCTTGGTTTCG \\
\hline G1542 & M9 Kpnl fwd & TTTGGTACCGGGAATTACAACAATCAGTCT \\
\hline G1543 & M9 BamHI rev & TTTGGATCCATAGCCACCTTGGTTTCGTG \\
\hline G1544 & M9 Sall_fwd & TTTGTCGACGGGAATTACAACAATCAGTCT \\
\hline
\end{tabular}

\subsubsection{Oligonucleotides for mutagenesis}

The listed primers were used for site-directed mutagenesis to obtain a plasmid for mCherry-FRBemerin GIn228His expression in cells.

\begin{tabular}{ll} 
Name & Sequence $\mathbf{5}^{\prime} \rightarrow \mathbf{3}^{\prime}$ \\
\hline \hline Emerin Mut F_Gln228His_fwd & CGCTCTGGGGCCATCTGCTGCTTTTCC \\
Emerin Mut F_GIn228His_rev & GGAAAAGCAGCAGATGGCCCCAGAGCG
\end{tabular}




\subsubsection{Oligonucleotides for sequencing}

Sequencing oligonucleotides were either obtained from Sigma-Aldrich or standard sequencing primers from GATC were used (PrimerScout tool was used, see https://www.gatcbiotech.com/de/).

\begin{tabular}{lll} 
Number & Name & Sequence $\mathbf{5}^{\prime} \rightarrow \mathbf{3}^{\prime}$ \\
\hline \hline G545 & pmCherry_seq_f & CGCTGAGGTCAAGACCACC \\
GATC & T7minus1 & AATACGACTCACTATAGGG \\
GATC & pQE-FP & CGGATAACAATTTCACACAG \\
GATC & pQE-RP & GTTCTGAGGTCATTACTGG \\
GATC & pET-RP & CTAGTTATTGCTCAGCGG \\
GATC & pEGFP_C2-FP & GATCACATGGTCCTGCTG \\
GATC & pcDNA3.1-RP/1 & CAAACAACAGATGGCTGGC \\
GATC & pcDNA3.1-FP & CTCTGGCTAACTAGAGAAC
\end{tabular}

\subsubsection{Vectors and plasmids}

2.1.10.1. Plasmids and vectors used in this work

\begin{tabular}{|c|c|}
\hline Number & Name \\
\hline 1233 & mCherry-FRB-LAP2 $\beta$ \\
\hline 1573 & mCherry-FRB-LBR \\
\hline 1490 & mCherry-FRB-LEMD1 \\
\hline 1424 & mCherry-FRB-LRRC59 \\
\hline 1495 & mCherry-FRB-PTP1B \\
\hline 1487 & mCherry-FRB-VAPB \\
\hline 1232 & mCherry-FRB-emerin \\
\hline 1417 & mCherry-FRB-emerin Pro183Thr \\
\hline 1418 & mCherry-FRB- emerin Pro183His \\
\hline 1419 & mCherry-FRB- emerin Leu225Arg-FS \\
\hline 1420 & mCherry-FRB- emerin Trp226* \\
\hline 1489 & mCherry-FRB- emerin Gln228His \\
\hline 1422 & mCherry-FRB- emerin $\Delta$ Val236-Phe241 \\
\hline 1423 & mCherry-FRB- emerin Phe240His-FS \\
\hline 1581 & HA-FRB-emerin \\
\hline - & HA-emerin Pro183Thr \\
\hline - & HA-emerin Pro183His \\
\hline - & HA-emerin Leu225Arg-FS \\
\hline - & HA-emerin Trp226* \\
\hline - & HA-emerin $\mathrm{G} \ln 228 \mathrm{His}$ \\
\hline - & HA-emerin $\triangle$ Val236-Phe241 \\
\hline- & HA-emerin Phe240His-FS \\
\hline 1241 & WRB-FRB-HA \\
\hline 1604 & pcDNA3-VAPB-ops28 \\
\hline
\end{tabular}




\begin{tabular}{ll} 
Number & Name \\
\hline \hline 1230 & EGFP2-GST-NLS-FKBP12 \\
1229 & EGFP2-NLS-FKBP12 \\
1603 & EGFP2-GST-M9-FKBP12 \\
1587 & FKBP12-Histone1-GFP \\
1632 & EGFP-FKBP12 \\
1051 & mCherry-emerin \\
1057 & mCherry-LAP2 $\beta$ \\
1220 & mCherry-LRRC59 \\
1129 & HA-emerin \\
1130 & HA-LAP2 $\beta$ \\
1502 & pET328-HZZ-tev-VAPB-op \\
1497 & pET328-HZZ-tev-PTP1B-op \\
1058 & pET328-HZZ-tev- LAP2 $\beta-o p$ \\
1052 & pET328-HZZ-tev- emerin-op- \\
1055 & pQE80-MBP-tev-TRC40---HZZ-tev-emerin-op \\
1498 & pQE80-MBP-tev-TRC40---HZZ-tev-PTP1B-op \\
1503 & pQE80-MBP-tev-TRC40---HZZ-tev-VAPB-op \\
1236 & pQE80-MBP-tev-TRC40---mCherry-tev-FRB-emerin \\
1226 & pQE80-MBP-tev-TRC40--- mCherry-tev- $\Delta 1-106-e m e r i n-o p$ \\
\hline
\end{tabular}

2.1.11. Proteins

\begin{tabular}{|c|c|}
\hline Name & Source \\
\hline Cy3-BSA-NLS & Kehlenbach lab \\
\hline Atto488-BSA-NLS & Kehlenbach lab \\
\hline GST-CAML-N & $\begin{array}{l}\text { Schwappach lab, } \\
\text { (Yamamoto and } \\
\text { Sakisaka, 2012) }\end{array}$ \\
\hline MBP-tev-TRC40/His-ZZ-tev-emerin-opsin & Plasmid \#1053 \\
\hline MBP-tev-TRC40/His-ZZ-tev-emerin-opsin Mut Pro183Thr & Schwappach lab \\
\hline MBP-tev-TRC40/His-ZZ-tev-emerin-opsin Mut Pro183His & Schwappach lab \\
\hline MBP-tev-TRC40/His-ZZ-tev-emerin-opsin Mut Leu225Arg-FS & Schwappach lab \\
\hline MBP-tev-TRC40/His-ZZ-tev-emerin-opsin Mut Trp226* & Schwappach lab \\
\hline MBP-tev-TRC40/His-ZZ-tev-emerin-opsin Mut GIn228His & Schwappach lab \\
\hline MBP-tev-TRC40/His-ZZ-tev-emerin-opsin Mut $\Delta$ Val236-Phe241 & Schwappach lab \\
\hline MBP-tev-TRC40/His-ZZ-tev-emerin-opsin Mut Phe240His-FS & Schwappach lab \\
\hline MBP-tev-TRC40/mCherry-tev-emerin-opsin & Plasmid \#1055 \\
\hline MBP-tev-TRC40/mCherry-tev- $\Delta 1-106$ emerin-opsin & Plasmid \#1226 \\
\hline MBP-tev-TRC40/mCherry-tev-FRB-emerin & Plasmid \#1236 \\
\hline MBP-tev-TRC40/His-ZZ-tev-FRB-PTP1B-opsin & Plasmid \#1498 \\
\hline MBP-tev-TRC40/His-ZZ-tev-FRB-VAPB-opsin & Plasmid \#1503 \\
\hline MBP-WRBCC & $\begin{array}{l}\text { Schwappach lab, } \\
\text { (Vilardi et al., 2011) }\end{array}$ \\
\hline Ran & $\begin{array}{l}\text { Kehlenbach lab, } \\
\text { (Melchior et al., 1995) }\end{array}$ \\
\hline
\end{tabular}




\subsubsection{Cell lines}

2.1.12.1. Mammalian cell lines

\begin{tabular}{|c|c|c|}
\hline Cell line & Characteristics & Origin \\
\hline $\begin{array}{l}\text { HeLa P4 } \\
\text { (P4 MAGI CCR5+ } \\
\text { Cells) }\end{array}$ & $\begin{array}{l}\text { Human adenocarcinoma cell line; } \\
\text { modified expressing CD4; adherent; } \\
\text { derived from cervix of a 31-year-old } \\
\text { woman }\end{array}$ & $\begin{array}{l}\text { NIH AIDS Reagent } \\
\text { Program; } \\
\text { (Charneau et al., 1994) }\end{array}$ \\
\hline U2-OS (U2OS) & $\begin{array}{l}\text { Human osteosarcoma cell line; adherent; } \\
\text { derived from a moderately differentiated } \\
\text { sarcoma of the tibia of a } 15 \text {-year-old girl }\end{array}$ & ATCC $^{\circledR}$ HTB96 \\
\hline
\end{tabular}

\subsubsection{Bacterial strains}

For cloning and protein expression different $E$. coli strains were used.

\begin{tabular}{ll} 
Strain & Features \\
\hline \hline BL21-Al & F- ompT hsdSB (rB- mB-) gal dcm araB::T7RNAP tetA \\
DH5 $\alpha$ & F- Ф80lacZ $\Delta$ M15 $\Delta$ (lacZYA-argF) U169 recA1 endA1 hsdR17 (rK-,mK+) \\
& phoA supE44 $\lambda$ - thi-1 gyrA96 relA1 \\
JM109 & endA1 glnV44 thi-1 relA1 gyrA96 recA1 mcrB+ $\Delta$ (lac-proAB) e14- \\
& {$\left[F^{\prime}\right.$ traD36 proAB + laclq lacZ $\Delta$ M15] hsdR17(rK- mK+) }
\end{tabular}




\subsection{Methods}

\subsubsection{Molecular Biology techniques}

\subsubsection{Transformation of plasmid- DNA into E. coli DH5 $\alpha$}

Chemically competent $E$. coli strains were thawed on ice for about 10 to 15 minutes. The plasmid DNA or ligation reaction was added to the cells and mixed. After this, an incubation time of 30 minutes on ice followed. The cells were exposed to a heat shock at $42{ }^{\circ} \mathrm{C}$ for 90 seconds and cooled down for another minute on ice. In the next step, cells were incubated with $450 \mu \mathrm{l} \mathrm{SOC}$ medium without antibiotic selection for 35 to 60 minutes at $37{ }^{\circ} \mathrm{C}$ on a Thermomixer ( $800 \mathrm{rpm}$ ) for recovery and bacterial growth. Afterwards, cells were plated on LB-agar containing the respective antibiotic and incubated at $37{ }^{\circ} \mathrm{C}$ overnight. With respect to the purpose of transformation (ligation or re-transformation), the amounts of cell suspension plated onto the LB-agar plates therefore varied.

\subsubsection{Isolation of plasmid-DNA}

The isolation of plasmid DNA was performed with either NucleoSpin ${ }^{\circledR}$ Plasmid (Macherey-Nagel) for small scale isolations and with the NucleoBond ${ }^{\mathrm{TM}}$ Xtra Midi kit (Macherey-Nagel) in case of large scale purifications.

For mini-preparations of DNA, $5 \mathrm{ml}$ bacterial cultures were prepared by using LB medium containing the appropriate antibiotic and a single bacterial colony was picked from an LB-agar plate for inoculation overnight at $37^{\circ} \mathrm{C}$, shaking at $140 \mathrm{rpm}$. The next day, $2 \mathrm{ml}$ of this bacterial culture were pelleted at $11000 \mathrm{~g}$ for one minute at $4{ }^{\circ} \mathrm{C}$ (Centrifuge $5415 \mathrm{R}$, Eppendorf) in $2 \mathrm{ml}$ tubes. The mini-preparation of DNA was purified according to the manufacturer's protocol (see section 2.1.4). The DNA elution step was performed with two times $25 \mu$ l elution buffer heated to $70{ }^{\circ} \mathrm{C}$ and incubated 2 minutes at $70^{\circ} \mathrm{C}$ prior to centrifugation.

For DNA purifications in a large scale, $250 \mathrm{ml}$ bacterial cultures were set up. The LB medium was supplemented with an antibiotic (according to the plasmids resistance) and inoculated with one bacterial clone (picked from an LB-agar plate) overnight in an Erlenmeyer flask at $37{ }^{\circ} \mathrm{C}$ at $140 \mathrm{rpm}$. The bacterial culture was pelleted by centrifugation at $5250 \mathrm{~g}$ for 15 minutes at $4{ }^{\circ} \mathrm{C}$ (Allegra ${ }^{\circledR}$ X-15R with rotor SX4750, Beckman-Coulter). The midi-preparation of DNA was extracted according to the manufacturer's protocol (see section 2.1.4). The isopropanol precipitated DNA was resuspended in $100 \mu$ l of desalted water.

Plasmid concentrations and purity were measured with the NanoDrop (NanoDrop 2000c software, Thermo Scientific) and adjusted to $1 \mu \mathrm{g} / \mu \mathrm{l}$ with desalted water in case of DNA produced in midi-preparations.

\subsubsection{Polymerase chain reaction}

The polymerase chain reaction (PCR) is used to amplify DNA sequences from a template DNA by means of thermostable DNA polymerases. For amplification of specific DNA regions small oligonucleotides, termed primers, are needed. Primers used in this work were designed to be 
complementary to the sequence of interest (about 20 nucleotides) and contained an overhang at the 5 '-end. For cloning reasons restriction enzyme sequence motifs were inserted as well. In the reverse oligonucleotide, also sequences coding for translation termination were inserted when desired. In general, the length of an oligonucleotide did not extent more than 30 base pairs including the features like restriction sites. For primer design and characterization, the Lasergene software as well as the Tm calculator, Multiple primer analyzer and PCR reaction setup tool for Phusion (Thermo Scientific homepage) were used. Another important factor needed for PCR are deoxyribonucleotide triphosphates (dNTPs) for the amplification.

PCR reactions were performed with the proof-reading Phusion High-Fidelity DNA Polymerase (Thermo Scientific) in a $50 \mu \mathrm{l}$ volume and set up according to manufacturer's instructions. The amount of DNA used as a template did not exceed $200 \mathrm{ng}$, primers were used at a concentration of $0.5 \mu \mathrm{M}$ and dNTPs at a concentration of $200 \mu \mathrm{M}$ and one unit of Phusion polymerase was added.

PCR amplification was done in a thermocycler with an initial DNA denaturation step at $98{ }^{\circ} \mathrm{C}$ for 30 seconds. A routine PCR was performed for 35 cycles, consisting of denaturation $\left(98^{\circ} \mathrm{C}\right.$ for 10 seconds), annealing ( 65 to $72{ }^{\circ} \mathrm{C}$ for 15 - 30 seconds, depending on the $\mathrm{G} / \mathrm{C}$ content of the primer) and elongation ( $72{ }^{\circ} \mathrm{C}$ for 15 - 30 seconds, adjusted to the construct's expected size). Typically, a final extension step followed at $72{ }^{\circ} \mathrm{C}$ for 10 minutes and the reactions were cooled to $4{ }^{\circ} \mathrm{C}$ for further processing.

PCR reactions were mixed with $6 \times$ DNA loading buffer and analyzed by agarose gelelectrophoresis (see section 2.2.1.5).

\subsubsection{Site-directed mutagenesis}

Site-directed mutagenesis was used to induce specific changes into a DNA sequence. In this work, the emerin mutant Gln228His was cloned by using this method. The primers, which were used for the PCR can be found in section 2.1.9.2.

The PCR - protocol used is based on the polymerase Pfu Ultra II (Agilent) and a standard 35 cycle PCR - protocol was run with an elongation temperature of $60{ }^{\circ} \mathrm{C}$, which was adjusted to the templates size. Afterwards the PCR-product was digested with $1 \mu$ I Dnl (Thermo Scientific) for three hours at $37^{\circ} \mathrm{C}$. Then, a transformation of $10 \mu \mathrm{l}$ reaction was performed in $E$. coli DH5 $\alpha$ for one hour (see section 2.2.1.1) and plated onto LB-agar plates. An overnight incubation at $37^{\circ} \mathrm{C}$ followed and the next day six clones were analyzed for correct insertion of the mutation.

\subsubsection{Agarose gel electrophoresis}

Agarose gel-electrophoresis is a method to separate nucleic acids according to their size. The different DNA fragments were visualized by the SafeView ${ }^{\mathrm{TM}}$ Classic DNA stain.

During cloning in this work, 1 to $2 \%$ agarose gels were used. The agarose was dissolved in $1 \mathrm{x}$ TAE buffer using the microwave. After the gel solution was cooled to $60^{\circ} \mathrm{C}$, the DNA stain was added at a dilution of 1:20000 and the gel was casted into a chamber including a comb for loading pockets. The solidified gel was placed into a running chamber filled with $1 x$ TAE buffer and samples supplemented with 6x DNA loading buffer were loaded onto the gel next to a suitable marker (GeneRuler $100 \mathrm{bp} / 1 \mathrm{~kb}$ DNA Ladder). Gel electrophoresis was performed depending on the degree of DNA separation at $120 \mathrm{~V}$ for about 45 minutes. DNA fragments determined for 
further cloning were cut out of the gel with a scalpel during visualization on a UV transilluminator and were purified with the NucleoSpin ${ }^{\circledR}$ Gel /PCR Clean-up kit (Macherey-Nagel) according to the manufacturer's instructions. In case DNA fragments resulted from an analytical restriction enzyme digestion, agarose gels were documented with the INTAS GeISTICK "touch" system.

\subsubsection{Restriction enzyme digestion}

Restriction enzymes (Thermo Scientific) were used to specifically cut DNA in order to insert or remove designed or gene based DNA sequences into vectors. Cloning strategies were planned with the DoubleDigest tool provided by Thermo Scientific. There, enzyme combinations, ratios and appropriate reaction buffers were suggested.

For preparative digestions, the whole amount of purified PCR - product $(50 \mu \mathrm{l})$ and about 4 to $5 \mu \mathrm{g}$ of plasmid DNA ( 20 to $30 \mu$ final volume) was used for digestion. The appropriate restriction enzyme buffer and not more than 1 unit of the enzymes were added for two hours at $37^{\circ} \mathrm{C}$.

For analytical digestions (e.g. analyzing DNA plasmids from mini-preparation) only 0.5 to $1 \mu \mathrm{g}$ of DNA was used per reaction and respectively less enzymes ( 0.2 units) were used for one hour at $37^{\circ} \mathrm{C}$.

After the digestion reaction, $6 \mathrm{x}$ DNA loading buffer was added to the restriction enzyme reaction mixture. Via agarose gel-electrophoresis the digested DNA was analyzed and simultaneously cleaned from enzymes. Bands with the correct size were cut from the gel with a scalpel after visualization with an UV transilluminator and purified for further cloning steps. For documentation, the GeISTICK "touch" system (INTAS) was used.

\subsubsection{Dephosphorylation of vectors}

During cloning of different constructs some cloning strategies were based on using one restriction enzyme only to digest at multiple sites and remove a DNA sequence and linearize DNA. In particular, these vectors were prone to re-ligate and normal ligation reactions could be impeded. To prevent this, a dephosphorylation reaction was performed with FastAP Thermosensitive Alkaline Phosphatase (Thermo Scientific). After digestion and purification from agarose gels, the plasmid DNA was dephosphorylated for 10 minutes at $37^{\circ} \mathrm{C}$ in AP reaction buffer and an enzyme inactivating step for $5 \mathrm{~min}$ at $75^{\circ} \mathrm{C}$ followed. The dephosphorylated DNA was immediately used for DNA ligation reactions.

\subsubsection{Ligation of DNA}

The ligation reaction was used to link an insert DNA sequence with the backbone of a plasmid DNA, both of which display complementary restriction overhangs. Here, specifically the T4 DNA ligase (Thermo Scientific) was used. A standard ligation reaction volume of $10 \mu$ l contained of $1 \mu \mathrm{l}$ ATP (100 mM), $1 \mu \mathrm{l}$ T4 DNA ligase reaction buffer (10x) (provided along with the enzyme), $0.5 \mu \mathrm{l}$ T4 DNA ligase as well as 20 - $50 \mathrm{ng}$ of backbone vector DNA and the insert DNA.

The DNA sequences were ligated in a molar ratio of 1:3 (vector to insert) and the reaction was carried out for one hour at room temperature. Half of the mixture was transformed into $E$. coli DH5 $\alpha$. 


\subsubsection{Sequencing of DNA}

All plasmid DNA cloned was sent for sequencing to the company GATC. A standard $1.5 \mathrm{ml}$ reaction tube was used to dilute the DNA in a final concentration of 30 to $100 \mathrm{ng}$ per $\mu \mathrm{l}$ in a final volume of $20 \mu \mathrm{l}$. Either GATC-standard sequencing primers (PrimerScout tool at GATC homepage) were chosen or customer specific primers (lab internal primers) were sent to GATC at a concentration of $10 \mathrm{pmol} / \mu \mathrm{l}$ as well in a volume of $20 \mu \mathrm{l}$.

\subsubsection{Biochemical techniques}

\subsubsection{SDS-PAGE}

A method used to separate proteins according to their molecular weight in an electric field is termed SDS (sodium dodecyl sulfate) polyacrylamide gel electrophoresis (SDS-PAGE) and was first described by Laemmli (1970). This system is based on a non-continuous, two-parted gel, which is placed in a Tris- $\mathrm{HCl} /$ Tris-glycine buffer environment and allows separation of proteins in a denatured and reduced state. The gel consists of a stacking and a resolving part. For the resolving gel concentrations between 8 to 15\% acrylamide were chosen depending on the protein size. The samples were combined with SDS sample buffer and boiled at $95^{\circ} \mathrm{C}$ for 5 minutes. The gels were placed into the Hoefer SE250 chamber and filled with Laemmli running buffer (1x). Besides the samples, a protein ladder (PageRuler Unstained or PageRuler Prestained (Thermo)) was loaded onto the gel. The gel was run with an electric current of $25 \mathrm{~mA}$ per gel and $300 \mathrm{~V}$ for about one hour. For pre-cast gradient gels (NuPAGE ${ }^{\circledR}$ Novex Bis-Tris (4 - 12\%)) MOPS SDS buffer $(1 \mathrm{x})$ was used as running buffer. For electrophoresis XCell SureLock ${ }^{\circledR}$ Mini-Cell chambers were used for about 50 minutes at $200 \mathrm{~V}$. After the protein separation was finished, the proteins were visualized by immunoblotting or Coomassie staining (for protein purification samples).

\subsubsection{Coomassie staining}

After SDS-PAGE was completed, the gels were washed once with desalted water. The proteins were fixed by using the Coomassie fixing solution for about 5 minutes on a shaker. After removal of the fixing solution, the actual Coomassie staining solution was applied. The incubation time can vary between minutes to hours, depending on the amount of protein separated on the gel. Hereafter, the gel is destained with desalted water. Only if there is a very high background staining, a Coomassie destaining solution is applied. The SDS gels stained with Coomassie were imaged with the LAS-3000 Imager (Fujifilm) and analyzed with ImageJ.

\subsubsection{Western Blotting and detection of proteins}

Western Blotting (Immunoblotting)

After protein separation via SDS-PAGE, the gels were blotted under wet conditions onto a Hybond ECL nitrocellulose membrane (GE Healthcare). This method is used to detect membranebound proteins via HRP- or fluorophore-coupled secondary antibodies as described below.

The gel was assembled for transfer (sponge, Whatman paper sheets, SDS gel, membrane, Whatman paper sheets, sponge) directly in Western blot transfer buffer (1x, supplemented with 
$20 \%$ methanol). The cassette including the gel and the membrane (facing the positive electrode) was placed into the blotting chamber and transfer was performed at $300 \mathrm{~V}$ and $400 \mathrm{~mA}$. When transfer was performed in a Mini Trans-Blot ${ }^{\circledR}$ Cell (Bio-Rad) chamber the voltage was lowered to $150 \mathrm{~V}$ and the current was set to $350 \mathrm{~mA}$. The transfer time depended on the size of the protein (gel percentage), but was at least $1.5 \mathrm{~h}$.

\section{Ponceau staining}

After blotting, the membrane was washed once with PBST (1x). To control the quality of protein transfer, a PonceauS staining solution was applied to the membrane for one minute. The dye was removed and the membrane was rinsed with $1 \%(\mathrm{v} / \mathrm{v})$ acetic acid. For further processing, the membrane was washed again with PBST.

\section{$\underline{\text { Immunological detection of proteins }}$}

To reduce unspecific binding of antibodies, the nitrocellulose membrane was blocked with $4 \%$ milk powder in PBST $(1 \mathrm{x})$ for 30 minutes. Afterwards the primary antibodies were diluted appropriately in 4\% milk-PBST solution (see section 2.1.7.1) and incubated $3 \mathrm{~h}$ at room temperature or overnight at $4{ }^{\circ} \mathrm{C}$. For an incubation on a rolling device, the membranes were placed in a $50 \mathrm{ml}$ tube.

After washing the blots three times for 10 minutes with PBST, the secondary antibodies were applied.

Either HRP- or fluorophore-coupled secondary antibodies (see section 2.1.7.2) were used for detection of proteins. In both cases, the secondary antibody (1:10000 diluted in 4\% milk-PBST) was incubated for one hour at room temperature.

The horseradish-peroxidase (HRP) -coupled antibodies were mainly used in experiments, where low protein amounts were known to be present and a very sensitive detection was needed. After the secondary antibody incubation, three washing steps, each 5 minutes, with PBST followed. Immobilon $^{\text {TM }}$ Western Chemiluminescent HRP Substrate (Millipore) was applied onto the membrane and proteins were detected by using light sensitive Amersham Hyperfilm ECL (GE Healthcare) or Medix XBU medical x-ray films (FOMA Bohemia) in combination with the automated CURIX60 (Agfa) developing machine.

For detection of fluorophore-coupled secondary antibodies bound to the primary antibody the LI-COR system was used. After secondary antibody incubation, which was done in dark LI-COR incubation boxes, the membrane was washed three times for 10 minutes with PBST and kept in the boxes. As a last step, the membrane was placed into 1x PBS. For protein detection, the membrane was transferred to the Odyssey ${ }^{\circledR}$ Sa Infrared Imaging System (LI-COR) and analyzed with the ImageStudio software (version 4.0.21, LI-COR).

\subsubsection{Expression and purification of tail-anchored proteins}

Tail-anchored proteins used in this work were co-expressed and co-purified in a complex with the ATPase TRC40 (e.g. MBP-tev-TRC40/His-ZZ-tev-emerin-opsin). The protocol for protein expression and purification is based on the method used by Favaloro et al. (2010). 
Plasmids for TA - protein expression (see section 2.1.10) were transformed in the $E$. coli strain BL21AI (Invitrogen) using the standard protocol (see section 2.2.1.1). An overnight pre-culture was prepared using LB medium supplemented with ampicillin at $37^{\circ} \mathrm{C}$. By using $5 \%$ of the preculture the large scale bacterial culture (ranging from 3 to 6 liter) was grown in LB medium supplemented with ampicillin at $30^{\circ} \mathrm{C}$ shaking at $130 \mathrm{rpm}$ until an $\mathrm{OD}_{600}$ of 0.6 was obtained. The expression of MBP-tev-TRC40 (under control of a T5 promotor) was induced with 0.05 mM IPTG for one hour at $30^{\circ} \mathrm{C}$. Then, the TA-protein (T7 promotor under control of an arabinose-inducible araBAD promotor) expression was induced with $0.25 \%(\mathrm{w} / \mathrm{v}) \mathrm{L}-$ Arabinose for four hours at $30{ }^{\circ} \mathrm{C}$. Cells were harvested by centrifugation at $5020 \mathrm{~g}$ for 30 minutes.

The first step of protein purification was the resuspension of the bacterial cells in TA-protein low salt (LS) buffer with freshly added protease inhibitors ( $1 \mu \mathrm{g} / \mathrm{ml}$ Aprotinin, Leupeptin-Pepstatin), $1 \mathrm{mM}$ PMSF and $20 \mathrm{mM}$ imidazole as well as $10 \mu \mathrm{g} / \mathrm{ml}$ DNase I. Cells were lysed using an Emulsiflex - C3 (Avestin) and pelleted by centrifugation at $100000 \mathrm{~g}$ for 30 minutes in an Avanti ${ }^{\mathrm{TM}}$ J-30I centrifuge with rotor JA 30.50Ti (Beckman Coulter). The supernatant was incubated on a rotator with Ni-NTA agarose (Qiagen) pre-equilibrated with LS buffer, at $4{ }^{\circ} \mathrm{C}$ to bind the Histagged TA-protein. After one hour, the resin was centrifuged at $250 \mathrm{~g}$ for 2 minutes and washed once with LS buffer containing $5 \mathrm{mM}$ ATP to remove bacterial heat shock proteins. Then a washing step with TA-protein high salt (HS) buffer was followed by another LS buffer washing step. The resin was loaded onto a column and protein was eluted with LS buffer containing $300 \mathrm{mM}$ imidazole. Fractions were collected and controlled for protein content with the Bradford assay solution. The eluted fractions were pooled and incubated with a pre-equilibrated amylose resin (NEB) for one hour at $4{ }^{\circ} \mathrm{C}$ to bind to the MBP-tagged TRC40, which in turn should be in complex with the TA-protein. Again, the amylose beads were washed with LS buffer including ATP, HS buffer and another time with LS buffer. The recombinant protein complex consisting of MBP-TRC40 and the His-tagged - TA-protein were eluted with LS buffer containing $20 \mathrm{mM}$

D-maltose. The purified protein complex was dialyzed overnight against TPB (1x) including protease inhibitors $(1 \mu \mathrm{g} / \mathrm{ml}$ each) and $2 \mathrm{mM}$ DTT.

\subsubsection{In vitro transcription and translation system}

For the in vitro transcription and translation of a tail-anchored protein, the TnT Quick Coupled Transcription/Translation system (Promega) was used according to the manufacturer's protocol. The amount of reagents used per reaction was reduced as described below. The plasmids used for this kit required a T7- or SP6-promotor and were diluted to $200 \mathrm{ng} / \mu \mathrm{l}$.

Reaction (total volume: $10 \mu \mathrm{l}$ )

$1 \mu$ I DNA (200ng/ $\mu \mathrm{l})$

8.8 $\mu \mathrm{l}$ TnT Master Mix

$0.2 \mu$ l Methionine (1mM stock)

The reaction was incubated for 90 minutes at $30{ }^{\circ} \mathrm{C}$ and was used to analyze the integration of the protein into microsomal membranes. To inhibit protein translation before performing further membrane integration steps, the reaction was incubated with $2.5 \mathrm{mM}$ puromycin for 10 minutes 
at $30{ }^{\circ} \mathrm{C}$. One equivalent* of rough microsomes $(1 \mu \mathrm{l}$ ) (see below 2.2.2.6.1) was added to the reaction for another hour at $30{ }^{\circ} \mathrm{C}$ to see, whether the in vitro translated proteins can be integrated into microsomal membranes (Walter and Blobel, 1983). By using puromycin only protein, which is post-translationally inserted into membranes, can be detected. Compared to TA-proteins produced in bacteria (2.2.2.4), this system benefits from the fact not being predetermined for the path of membrane insertion like TA-proteins being in complex with TRC40. Therefore, other post-translational routes for membrane insertion could be studied given that isolated rough microsomes, used as an ER-membrane source, contained all components like TRC40- and chaperones of other assisted pathways.

\subsubsection{Membrane integration assay}

In this work, membrane integration assays are based on the glycosylation of a C-terminal tag of the putative TA-INM-protein of interest and were performed either with microsome- or cellderived membranes. Similar C-terminal protease protection and glycosylation assays were intensively used to study the membrane insertion of ER proteins (Yabal et al., 2003; Brambillasca et al., 2005; Brambillasca et al., 2006).

\subsection{Rough microsomes}

The membrane integration of tail-anchored proteins was analyzed by using dog pancreas rough microsomes (Walter and Blobel, 1983). As established by Favaloro et al. (2010) and Vilardi et al. (2011), rough microsomes (RM) were incubated with the protein of interest for one hour at $30^{\circ} \mathrm{C}$ (shaking at $300 \mathrm{rpm}$ on a Thermomixer). Due to the fact that our protein of interest, e.g. MBPtev-TRC40/ His-ZZ-tev-emerin-opsin has a small opsin (op) tag at the C-terminal end, it can be glycosylated on this tag (Adamus et al., 1991). As a consequence, a shift in molecular weight can be detected via western blotting upon membrane integration and proper orientation in the membrane. As a prerequisite for the detection of proteins inserted into ER-derived microsomal membranes, the main enzyme performing $\mathrm{N}$-glycosylation on the ER-lumenal side, the oligosaccharyltransferase (Aebi, 2013), need to be present and intact inside the isolated microsomes. For detection of the protein via Western blot, an anti-opsin antibody was used (Adamus et al., 1991).

The reaction was set up the following:

$20 \mu \mathrm{l}$ reaction volume in $\mathrm{HK}$ buffer:

200 ng MBP-tev-TRC40/ His-ZZ-tev-emerin-op

$1 \mu$ rough microsomes ( 1 equivalent $*$ )

$1 \mathrm{mM}$ ATP (lithium salt)

$1 \mu \mathrm{l} \mathrm{Mg}(\mathrm{OAc})_{2}$ (50 mM stock)

\footnotetext{
* One equivalent (eq) is defined as the amount of a fraction derived from $1 \mu$ l of RM suspension at a concentration of 50 A280 units $/ \mathrm{ml}$. One eq is roughly derived from $1 \mathrm{mg}$ of tissue (dog pancreas) (Walter and Blobel, 1983).
} 


\subsection{Semi-permeabilized cells}

Instead of microsomes, semi-permeabilized cellular membranes can be used for membrane integration experiments. Trypsinized HeLa P4 cells were resuspended in PBS. The cells were counted with Casy 1 (Schärfe System) and centrifuged at $300 \mathrm{~g}$. Four million cells were resuspended in $400 \mu \mathrm{l}$ ice cold TPB including $2 \mathrm{mM}$ DTT, $0.1 \mathrm{mM}$ PMSF and protease inhibitors $(1 \mathrm{\mu g} / \mathrm{ml}$ each). The detached cells were permeabilized with $0.01 \%$ digitonin for $5 \mathrm{~min}$ on ice and the reaction tube was inverted several times. The permeabilized cells were washed three times with cold TPB and resuspended in TPB, counted again and diluted in TPB to a final concentration of 10000 cells/ $\mu$ l. The reaction for the membrane integration assay using HeLa cell membranes was prepared as described below.

\section{$100 \mu$ reaction volume in TPB (1x): \\ 200000 HeLa cells \\ 200 ng TA-protein complexed with TRC40 \\ $1 \mathrm{mM}$ lithium ATP}

The reaction was placed on a thermomixer at $30{ }^{\circ} \mathrm{C}$ for one hour at $300 \mathrm{rpm}$ shaking. A control reaction was kept for one hour at $4{ }^{\circ} \mathrm{C}$

The mixture was centrifuged at $16000 \mathrm{~g}$ for 20 minutes at $4{ }^{\circ} \mathrm{C}$ and the cells were washed with $100 \mu \mathrm{l}$ TPB. After 10 minutes of centrifugation at $16000 \mathrm{~g}$, the pellet fraction containing the cellular membranes was dissolved in SDS sample buffer and placed into an ultrasonic bath to completely solubilize the cell membranes. Samples were subjected to SDS-PAGE and Western Blotting.

\section{Deglycosylation of membrane-integrated proteins}

An additional step before addition of SDS sample buffer could be the deglycosylation of the membrane integrated protein. The TA-protein of interest should be integrated into microsomal and cellular membranes. The C-terminal opsin-tag of these proteins would be facing the ER lumen and an $\mathrm{N}$-glycosidic linkage of an oligosaccharide to the side chain amide of the asparagine residue of the opsin tag could only be catalyzed by the ER- luminal oligosaccharyltransferase (Aebi, 2013). The N-glycosylation of the opsin tag can be cleaved off by endoglycosidases. Either Endoglycosidase $\mathrm{H}$ (EndoH), which specifically cleaves high mannose carbohydrates, or the more general acting enzyme Peptide - $N$-Glycosidase $F$ (PNGase F) was used (see section 2.1.6.1). Deglycosylation was performed with $1 / 10$ of the final sample volume $(100 \mu \mathrm{l})$. First, the sample was incubated with $1 \mu \mathrm{l}$ of glycoprotein denaturing buffer at $99{ }^{\circ} \mathrm{C}$ for 10 minutes. In case of EndoH, $2 \mu \mathrm{l}$ of G5 reaction buffer (sodium citrate based) were added and filled up to $20 \mu \mathrm{l}$ with water. When PNGase F was used, $2 \mu$ of G7 reaction buffer (sodium phosphate based) and $2 \mu \mathrm{l}$ of NP-40 (10\% stock) were added. Deglycosylation reactions were performed for 1.5 hours at $37^{\circ} \mathrm{C}$. After dissolving the samples in SDS sample buffer, they were analyzed as described in section 2.2.2.6.1. The comparison of a sample lacking the enzyme with the deglycosylated sample should reveal a reduction of the higher molecular weight band of the protein. This can be detected by SDS-PAGE followed by immunoblotting using of the anti-opsin antibody. 


\subsection{Fractionation of cellular membranes by using a carbonate buffer}

Carbonate extraction allows the discrimination between proteins stable integrated into the membrane, meaning interacting with lipids and such membrane proteins only associated via protein-protein interactions with the membrane (Fujiki et al., 1982). When using sodium carbonate at $\mathrm{pH} 11$, protein-protein interactions are disrupted, but interactions between protein and lipid remain unaffected. In membrane integration experiments described in the above section 2.2.2.6.2, only protein, which was stably inserted into the membrane was of interest. Therefore, a carbonate treatment should enrich the membrane inserted protein, which is displayed in case of the membrane integration assays by a glycosylated, higher molecular weight band of the protein by immunoblotting and using an anti-opsin antibody.

After membrane integration assays were performed either with rough microsomes or semipermeabilized cell membranes, cells were spun down at $16000 \mathrm{~g}$ for 10 minutes at $4{ }^{\circ} \mathrm{C}$ and washed once with TPB. To the pellet fraction, $50 \mu \mathrm{l}$ carbonate buffer was added to dissolve the pellet followed by the addition of $50 \mu \mathrm{l} \mathrm{H}_{2} \mathrm{O}$ (final carbonate concentration: $100 \mathrm{mM}$ ). The extraction was performed for 30 minutes at $4{ }^{\circ} \mathrm{C}$ while the tube was inverted several times. Next, an ultracentrifugation at $100000 \mathrm{~g}$ followed for 30 minutes at $4{ }^{\circ} \mathrm{C}$. The supernatant as well as the pellet fraction was dissolved in equivalent amounts of SDS sample buffer and prepared for SDS-PAGE and immunoblotting.

\subsubsection{Cell biology techniques}

\subsubsection{Cultivation of adherent cells}

The adherent cell lines HeLa P4 and U2OS (Charneau et al., 1994, ATCC ${ }^{\circledR}$ HTB96) (see 2.1.12.1) were grown in Dulbecco's Modified Eagle Medium (DMEM) supplemented with $10 \%$ fetal bovine serum (FCS) (v/v), $2 \mathrm{mM} \mathrm{L-glutamine,} 100 \mathrm{U} / \mathrm{ml}$ penicillin and $100 \mu \mathrm{g} / \mathrm{ml}$ streptomycin. In case of siRNA transfections cells were grown without antibiotics as indicated. These cell lines were cultured at $37{ }^{\circ} \mathrm{C}$ and $5 \% \mathrm{CO}_{2}$ in a humid atmosphere.

Cells were cultured in a $10 \mathrm{~cm}$ cell culture plate and for most experiments seeded either in a 24or 6 -well plate. Generally, they were passaged twice a week at $80 \%$ confluency. HeLa cells were diluted at a ratio of $1: 10$, U2OS cells at a ratio of 1:5. For passaging, cells were washed once with PBS and incubated with $0.025 \%$ trypsin/EDTA at $37{ }^{\circ} \mathrm{C}$ until cells detached. Trypsin was inactivated by addition of cell culture medium. After resuspension and dilution of the cells, they were transferred to a new culture plate. All cell culture work was performed under a tissue culture hood.

\subsubsection{Coating coverslips with Poly-L-lysine}

For most of the experiments, coated coverslips were used. To improve the attachment of the cells to the glass surface, the positively charged synthetic amino acid Poly-L-lysine is used. The glass coverslips were washed with isopropanol for a few minutes. After aspiration, they were washed with sterile, deionized water and incubated with a Poly-L-lysine solution (1:10 dilution in water) for at least 30 minutes. A last washing step with water followed and the coverslips were dried on a Whatman paper. They were sterilized by exposing them to UV light for 3 minutes at $0.12 \mathrm{~J} / \mathrm{cm}^{2}$. 


\subsubsection{Transient transfection of DNA}

Transient transfection of plasmid DNA into HeLa P4 cells was performed with the calcium phosphate (Ca-P) method (Chen and Okayama, 1987). This method was used for DNA transfection with the purpose of protein localization studies and for creating a stable U2OS cell line.

For transfection in a 24-well scale, the cells were seeded one day prior transfection to obtain a confluency of about $50-60 \%$ on the day of transfection. For sterile working conditions, all cell culture work including the preparation of transfection mixtures were performed under a laminar flow cabinet.

The culture volume of one well of a 24-well plate is $500 \mu \mathrm{l}$. For a transfection mixture in this format, $20 \mu \mathrm{CaCl}_{2}$ (250 mM sterile solution) were added to $0.7 \mu \mathrm{g}$ plasmid DNA in a reaction tube and mixed on a vortexer for 5 seconds at reduced power. Then, $20 \mu$ sterile HEPES buffer (2x) was added and immediately vortexed for 10 seconds at full speed. This was followed by an incubation period of 25 minutes at room temperature to allow the formation of calciumphosphate-DNA complexes. The mixture was added to the cells and they were grown at 3 or $5 \% \mathrm{CO}_{2}$ at $37^{\circ} \mathrm{C}$ for another 20 to 40 hours. For co-transfections of two plasmids, $0.4 \mu \mathrm{g}$ of each was used, unless indicated otherwise. 


\subsubsection{RNA interference (RNAi)}

For reduction of mRNA and protein levels of a distinct target protein (Tuschl, 2001), two different transfection methods were used. A list of all used duplex short interfering RNAs (siRNAs) can be found in section 2.1.8.

\subsection{Transfection of siRNAs with calcium phosphate method}

This kind of siRNA transfection was performed according to the method described in section 2.2.3.3 and cells were used at a confluency of about $70 \%$ at the day of transfection. The respective siRNA was diluted from a $100 \mu \mathrm{M}$ stock to a $20 \mu \mathrm{M}$ working solution in RNase - free water. For one 24-well (final volume: $500 \mu \mathrm{l}$ ) 40 to $80 \mathrm{nM}$ of duplex siRNA was added to $20 \mu \mathrm{l}$ $\mathrm{CaCl}_{2}$ (250 mM sterile solution) and vortexed at a low speed for 5 seconds in a reaction tube. $20 \mu \mathrm{l}$ of HEPES buffer were added and mixed for another 10 seconds at high speed. After 25 minutes of incubation, the culture medium was changed to DMEM lacking antibiotics. The cells were cultured at $3 \% \mathrm{CO}_{2}$ at $37{ }^{\circ} \mathrm{C}$ overnight and washed twice with PBS. Normal DMEM was added and cells were kept at $5 \% \mathrm{CO}_{2}$ again. Depending on the target, the period of knockdown (KD) varied from 48 to 72/96 hours and therefore cells were split after the first day of transfection. After a defined knockdown period, cells were used for immunofluorescence studies or cell lysates were taken for protein level analysis.

\subsection{Transfection of siRNAs with Lipofectamine 2000}

Cells were seeded one day before transfection to obtain cells at about $50 \%$ confluency for transfection. For a 24-well (final volume: $500 \mu \mathrm{l}$ ), the siRNA (40-80 nM) was diluted in $50 \mu \mathrm{l}$ OptiMEM and mixed gently. $1.5 \mu \mathrm{l}$ Lipofectamine 2000 was diluted in $50 \mu \mathrm{l}$ Opti-MEM as well. After 5 minutes of incubation, the two solutions were combined in one reaction tube and gently mixed. An incubation period of 20 minutes followed. Before adding the mixture to the cells, the medium was changed to DMEM lacking antibiotics. In order to reduce the toxicity for the cells, the medium was changed again after 5 hours. Cells were further kept at $37{ }^{\circ} \mathrm{C}$ and $5 \% \mathrm{CO}_{2}$ for the desired time span.

\subsubsection{Indirect Immunofluorescence for protein detection}

HeLa P4 or U2OS cells were grown on coverslips for 24 to 48 hours in a 24-well format. The coverslips were washed once with PBS and cells were fixed with $3.7 \%$ formaldehyde for 10 minutes at room temperature. Cells were washed with PBS twice and permeabilized with $0.5 \%$ triton X-100 in PBS for 5 minutes at room temperature. After two washing steps with PBS, the cells were incubated with a blocking solution containing $2 \%$ bovine serum album (BSA) in PBS for 30 minutes at room temperature to reduce unspecific binding of the antibodies applied in the further procedure. From the blocking step on, the cells were kept in a humid, light-protected chamber. Primary antibodies were added in an appropriate dilution for one hour in $2 \%$ BSA-PBS solution at RT. After two washing steps (one short and two for 3 minutes), the secondary antibody was diluted in 2\% BSA-PBS again and applied for another hour under the same conditions. Then the slides were washed three times with PBS and once with water. At this point, 
either a Hoechst 33258 staining (stock: $1 \mathrm{mg} / \mathrm{ml} ; 1: 6000$ in PBS) was performed for 2 min at RT or mounting medium containing DAPI was used. Cells were dried before mounting.

\subsubsection{In vitro protein import assay}

First described by Adam et al., 1990, permeabilized cells are used to study the import of proteins into nuclei. This assay allows to specifically analyze and reconstitute the individual requirements for nuclear transport of soluble proteins (import and export) for example energy - and temperature - dependence, existence of an NLS/NES or additional other cytosolic factors (Kehlenbach et al., 1998).

In the present work, the in vitro import assay was used to study the integration of membrane proteins into the ER and to the nuclear envelope in a microscopy-based approach. The transport of a recombinant INM-protein together in a complex with TRC40 to the ER and the INM was analyzed.

HeLa P4 cells were seeded on Poly-L-lysine coated coverslips one day before the import assay was performed. On the day of the experiment, cells showed about 60 to $70 \%$ confluency. They were washed once with PBS and then rinsed with transport buffer (TPB, 1x) supplemented with protease inhibitors ( $1 \mu \mathrm{g} / \mathrm{ml}$ Aprotinin, Leupeptin-Pepstatin, $0.1 \mathrm{mM}$ PMSF) and $2 \mathrm{mM}$ DTT. The coverslips were transferred to an ice-cold metal block. Permeabilization was performed with $0.007 \%$ digitonin for $5 \mathrm{~min}$. The status of permeabilization was controlled by a trypan blue staining. After three washing steps with cold TPB, the reaction mixture for protein import was prepared as follows:

$40 \mu$ final volume in TPB (1x):

$1 \mu \mathrm{l}$ ATP regenerating system (ATP; creatine phosphokinase, creatine phosphate (2:1:2))

$7 \mu$ cytosol ( $9 \mathrm{mg} / \mathrm{ml} \mathrm{stock)}$

(1.9 $\mu$ M Ran)

0.5 - $2 \mu \mathrm{M}$ TRC40/INM-protein complex

The coverslips were moved to a dark, humid incubation chamber and the reaction mixture was added immediately. The transport reaction was performed at $37^{\circ} \mathrm{C}$ for 1.5 hours. Additionally, to the substrate of interest control proteins like Cy3- or Atto488-BSA-NLS were used and a control reaction at $4{ }^{\circ} \mathrm{C}$ was prepared for the main and the control substrate as well. Afterwards, cells were washed once with TPB and once with PBS and were fixed with formaldehyde.

\subsubsection{Development of a stable cell line expressing the FKBP12-reporter protein}

The osteosarcoma cell line U2OS is well known for its very large and flat cell morphology and therefore can be very useful for microscopy approaches. For the rapamycin-based INM localization assay (see section 2.2.4.2.2), a stably expressing EGFP2-GST-NLS-FKBP12 cell line was thus created. As a positive selection marker G418 (Gentamycin) was used. Resistance to G418 is conferred by a neomycin resistance gene, which was delivered with the transfected plasmid containing the gene of interest (FKBP12).

First, the sensitivity of U2OS cells to the selection marker G418 was tested to determine the optimal concentration of drug for the selection. One day prior introducing the antibiotic 
selection, cells were seeded in a 24-well plate with a density of 80000 cells/well to obtain a confluency of about $70 \%$ when selection is started. Increasing amounts of G418 were added to duplicate wells of cells plated in culture medium (see above, DMEM including supplements). Concentrations ranging from $100 \mu \mathrm{g} / \mathrm{ml}$ up to $1 \mathrm{mg} / \mathrm{ml}$ were used and a non-treated well was included as a control. The appropriate concentration for selection was found with respect to the following criteria.

With a low dose, cells were still viable after one week and did not show any signs of toxicity. As opposed to this, a high dose would result in clear signs of toxicity and all cells would be dead early on. The optimal dose of G418 should be found in between and is determined to be the lowest concentration at which no living cells are found after the course of one week.

In case of the U2OS cells, with $800 \mu \mathrm{g} / \mathrm{ml}$ of $\mathrm{G} 418$ all cells were dead after 7 days, therefore it was used as the optimal dose for selection.

For transfection of the cells with the FKBP12 construct, several DNA concentrations were tested beforehand and a $10 \mathrm{~cm}$ plate was transfected with $24 \mu \mathrm{g}$ of plasmid DNA with the calcium phosphate method and a control plate, only transfected with the reagents, was cultured as well. Cells were about $70 \%$ confluent on the day of transfection. Two days after transfection selection was started after passaging the cells and using the G418 containing culture medium. The cell growth and state was observed daily and medium was replaced every three days. After two weeks colonies of surviving cells began to appear. These cells were trypsinized, combined and seeded on new plates. They were further cultivated for one week with optimal dose of G418 and were frozen as a mixture of cells positive for EGFP2-GST-NLS-FKBP12. At the same time, the cells were analyzed for their expression of the FKBP12-reporter construct. Localization of the FKBP12reporter was examined by immunofluorescence and protein levels were controlled by SDS-PAGE followed by immunoblotting. After confirmation of correct localization (see Appendix, Supplementary figure 1, B) and size of the GFP-FKBP12 reporter protein of the stable transfected cells, the cells were controlled for their actual reporter protein expression with the FACSCanto ${ }^{\mathrm{TM}}$ II (BD). About $30 \%$ of the cells were positive for GFP-reporter protein expression. To increase the amount of G418 resistant and GFP-positive cells, the GFP-positive cells were sorted with a FACS Aria II (BD) at the cell sorting facility of the UMG (Appendix, Supplementary figure 1, A). Finally, a mixture of stably expressing EGFP2-GST-NLS-FKBP12 U2OS cells was obtained and they were cultivated with only $300 \mu \mathrm{g} / \mathrm{ml} \mathrm{G} 418$ to maintain the selection pressure until expansion of the cell line was completed. Afterwards, they were frozen at $-80^{\circ} \mathrm{C}$ and were transferred to liquid nitrogen for long-term storage. A part of the cells was further cultivated and used in rapamycinINM-localization studies (Appendix, Supplementary figure 2).

\subsubsection{Microscopy techniques}

\subsubsection{Confocal microscopy}

Images were acquired with the Zeiss LSM 510 meta confocal microscope based on the Axiovert 200M. In general, images were taken with the LCI Plan-Neofluar 63x/1.3 Imm Corr DIC M27 objective. The objective was adjusted to the water-based Immersol W 2010 immersion oil. As an excitation light source for visualization at the microscope the $\mathrm{X}$-cite 120 mercury lamp series was used. 
Depending on the fluorophores or fluorescent proteins used in the specimen, distinct filter settings in combination with lasers were used to exclude cross-talk between the channels. In general, up to four different channels were imaged. A Diode-laser was used to excite molecules at a wavelength of $405 \mathrm{~nm}$ like the DNA intercalating dyes Hoechst 33258 or DAPI. For detection of secondary antibodies conjugated to AlexaFluor488 dye or EGFP/YFP constructs the Argon488 laser and for AlexaFluor594 and mCherry-tagged proteins the HeNe594 laser was used. The farred spectrum for secondary antibodies AlexaFluor633 and-647 was covered with the HeNe633 laser. Settings for the output of a laser were kept at a pre-adjusted level to reduce bleaching effects. The channel intensity was controlled either by the amplifier gain value (fine adjustment) or the transmission value. The degree to which background signals were reduced (amplifier offset value) was controlled with the palette tool in the LSM software.

For co-localization studies, the optical slice was kept at an equal value by regulation of the pinhole size for the different channels. Generally, the scan speed was set to a value of six and four images were taken and averaged. To obtain a higher resolution image, a lower scan speed was used. When working with non-fixed cells, a faster scan speed was used than for fixed-cell specimens and the temperature-correction ring of the $63 \mathrm{x}$ objective was set to $37^{\circ} \mathrm{C}$, when working with a heated chamber.

\subsubsection{Localization studies}

\subsection{Differential permeabilization of cells}

Using different reagents for permeabilization of cells is an established method to gain insights how a protein of interest is distributed and localized inside the cell and additional information about the topology of a protein can be obtained (Adam et al., 1990). This assay is based on the epitope accessibility under certain treatments and has been used for many INM-protein studies (Bengtsson and Otto, 2008; Buch et al., 2009).

HeLa P4 cells were seeded on coverslips (24-well format) and transfected with a plasmid containing the membrane protein and a tag (either hemagglutinin (HA) or mCherry). After $24 \mathrm{~h}$ of transfection, coverslips were washed with PBS and the different kinds of permeabilization techniques were applied to the cells.

In case of permeabilizing cells with digitonin, a non-ionic detergent, a $0.007 \%$ digitonin-TPB solution was applied onto the cells for $5 \mathrm{~min}$ on ice. After two washing steps with TPB and once with PBS, the cells were fixed with $3.7 \%$ formaldehyde in PBS for $10 \mathrm{~min}$ at RT and washed once with PBS. Using this permeabilization method, selectively the plasma membrane is permeabilized, whereas organellar membranes like the nuclear and the ER membrane remain intact due to their low levels of cholesterol, therefore only proteins facing the cytoplasm can be detected.

For Triton X-100 permeabilization, cells were initially fixed with 3.7\% formaldehyde in PBS for 10 min at RT and washed once with PBS. Followed by two washing steps with PBS the cells were permeabilized with $0.5 \%$ Triton X-100 in PBS for 5 min at room temperature.

This kind of treatment allows to permeabilize all membranes of cellular compartments like the nucleus. Thus, nuclear as well as ER-lumenal epitopes of proteins are accessible for antibody binding.

After both permeabilization protocols, cells were subjected to immunofluorescence and were subsequently mounted with Mowiol including DAPI or Dako Fluorescent mounting medium. 


\subsection{Rapamycin-based INM-localization assay}

In order to study the localization of a protein of interest to the inner nuclear membrane, a rapamycin-based dimerization mechanism was used. An INM-localization assay was therefore established, which is generally based on the binding a two component-system induced by the addition of rapamycin. The detailed information about the mechanism can be found in section 3.2.2.1. The basis of rapamycin-induced dimerization was used in several studies in another context (Ohba et al., 2004; Haruki et al., 2008).

Generally, there are three different versions of this assay used in this work. One version of the assay is referred to as in vitro rapamycin assay in this work and uses a permeabilization step before treatment of the cells with rapamycin and subsequent fixation of the cells.

Here, HeLa P4 cells were seeded on coverslips at $30 \%$ confluency ( 70000 cells/24-well). The next day the cells were transfected with a plasmids coding for FKBP12-containing plasmid (Table 2, right) and a vector containing the protein of interest fused to an FRB cassette (Table 2, left) via the Ca-P method for 24 or 48 hours as indicated. After the transfection period, they were washed with PBS once and permeabilized with $0.007 \%$ digitonin in TPB $(1 \mathrm{x})$ including protease inhibitors $(1 \mu \mathrm{g} / \mathrm{ml}$ Aprotinin, Leupeptin-Pepstatin, $0.1 \mathrm{mM}$ PMSF) and $2 \mathrm{mM}$ DTT for 5 minutes on ice. Cells were washed three times with TPB ( $1^{\text {st }}$ wash: short; $2^{\text {nd }}$ and $3^{\text {rd }}$ wash for 3 minutes each). The permeabilization status was controlled on an additional slide with trypan blue solution. Afterwards, cells were treated with $200 \mathrm{nM}$ rapamycin in TPB for $10 \mathrm{~min}$ on ice to allow dimerization between FKBP12 and the FRB domain. Again, cells were washed with TPB and once with PBS. Cells were fixed with 3.7\% formaldehyde in PBS for 10 minutes at room temperature. After washing with PBS, cells were subjected to immunofluorescence microscopy.

When this assay was carried out with the initial permeabilization step, followed by addition of rapamycin directly at the microscope with subsequent imaging of the effect on FKBP12-reporter protein distribution in real time, it is reffered to as in vitro-kinetics rapamycin assay.

In contrast to the "in vitro"-versions, rapamycin can simply be added to the culture medium of living cells for 10 to 30 minutes, followed by a washing and fixation step. This assay is referred to as in vivo rapamycin assay, but was rarely used as explained in section 3.2.2.1. 
Table 2: Overview of expression constructs used for rapamycin assays. Left column shows all available FRB-containing constructs and in the right column the different FKBP12-containing constructs are listed.

\begin{tabular}{|l|l|}
\hline \multicolumn{2}{|c|}{ Rapamycin assay constructs with } \\
\hline \multicolumn{1}{|c|}{ FRB cassette } & \multicolumn{1}{|c|}{ FKBP12 cassette } \\
\hline HA-FRB-emerin & EGFP $_{2}$-GST-NLS-FKBP12 \\
\hline mCherry-FRB-emerin & EGFP $_{2}$-NLS-FKBP12 \\
\hline mCherry-FRB-Lap2 $\beta$ & EGFP $_{2}$-GST-M9-FKBP12 \\
\hline mCherry-FRB-LBR & FKBP12-Histone1-EGFP \\
\hline mCherry-FRB-LEMD1 & FKBP12-EGFP \\
\hline mCherry-FRB-LRRC59 & \\
\hline mCherry-FRB-PTP1B & \\
\hline mCherry-FRB-VAPB & \\
\hline WRB-FRB-HA & \\
\hline
\end{tabular}




\section{Results}

\subsection{Post-translational membrane insertion of putative tail-anchored proteins}

In this work, proteins destined for the INM were analyzed. As a first step, their cellular localization was determined (section 3.1.1.1), followed by anaylsis of their membrane insertion mechanism into the endoplasmic reticulum (ER) using biochemical membrane integration assays (section 3.1.2). A specific set of membrane proteins (Table 3), among them the established INM-proteins emerin and LAP2 $\beta$, was investigated in this project, which due to their similar sequence properties are proposed to belong to the group of tail-anchored proteins.

Some of these proteins like emerin, LAP $2 \beta$ were confirmed to be integral membrane proteins of the nuclear envelope in a proteomics screen (Schirmer et al., 2003) and others like PTP1B, VAPB and LRRC59 have been reported to localize to the INM (Yip et al., 2012; Tran et al., 2012; Zhen et al., 2012), whereas LEMD1 was included in this study because it shares a characteristic LEMdomain with other INM-proteins like emerin and MAN1 (Yuki et al., 2004). Furthermore, emerin, VAPB and PTP1B were predicted to belong to the group of TA-proteins in a bioinformatics screen (Kalbfleisch et al., 2007). A detailed description of these proteins can be found in section 1.2.5.

Table 3: List of the investigated integral membrane proteins including characteristics and possible functions. Polypeptide length, species, molecular weight, sequence properties and functions are indicated.

\begin{tabular}{|c|c|c|c|c|c|c|}
\hline Protein & $\begin{array}{l}\text { Total } \\
\text { length }\end{array}$ & Species & $\begin{array}{l}\text { Predicted } \\
\text { molecular } \\
\text { weight } \\
(\mathrm{MW})[\mathrm{kDa}]\end{array}$ & $\begin{array}{l}\text { C- } \\
\text { terminal } \\
\text { TMD }\end{array}$ & $\begin{array}{l}\text { Additional } \\
\text { sequence } \\
\text { features }\end{array}$ & $\begin{array}{l}\text { Proposed/confirmed } \\
\text { function }\end{array}$ \\
\hline emerin & 254 аa & human & 29 & $\checkmark$ & $\begin{array}{l}\text { LEM-domain, } \\
\text { APC-like domain } \\
\text { (adenomatous } \\
\text { polyposis coli) }\end{array}$ & $\begin{array}{l}\text { Nuclear actin network, } \\
\text { regulation of } \beta \text {-catenin } \\
\text { signaling, } \beta \text {-tubulin medi- } \\
\text { ated linkage to centrosome }\end{array}$ \\
\hline LAP2 $\beta$ & 452 aа & rat* & 50 & $\checkmark$ & $\begin{array}{l}\text { LEM-like } \\
\text { domain, LEM- } \\
\text { domain }\end{array}$ & $\begin{array}{l}\text { chromatin-binding, } \\
\text { regulation of lamina } \\
\text { growth, transcriptional } \\
\text { repression }\end{array}$ \\
\hline VAPB & 243 аa & human & 27 & $\checkmark$ & $\begin{array}{l}\text { MSP-domain, } \\
\text { coiled coil } \\
\text { domain }\end{array}$ & $\begin{array}{l}\text { COPI-coated vesicle } \\
\text { transport, UPR, cellular } \\
\text { calcium homeostasis, sterol } \\
\text { regulation }\end{array}$ \\
\hline PTP1B & 435 аa & human & 50 & $\checkmark$ & $\begin{array}{l}\text { catalytical } \\
\text { phosphatase } \\
\text { domain }\end{array}$ & $\begin{array}{l}\text { UPR, regulation of ephrin } \\
\text { receptor signaling and } \\
\text { trafficking }\end{array}$ \\
\hline LEMD1 & 181 аа & human & 20 & $\checkmark$ & LEM-domain & $\begin{array}{l}\text { chromatin-binding, } \\
\text { cancer progression }\end{array}$ \\
\hline LRRC59 & 307 aа & human & 35 & $\checkmark$ & $\begin{array}{l}\text { leucine-rich } \\
\text { repeats, } \\
\text { coiled-coil } \\
\text { domain }\end{array}$ & $\begin{array}{l}\text { Ribosome-binding, growth } \\
\text { factor transport to the } \\
\text { nucleus, cell-cell adhesion }\end{array}$ \\
\hline
\end{tabular}




\subsubsection{Verification of the membrane localization of putative INM-proteins}

\subsubsection{Localization of putative INM-proteins}

First of all, the selected proteins were analyzed for their localization in HeLa P4 cells by immunostaining for the endogenous membrane proteins, in so far as reliable and established antibodies were available for the protein of interest (Figure 8). Images were acquired at a confocal microscope.

As a reference protein for nuclear envelope staining, lamin $A / C$ was used. The staining of endogenous emerin revealed a localization at the nuclear envelope and a slight staining for ER membranes. For LAP $2 \beta$ as well a distribution at the NE and the ER could be observed. The protein LRRC59 showed a more prominent localization to ER membranes and less "nuclear rim" localization compared to the localization pattern of emerin and LAP $2 \beta$. Furthermore, VAPB showed a localization at the ER, which compared to all other proteins was more punctate. All localization patterns obtained by immunofluorescence staining for endogenous proteins were in accordance with the observations made in literature. PTP1B and LEMD1 were not analyzed for their endogenous localization due to the lack of appropriate antibodies. Aside from this, LEMD1 was reported to be a protein specifically expressed in testis (Yuki et al., 2004) and thus probably a detection in HeLa cells would not be possible.

Another approach used to examine the membrane localization of the selected proteins, was the overexpression of recombinant proteins. In this case, HeLa P4 cells were transfected with mCherry- or hemagglutinin (HA)-tagged proteins. The well-studied proteins emerin and LAP2 $\beta$ were overexpressed as HA- and mCherry versions of the proteins and therefore required an immunofluorescence staining prior to imaging. Both versions of emerin and LAP $2 \beta$ localized to membranous structures. The morphological pattern observed for both proteins indicated a localization to the NE and the ER (Figure 9). The comparison of both variants (HA- and mCherrytagged) revealed a more prominent ER localization and a visible nuclear rim for emerin of its mCherry version, whereas the nuclear rim of the HA-protein was thinner and a fraction of emerin was found at the ER in a more "bulky" appearance. For LAP2 $\beta$ similar observations concerning the morphology of the two versions were made. The proteins PTP1B (Walton and Dixon, 1993), LRRC59 (Zhen et al., 2012), VAPB (Skehel et al., 2000) and LEMD1 were expressed with an Nterminal mCherry tag. For the three first-mentioned proteins, the expected ER localization was observed in this experiment and additionally a moderate NE-rim was displayed in some cells.

Especially LEMD1, which belongs to the LEM-domain containing proteins (Berk et al., 2013b), often showed, additionally to an ER localization aggregate-like dots around the nucleus and at regions of the ER. In context to the pronounced localization at the ER, which was observed for all proteins to a different extent, it was reported that overexpressed transmembrane-fusion proteins tend to accumulate in the peripheral ER presumably due to a saturation of their binding sites at the NE (Schirmer and Gerace, 2005).

Altogether, immunostaining of endogenous proteins and overexpression of the investigated potential TA-INM-proteins revealed a localization at the ER and the nuclear envelope with varying ratios of ER to NE localization depending on the protein. The initial experiments proved an ER and NE localization of the investigated proteins, but were not sufficient to specify the localization exactly to the INM or ONM. 

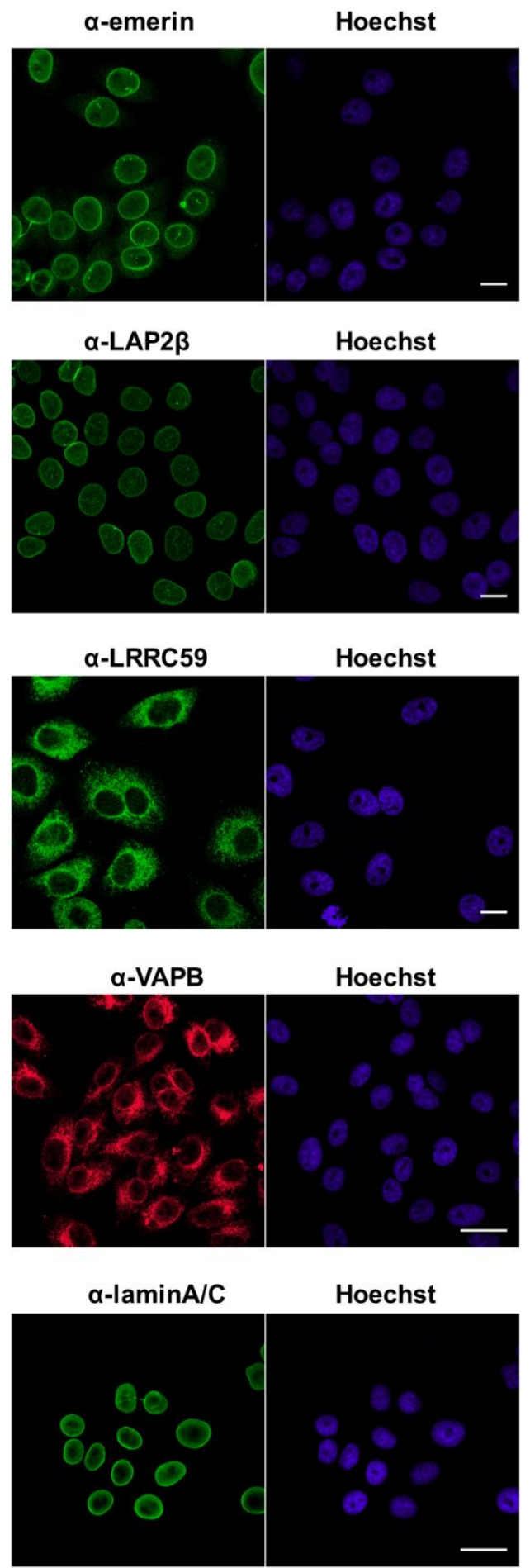

Figure 8: Endogenous localization of investigated putative TA-INM-proteins in HeLa P4 cells. Primary anti-emerin (Genosphere), -LAP2 $\beta,-$ LRRC59, -VAPB and lamin A/C antibodies were used for immunostaining as indicated in section 2.1.7.1. Secondary AlexaFluor488 or 594-conjugated antibodies (see section 2.1.7.2) were used. Scale bars: $15 \mu \mathrm{m}$. The polyclonal anti-emerin antibody (Genosphere) was generated as a custom-specific product and characterized for its specificity (see Appendix, Supplementary figure 3). 


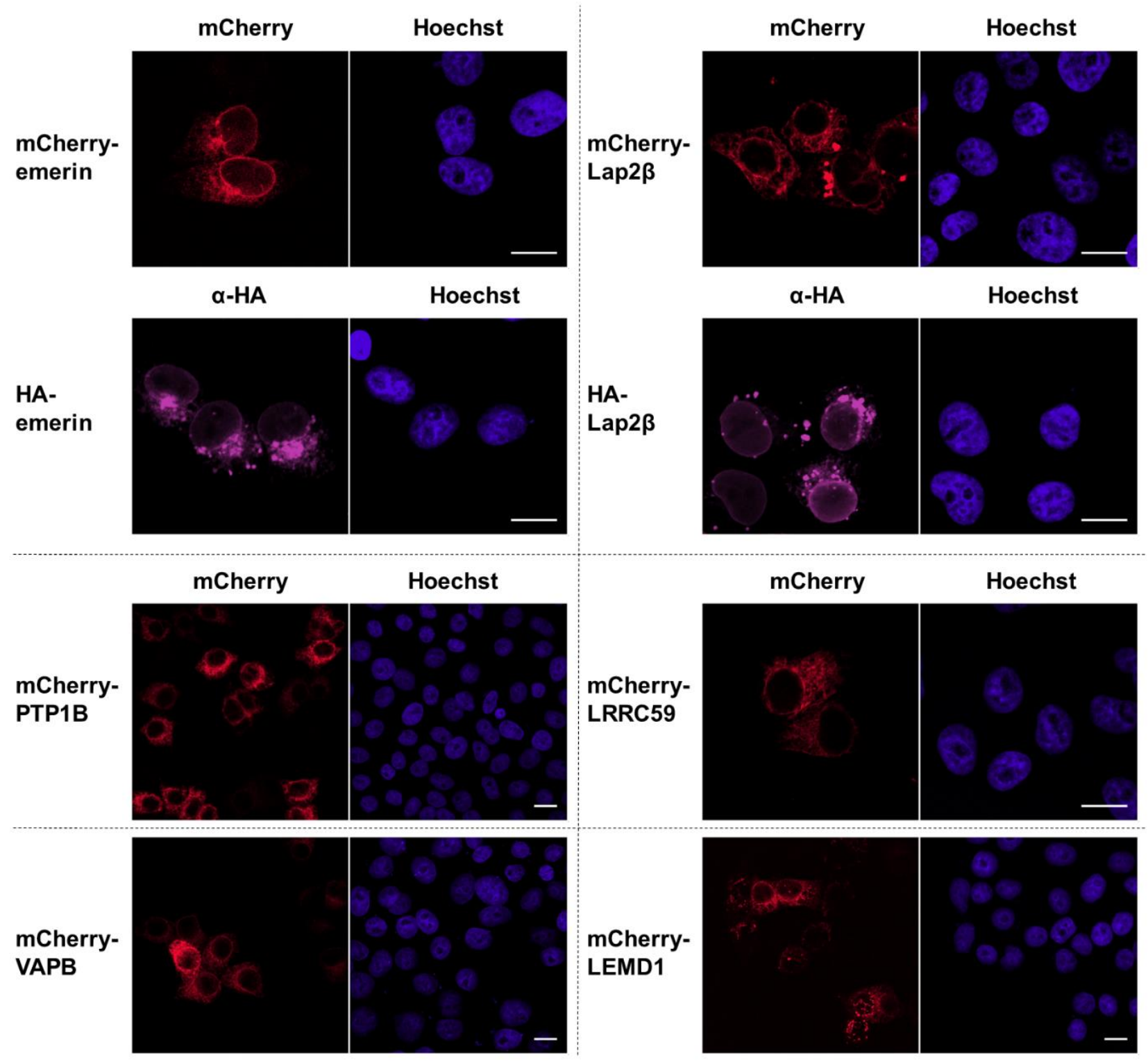

Figure 9: Localization of overexpressed putative INM-proteins. HeLa cells were transfected with plasmids coding for differently tagged versions of emerin, LAP2 $\beta$, mCherry-PTP1B, -LRRC59, -VAPB and-LEMD1. Proteins with HA-tag were immunostained with $\alpha$-HA. Scale bars: $15 \mu \mathrm{m}$. 


\subsubsection{Membrane insertion mechanisms of putative INM-proteins}

In this chapter, the membrane integration mode of putative INM-proteins is studied. It focuses on the TRC40 insertion pathway as a main route taken by tail-anchored proteins. The proteins selected for investigation were chosen regarding their transmembrane domain characteristics. All examined proteins are specified by only one hydrophobic transmembrane segment, which is in close proximity to the C-terminus and therefore potentially belong to the class of TA-proteins (chapter 1.2.2.2.1). Therefore, the TRC40-pathway as a major possible route of ER membrane insertion was taken into account for the selected proteins (Table 3).

As explained in section 2.2.2.6, two approaches were used to study membrane integration in this work. The first makes use of purified rough microsomes (RM) (Walter and Blobel, 1980) and for the second, semi-permeabilized HeLa cells (SPCS) served as a membrane source to test integration of putative TA-INM-protein. Furthermore, either in vitro translated (section 3.1.2.2.1) or purified TA-protein, which was bacterially expressed and purified in a complex with TRC40, was used.

\subsubsection{In vitro translated putative TA-INM-proteins integrated into rough microsomal membranes}

The in vitro transcription and translation reactions (TNT-kit, Promega), which are based on utilizing a reticulocyte lysate incubated with the plasmid encoding for the protein of interest, provided the potential TA-INM-proteins (section 2.2.2.5). The translated protein was added to a reaction mixture with rough microsomes in presence of ATP and the insertion reactions were incubated for 1.5 hours. Afterwards, the samples were subjected to SDS-PAGE followed by Western Blotting. Plasmids coding for the protein of interest, which were incubated with the reticulocyte lysate, also encoded a 13 amino acids long C-terminal opsin-tag (Adamus et al., 1991). In this opsin-tag a glycosylation site was included and thus was used to detect the protein, which was post-translationally integrated into the membrane. The detection of the posttranslational modification is only possible if the C-terminal part of the protein is oriented to the luminal side of the ER. There, the oligosaccharyltransferase was responsible for the ER-specific $\mathrm{N}$-glycosylation (Aebi, 2013) at the glycosylation site of the opsin-tag. Membrane inserted proteins could be detected by using an anti-opsin antibody. As a consequence of a membrane integration of a protein, a higher molecular weight band was detected by using the anti-opsin antibody. This shift in molecular weight occurred due to the $\mathrm{N}$-glycosylation process after membrane insertion (chapter 2.2.2.6.1). For the proteins emerin, LAP2 $\beta$, PTP1B and VAPB the in vitro expression and membrane insertion into RM was performed.

First of all, emerin was studied for a possible post-translational membrane insertion (Figure 10 A). The protein synthesis using the reticulocyte lysate was affected by addition of the translational inhibitor puromycin and protein synthesis of emerin was completely abolished (Figure $10 \mathrm{~A}$, lane 1). To ensure that only post-translationally integrated proteins were detected, prior to performing the membrane insertion step and adding the RM, puromycin was added to block protein synthesis and exclude the possibility to detect a co-translationally ER-inserted substrate. After HZZ-emerin-opsin was synthesized in a cell-free system, it was detected in its higher molecular weight form. This glycosylated protein must have been membrane integrated into rough microsomes (Figure 10, A, lane 4). After blocking protein synthesis with puromycin, a 
membrane integrated emerin form was observed as well (Figure 10, A, lane 5, indicated by "opsinG"). These findings proved emerin to take a post-translational pathway for ER-membrane insertion.

To further show that the reaction specifically depends on the TRC40-pathway, short, inhibitory fragments of the ER-membrane receptors of the TRC40-pathway were added to the insertion reaction, each at a concentration of $1 \mu \mathrm{M}$. WRBcc is the coiled-coil fragment of the ER-membrane receptor WRB (Vilardi et al., 2011) and CAML-N comprises a short amino-terminal portion of the ER-receptor CAML (Yamamoto and Sakisaka, 2012). Both fragments were shown to inhibit the membrane insertion of TA-proteins at the ER in the two abovementioned studies. The insertion of HZZ-emerin-op was inhibited or at least strongly reduced (Figure 10, A, lane 6 and 7), when the short, inhibitory fragments had been added.

A

$1 \mu \mathrm{M}$

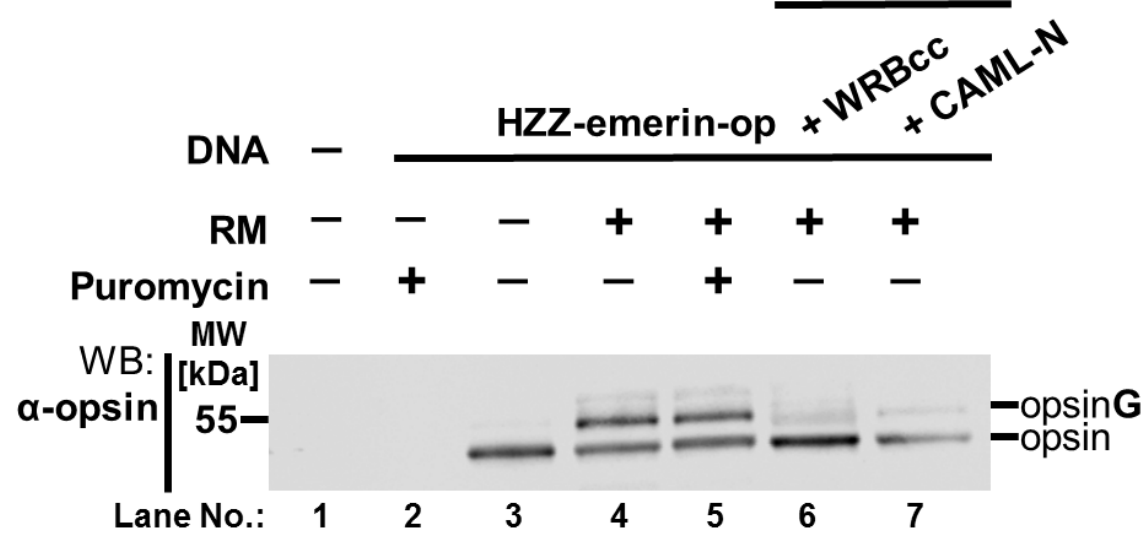

B

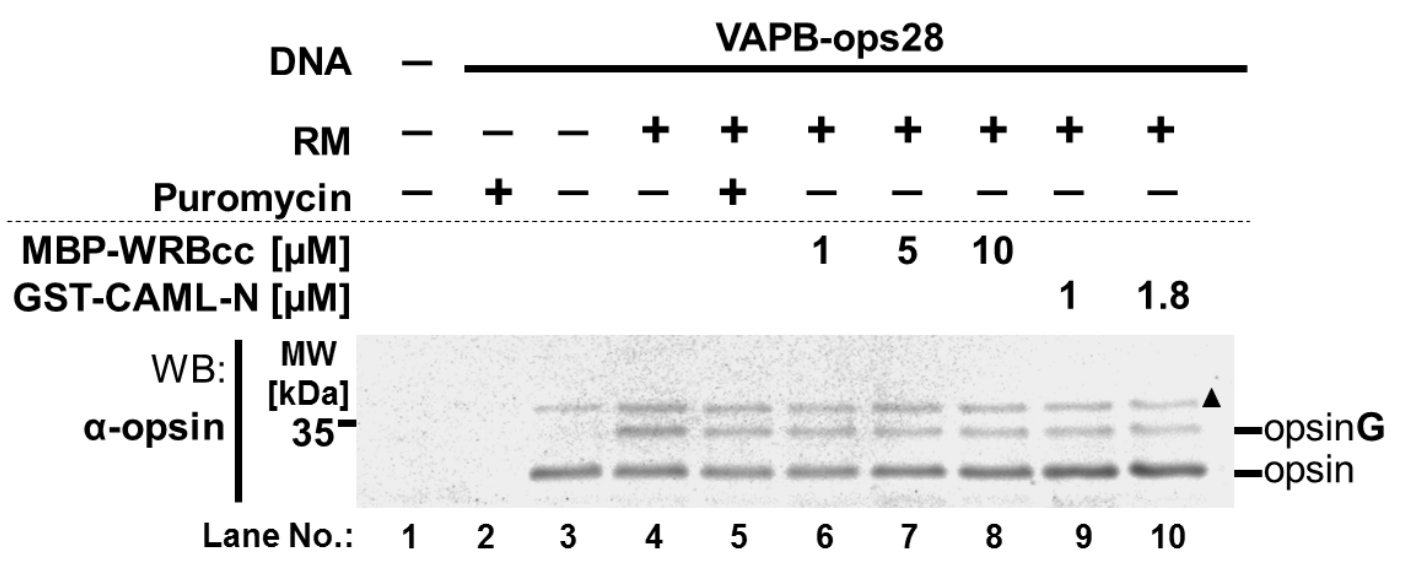

Figure 10: Membrane integration of in vitro translated HZZ-emerin-opsin and VAPB-ops28. By the use of an in vitro transcription/translation system (TNT-kit, Roche) HZZ-emerin (A) and VAPB-ops28 (B) was produced and subsequently a membrane insertion reaction with rough microsomal membranes was carried out in the presence of ATP. As indicated, rough microsomes (RM), the translational inhibitor puromycin (2.5 mM were incubated for 10 min prior to RM addition) or fragments of MBP-WRBcc and GST-CAML-N were added at the indicated concentrations. The glycosylated, higher molecular weight form of the protein is indicated by "opsinG" and was detected by SDS-PAGE followed by immunoblotting using an anti-opsin antibody. 
Apart from emerin, VAPB, another predicted TA-INM-protein, was studied for its membrane insertion mechanism. The in vitro translation of VAPB was carried out using different plasmids for VAPB. First the plasmid encoding for HZZ-VAPB-opsin was tested for membrane insertion. The plasmid DNA is based on a pET328 vector and encoded for a VAPB version with an N-terminal His-ZZ-tag (HZZ) and a C-terminal 13 aa long opsin-tag (Favaloro et al., 2008) with a size of $44 \mathrm{kDa}$.

The protein was translated in the reticulocyte lysate and detected by SDS-PAGE followed by immunoblotting with the anti-opsin antibody as a prominent band observed running a bit higher than the $40 \mathrm{kDa}$ protein standard. When this blot was carefully inspected, a second VAPB band could be observed even right after synthesis in all lanes (Figure 11, A, asterisk), which might be explained by a post-translational modification. The band at about $40 \mathrm{kDa}$ for HZZ-VAPB-op could also be a cleaved variant, which lacks a typical N-terminal MSP-domain (14 kDa), whereas the higher band (Figure 11, B, indicated by a black triangle) could be the non-cleaved version (Gkogkas et al., 2011; Deidda et al., 2014). After incubation with RMs, even with or without puromycin treatment, only a very slight band with a higher MW was detected (Figure 11, A, indicated by red asterisk).

Therefore, the expression and translation of the alternative construct VAPB-ops28 was carried out and the membrane insertion into RM was performed. The only difference between the two VAPB versions can be found in the N-terminal tag and the opsin-tag. The VAPB-ops28 (Fasana et al., 2010; Brambillasca et al., 2005) had no N-terminal tag and a longer version of the opsin-tag, which lacks the typical 19 instead of 13 aa long. Surprisingly, for VAPBops 28 an additional, shifted band appeared (Figure 11, B, circle) in between the two initial bands, when proteins were detected with an anti-opsin antibody. No matter, whether puromycin was added or not, a shifted, higher MW band was observed (indicated by circle). The result implies a post-translational mode of membrane insertion for VAPB. Similar to the membrane integration assay for emerin, where inhibitory fragments of the ER-receptors WRB and CAML of the TRC40-pathway were added, VAPB-ops28 was integrated into RMs (Figure 11, B). By adding the same concentration of $1 \mu \mathrm{M}$ of each fragment, no reduction of the shifted, glycosylated band (Figure 10, B, indicated with opsinG) was seen even if higher concentrations of the inhibitory fragments WRBcc and CAML-N were used (Figure 10, B, lane 8 and 10). In this case, the post-translational insertion of VAPB seemed to be unaffected by addition of the inhibitory fragments and was hence concluded to occur independently of TRC40. As a positive control substrate for a TRC40-dependent ER membrane insertion, emerin was used when performing the VAPB-ops28 integration reactions.

The protein LAP2 $\beta$ was analyzed for its membrane insertion mode in RM, after a HZZ-LAP2 $\beta$ opsin version was expressed in vitro. After 1.5 hours of incubation with RM and ATP, indeed an additional band higher than $70 \mathrm{kDa}$ was confirmed by using an anti-opsin antibody (Figure 11, C). A preincubation with the protein synthesis inhibitor puromycin (Figure 11, C, lane 3) did not abolish the shifted band, strongly indicating that the membrane insertion mechanism for LAP2 $\beta$ occurs via a post-translational mode.

In case of the phosphatase PTP1B, a higher molecular weight band above $70 \mathrm{kDa}$ was detected on the blot after incubation with RM (Figure 11, D, lane 2 and 3, indicated by opG). Especially for the two reactions, in which RM were added, appeared to be very blurry (Figure 11, D, lane 2,3). 
These "blurred" protein bands could perhaps be explained by a highly post-translationally modified protein.

The detected higher MW band led to the conclusion that for PTP1B, a post-translational insertion is possible. Whether it uses the TRC40 or another post-translational pathway, remained unclear from results obtained in this work.

A

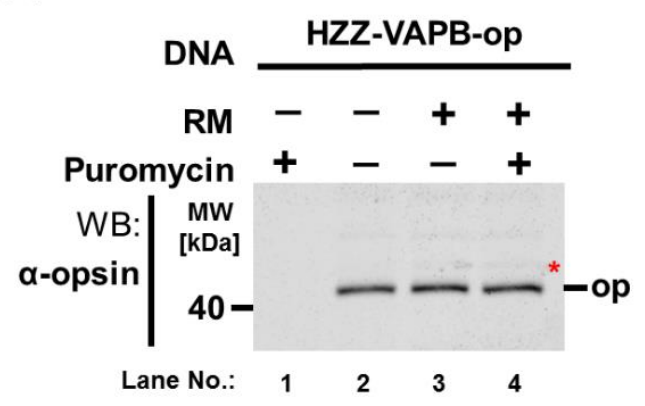

C

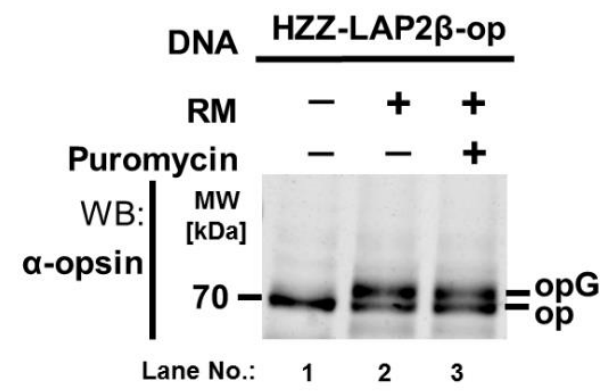

B

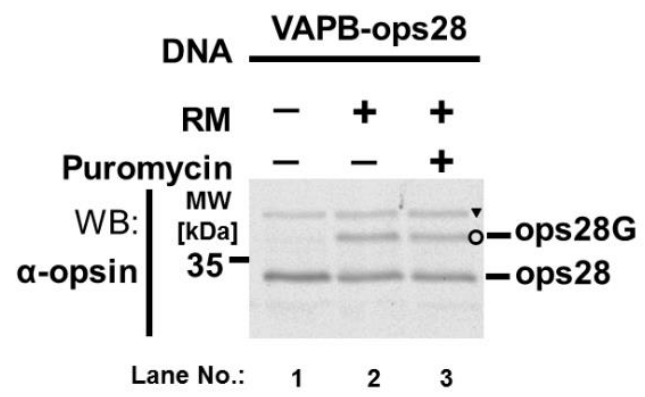

D

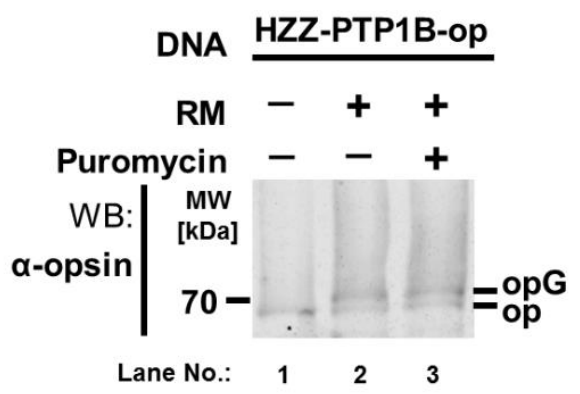

Figure 11: Membrane integration of in vitro translated HZZ-VAPB-op (A), VAB-ops28 (B), LAP2 $\beta$ (C) and PTP1B (D) into RMs. A reticulocyte lysate based in vitro translation was performed for selected plasmids coding for proteins mentioned above and incubated with RM according to the protocol (chapter 2.2.2.5). As stated, rough microsomes (RM) and the translational inhibitor puromycin ( $2.5 \mathrm{mM}$ was incubated for 10 min prior to RM addition) were added besides ATP, which was present in all reaction (not indicated). After SDS-PAGE and immunoblotting, the membrane integrated proteins were detected by using an antiopsin antibody. "G" indicates the glycosylated, higher molecular weight form of a protein. Red asterisk (*) in (A) indicates a very faint, higher molecular weight band in lane 3 and 4 of VAPB and the triangle ( $\mathbf{v})$ in (B) indicates a band detected by the opsin-antibody, which seemed to be irrelevant for membrane integration, whereas the glycosylated and membrane integrated band is indicated by a circle (o).

Taken together, the in vitro translated proteins emerin, LAP2 $\beta$, PTP1B and VAPB seem to integrate post-translationally into RMs. Especially for HZZ-emerin-op, a clear dependence on the TRC40-pathway was demonstrated, when inhibitory fragments of the TRC40-machinery were used. In contrast to this, membrane insertion of VAPB-ops 28 seemed to occur independently of the TRC40-route, pointing to an alternative post-translational pathway. For LAP2 $\beta$ and PTP1B the specific mode of post-translational integration was not further investigated using in vitro translated proteins. 


\subsubsection{Characterization of membrane insertion of emerin utilizing the TRC40- pathway for membrane insertion at the ER as a tail-anchored protein}

This chapter focuses in more detail on the membrane integration process of the INM-protein emerin not only using an in vitro transcription and translation system (section 3.1.2.1), but also using co-expressed HZZ-emerin-op in complex with TRC40 purified from bacteria. This recombinant protein complex was subsequently used in membrane integration assays. Additionally, emerin can be produced in an in vitro transcription/translation system as was shown above. As well the insertion of emerin into rough microsomal membranes was studied. Moreover, the dependency of emerin on the TRC40-mechanism was examined in TRC40 immuno-depleted cells.

\subsection{Membrane integration of bacterially expressed and purified emerin into RM and semi-permeabilized cells}

\subsection{Co-expression of emerin with TRC40}

To express the membrane protein of interest, a well-established co-expression and -purification system was utilized to obtain a membrane protein in a soluble state (chapter 2.2.2.4). Proteins were expressed by use of a particular E. coli strain BL21AI, which allowed the induction of protein expression under control of a specific arabinose-inducible promotor. Initially, a pool of MBPTRC40 was induced for an hour, then the expression of a putative tail-anchored protein, here emerin, was selectively induced for 4 hours to form a complex with TRC40 (Favaloro et al., 2010). Below, a schematic view of a tail-anchored protein, mCherry-FRB-emerin*, complexed with MBPTRC40 is shown (Figure 12, A).

The amylose resin eluted fraction, which is displayed in the rightmost lane of Figure 12, shows a $80 \mathrm{kDa}$ band representing MBP-tagged TRC40 and two lower bands at around 65 to $75 \mathrm{kDa}$ belonging to mCherry-FRB-emerin. The appearance of the higher mCherry-FRB-emerin band was observed for other mCherry-fusion proteins in several other experiments as well, when samples (combined with SDS-sample buffer) were boiled at $95{ }^{\circ} \mathrm{C}$. The identity of both bands was confirmed to belong to mCherry-FRB-emerin by using an anti-RFP and anti-emerin antibody (data not shown). Depending on the specific TA-protein co-expressed with TRC40, an amount of $5 \mathrm{mg}$ could be obtained from a 4 to 6 Liter bacterial culture. 
A

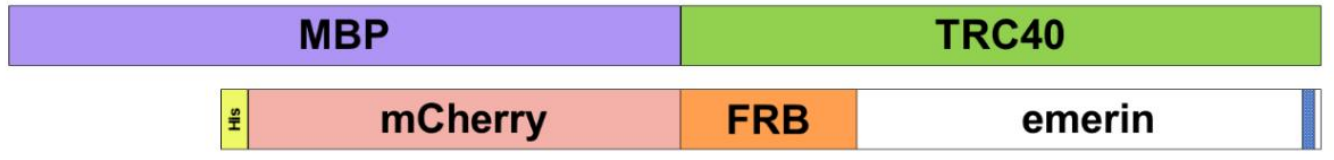

B

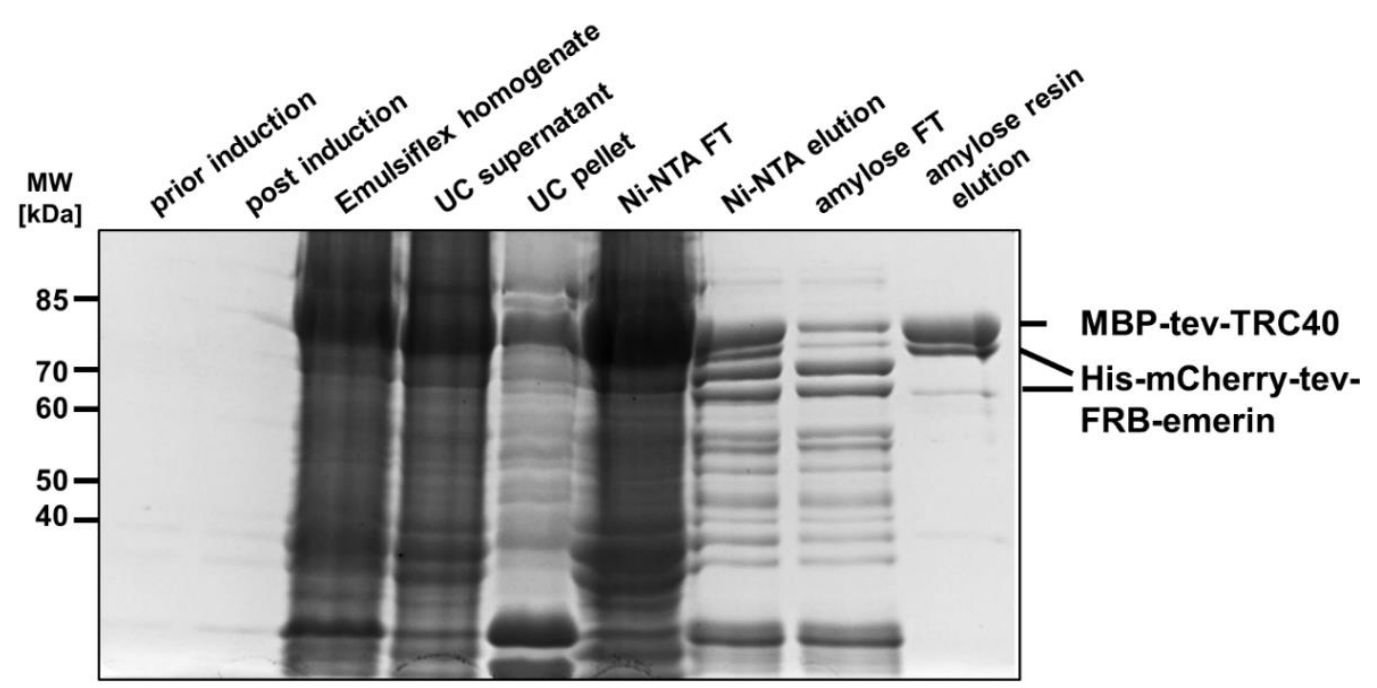

Figure 12: Co-expression and -purification of emerin in a complex with TRC40. A scheme of a co-purified emerin version together with TRC40 is depicted (A). The composition of the protein complex is indicated by colored and labelled boxes. The small, yellow box displays a 10x His-tag on the N-terminus of emerin. In (B), a typical protein purification is shown for mCherry-FRB-emerin. E. coli BL21Al cells were homogenized and the protein was purified using Ni-NTA and amylose resins according to the protocol (section 2.2.2.4). Ultra-centrifugation is indicated by UC, flow-through by FT. 


\subsection{Membrane integration of emerin into RM and SPC}

Due to its sequence features (section 1.2.5, Table 1) emerin was proposed to belong to the specific group of TA-proteins and assumed to use the TRC40-mediated membrane insertion mechanism to integrate into the $E R$, as a first membrane entry site of its transport process to the INM (Laba et al., 2014).

In this context, the mode of membrane insertion was studied by using rough microsomes (Walter and Blobel, 1983) or semi-permeabilized cells as described in section 2.2.2.6. In comparison to the rough microsome membrane insertion assays performed with in vitro translated protein (section 3.1.2.1), a purified TRC40/emerin protein complex, as described in the previous chapter, was used. Being aware of the proposed classification of emerin as a TA-protein using the TRC40route for membrane integration, it was beneficial to use the bacterially produced emerin, because it already existed in a complex with an important component of this pathway. The purified emerin protein-complex, consisting of TRC40 bound to emerin, described in this paragraph, is compared to the reticulocyte lysate translated protein, a more pre-determined approach. The in vitro translation of membrane proteins in contrast is a more unbiased way of protein expression and therefore allows to study post-translational membrane insertion in general (e.g. unassisted or chaperone-dependent ways) and is not restricted due to a predefined binding to TRC40. In the following experiments, exactly this binding to TRC40 was used to facilitate membrane insertion reactions.

His-ZZ-emerin-opsin in complex with MBP-TRC40 (Figure 13) was used in the insertion assays. The His-ZZ tagged version of this protein was used, because compared to other mCherry-tagged and purified emerin fusion proteins, the $\mathrm{N}$-terminal tag is relatively short (13 $\mathrm{kDa})$ in relation to emerin itself $(29 \mathrm{kDa})$. In general, the assay conditions were tried to be kept as close to the physiological situation as possible. The most important feature of this emerin construct is the small, C-terminal opsin-tag (Adamus et al., 1991). This small portion is C-terminally fused to emerin and has a length of only 13 aa, as mentioned in context with the in vitro translation experiments. Due to the presence of a glycosylation site within the opsin-tag, the protein can be glycosylated. After the membrane integration assay was performed, the proper insertion of a TAprotein at the ER membrane, facing the ER lumen with its C-terminal end, can be detected due to the glycosylation of the opsin-tag. A specific ER-lumenal glycosylation, referred to as $\mathrm{N}$ glycosylation is mediated by the oligosaccharyltransferase (Aebi, 2013). A glycosylated, higher molecular weight protein, which consequently must have been membrane-integrated, can be detected with an anti-opsin antibody, which was already used for the experiments with in vitro synthesized protein (section 3.1.2.1). 


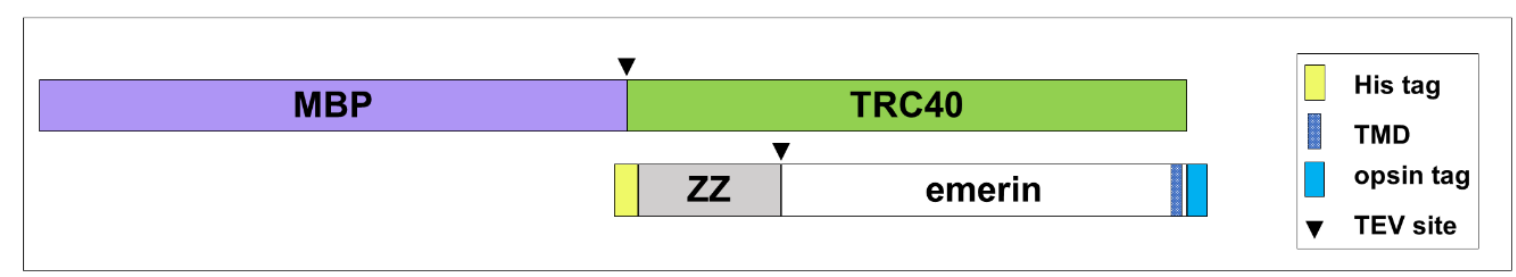

Figure 13: Schematic view of a protein complex consisting of HZZ-emerin-op and MBP-TRC40. Sizes of the single components are displayed according to their actual molecular weight. Legend explains individual portions and features of the fusion protein (box, right side).

Bacterially translated emerin was first tested for membrane integration in rough microsomes. There, HZZ-emerin-opsin was observed to be glycosylated, seen by a shifted protein band (indicated with opsinG) in reactions including lithium ATP as an energy source and performed at $30{ }^{\circ} \mathrm{C}$ (Figure 14 , lane 3 ).

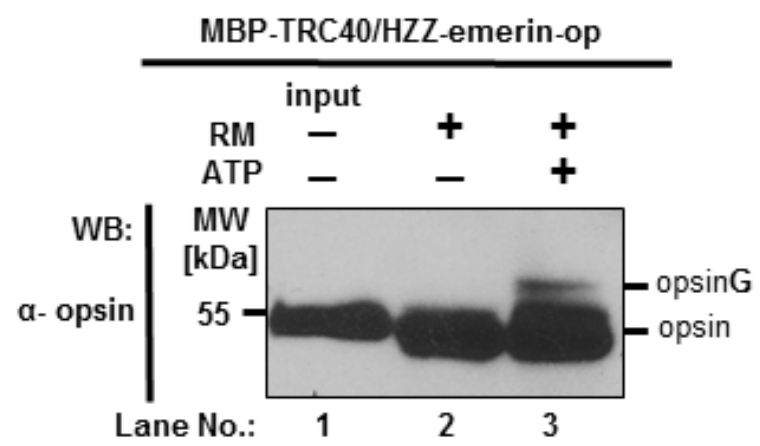

Figure 14: HZZ-emerin-opsin is able to insert into rough microsomal membranes. The purified proteinTA-protein complex was incubated with rough microsomes and lithium ATP for 30 minutes at $30^{\circ} \mathrm{C}$. The analysis of membrane insertion was done by SDS-PAGE and immunoblotting, using an anti-opsin antibody to detect HZZ-emerin-op. The protein in its membrane-integrated and glycosylated form could be detected by a higher MW band indicated with "opsinG".

The next step was to test HZZ-emerin-opsin membrane insertion in digitonin-permeabilized HeLa cells. The semi-permeabilized cells were obtained by treating HeLa P4 cells with digitonin for selective permeabilization (2.2.2.6.2) and represent another possible ER-membrane source than RM. A further advantage of using permeabilized cells is the fact, that they provide a more flexible system than RM. The possibility to modulate protein levels of distinct proteins by knockdown or overexpression experiments could be used to examine the influence on membrane insertion for instance.

Additionally, to the energy-dependency of the insertion process observed in RM, the temperature, at which the reaction was performed, seemed to play an important role (Figure 15, lane 2), because cells incubated with the protein at $4{ }^{\circ} \mathrm{C}$, did not show any insertion even though energy was provided. It was further shown that a portion of HZZ-emerin-opsin shifted to the glycosylated state at $30^{\circ} \mathrm{C}$ upon ATP addition (Figure 15 , lane 3 ).

To specifically address the initial question, whether emerin is delivered and integrated by the TRC40-pathway, the influence of the short inhibitory fragments of the ER-receptors WRB and CAML (Vilardi et al., 2011; Yamamoto and Sakisaka, 2012) was tested in semi-permeabilized cells. 
With both, the coiled-coil cytosolic domain of WRB (WRBcc) (Vilardi et al., 2011) and the aminoterminal cytosolic portion of CAML (CAML-N) (Yamamoto and Sakisaka, 2012), the membrane integration of HZZ-emerin-opsin was inhibited, because a competitive situation for membrane insertion was created (Figure 15, lanes 5 and 9). The fragments were titrated in increasing concentrations to the insertion reactions. The more of an inhibitory fragment was used, the more the membrane integration of emerin was inhibited (Figure 15, lanes 5-12). Even a very low concentration of $30 \mathrm{nM}$ GST-CAML-N, resulted in a visible reduction of membrane integrated HZZ-emerin-op and therefore strongly indicates that the TRC40-pathway plays a major role for membrane integration of emerin.

To further ensure the higher MW band was caused by glycosylation of emerin, PNGaseF (Takahashi, 1977), a deglycosylating enzyme, was added to one-tenth of the reaction and incubated. Indeed, the shifted protein band must have been glycosylated, because nearly a complete reduction for the upper band was seen compared to the buffer control (Figure 16, lane 3 and 4). Due to the use of PNGaseF, it could be ensured that only $\mathrm{N}$-linked glycans were specifically removed from the protein and that as assumed emerin was integrated into ER membranes of the SPCS, which were intact and still contained the responsible oligosaccharyltransferase.

All results obtained from the membrane insertion in either RM or SPCs using a purified TRC40/emerin complex indicate that emerin post-translationally integrates into ER-derived membranes via the TRC40-assisted route in an energy- and-temperature dependent manner (Stefanovic and Hegde, 2007) in vitro.

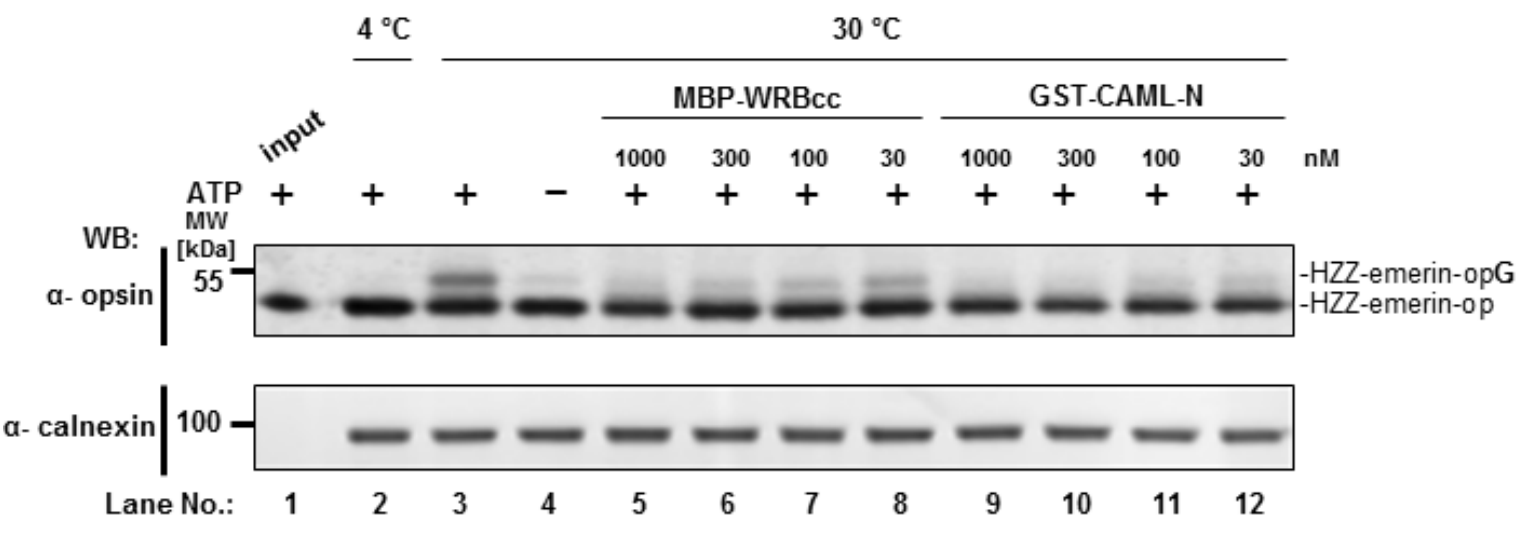

Figure 15: Membrane insertion of HZZ-emerin-opsin into semi-permeabilized cell membranes. HeLa cells permeabilized with digitonin and incubated with the TRC40-co-purified protein HZZ-emerin-opsin at 4 or $30^{\circ} \mathrm{C}$, with or without ATP as an energy source. MBP-WRBcc or GST-CAML-N was added in increasing concentrations ( 30 to $1000 \mathrm{nM}$ ). The pellet fractions of the membrane insertion samples were analyzed by SDS-PAGE followed by western blotting. Detection of protein was carried out using an anti-opsin antibody and the membrane-integrated, glycosylated protein was detected as a higher MW version of the HZZ-emerin-opsin, indicated by "opG". An anti-calnexin antibody was used as a loading control. 


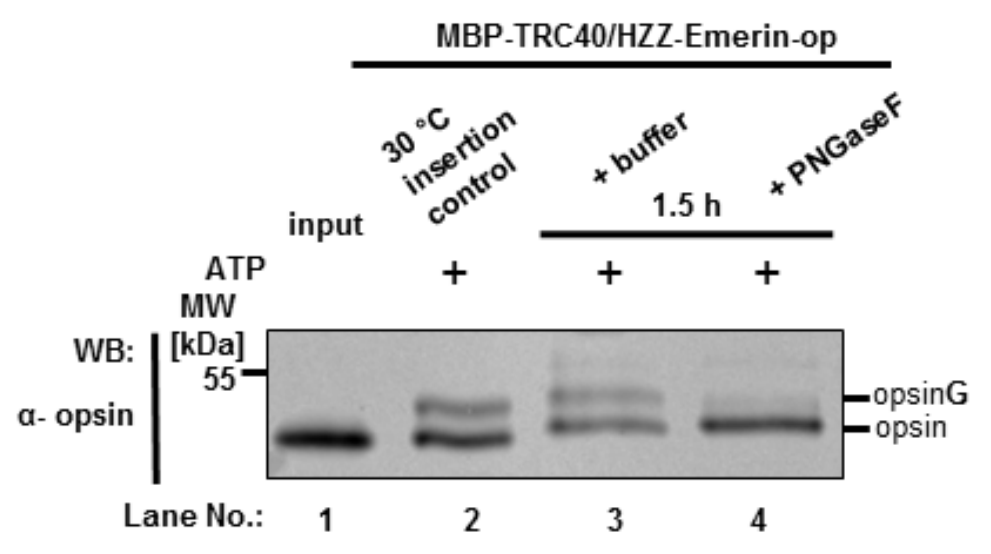

Figure 16: Deglycosylation of HZZ-emerin-opsin integrated into semi-permeabilized cells. After performing a standard insertion reaction with ATP at $30{ }^{\circ} \mathrm{C}$, the samples were subjected to carbonate fractionation (see section 2.2.2.6.2.1) and about $20 \%$ of the pellet fractionwas used to deglycosylate the protein with PNGaseF. Either only the PNGase buffer was used (10\%) or the reaction was performed in the presence of the enzyme (PNGaseF; 10\%) for $1.5 \mathrm{~h}$. For protein input, entirely untreated protein was used. The amount loaded for the initial membrane insertion reaction at $30^{\circ} \mathrm{C}$ as a control (lane 2) was comparable to the deglycosylation samples. The samples were analyzed by SDS-PAGE followed by western blotting. Detection of protein was carried out using an anti-opsin antibody and the membrane-integrated, glycosylated protein was detected as a higher MW version of the HZZ-emerin-opsin, indicated by "opsinG". 


\subsubsection{Membrane insertion of in vitro translated HZZ-emerin-op is affected by TRC40-depletion}

Due to the observation that the membrane integration of emerin, which is in a complex with TRC40, is inhibited by short fragments of the ER-receptors WRB and CAML in rough microsomes or semi-permeabilized cells, emerin most likely is a TRC40-dependent substrate. Therefore, emerin generated by the in vitro translation system was used to further support this finding.

Therefore, a depletion experiment was carried out by Fabio Vilardi (Pfaff et al., 2016). The reticulocyte lysates, which are provided by the in vitro transcription and translation system, were depleted with antibodies against either TRC40 or Hsc70. The Hsc70 depletion was performed besides depletion of TRC40 to exclude emerin using an alternative mechanism for posttranslational insertion of TA-proteins (Abell et al., 2007; Rabu et al., 2008). Afterwards, the standard protocol for membrane insertion into rough microsomes was used to integrate HZZemerin-opsin (section 2.2.2.5).

A pronounced reduction of the glycosylated protein, seen as a higher MW band (Figure 17, indicated with "opG") was observed for TRC40-depeleted lysates, while there was no change in Hsc70 depleted lysates and control treated lysates.

The results once more strongly indicate that TRC40 has a crucial function for the posttranslational membrane integration of emerin and that emerin might thus be a true tail-anchored protein.

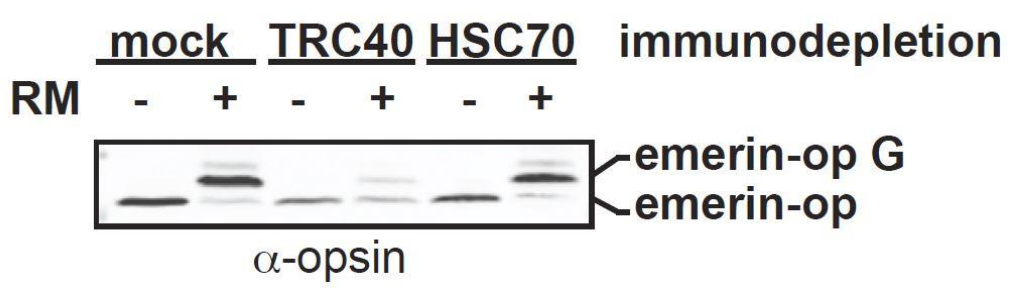

Figure 17: Membrane insertion of HZZ-emerin-op with immunodepleted reticulocyte lysate (performed by Fabio Vilardi, see Pfaff et al., 2016). Lysates used for in vitro transcription and translation were immunodepleted for TRC40 and Hsc70. Additional non-treated cells (mock) served as a positive control for membrane insertion. The membrane inserted protein was detected by using an anti-opsin antibody.

\subsubsection{Investigation of INM-protein transport using an in vitro import assay}

In addition to the biochemically performed membrane integration assays described in the above section 3.1.2, an in vitro transport assay was used to investigate membrane localization or at least association of bacterially produced TRC40/TA-protein complexes in a microscopy-based approach. The reaction performed in this experiment can be seen as the analogous or "microscopic version" of the membrane insertion experiments in semi-permeabilized cells. This kind of in vitro transport assay used in this project, is a well-established method, which originally was used for studying either import or export of soluble proteins (Adam et al., 1990; Kehlenbach et al., 1998).

Besides the biochemical membrane insertion assays, the in vitro import assays were also performed in digitonin-permeabilized HeLa P4 cells (section 2.2.2.5) to examine, whether the 
membrane integration, which was biochemically detected, could be visualized in cells as well. The proteins were purified and co-expressed by the same means as described for the HZZemerin-opsin.

In the following, the membrane association of different emerin variants as well as VAPB and PTP1B were examined in these in vitro import assays using confocal microscopy.

Due to the specific co-expression and purification of the putative TA-protein of interest with TRC40, the proteins were in a kind of pre-determined state and were expected to also use the TRC40-pathway for membrane insertion. Therefore, a general localization of the studied proteins at least to the ER would be expected. Emerin, VAPB and PTP1B should not only be studied for being TA-proteins in terms of their membrane integration mechanism, but also in light of being INM-proteins and using the ER-membrane as a first entry site (Rapoport, 1992; Kutay et al., 1993) on their way to the INM. Furthermore, a localization not only to the ER but also to the nuclear envelope (seen by a "nuclear rim") would consequently be expected for the selected proteins, given that "required" factors are available for targeting of a protein to the NE in this permeabilized cell-system.

Three different emerin versions were tested in this assay. Import reactions for mCherry-emerinopsin, mCherry-FRB-emerin and a mCherry- $\Delta 1$-106-emerin-opsin each in a complex with MBPTRC40 were prepared and the only two components added apart from the protein was an energyregenerating system and cytosol (cytosolic extract from a HeLa suspension cell line). Each import reaction was performed directly on coverslips, on which HeLa cells were seeded one day prior to the assay. Generally, these import assays are performed at $37{ }^{\circ} \mathrm{C}$ and $44^{\circ} \mathrm{C}$, because for all transport processes temperature can be a crucial parameter.

The mCherry-emerin-opsin was used, because the mCherry-tag provides an easy possibility to detect the protein at the microscope and this variant can be immunostained additionally for its C-terminal opsin-tag to determine localization inside the cell.

Furthermore, the MBP-TRC40/mCherry-FRB-emerin (section 3.1.2.2.1.1), was included, because of its possible usage in a rapamycin-INM-localization assay, which will be described in detail in chapter 3.2.2.1. Irrelevant of knowing the details and mechanism of this rapamycin assay, the localization of this variant compared to the first construct, which does not contain such a FRBdomain, were compared.

In addition to the full length (254 aa) versions of emerin, a shortened emerin variant with a deletion of the residues 1-106 was investigated, because it was reported to efficiently localize to the nuclear envelope even though, a large N-terminal portion of emerin was lacking (Tsuchiya et al., 1999).

When the import assays were performed at $37^{\circ} \mathrm{C}$ and an energy-regenerating system as well as cytosolic extract was added, for all different emerin variants a localization at the ER and a NE could be observed (Figure 18). According to this, the soluble control cargo-protein Atto488-BSANLS showed a temperature-dependent import, which was seen by an accumulation of Atto488signal inside the nuclei and nucleoli. In contrast at $4{ }^{\circ} \mathrm{C}$, the control protein showed no import into the nucleus and further for none of the emerin versions, a NE localization was detectable at this temperature. Instead a slight association of emerin to the ER seemed to occur and a "punctate" pattern was observed. The strongest NE-localization was could be observed with the mCherry- $\Delta 1-106$-emerin-opsin deletion mutant (Tsuchiya et al., 1999). Comparing the 
localization of mCherry-FRB-emerin with the mCherry-emerin-opsin variant lacking the FRBcassette, no obvious difference in localization was seen, when looking at the anti-opsin compared to the anti-RFP staining (Figure 18, green signal). Altogether, for the analyzed emerin protein variants a localization or association at the ER membrane was detected and sometimes a more pronounced nuclear rim was observed indicating a localization the nuclear envelope.

Other proteins, which were investigated for the possibility of transport to the nuclear membranes, were VAPB and PTP1B. Both were expressed as HZZ-tagged proteins. After performing the import reactions under the same conditions as for emerin, VAPB localized to a structure, which is most likely the ER (Figure 19, upper panel). Compared to emerin, where at least some part was observed at the NE, VAPB did not reveal any "nuclear rim" localization. A similar observation was made for HZZ-PTP1B-opsin, which showed no NE localization at all, although a perinuclear localization was detected (Figure 19, mid panel). The pattern observed for PTP1B was even more discontinuous than the "ER" localization observed for VAPB, therefore contrary to the observations made with in vitro translated PTP1B in membrane insertion assays, under these specific in vitro import assay conditions PTP1B might hypothetically only be associated and not integrated into the membrane.

Taken together, the membrane integration assays performed with in vitro translated proteins showed a possible post-translational insertion at the ER for emerin, LAP2 $\beta$, VAPB and PTP1B. Focusing on the membrane protein emerin, it was demonstrated that with either in vitro translated or bacterially expressed protein together in a complex with TRC40, a post-translational membrane insertion was utilized by emerin but not by VAPB in comparison. After having a closer look on the specific post-translational mechanism, the membrane integration of emerin was shown to depend on the TRC40-pathway, when inhibitory fragments of WRB and CAML were used in RM or SPCs independent of what kind of emerin variant (in vitro translated or purified in complex with TRC40) was used.

Additionally, depletion experiments showed, how strongly emerin depends on the TRC40 machinery. As a consequence, emerin is strongly suggested to belong to the group of tailanchored proteins and seems to rely on the TRC40-mediated membrane integration.

Corresponding to the biochemical assays, an ER localization and thus as well a localization at the ONM which is continuous to the ER, is most likely to be seen for emerin in the in vitro import assay.

Overall, a statement about the exact subcellular localization of a protein is not possible on the basis of this method. These in vitro transport assays clearly illustrate the limitation of information provided concerning the exact subcellular localization of a protein.

As a consequence of this, the next chapter addresses the available options to determine the localization of a protein at the INM and presents a new approach for doing this. 


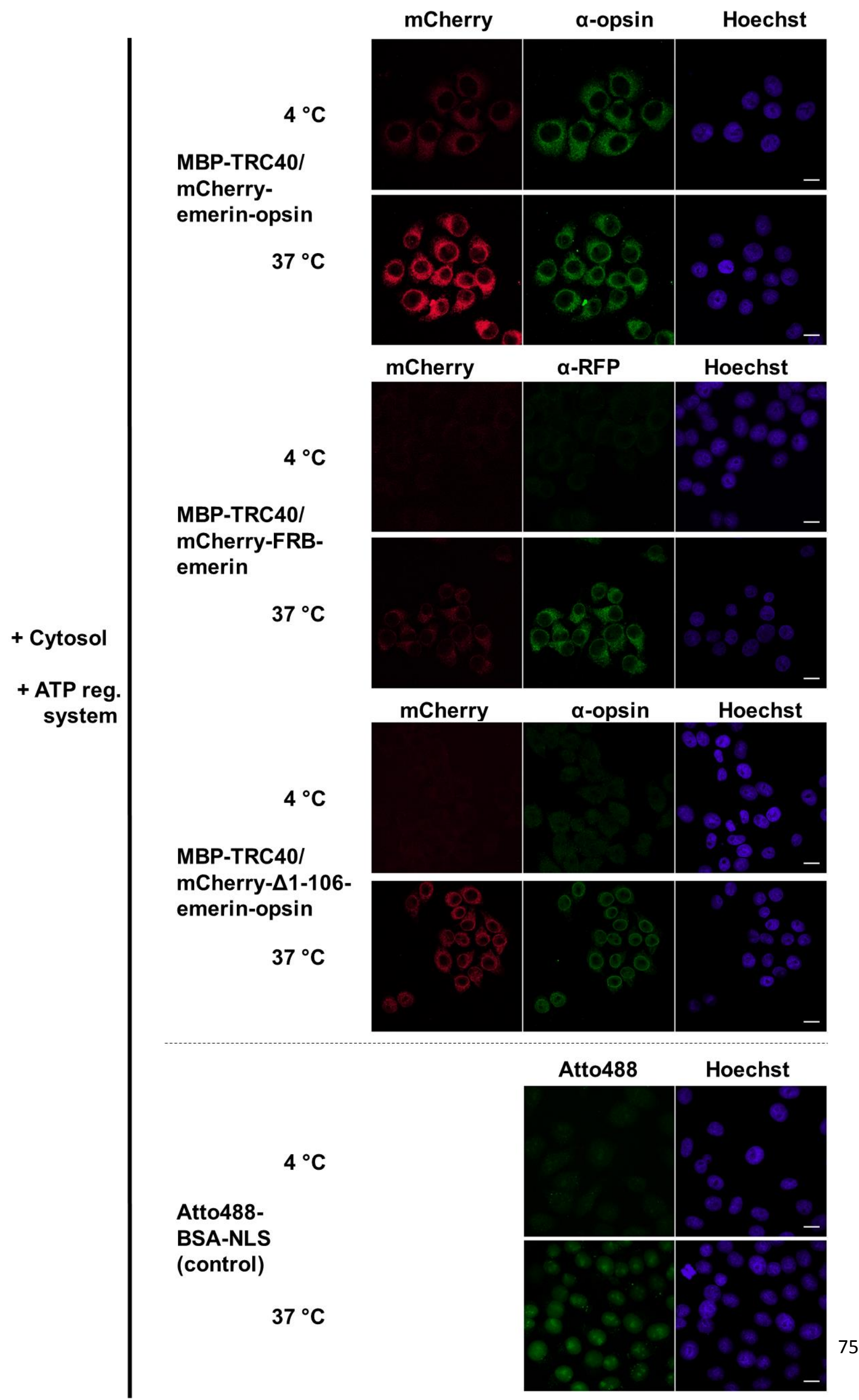


Figure 18: In vitro transport assay to the NE using different emerin variants. Transport reactions of a TAprotein together with TRC40 to the ER membranes or NE were performed directly on the coverslips. One day prior to the transport assay, HeLa P4 cells were seeded on coverslips. After digitonin-permeabilization of the cells, the transport reaction was set up. The amount of protein in a complex with TRC40 used per import reaction varied for all different emerin fusion proteins (mCherry-emerin-op: $5 \mu \mathrm{g}(1.8 \mu \mathrm{M})$; mCherry-FRB-emerin: $1.8 \mu \mathrm{g}(0.5 \mu \mathrm{M})$; mCherry- $\Delta 1$-106-emerin-op: $4.5 \mu \mathrm{g}(2 \mu \mathrm{M}))$. The reaction was completed by addition of cytosol and ATP-regenerating system to the protein and the mixture was added to the cells. Transport was performed at $37^{\circ} \mathrm{C}$ for one hour and an additional control reaction at $4{ }^{\circ} \mathrm{C}$ was prepared. Atto488-BSA-NLS served as a general control for the assay and should localize to the nucleoplasm as a soluble cargo protein. The fluorescent signal in the red (mCherry) or the green ( $\alpha$-opsin) channel indicates integration of the protein into the ER and the NE (arrow). Scale bars: $15 \mu \mathrm{m}$. 


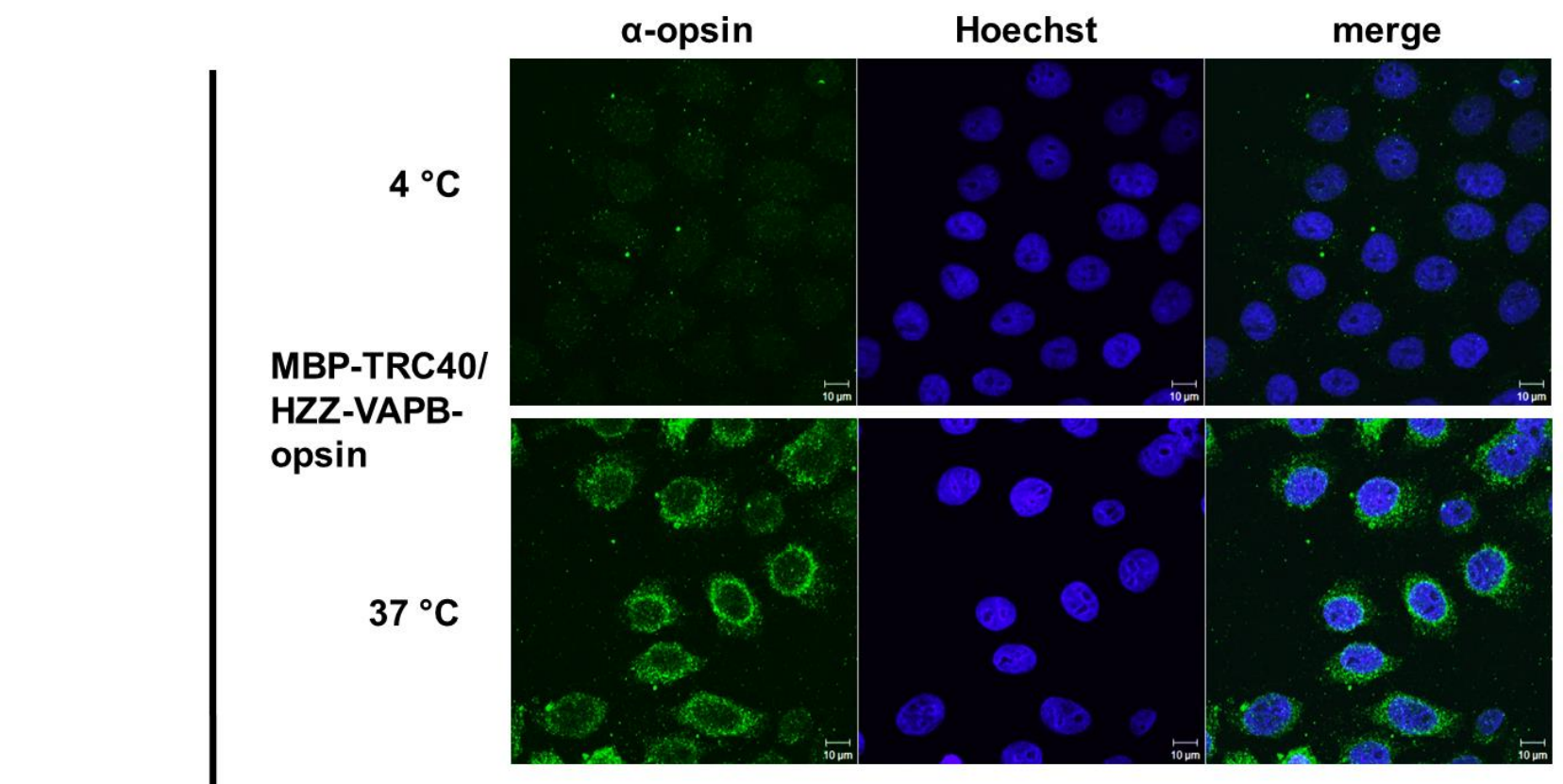

+ Cytosol

+ ATP reg. system

MBP-TRC40/

HZZ-PTP1B-

opsin

$4{ }^{\circ} \mathrm{C}$

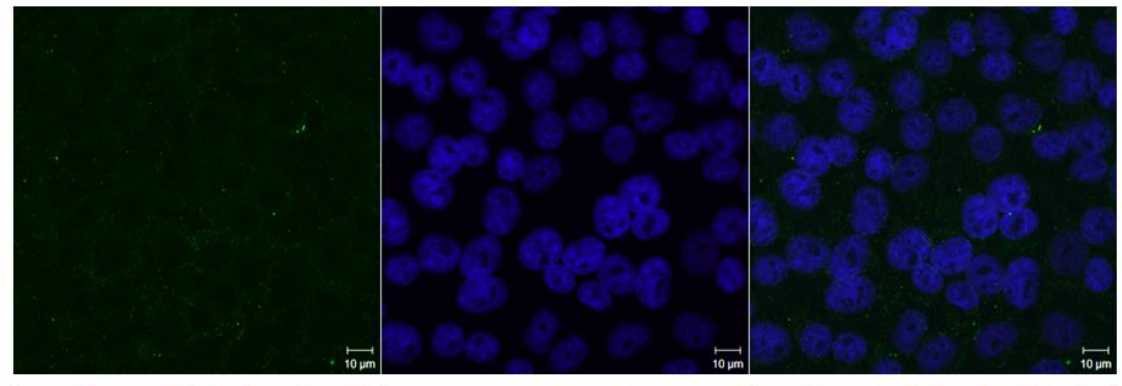

$37^{\circ} \mathrm{C}$

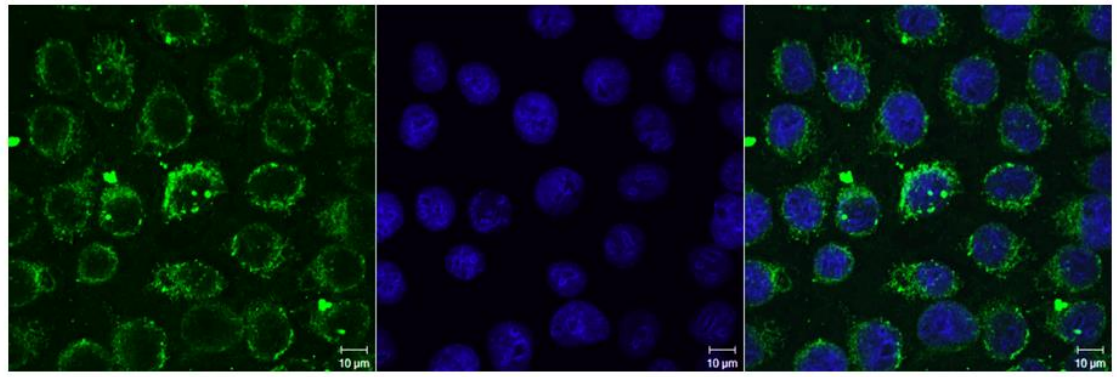

Cy3

Hoechst

merge

Cy3-BSA-NLS (control)

$37^{\circ} \mathrm{C}$
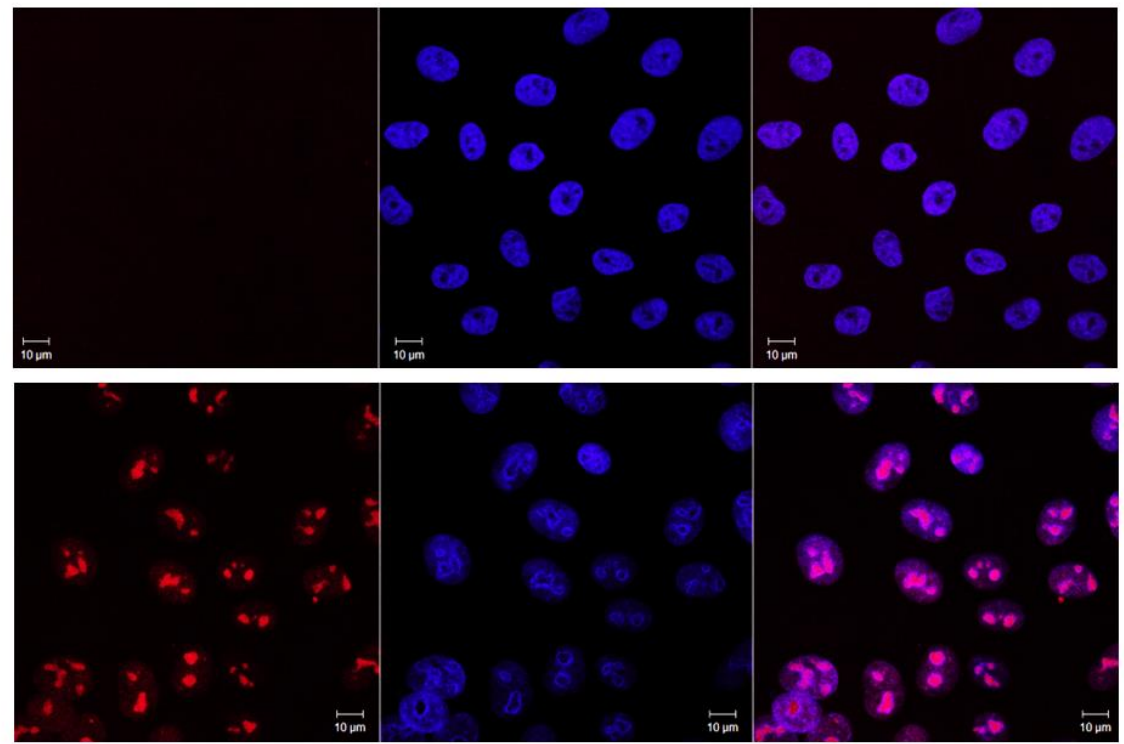
Figure 19: In vitro transport assay to the ER and NE using VAPB and PTP1B expressed in a complex with TRC40. Transport reactions of a putative TA-protein together with TRC40 to the ER membranes or NE, were performed directly on the coverslips. One day prior to the transport assay, HeLa P4 cells were seeded on coverslips. After digitonin-permeabilization of the cells, the transport reaction was set up. The amount of TRC40/TA-protein-complexes used per import reaction was for VAPB $2.7 \mu \mathrm{g}(0.6 \mu \mathrm{M})$ and for PTP1B $1 \mu \mathrm{g}(1 \mu \mathrm{M})$. The reaction was completed by addition of cytosol and ATP-regenerating system to the protein and the mixture was added to the cells. Transport was performed at $37^{\circ} \mathrm{C}$ for one hour and an additional control reaction at $4{ }^{\circ} \mathrm{C}$ was prepared. Cy3-BSA-NLS served as a general control for the assay and should localize to the nucleoplasm as a soluble cargo protein. The fluorescent signal in the green channel ( $\alpha$-opsin) indicates integration of the protein into the ER and perhaps the NE. Scale bars: $10 \mu \mathrm{m}$.

\subsection{Localization of putative TA-INM-proteins}

This section deals with possibilities to specifically study the localization of putative TA-proteins to the inner nuclear membrane. Due to the close proximity of both ONM and INM (Franke et al., 1981) and the fact that the ONM is continuous with the ER, it is not easy to discriminate to which of these membranes a protein exactly localizes. Using basic confocal microscopy does not allow the differentiation between these two membranes due to the restricted resolution caused by the diffraction limit. The localization patterns observed after immunofluorescence stainings, overexpression studies (Figure 8, Figure 9) or in vitro import assays (section 3.1.3) for example revealed emerin to be localized at the nuclear envelope or at least associated with the nuclear envelope and the ER, but whether the "nuclear rim" seen in these experiments pointed to an ONM or INM targeting could not be distinguished.

Instead of using biochemical methods like subcellular fractionation experiments to determine the localization compartment of a protein inside a cell, in this study, two microscopy-based approaches were used to confirm the localization of a protein at the INM.

By using a differential permeabilization approach (section 3.2.1) as well as a newly introduced version of a rapamycin-based dimerization assay (section 3.2.2) the subcellular distribution of proteins was investigated.

\subsubsection{Differential permeabilization approaches revealed emerin, LAP2 $\beta$ and LRRC59 to localize at the INM in contrast to the ER-membrane receptor WRB}

At the beginning of this study, the detection of endogenous putative TA-INM-proteins and the overexpressed versions of these proteins (chapter 3.1.1) revealed them to localize both at the ER and membranes of the NE. For proteins visualized in these experiments and found at the NE, it was not possible to make a clear statement about an ONM or INM localization. A prediction of the distinct membrane was not possible so far but would be essential for studying the transport of a protein to its destination. As already mentioned above, a commonly used method to get information about the subcellular localization of a protein is the differential permeabilization method.

This method was used to characterize the subcellular localization of tagged versions of the proteins emerin, LAP2 $\beta$ and LRRC59 as putative TA-INM-proteins in detail. In general, proteins were visualized via their tag (either HA or mCherry), which in turn gave information about the compartment or organelle the protein mainly localizes to. To figure out, whether a protein might 
not only localize to the NE, but to discriminate between ONM and INM, this differential permeabilization procedure was used, followed by immunostaining (see sections 2.2.4.2.1 and 2.2.3.5).

In this approach, Triton X-100 and digitonin were used as permeabilization reagents. On the one hand, cells were treated with Triton X-100 after fixation, which makes proteins of both the INM and ONM accessible for primary antibodies. In contrast to this, digitonin, as a mild detergent, is applied prior to fixation. Because of different amounts of cholesterol found in the plasma membrane compared to the membranes surrounding organelles like ER or the nucleus, a selective permeabilization of only the plasma membrane is caused by using digitonin (Nishikawa et al., 1984).

Due to the fact, that only the plasma membrane is disrupted and other organelle membranes remain intact, the primary antibodies are not able to access the INM and the nuclear interior. By comparison of Triton X-100- versus digitonin-permeabilized cells, differences in the specific subcellular localization can be seen (Adam et al., 1990; Bengtsson and Otto, 2008; Buch et al., 2009).

To be able to differentiate between regions inside the cell the indirect immunofluorescence for mCherry-tagged proteins was performed with an anti-RFP antibody and for the other proteins an anti-HA antibody was used. Thus far, the ER-receptor WRB of the TRC40 route is known to reside at the ER membrane (Vilardi et al., 2011) and was therefore used as a negative control for INM localization. In comparing the outcome for both permeabilization conditions, for WRB-HA, a pattern of ER and NE localization was seen, which seemed to be very similar for the different detergents used (Figure 20). By contrast, the endogenous nuclear lamina component lamin $A / C$ showed a prominent "nuclear rim" staining after Triton X-100 treatment (Figure 20, upper lane) but is not detected at the NE upon digitonin permeabilization. The well-studied proteins emerin and LAP2 $\beta$ showed independently of the size of their N-terminal tag (mCherry or HA), a distribution throughout the ER when treated with digitonin, whereas a NE localization was observed after Triton X-100 treatment. For mCherry-LRRC59 (Figure 20, bottom lane) the observed NE localization was not as distinct and pronounced as for emerin and LAP $2 \beta$. Compared to the pattern demonstrated for emerin, the Triton X-100 treated mCherry-LRRC59 cells showed only slightly more nuclear rim staining than the digitonin treated cells. Thus, LRRC59 might not be present at the INM to the same degree like emerin indicated by a weak nuclear rim localization. Perhaps the abundance of LRRC59 at the INM is relatively low compared to emerin protein levels for example.

On the basis of this experiment it was possible to distinguish the localization of a protein at the ER membrane or ONM versus a localization at the INM. With a Triton X-100 permeabilization, both tagged emerin and LAP $2 \beta$ versions, as well as LRRC59 could be shown to localize in addition to the ER at the "nuclear rim", which is representative for an INM localization. 
RESULTS
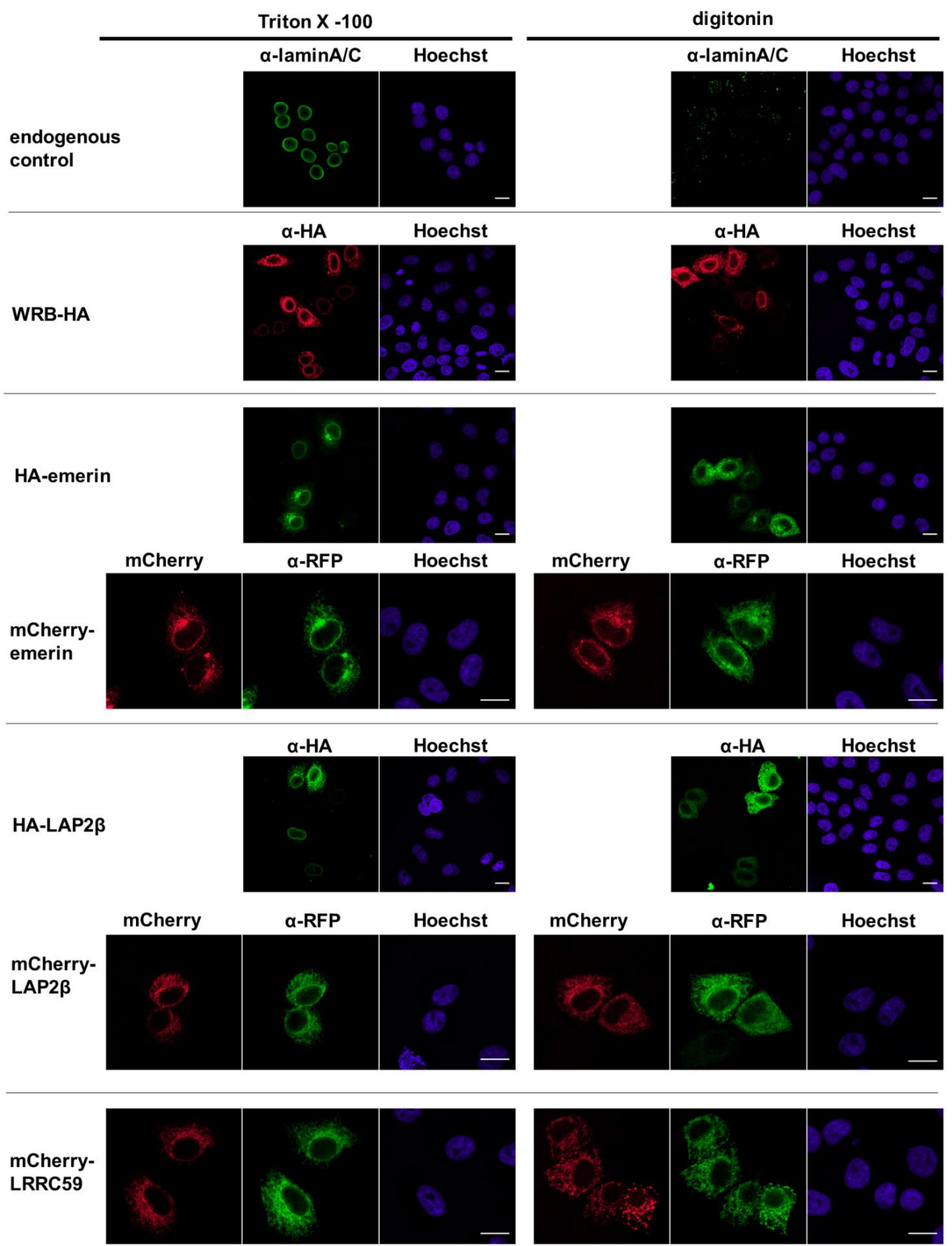

Figure 20: Subcellular localization of membrane proteins. HeLa P4 cells were transfected with plasmids coding for WRB-HA and tagged versions of emerin and LAP2 $\beta$ and mCherry-LRRC59. Cells were permeabilized either with Triton X-100 or digitonin and immunostained against the HA or RFP tag. As a control for differential permeabilization the nuclear lamina component lamina/C was used, which is detectable with Triton X-100 only. Scale bars: $15 \mu \mathrm{m}$. 


\subsubsection{Discrimination between ONM and INM localization using a rapamycin-based localization assay}

\subsubsection{Establishing a rapamycin-based INM-targeting assay}

For discrimination of membrane protein targeting to the INM or ONM, which is continuous with the ER membrane, a rapamycin based protein localization assay was established. With this approach, the localization of already established INM-proteins can be confirmed and the targeting of potential INM-proteins can be investigated.

The kinase mTOR or FRAP (= FKBP-12-rapamycin associated protein), which is involved in many signaling pathways, can interact with FKBP12 (= $12 \mathrm{kDa}$ FK506/rapamycin-binding protein) via a macrolide, termed rapamycin (Chiu et al., 1994; Stan et al., 1994; Choi et al., 1996). The structural basis of this binding between FKBP12-rapamycin to the FKBP12-Rapamycin- Binding (FRB) domain was investigated by Choi et al. (1996), Liang et al. (1999) and La Banaszynski et al. (2005) in detail. It was shown that in presence of rapamycin, FKBP12 is bound by the drug first, then FKBP12-rapamycin is able to bind to mTOR. Rapamycin (= Sirolimus) is produced by the bacterium Streptomyces hygroscopicus and is known for its antifungal properties (Singh et al., 1979). The rapamycin dimerization mechanism has been successfully used for trapping of reporter proteins at the nuclear lamina (Ohba et al., 2004). Furthermore, this fusion system was utilized in an anchor-away (AA) approach in yeast to deplete a protein of interest from the nucleus and bind it to an abundant cytoplasmic protein (Haruki et al., 2008).

In the approach used in this work, a two-component system is defined as the following: One component is a small portion of mTOR, termed FRB domain (Chen et al., 1995; Zheng et al., 1995). It has a size of $11 \mathrm{kDa}$ and was cloned into a plasmid together with the protein of interest ("TAprotein") e.g. mCherry-FRB-emerin. The second component is FKBP12, this dimerization partner is expressed in a GFP-tagged version containing an NLS (Figure 21). Several constructs for the rapamycin-dimerization assays were created for the FKBP12 reporter and expression constructs containing the FRB domain of several investigated membrane proteins are available (Table 2).

When rapamycin is added to the specific experimental setup, the nuclear, soluble FKBP12 reporter is recruited to the protein of interest containing the FRB cassette at the INM, if it is indeed present at the nuclear rim (Figure 21). Upon rapamycin addition, a change in localization of EGFP 2 -GST-NLS-FKBP12 from a homogenous distribution inside the nucleus to a localization at the nuclear periphery, can be observed. 


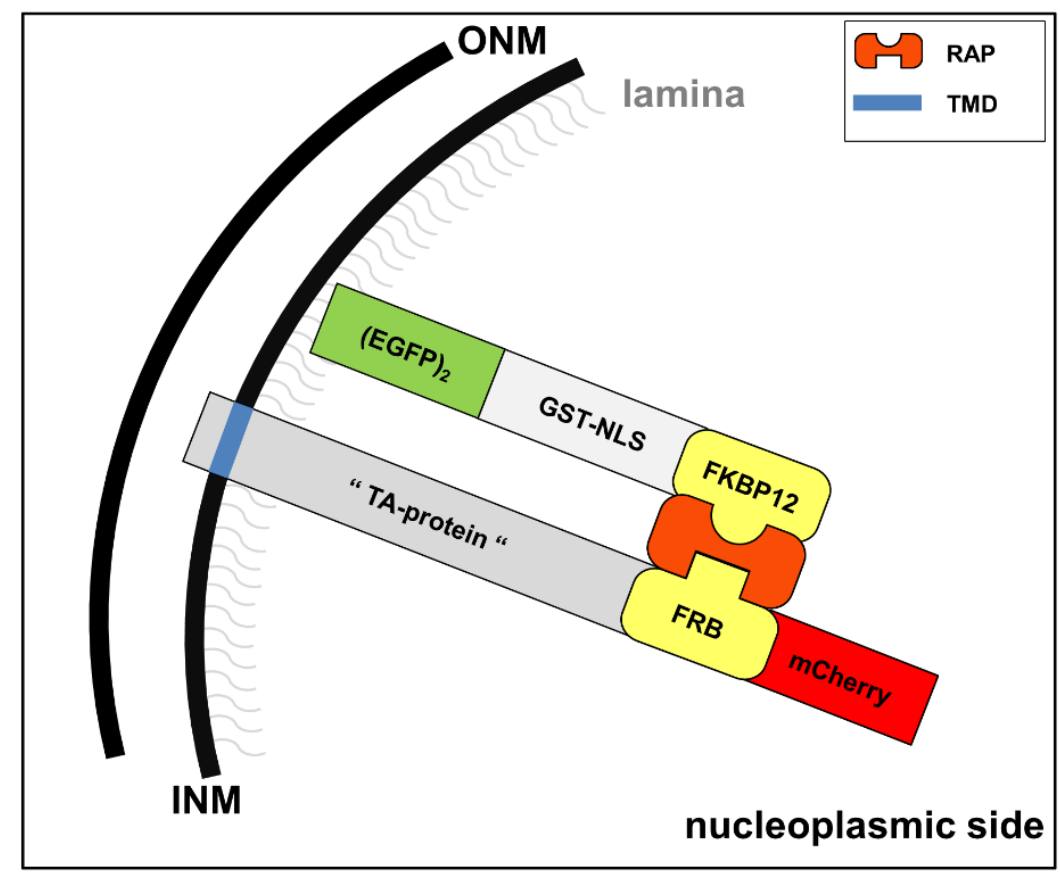

Figure 21: Schematic view of the rapamycin-based dimerization of FKBP12- and FRB- containingproteins at the INM. Upon addition of rapamycin (RAP, orange), the soluble GFP-NLS-containing FKBP12 reporter protein is able to localize to the nuclear periphery and binds to the FRB cassette of a protein localized to the INM. The "TA-protein" of interest (e.g. emerin) is integrated via its transmembrane domain (TMD, blue) into the INM as depicted in the scheme.

During development and optimization of this assay, the first rapamycin assays were carried out in living cells. These experiments were performed by using emerin as an INM model protein. mCherry-FRB-emerin was co-transfected with EGFP2-NLS-FKBP12 in HeLa P4 cells for one day, afterwards rapamycin was added to the culture medium to living cells.

This assay was thus referred to as in vivo rapamycin assay. The overexpressed mCherry-FRBemerin was localized at the INM (Figure 21, displayed by mCherry-FRB- "TA-protein") and a soluble EGFP 2 -GST-NLS-FKBP12 could bind to the FKBP12 cassette of the GFP-reporter via interaction with rapamycin and therefore a peripheral FKBP12 rim was detected (in vivo data not shown). An important observation made during analysis of this assay was, that the FKBP12 reporter did not completely localize inside the nucleus. In quite a few cells, the FKBP12 protein was found as well to a certain degree in the cytoplasm. This might be explained by the presence of newly synthesized protein occurring in the cytoplasm, as the FKBP12 reporter (EGFP2-GST-NLSFKBP12) was intentionally designed to contain several tags to increase the size of the protein and prevent a passive diffusion mechanism.

In accordance with this idea, in EGFP 2 -GST-NLS-FKBP12 transfected cells, the reporter mainly localized to the nucleus and was retained inside the nucleus most probably due to its size, which is above the diffusion limit of the NPC (Paine et al., 1975), but there obviously was some FKBP12 reporter localizing in an unintended way as it was clearly observed in the in vivo study.

To address the problem of cytoplasmic localization of FKBP12, the conditions of the assay were changed from an in vivo situation to a situation using semi-permeabilized cells for the rapamycin assay. 
As a consequence, this kind of approach was named in vitro rapamycin assay (2.2.4.2.2). To ensure a proper localization of the GFP-FKBP12 reporter protein inside the nucleus, a permeabilization of the cells with digitonin was performed. Due to the permeabilization the cytosol content was released and most of the background FKBP12 fluorescence in the cytoplasm was removed.

Based on the idea of the in vitro rapamycin assay, a third version of this rapamycin system was tested and referred to as in vitro-kinetics rapamycin assay. To specifically confirm the FKBP12 reporter to be present inside the nucleus only, this assay was performed under real time conditions. The cells were selected and imaged before addition of rapamycin, which allowed to control the correct targeting of EGFP 2 -GST-NLS-FKBP12 inside the cells for the chosen area. Upon rapamycin treatment, images were taken after pre-determined time points. Due to the series of images taken, information about the kinetics of the rapamycin induced dimerization reaction for the soluble GFP-FKBP12 could be obtained.

Taken together, all types of developed rapamycin-assays, only allow to make a qualitative but not quantitative statement about the localization of a protein of interest to the INM. A nuclear rim of EGFP ${ }_{2}$-GST-NLS-FKBP12 can be seen as a confirmed localization at the INM. No change in localization of the FKBP12 reporter protein is judged as the protein not being present at the INM. In context to this, it has to be mentioned that the amount of protein being present at the INM might be a limiting factor for detection of the protein in this system and therefore, very low amounts of protein at the INM might not be detected in this specific assay setup. In the following, the in vitro rapamycin assay versions were frequently used to obtain information about protein localization at the INM.

\subsubsection{Analysis of INM-localization of emerin, LAP2, PTP1B, LRRC59, VAPB and LEMD1 using an in vitro-kinetics rapamycin assay}

Due to the limitations given by methods like immunofluorescence and overexpression studies it was not easy to verify if a protein localizes specifically to the inner nuclear membrane as mentioned in chapter 3.2.1.

As a consequence of this, a newly developed rapamycin based assay was utilized to confirm the localization of a protein at the INM. Using a differential permeabilization assay an INM localization was already shown for emerin, LAP2 $\beta$ and LRRC59.

In this section, all of the selected putative TA-INM-proteins (Table 1) were also studied with this localization assay. For the proteins emerin, LAP2 $\beta$, PTP1B, LRRC59, VAPB and LEMD1 in vitrokinetics rapamycin assays were carried out. As described in section 3.2.2.1, the advantage compared to the regular in vitro assay version is, that prior to the addition of rapamycin, the cells can be chosen specifically concerning their transfection efficiency and morphology for both the mCherry-FRB-TA-protein and the "GFP-FKBP12" reporter. Due to the permeabilization step prior to the rapamycin treatment and the choice of specific cells for imaging, it can be ensured that in the imaged cells no residual cytoplasmic GFP-reporter is left, which could in turn bind to proteins at the ONM/ER and provide false positive results.

After co-transfection of the putative TA-protein together with the EGFP 2 -GST-NLS-FKBP12 reporter and permeabilization of the cells, cells were selected and an image was taken prior to rapamycin addition (-rap). Upon rapamycin addition, the change in FKBP12 reporter distribution 
was monitored until no further change in distribution of FKBP12 could be visually detected anymore. After a series of images were taken, a final image was acquired representing the post rapamycin state (indicated as +rap condition in Figure 23).

As a well-studied INM-protein, emerin was analyzed for its INM-localization in the role of being a positive control for targeting to the INM (Figure 22). For emerin, the shift and recruitment of the FKBP12 reporter occurred rapidly. Already after 7 seconds post rapamycin addition and starting a time series, first stages of rim formation were visible (Figure 22, arrow).

\section{mCherry-FRB-emerin transfected cells}

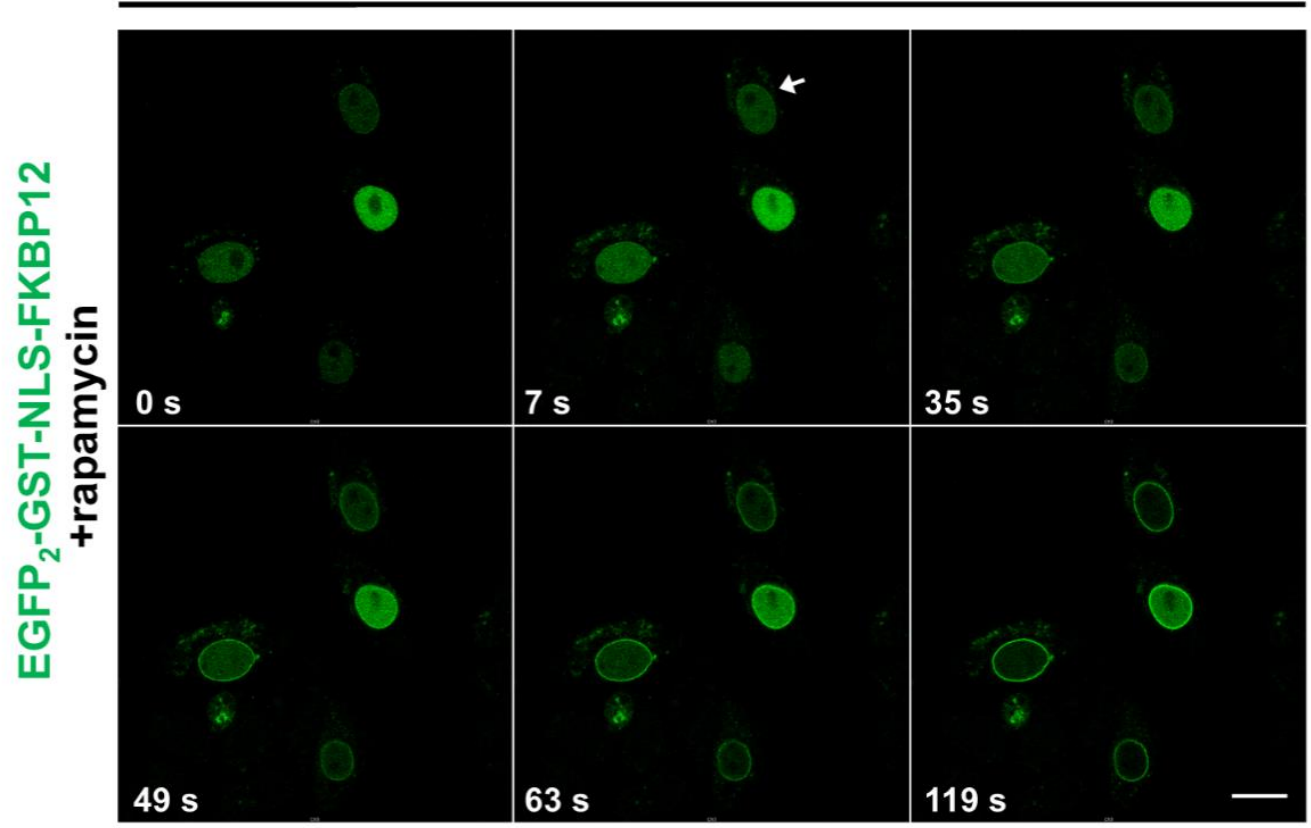

Figure 22: Time course of rapamycin-induced change in localization of the GFP-FKBP12 reporter in emerin transfected cells. An image time series of the change in GFP-FKBP12-reporter localization in mCherry-FRB-emerin transfected cells is shown over a time span of 120 seconds. Images were taken every 7 seconds, but only specific time points are illustrated above. The displayed images show the kinetics of the experiment performed for emerin in Figure 23. The localization of emerin for each specific cell seen above can be inspected for-/+ rapamycin conditions in Figure 23. The arrow indicates the initial "INMrim" formation. Scale bar: $20 \mu \mathrm{m}$.

Generally, all above mentioned proteins were detected at the INM and showing a formation of a GFP-rim at the nuclear periphery accompanied by a reduction of GFP-signal inside the nucleus (Figure 23). The percentage of cells not responding at all to rapamycin treatment varied between the different constructs.

Further it could be seen that the extent to which the EGFP 2 -GST-NLS-FKBP12 reporter proteinrecruitment to the nuclear periphery occurred, differed a lot between the investigated proteins. For LAP2 $\beta$ a very distinct FKBP12-rim staining was observed and already after 25 seconds the first "rims" appeared to be visible. Similar to LAP2 $\beta$, a shift in FKBP12-reporter localization to the INM was detectable for PTP1B after 20 seconds upon addition of rapamycin. An additional observation for the GFP-rim formation in case of PTP1B was that FKBP12 seemed to be enriched 
at certain spots throughout the NE. The detected rim was not as homogenous as observed for emerin or LAP2 $\beta$.

According to the experiment, VAPB can be localized to the INM as well, but shows an overall less efficient recruitment of FKBP12 to the NE. GFP-rims were already visible after 30 seconds.

LRRC59 shows a change in distribution for GFP-FKBP12 after about 40 seconds upon rapamycin treatment in some cells, although in general more residual GFP-reporter can be observed compared to LAP2 $\beta$ or emerin. Imaging LEMD1 revealed as well a localization to the INM, even though the "nuclear rim" seemed to be thinner and not as prominent as for strongly reacting proteins like emerin. The reaction time until first rims were visible for LEMD1 was about 2 minutes, which is compared to all other proteins quite long.

Using this in vitro-kinetics rapamycin assays to follow changes in GFP-FKBP12 distribution in a real-time, it was possible to confirm all selected proteins, including emerin, LAP2 $\beta$, PTP1B, LRRC59, VAPB and LEMD1 to be present at the INM. Most of them have been implicated to reside at the INM at least partially by literature and were reported to localize to the ER, which was as well seen by looking at the localization pattern of the mCherry-tagged protein itself. In future, other proteins can be easily examined for INM-localization by performing this assay, but it has to be said that the assay only allows a qualitative statement about INM localization due to the unequal transfection levels of the cells. 


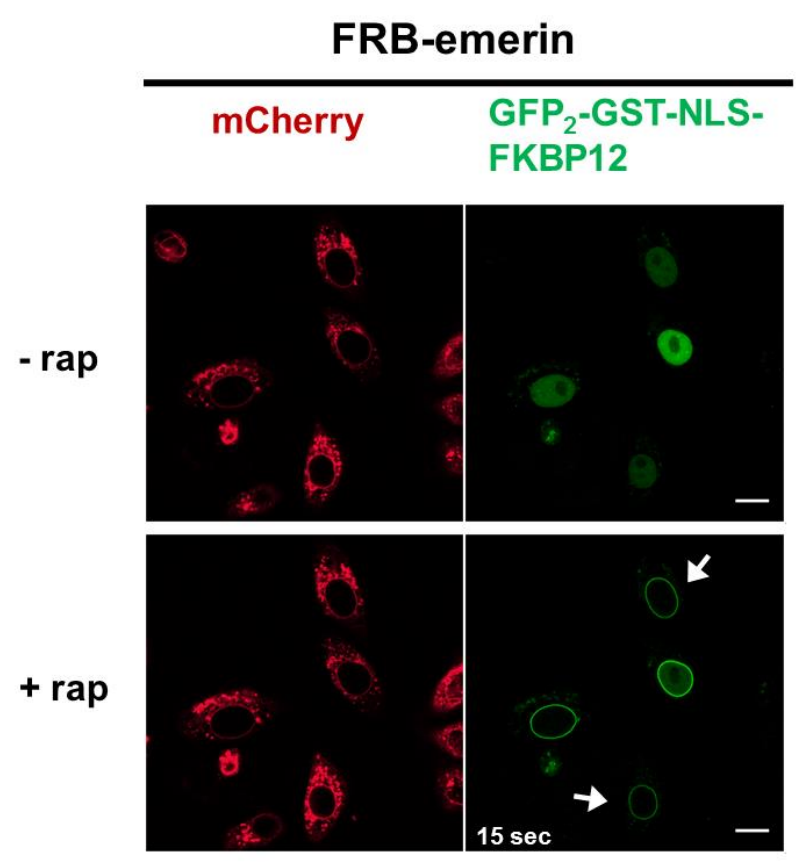

FRB-PTP1B

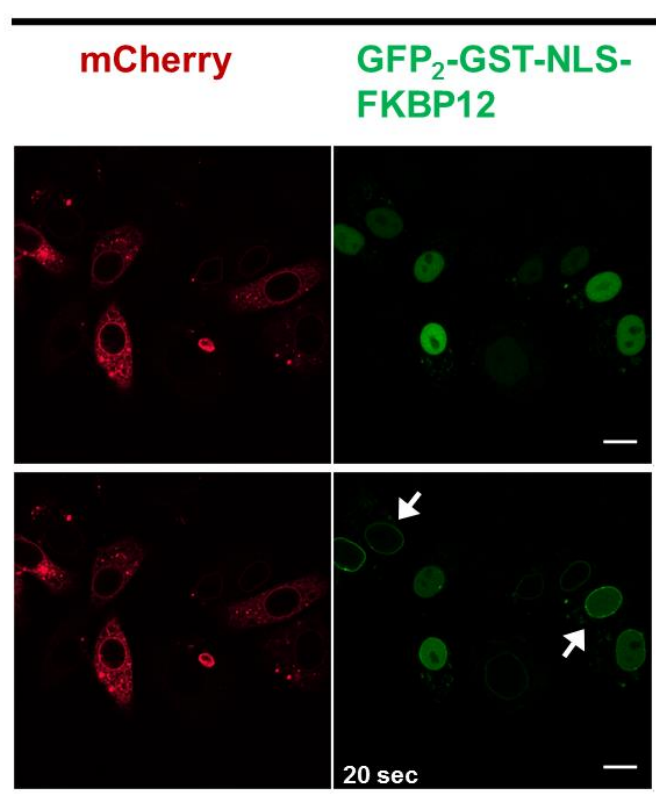

FRB-VAPB

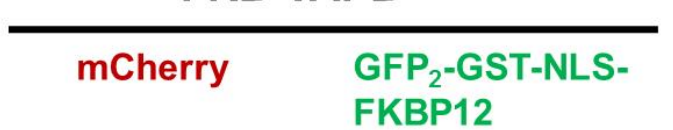

FKBP12

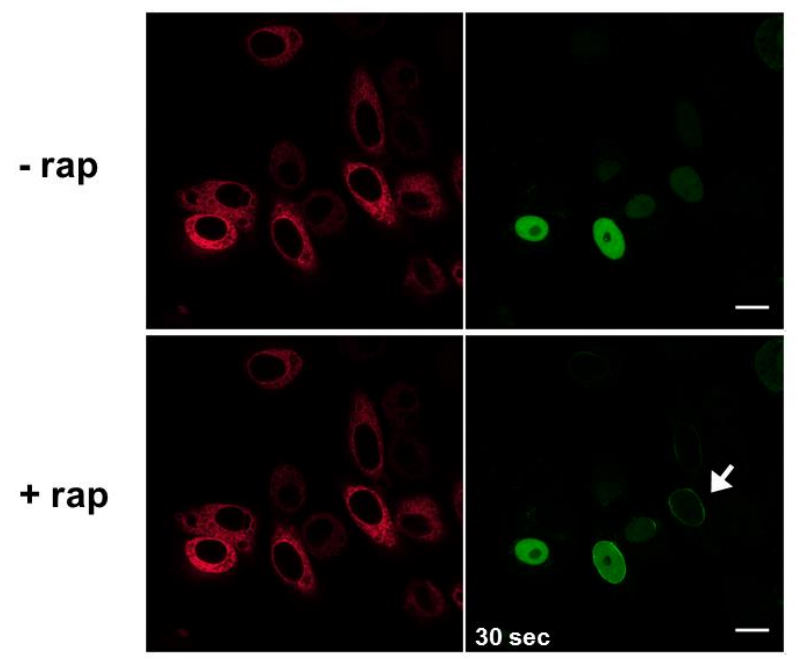

FRB-LAP2 $\beta$

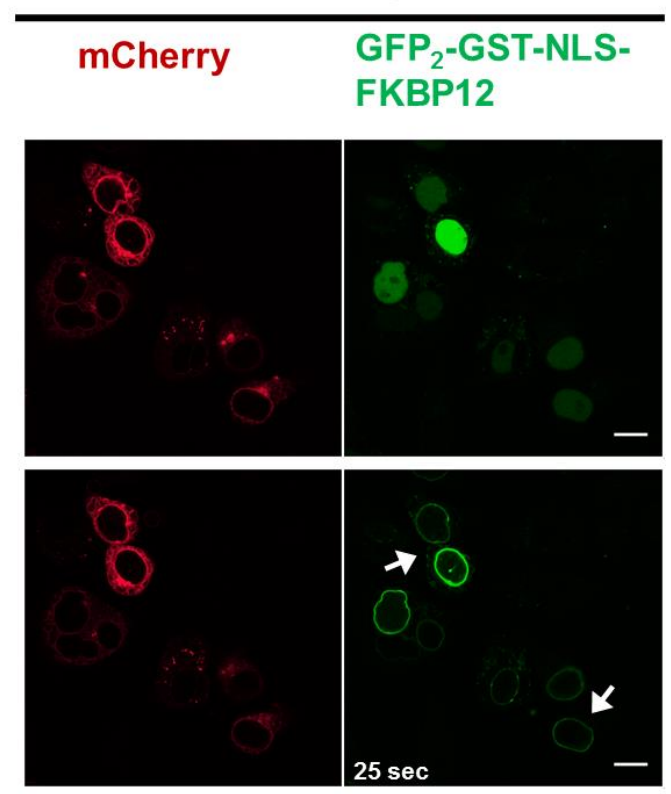

FRB-LRRC59

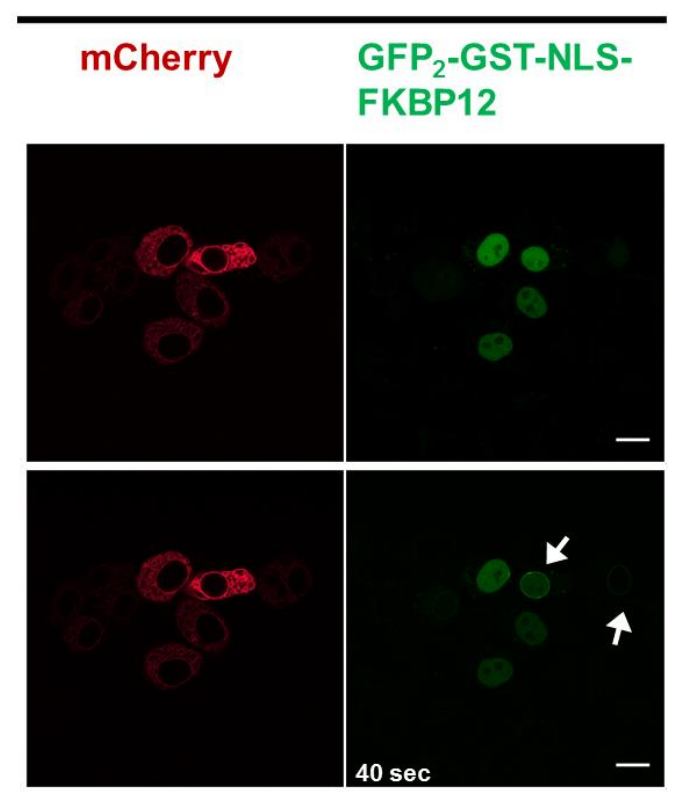

FRB-LEMD1

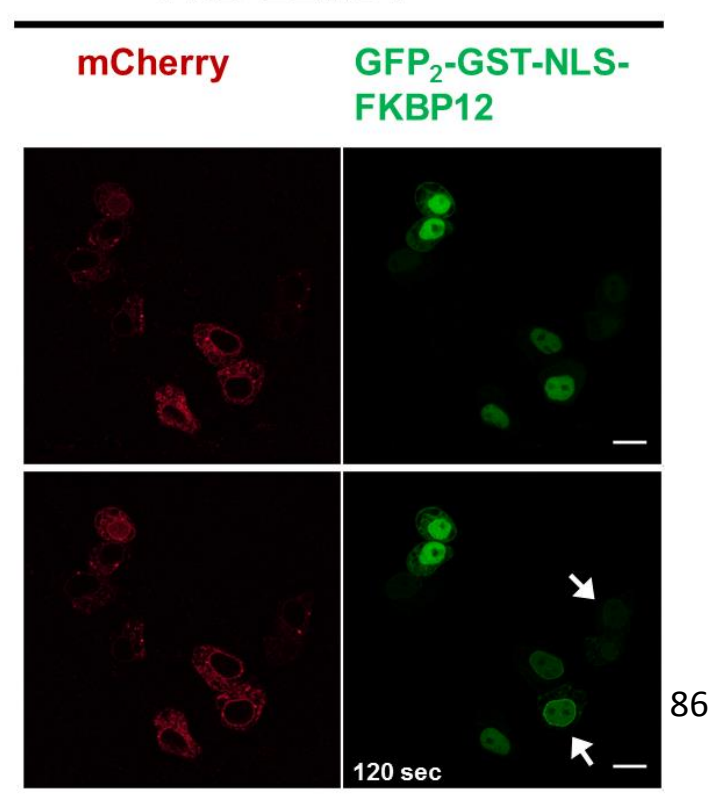


Figure 23: Emerin, LAP2 $\beta$, PTP1B, LRRC59, VAPB and LEMD1 can be found at the INM using an in vitrokinetics rapamycin assay. HeLa cells were transfected with the mCherry-FRB-versions of emerin, LAP2 $\beta$, PTP1B, LRRC59, VAPB and LEMD1 together with the EGFP ${ }_{2}$-GST-NLS-FKBP12 reporter for $48 \mathrm{~h}$ and the in vitro-kinetics rapamycin assay was performed. Cells were imaged prior to rapamycin addition (-rap) and several minutes after rapamycin treatment (+rap) until no further change in FKBP12 distribution could be detected anymore. The time indicated in seconds refers to the duration until first GFP-FKBP12 rims appeared to be visible for this specific experiment. Arrows indicate cells responding on rapamycin treatment, indicated by a nuclear "GFP-rim". Scale bars: $15 \mu \mathrm{m}$.

\subsection{Confirmation of INM localization of emerin using the in vitro rapamycin assay}

Emerin was used as a model protein to establish and optimize the rapamycin-assay. Therefore, mCherry-FRB-emerin and HA-FRB-emerin were cloned (Table 2) to find the optimal design for the FRB-containing protein, as a counterpart a soluble, NLS-containing fluorescent FKBP12 reporter protein was created. Plasmids coding for the larger version EGFP 2 -GST-NLS-FKBP12 and a smaller protein $\mathrm{EGFP}_{2}$-NLS-FKBP12 were used for the co-transfections with the FRB-containing protein in HeLa P4 cells.

The in vitro rapamycin assay showed a clear difference in localization for both the mCherry-FRBand HA-FRB-emerin versions before and after treatment with rapamycin at a concentration of $500 \mathrm{nM}$ for 10 minutes on ice. Instead of being homogenously distributed in the nucleoplasm, the soluble reporter EGFP 2 -GST-NLS-FKBP12 was found at the nuclear periphery upon addition of the drug (Figure 24). For both emerin versions, their FRB-cassettes were accessible at the INM and could bind to the soluble FKBP12 reporter upon rapamycin addition. The signal detected for the FKBP12-protein was observed as a green "nuclear rim" after rapamycin treatment, whereas it was homogenously localized inside the nucleus without rapamycin treatment (Figure 24). This indicates that the "nuclear rims" seen for mCherry-FRB- or HA-FRB-emerin are indeed "INM rims" and the proteins are present at the INM. For mCherry-FRB-emerin the rapamycin assay was performed with two different kinds of FKBP12 reporters (EGFP2-GST-NLS-FKBP12 and EGFP2NLS-FKBP12), which both showed a very similar extent of responsiveness and nuclear periphery localization upon rapamycin treatment (Figure 24, upper panels).

In this experiment, additionally WRB-FRB-HA was investigated for a possible INM localization. WRB, the ER-receptor of the TRC40-membrane insertion mode, was reported to mainly localize at the ER (Vilardi et al., 2011) and to our knowledge was not shown or implicated to localize to the INM. In the assay, WRB-FRB-HA cells did not show any other distribution for the green reporter before and after applying the rapamycin solution (Figure 24, lower panel). Corresponding with the reports about WRB until now, this result indicated WRB not being detectable at the INM with this assay. According to a predicted topology model for WRB inside the ER membrane (Vilardi et al., 2011), the FRB-cassette was positioned together with the HAtag on the C-terminus of WRB in case of the WRB-FRB-HA construct. Therefore, FRB should be facing the cytoplasmic side as seen in other studies for example in case of a WRB-CFP expression construct (Vilardi et al., 2011). The observation of WRB not being present at the INM or at least not being visually detectable within the context of the rapamycin assay, WRB was used as a negative control for INM localization. 
In addition to using WRB as a negative control, the INM protein LBR was tested besides emerin as a possible positive control. LBR, as a typical multi-spanning INM-protein, was transfected as mCherry-FRB-LBR together with a EGFP 2 -GST-NLS-FKBP12 reporter protein. As expected, the FKBP12 was observed to form a nuclear "GFP-rim" at the INM upon rapamycin addition (data not shown).

To further show that dimerization of the FRB cassette with an FKBP12 construct is not restricted to the inside of the nucleus, a short GFP-FKBP12 reporter was expressed. Its localization was observed all over the cell, present inside as well as outside of the nucleus (Figure 25, right panel, -rap). When co-expressed with mCherry-FRB-emerin and treated with rapamycin, for this GFPFKBP12 reporter a "GFP-nuclear-rim" was found, but also a ER-like pattern was observed on the cytoplasmic side for the green reporter. It is plausible to obtain such a pattern on the cytoplasmic side, because mCherry-FRB-emerin localizes as well to the ER and binding of the FKBP12 cassette should be possible at this compartment (Figure 25, right panel, +rap).

Furthermore, the localization of mCherry-FRB-emerin was tested in an in vivo-rapamycin approach using U2OS cells stably expressing the EGFP2-GST-NLS-FKBP12 reporter protein (Appendix, Supplementary figure 1). As expected, the GFP-FKBP12 reporter shifted to the nuclear periphery upon addition of rapamycin implying emerin to be present at the INM (Appendix, Supplementary figure 2). In the light of this assay performed in vivo, it was repeatedly noted that many cells showed additionally to the nuclear distribution a cytoplasmic localization of the FKBP12-NLS containing reporter. Thus, it cannot be excluded that the FKBP12 reporter had bound to the FRB-cassette of mCherry-FRB-emerin, which localized as well at the ER/ONM.

This experiment illustrated again that the rapamycin assay performed in living cells is a relatively simple and quick way to gain a first impression, whether a protein can be localized at the INM. Digitonin permeabilization should be considered as cells sometimes display a considerable amount of FKBP12 reporter outside the nucleus. As a consequence of this, the cytoplasmic FKBP12 cassette can also bind to proteins localized at the ER or ONM as shown for the short FKBP12-reporter mentioned above (Figure 25). A "false positive" nuclear rim pattern of the FKBP12 could not be excluded. With respect to these observations, the in vitro-version of the rapamycin assay using permeabilized cells, can be seen as the more reliable type of assay and was primarily carried out.

Altogether, mCherry-FRB-emerin was also shown to localize to the INM using the time-saving in vitro-version of the rapamycin assay. Further, the ER-receptor WRB was tested for a possible INM localization, but was not detected at the INM in agreement with its functions reported in literature. WRB-FRB-HA was therefore used as a negative control for INM-localization. In contrast to that, a second positive control examined was the multi-spanning protein LBR, which showed indeed a localization at the INM, but was not regularly used due to a very low transfection rate and low expression in cells (Figure 26). Moreover, the functionality of the FRB-FKBP12 dimerization system was demonstrated to occur outside the nuclear compartment as well with a reporter, that was recruited to an FRB-protein at the ER membrane.

In summary, for every new protein investigated in the rapamycin assay, emerin, as an established INM protein (Manilal, 1996; Yorifuji et al., 1997), was used as a positive control to compare the efficiency of the FKBP12 recruitment to the INM. Based on the rapamycin assays with emerin, the newly established rapamycin assay was demonstrated to be a system, which can be performed in its in vitro-version to obtain valuable information about a localization of a protein and can easily be controlled by expression of reference proteins. 


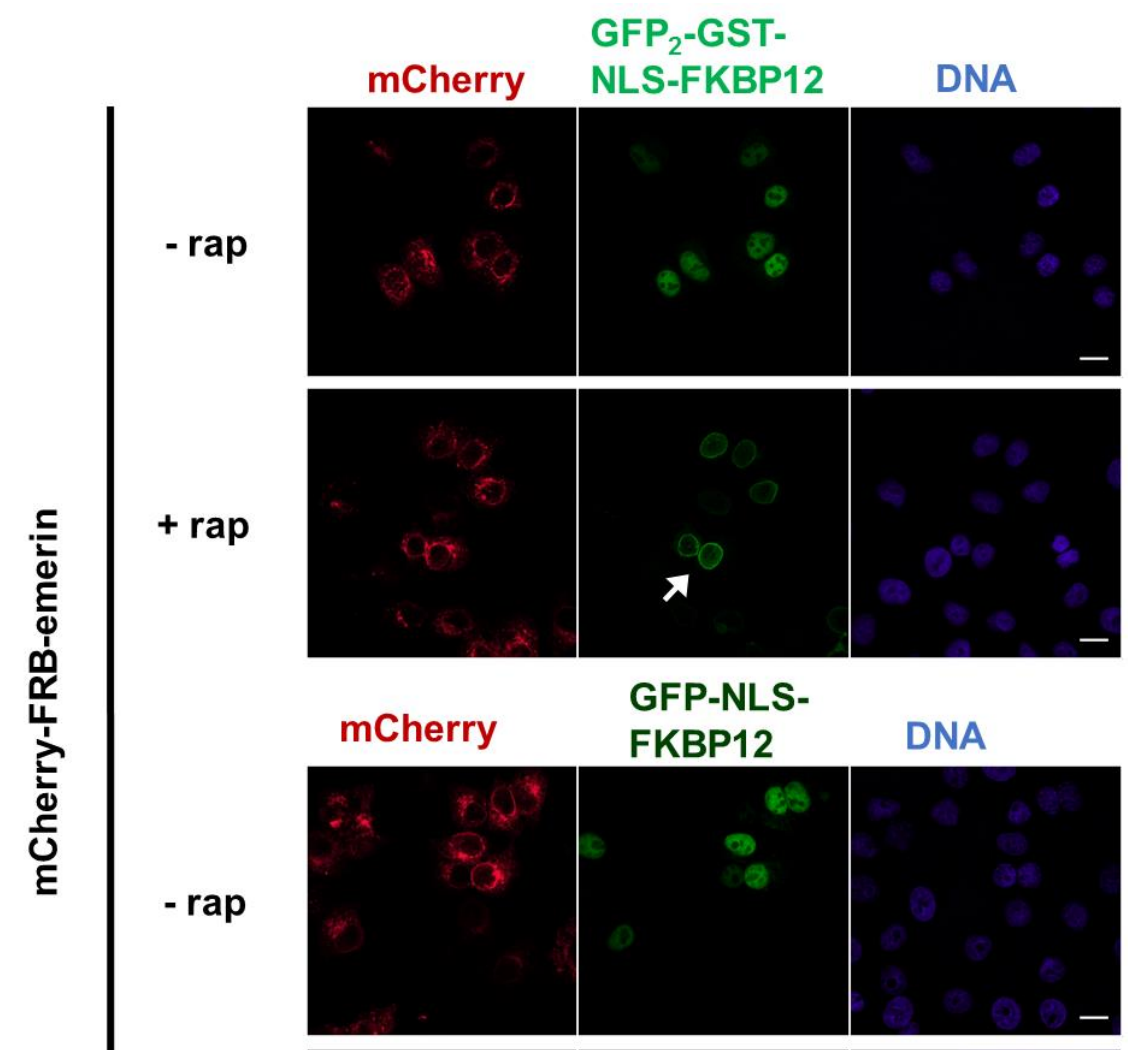


Figure 24: In vitro rapamycin-based INM-localization assay for emerin and WRB. HeLa cells were transfected with either mCherry- or HA-FRB-emerin and WRB-FRB-HA and a GFP-FKBP12 reporter protein for $24 \mathrm{~h}$ and the rapamycin assay was carried out as in the in vitro-version (see section 2.2.4.2.2). Cells were either untreated (-rap) or $500 \mathrm{nM}$ rapamycin (+rap) was added for 10 minutes. Proteins were either detected by their mCherry-tag or an immunostaining was performed using an anti-HA antibody. Arrows indicate cells responding on rapamycin treatment, indicated by a nuclear "GFP-rim". Scale bars: $15 \mu \mathrm{m}$.
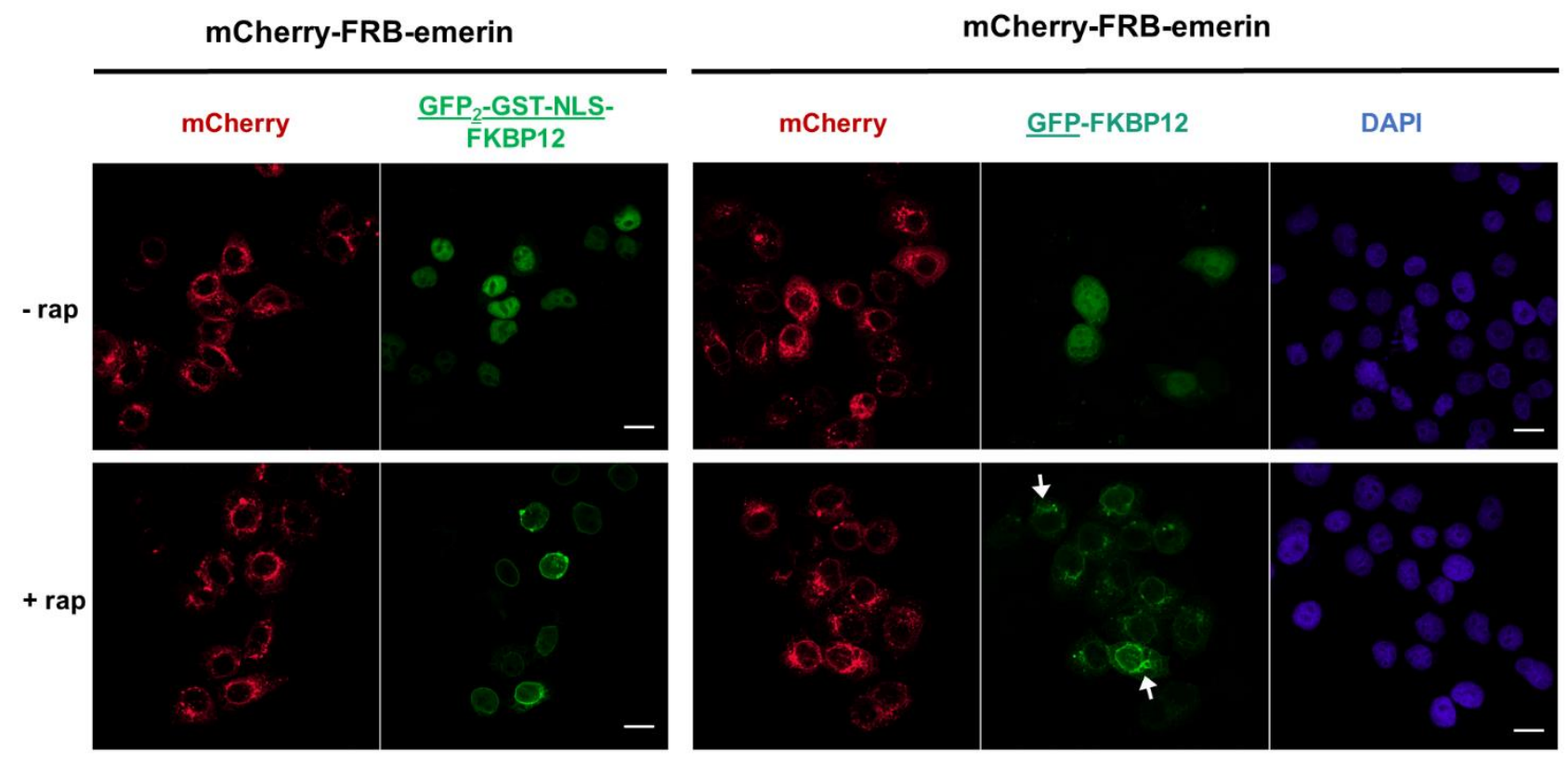

Figure 25: A short, soluble FKBP12 reporter is functional in other compartments than the nucleus and can bind the ER-fraction of mCherry-FRB-emerin. HeLa P4 cells were transfected with mCherry-FRBemerin and either EGFP 2 -GST-NLS-FKBP12 or a short version EGFP-FKBP12 for comparison of localization. An in vitro rapamycin experiment was performed. Cells were either untreated (-rap) or $200 \mathrm{nM}$ rapamycin (+rap) was added for 10 minutes. Arrows indicate the FKBP12 reporter binding at the ER. Scale bars: $15 \mu \mathrm{m}$. 


\subsection{Alternative FKBP12 reporters can be used to determine the localization of a protein to the INM}

Additionally, to the standard EGFP 2 -GST-NLS-FKBP12 reporter, alternative FKBP12 constructs (Table 2) were tested in the rapamycin assay in the following section during the optimization process of the rapamycin assay. As a standard FKBP12 reporter, a long version containing $\mathrm{EGFP}_{2}-$ GST-NLS-FKBP12 was used. For this construct a predominant nuclear localization was observed, but also a fraction was observed to be present in the cytoplasm probably due to its synthesis there. In the in vitro performed rapamycin assays using digitonin-permeabilized cells, this cytoplasmic background fluorescence of the GFP-FKBP12 reporter was eradicated by permeabilization followed by several washing steps. Nonetheless two alternative FKBP12reporter proteins were examined for a more distinct localization and reactivity when used for the rapamycin assay.

An EGFP 2 -GST-M9-FKBP12 was used as it contains a M9 non-classical NLS (section 1.1.2), which can be recognized by transportin (Pollard et al., 1996). The import therefore would be facilitated not by the classical transport receptors of the importin $\beta$ family. The M9-FKBP12 was tested in combination with emerin, LAP2 $\beta$ and PTP1B. No difference between the M9-FKBP12 (Figure 26, left column, -rap) compared to the standard NLS-FKBP12 reporter (Figure 23, -rap) localization per se was observed in permeabilized cells looking at conditions without rapamycin, both displayed a homogenous nucleoplasmic localization. When the M9-FKBP12 was used in combination with an mCherry-tagged protein, a recruitment of FKBP12 to the nuclear periphery could be observed to the same extent as for the NLS-FKBP12 reporter. Therefore, M9-FKBP12 can be recommended for use in future rapamycin assays as well.

The second FKBP12 version tested, was an FKBP12-Histone1-GFP (FKBP12-H1-GFP) reporter protein. Histone $\mathrm{H}^{0}{ }^{0}$ (Doenecke \& Tonjes, 1986) was used, because of its known nuclear localization, assuming it to be retained more in the nucleus than the soluble FKBP12 versions used before. The localization pattern observed without any treatment was nuclear, but in contrast to the previous described FKBP12 reporter very inhomogeneous with pronounced nucleolar localization. When performing a rapamycin assay for this specific construct together with cells co-transfected with emerin, only a slight change in the localization of the HistoneFKBP12 to the nuclear rim could be observed (Figure 26, right upper panel, arrows). For LAP2 $\beta$ and PTP1B a barely detectable change in fluorescence distribution could be observed as well. The rapamycin effect was most visible, when looking at the prominent nucleolar localization (-rap), which disappeared upon rapamycin treatment (+rap) observed for example with mCherry-FRBPTP1B (Figure 26,+rap, circle).

Testing the alternative FKBP12-reporter proteins showed that the EGFP2-GST-M9-FKBP12 can be used as a standard, nuclear localized FKBP12 reporter and showed as well a similar extent of reactivity and change in distribution upon rapamycin addition as the NLS-containing FKBP12 did. In contrast to the EGFP 2 -GST-M9-FKBP12 reporter, the FKBP12-Histone1-GFP seemed to localize to the nucleus, but due to an initial inhomogeneous localization inside the nucleus (Figure 26, right panel, -rap), it is not useful for the detection of a protein at the INM, which is the main purpose for this developed rapamycin assay. 


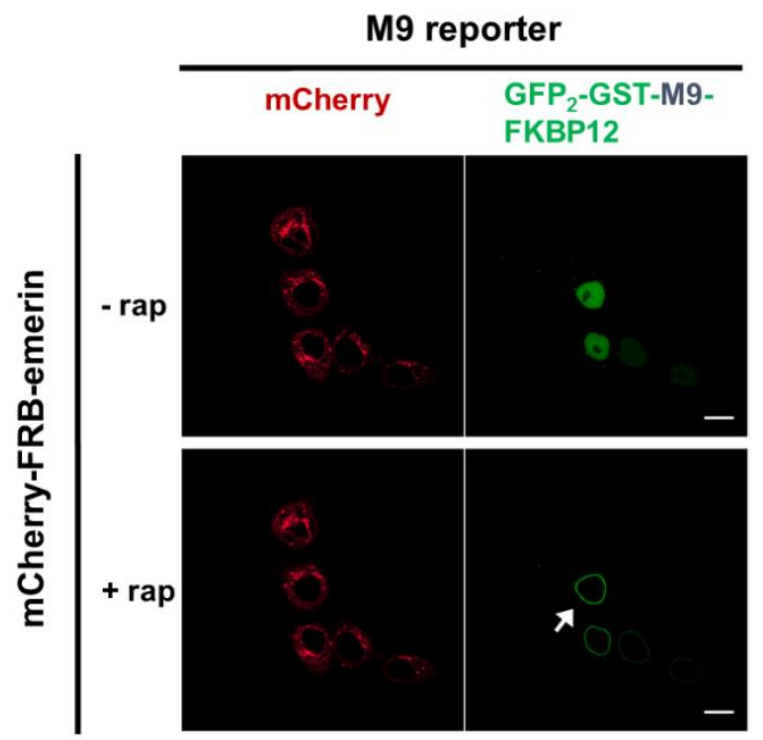

Histone1 reporter
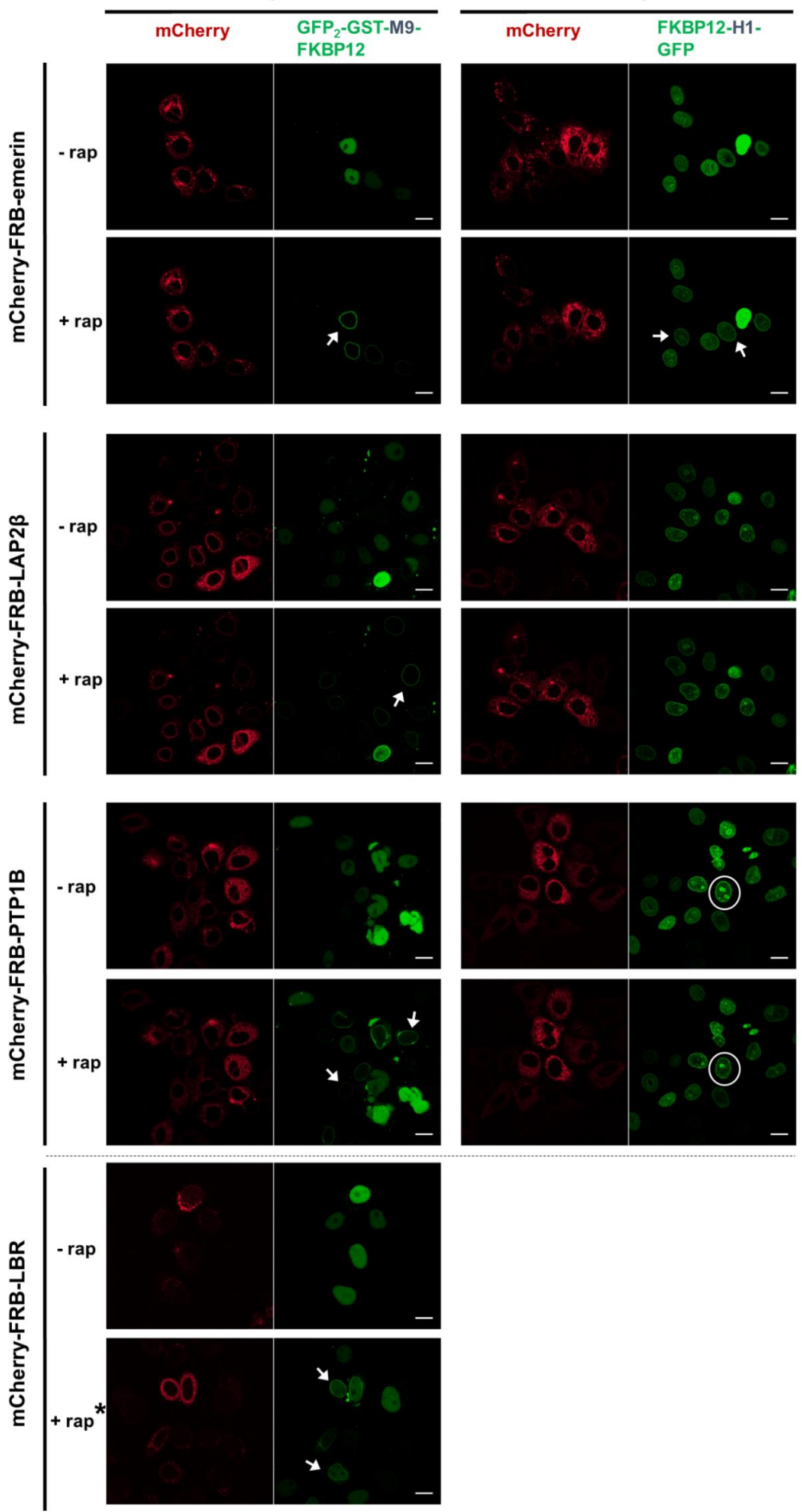
Figure 26: Alternative FKBP12-GFP reporter proteins are functional in the rapamycin-assay. HeLa P4 cells were transfected with the alternative FKBP12 constructs (GFP ${ }_{2}$-GST-M9-FKBP12 or FKBP12Histone1-GFP) for $24 \mathrm{~h}$ and used in an in vitro-kinetics rapamycin assay. Arrows indicate cells responding on rapamycin treatment, indicated by a "GFP-rim". Scale bars: $15 \mu \mathrm{m}$. * The polytopic INM-protein LBR serves as an alternative positive control. Independent images for +/rapamycin are shown for mCherry-FRB-LBR due to the fact that very little transfected cells were found and attempts to initially select cells (as it is done in the in vitro-kinetics rapamycin assay), which in the end responded upon rapamycin treatment, failed.

\subsection{Characterization of INM-trafficking of emerin}

Among all studied putative TA-proteins, emerin was confirmed to be a TA-protein and was by far the protein with the most distinct results for membrane integration (section 3.1.2.2) as well as in INM-localization experiments (sections 3.2.1, 3.2.2.2.1). As a consequence, it was selected for further characterization of the transport process to the INM (Pfaff et al., 2016).

First of all, the influence of the TRC40-machinery on nuclear envelope targeting of emerin was studied (section 3.3.1). Along these lines, emerin was examined for its interactions with components of the TRC40-mediated route in an in situ approach (section 3.3.2). Because the localization of emerin at the INM was reported to be affected by mutations in emerin and especially in or close to its transmembrane domain, a set of emerin mutations associated with the neuromuscular disease Emery-Dreifuss muscular dystrophy, was selected for further investigation (3.3.3.1). These emerin mutants were first biochemically characterized for their TRC40-dependent membrane integration (3.3.3.2) and secondly investigated for their targeting to the INM by using microcopy-based approaches (3.3.3.3).

\subsubsection{Depletion of TRC40 and WRB reduces the levels of emerin at the NE}

A knockdown of the key protein of the post-translational protein insertion pathway, TRC40 was performed and emerin was examined on protein level as well as by immunostaining and analyzed by confocal microscopy.

After a knockdown (for method description see section 2.2.3.4.1) for TRC40 was performed with different siRNAs (section 2.1.8 ), a reduction of about 95\% (see Figure 28; B) was observed on protein level and the endogenous TRC40 pattern was nearly completely abolished on the cellular level (Figure 27, upper panel). The total protein levels of emerin remained unchanged in TRC40depleted cells (Figure 28, A). In contrast to this, indirect immunofluorescence revealed an effect on emerin localization resulting in a loss of NE fluorescence intensity (Figure 27, upper panel 2nd column) compared to cells treated with a non-targeting control siRNA (nt siRNA, see 2.1.8). As a negative control, the INM-protein LBR was used. It is a polytopic membrane protein and predicted to insert co-translationally into membranes (Laba et al., 2014). LBR protein levels and localization remained unaltered by TRC40 knockdown, as expected (Figure 27, upper right; Figure 28).

In addition to the TRC40 depletion, as the soluble part of the post-translational machinery, the membrane-receptor WRB was downregulated (Yamamoto and Sakisaka, 2012). After the downregulation of WRB was performed, about $90 \%$ decrease on protein level was detected via western blotting, whereas no immunofluorescence data could be compiled for WRB itself due to 
the lack of a reliable WRB antibody. Emerin localization was reduced at the nuclear envelope and the rim staining occurred to be not as continuous and strong compared to control siRNA treated emerin cells (Figure 27, B) and as well the protein level for emerin was not significantly changed as seen with a TRC40 knockdown (Figure 28, D). The oligosaccharyltransferase STT3B was unaffected in immunofluorescence staining, because it wasproposed to use the SRP-Sec61dependent co-translational membrane insertion pathway for membrane insertion instead (Figure 27, B). Surprisingly, the downregulation of WRB resulted in a significant reduction of TRC40 both by western blot detection and by immunofluorescence staining (Figure 27, upper left; Figure 28). Almost entirely the localization of TRC40 was abolished similar to the pattern observed with a TRC40 knockdown.

In summary, this RNAi studies strongly indicated that the nuclear envelope localization of emerin depends on the TRC40-pathway. For the first time in this work an influence of the TRC40-pathway on the targeting of emerin was shown in vivo.

A

TRC40 RNAi

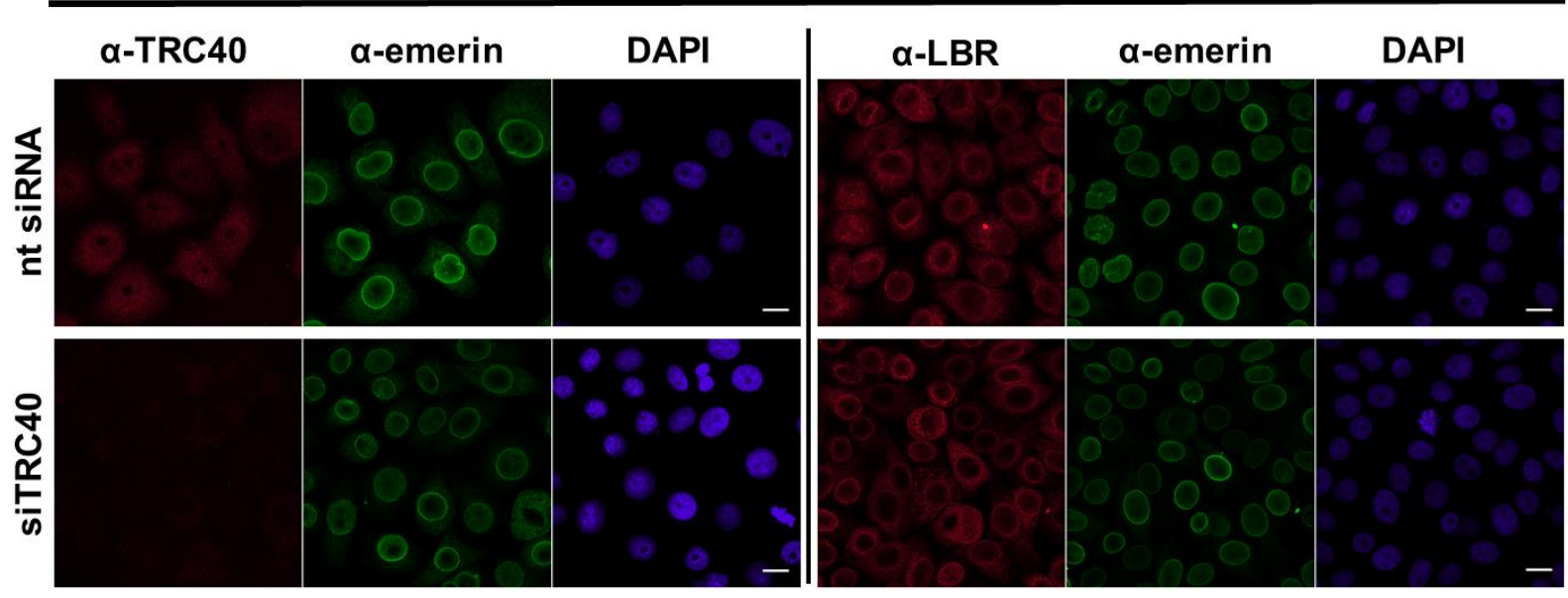

B

WRB RNAi

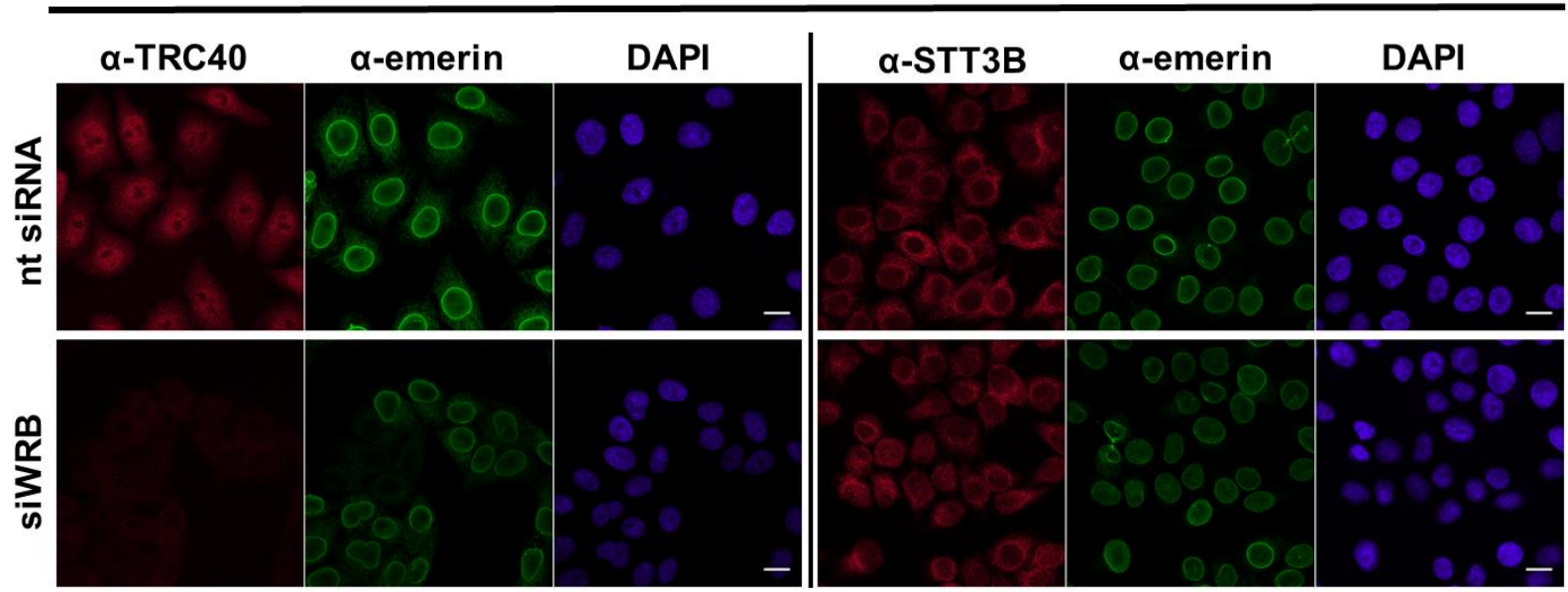

Figure 27: Downregulation of TRC40 and WRB affect the localization of emerin at the NE. HeLa P4 cells were transfected with a siRNA against TRC40 (siTRC40, $40 \mathrm{nM}$ ) (A) and WRB (siWRB; $10 \mathrm{nM}$ ) (B) for $96 \mathrm{~h}$. The localization of endogenous TRC40, emerin, LBR and STT3B was analyzed in knockdown and control treated cells and detected by immunofluorescence using the respective antibodies. Scale bars: $15 \mu \mathrm{m}$. 

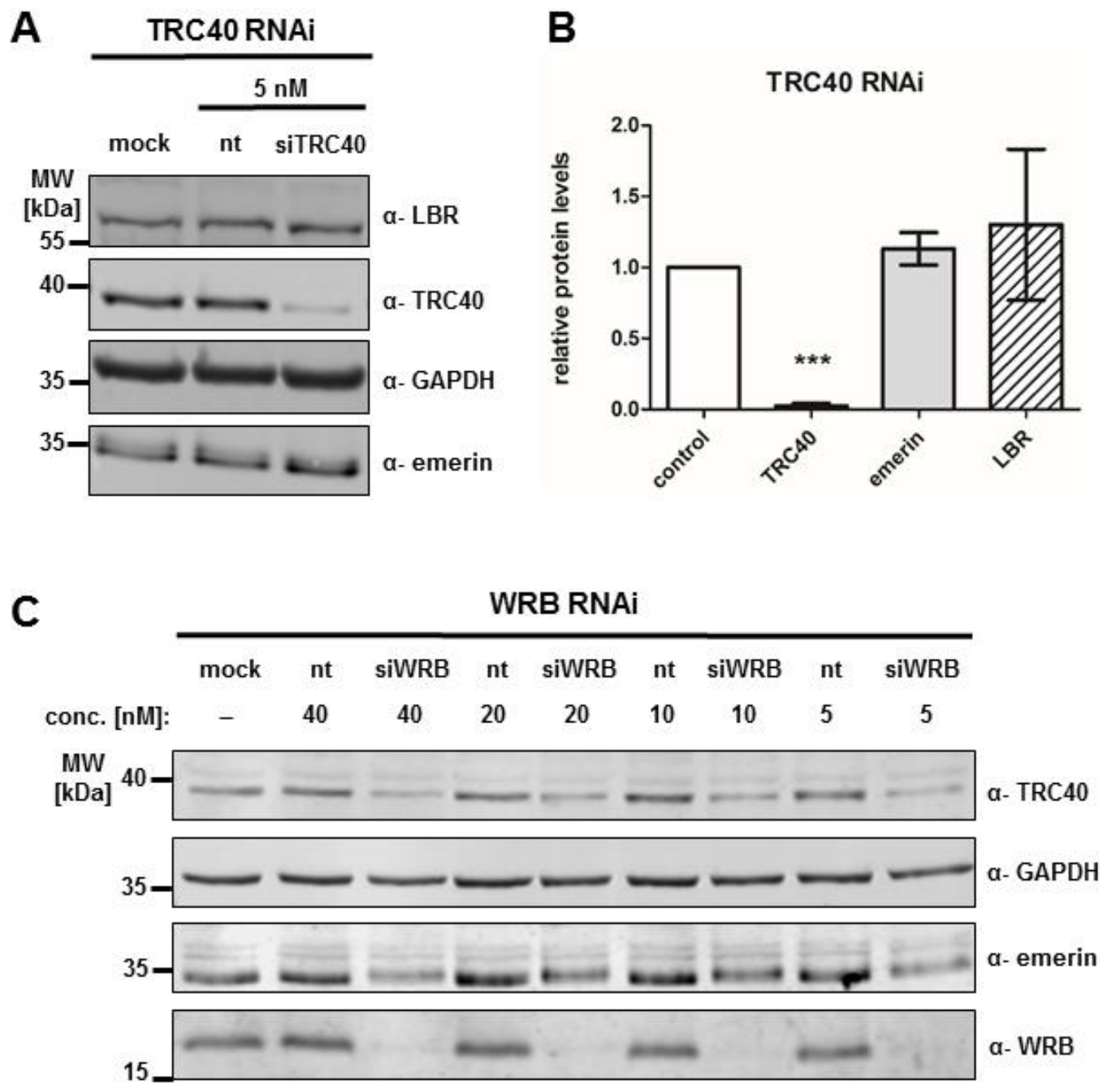

D

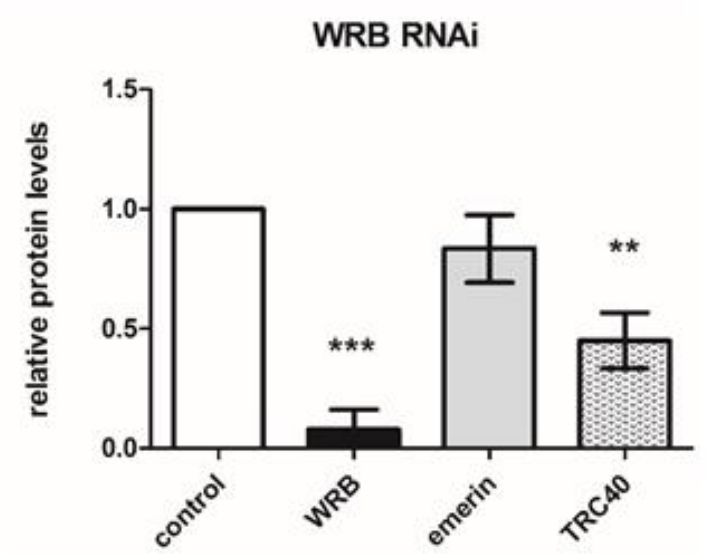

Figure 28: Emerin protein levels are unaffected by downregulation of TRC40 or WRB. RNAi mediated knockdown of either TRC40 (A, B) or WRB (C, D) was performed for $96 \mathrm{~h}$ at 4 different concentrations $(5,10,20,40 \mathrm{nM})$ in HeLa P4 cells as indicated. (A) Representative western blot of TRC40 RNAi (5 nM) is shown. (C) Western blot of WRB, emerin and TRC40 protein levels for different siRNA concentrations in WRB knockdown cells is shown (B, D) Quantification of protein levels for either TRC40, emerin and LBR in TRC40 knockdown cells or WRB, emerin and TRC40 in WRB knockdown cells. Protein levels of control (nt siRNA) treated cells compared to knockdown cells are shown and protein levels were normalized against GAPDH (loading control). Analysis was done by SDS-PAGE followed by western blotting using the indicated antibodies. Error bars indicate the standard deviation of the mean protein levels of 4 different siRNA treatments used in a single experiment. ${ }^{* *} \mathrm{P}<0.001,{ }^{* *} \mathrm{P}=0.0025$ (Student's t-test). 


\subsubsection{Emerin interacts with TRC40 in an in situ approach}

The results obtained from the RNAi experiments in the previous section not only confirm the dependency of emerin on the TRC40 mechanism for ER membrane integration, but strongly suggest an influence of the TRC40 system on the localization of emerin at the INM in vivo. It most probably can be seen as a crucial process on its way to the INM.

A proximity ligation assay (PLA) (Fredriksson et al., 2002) was therefore used to analyze, if an interaction of emerin with TRC40 can be detected in situ.

The experiment was performed by Cara Jamieson and details as well as further controls included in the experiment are reported in Pfaff et al., 2016. In this PLA experiment, TRC40-myc was transfected in HeLa P4 cells. The single antibodies used for detection of TRC40-myc, emerin, Sec61 $\beta$ and STT3B were pre-tested and incubated with PLA-probes to exclude unspecific interaction for the assay (Figure 29, A). In this assay, Sec61 $\beta$ served as a positive control for TRC40 interaction (Favaloro et al., 2008; Stefanovic and Hegde, 2007) and the oligosaccharyltransferase STT3B was supposed to use an SRP-dependent ER insertion mechanism and was thus being used as a negative control. To substantiate the signal specificity of emerin interactions, the well-known interaction partner lamin A was tested for its interaction with emerin (data not shown, see (Pfaff et al., 2016)).

When the proximity ligation reactions were performed for emerin, Sec61 $\beta$ and STT3B together in cells, which overexpressed TRC40-myc (Figure 29, A, right panel), for all of the three proteins interaction sites were observed (red dots). The principle behind this technique is, that proteins which are in close proximity (30-40 nm apart), can be ligated and interaction spots can be detected due to the fact that light is emitted, when a rolling circle DNA amplification was initiated by ligation of the PLA probes bound to the primary antibodies against the specific proteins. Red dots can be counted and the specific position of interaction is displayed in situ.

For the positive control substrate Sec61 $\beta$, interactions with TRC40-myc were found in high number (about 50 dots per cell) (Figure 29, B) as expected. Contrary to this, very few dots per cell were counted for STT3B. Within these two extreme numbers of dots emerin-TRC40 interactions were observed with approximately 12 dots per cell. The localization of the emerinTRC40 interaction was mainly observed outside the nucleus, which would correspond with the subcellular localization of TRC40 reported together with its function in the cytoplasm of carrying out protein delivery to the ER membrane.

In summary, it can be stated that the proximity ligation assay revealed an interaction of endogenous emerin and overexpressed TRC40-myc in situ. This strongly supports the in vivo findings, which showed that the knockdown of TRC40 resulted in a reduction of emerin at its destination, the INM. Furthermore, PLA allowed the visualization of the place of interaction, which in case of emerin and TRC40 was mainly the cytoplasm (Figure 29, A). 

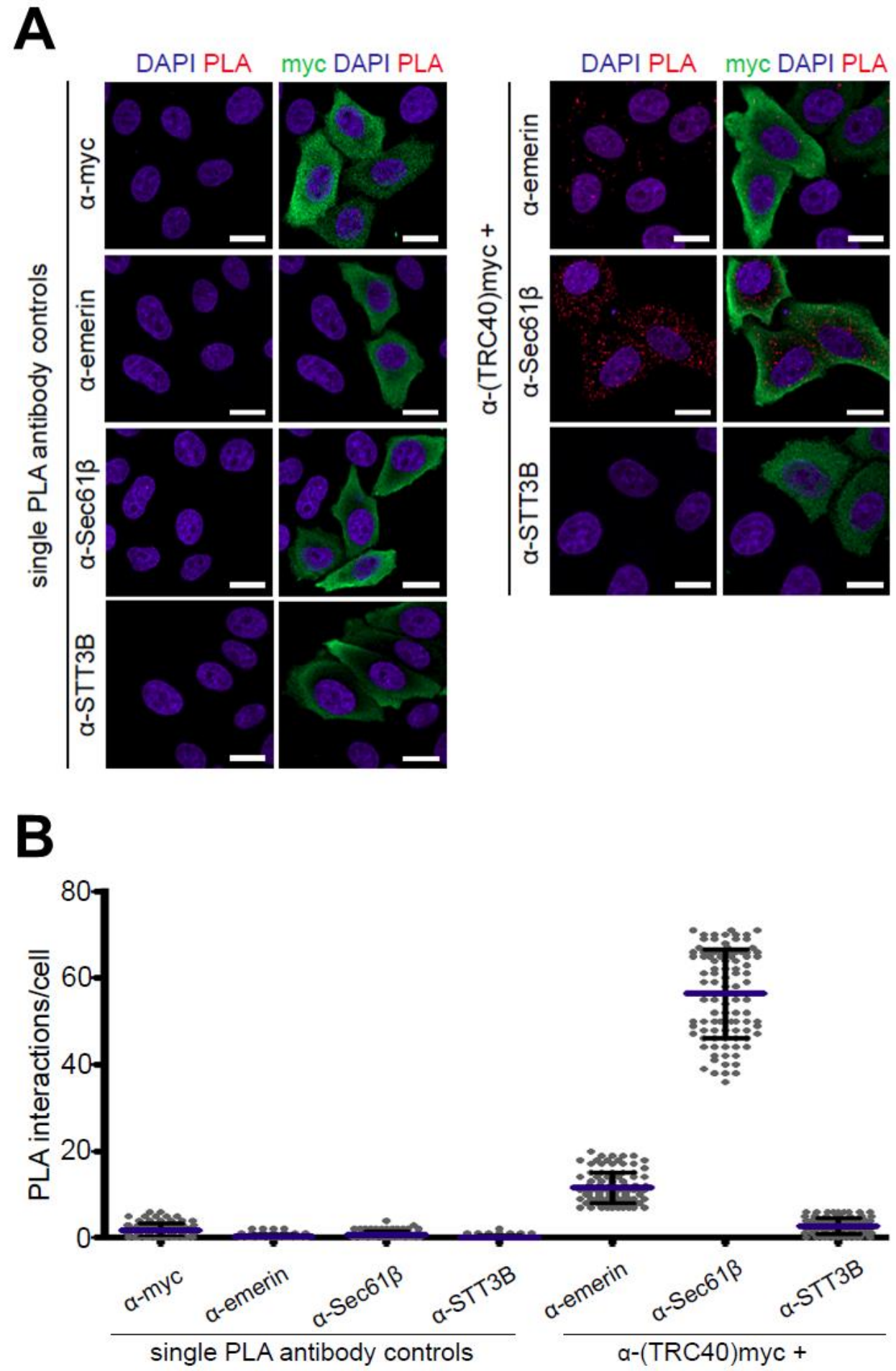

Figure 29: Emerin interacts with TRC40-myc in situ (performed by Cara Jamieson (see Pfaff et al., 2016)). (A) Single PLA antibody controls for labelling of binding partners of interest are shown (A, left panel). They were pre-tested to determine specific dilutions and to exclude unspecific interactions. PLA experiments with transfected TRC40-myc were performed for emerin and the control proteins Sec61 $\beta$, STT3B to detect possible interactions ( $A$, right panel). Both antibodies corresponding to the potential interaction partners were used accordingly and incubated with the appropriate PLA probes. Each dot represents a single protein-protein interaction. Nuclei were stained with DAPI. Scale bars: $10 \mu \mathrm{m}$. (B) Dot plot of PLA interactions per cell is shown ( $n=2 ; 100$ cells were scored for each experiment). 


\subsubsection{Investigation of effect of changes in the C-terminal portion of emerin on targeting} to the INM

After having illustrated the importance of the TRC40-system for the membrane insertion and targeting of emerin in vitro (section 3.1.2.2.1.2) and also in a more physiological approach for living cells (section 3.3.1), the C-terminal portion of emerin, which is required for membrane anchoring and integration, was examined. This single transmembrane segment at the very Cterminus was specifically looked at in terms of the process of trafficking to the INM in considering the characteristics of this C-terminal portion of emerin like the hydrophobicity (Table 1). Two major localizations for emerin were reported. It is mainly localized at the INM, but also a defined role for emerin at the ER was reported (Salpingidou et al., 2007). Considering that C-terminal added protein-tags can affect the post-translational membrane insertion and localization mechanism of emerin, the focus of studying the influence of the C-terminus was to possibly detect differences for NE-targeting by changes on the amino acid level. Related to this, there were reports about several changes in the TMD region of emerin associated with the neuromuscular disease Emery-Dreifuss muscular dystrophy (EDMD) (Emery and Dreifuss, 1966; Emery, 1989). Accordingly, a selection of mutations related to EDMD was analyzed for their membrane insertion, subcellular distribution and targeting to the INM in the following sections.

\subsubsection{Characteristics of the selected emerin mutant variants}

For some emerin mutations associated with EDMD a changed subcellular distribution compared to wild-type emerin has been reported. Analysis of these mutants could therefore provide a possibility to gain more insight in emerin targeting

All emerin mutants that were selected for characterization of their localization and distribution at the INM (Figure 30, A) have been reported to be involved in Emery-Dreifuss muscular dystrophy and range from single point mutations to mutants almost entirely lacking the TMD (Yates, JR et al., 1999) (Manilal et al., 1998; Nagano et al., 1996; Mora et al., 1997; Nigro et al., 1995; Ognibene et al., 1999; Vohanka et al., 2001; Ellis et al., 1999; Yates, JR et al., 1999; Tarpey et al., 2009). These emerin mutants were chosen based on the presence of a mutation in the Cterminal portion of the protein, which harbors the transmembrane segment. As the hydrophobicity of a TMD is known to play a crucial role in membrane integration of TA-proteins (Rabu et al., 2008; Rabu et al., 2009; Johnson et al., 2013), the hydrophobicity was calculated for each mutant (Figure 30, B).

Changes in the hydrophobicity or complete deletion of the TMD is expected to have drastic effects on the membrane localization of a protein. Therefore, the mutant Trp226* (Nagano et al., 1996) completely lacking the TMD, mutant $\Delta$ Val236-Phe241 (Manilal, 1999), where half of the TMD is missing and the mutants Leu225Arg-FS (Yates, JR et al., 1999) and Phe240His-FS (Vohanka et al., 2001), which contain a frame-shift were selected. For the mutant $\Delta$ Val236Phe241 where only half of the TMD is still present a drastic reduction in hydrophobicity of the TMD was found. To test whether the regions flanking the TMD can also have an effect on proper membrane targeting, the mutants Pro183Thr and Pro183His (Ellis et al., 1999; Yates, JR et al., 1999) were chosen as the mutations are located upstream of the transmembrane domain. The Pro183Thr mutant was shown to have a decreased binding affinity for SUN, another INMinteraction partner (Haque et al., 2010). Whereas another study clearly reported the interaction 
of important binding partners (Lamin and BAF) at the INM to be unaffected (Haraguchi et al., 2004). Due to that, this particular region might be important for EDMD not only because of localization defects, but in terms of proper function of emerin at the INM. Furthermore, the selfassembly function of emerin was reported to be influenced for both mutants (Herrada et al., 2015). Finally, the mutant GIn228His (Tarpey et al., 2009) was selected, as it contains only one mutation in the TMD region and shows a similar hydrophobicity of the TMD as wild-type emerin. Potentially the glutamine at position 228 is a key residue for interaction with components of the TRC40 pathway. This diverse set of emerin mutations, which show differences for their predicted hydrophobicity, was used to analyze the membrane insertion of emerin in the next chapter.

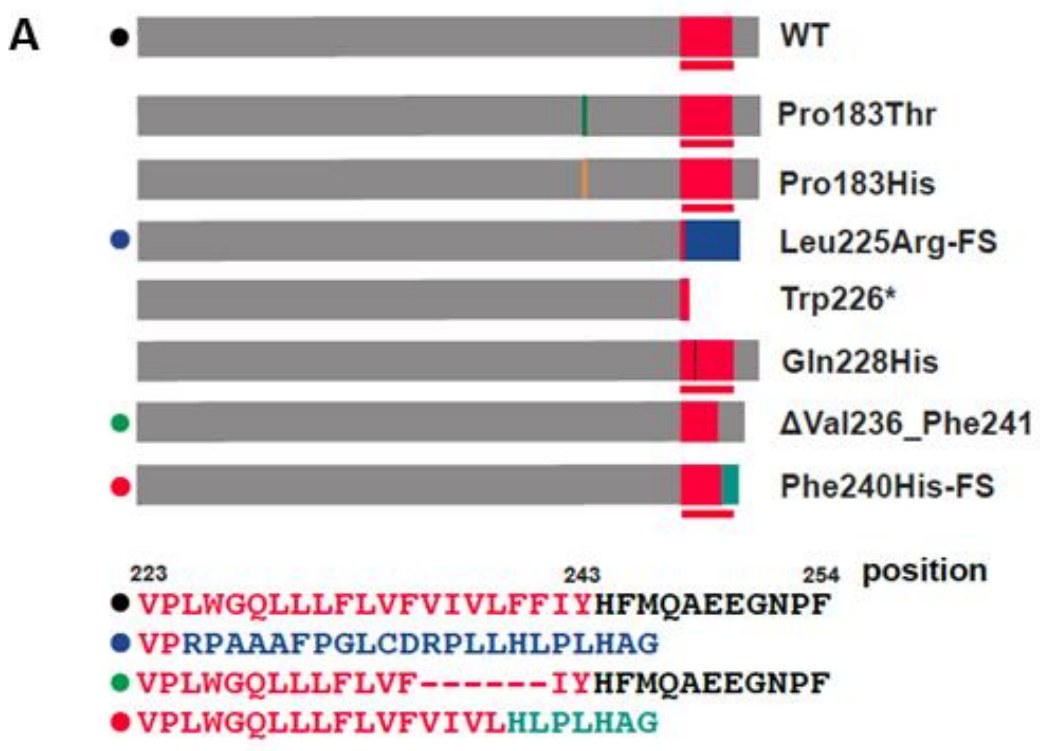

B

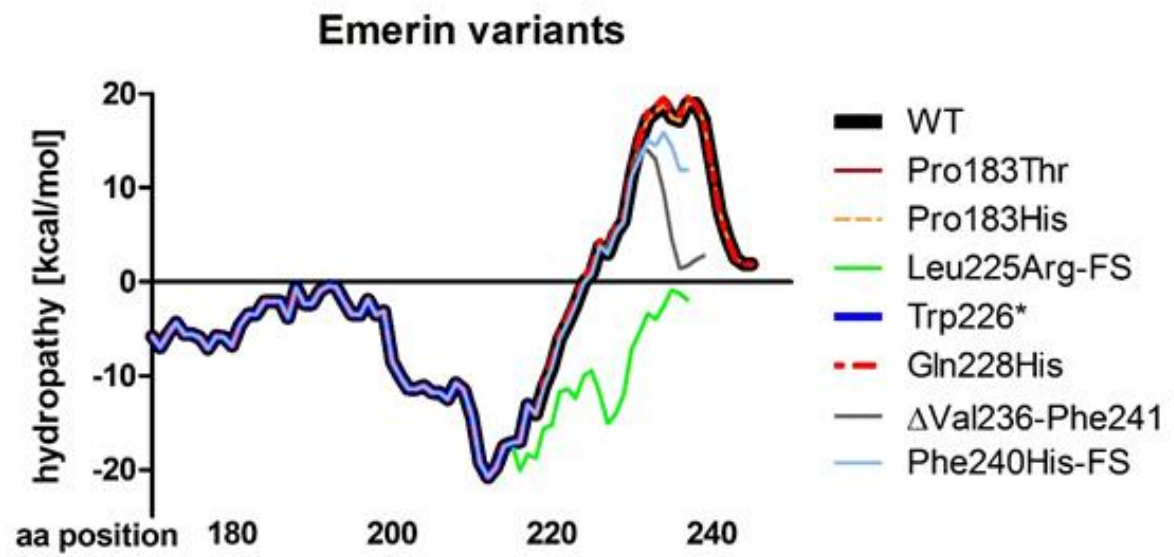

Figure 30: Schematic view of emerin mutant variants and the predicted hydrophobicity of their Cterminal region. (A) Schematic drawing of emerin WT (254 aa) compared to mutant versions. The TMD (red), as well as the position of the mutation within the C-terminal sequence is indicated (bar or highlighted). (B) A hydropathy plot of the C-terminal portion of emerin (aa 170-254) is shown for all emerin mutants. Hydropathy (data were calculated by using Membrane Protein Explorer (MPEX) (Snider et al., 2009) (window size: 19, Wilmey-White Hydropathy Scale: interfacial, water to bilayer). 


\subsubsection{TRC40-dependent membrane insertion of emerin mutants}

The membrane insertion of wild type emerin was shown to strongly depend on the posttranslational TRC40-mediated mechanism (chapters 3.1.2.2.1, 3.1.2.3). Further RNAi experiments in vivo demonstrated that targeting of emerin to the INM was affected upon knockdown of TRC40. (section 3.3.1). In the view of these results, the emerin mutants were examined for their TRC40-dependent membrane insertion in vitro.

\subsection{Purification of emerin mutants in a complex with TRC40}

For membrane insertion experiments, which are performed in the next section, the described emerin mutants were co-expressed with TRC40 and purified in bacteria as it was already shown in section 3.1.2.2.1.1. The specific purification experiment shown was performed by Jhon Rivera. The subset of emerin mutants (as HZZ-"emerin mutant"-opsin version) was purified in a complex with MBP-TRC40 (Figure 31). For the point mutation variants Pro183Thr, Pro183His and Gln228His a moderate amount of protein compared to the wild type was co-purified, whereas for the frame-shift mutant Leu235Arg-FS hardly any protein was detectable. The mutants Trp226* and $\Delta$ Val236-Phe241, were assumed to have a low probability for membraneassociation based on their lower hydrophobicity (Figure 30, B) and indeed a reduced binding to TRC40 was detected. For the emerin mutant Phe240His-FS, a reduced hydrophobicity was calculated and therefore an impaired binding to TRC40 and the low amounts seen for the coexpression are not surprising (Figure 31). According to the calculated hydrophobicity and the available information about properties of the individual mutants, the observed binding of TRC40 to the mutated emerin versions was as expected.

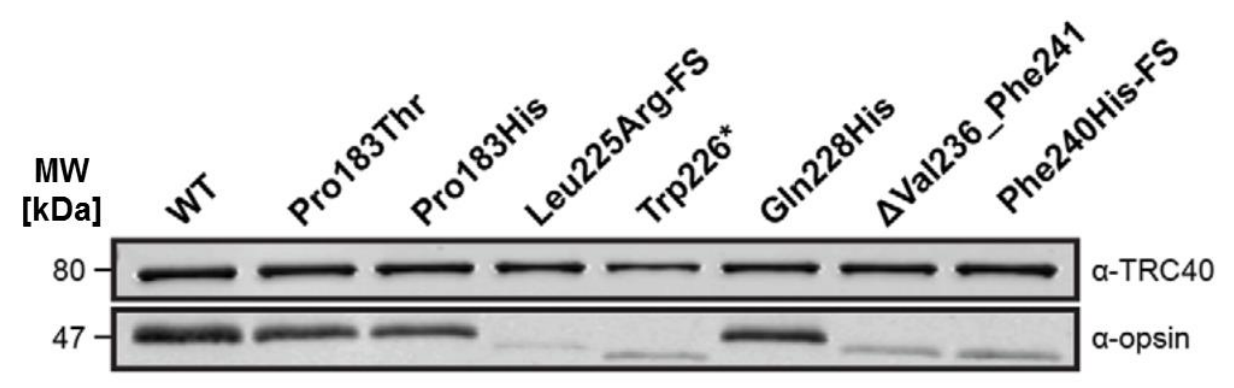

Figure 31: Co-purification of emerin mutants with TRC40 (performed by Jhon Rivera, see Pfaff et al., 2016). Comparable amounts of eluted fractions of the indicated emerin mutants in complex with TRC40 are shown. Detection of co-purified emerin mutants was performed by SDS-PAGE, followed by western blotting using an anti-opsin antibody.

\subsection{Membrane integration of emerin mutants in RM}

The co-purification of emerin mutants with TRC40, showed that almost all selected mutants were able to bind to the TRC40, which is involved in the delivery of the proteins to the ER membrane. To examine not only the possible binding of TRC40 to emerin mutants, membrane insertion assays were carried out using the purified protein complexes. 
In this membrane integration assay rough microsomes as an ER-derived membrane source were used (experiment was performed by Jhon Rivera). The aim of the experiment was to analyze the membrane integration competence of these emerin versions.

In general, all emerin mutants tested resulted in a reduced insertion of the proteins into rough microsomes compared to wild type emerin (Figure 32). It should be mentioned that the emerin mutants Leu235Arg-FS and Trp226* were not studied for their membrane insertion due to the low amounts of protein obtained in the purification, anyway the Trp226* mutant probably would not be able to insert into membranes due to the absence of the TMD. The proline mutations upstream of the transmembrane domain showed a reduction of glycosylated protein of about $40 \%$ compared to the wild type. A more severe effect on membrane integration ability was found for the $\Delta$ Val236-Phe241 (approx. 70\% decrease) and the Phe240His-FS variant ( $>90 \%$ decrease), which corresponded to the low efficiency in binding to TRC40 demonstrated in the co-expression experiment above. With respect to the results obtained by this experiment, all mutants studied in this insertion assay would be expected to localize to a membrane-bound form (Figure 32, A, HZZ-emerin-op G).
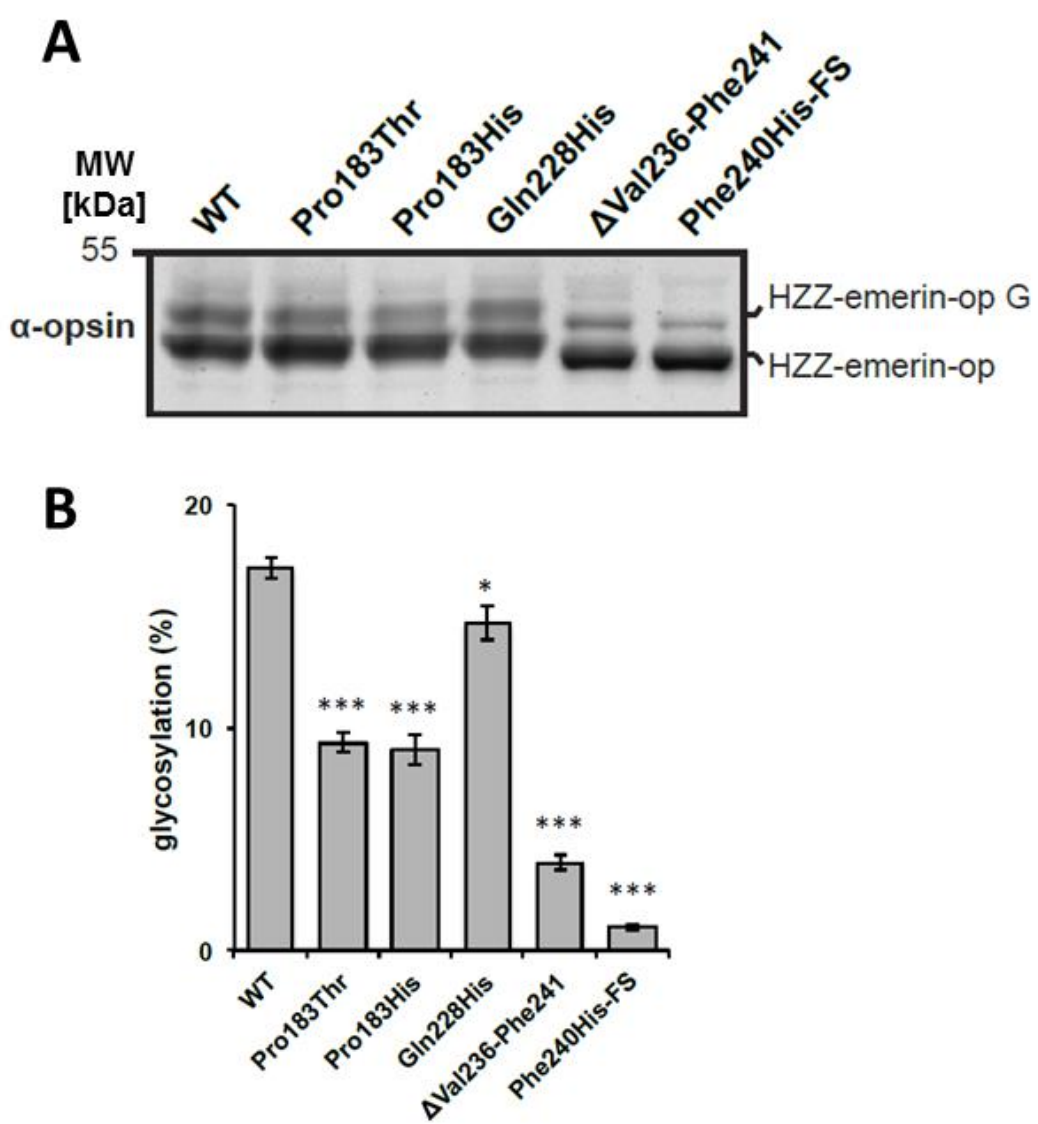

Figure 32: Emerin mutants show an altered membrane integration (performed by Jhon Rivera, see Pfaff et al., 2016). (A) Membrane insertion reactions were performed in rough microsomes using the purified protein complexes for the indicated HZZ-emerin-opsin variants according to the protocol 2.2.2.6.1. Trp226 and Leu225Arg-FS mutants, which do not contain a TMD, were excluded due to low protein amounts obtained by purification. Detection of membrane integrated protein was performed by SDS-PAGE, followed by western blotting using an anti-opsin antibody. "opsinG" indicates the higher MW, glycosylated and membrane integrated form of the protein. (B) Quantification of the membrane insertion results in (A). Error bars indicate the standard deviation of four independent experiments. $* \mathrm{P}<0.05,{ }^{* * * \mathrm{P}}<0.001$ (Student's t-test). 


\subsubsection{Targeting of emerin mutants to the NE}

\subsection{Morphology and localization of emerin mutants within cells}

As all purified emerin mutant versions showed reduced binding to TRC40 and also defects in the efficiency of post-translational insertion into RM membranes, the next step was, to investigate a possible effect of the altered membrane insertion on localization of the protein inside the cell. In particular, the INM localization was to be addressed by performing differential permeabilization assays. As shown for other membrane proteins in section 3.2.1, the subcellular localization of wild type HA-emerin compared to emerin mutants was examined. HeLa P4 cells were transfected with plasmids coding for HA-emerin or mutant variants. After two days of transfection the cells were processed according to the protocol (section 2.2.4.2.1). In this experiment digitonin selectively permeabilizes the plasma membrane and only allows detection of proteins within compartments facing the cytoplasm, whereas Triton X-100 permeabilizes all cellular membranes and proteins present in the nuclear interior, can be accessed as well and visualized.

In this experiment, endogenous laminA/C was immunostained as a control. Digitonin-treated cells did not show any lamin A/C signal, but with Triton X-100 permeabilization the nuclear membrane was perforated as well and antibodies were able to access the INM (Figure 33, upper panel).

The localization pattern obtained for wild type HA-emerin with digitonin permeabilization was predominantly showing ER and a slight nuclear rim (Figure 33), whereas using Triton X-100, a pronounced nuclear rim staining could be observed and hardly any ER was detectable. This NE envelope staining can be seen as a prominent localization of emerin to the INM, which would not be accessible with digitonin permeabilization only. Compared to the wild type, for mutant Pro183Thr and Pro183His as well as for $\mathrm{Gln} 228 \mathrm{His}$ a similar cellular distribution could be observed (Figure 33). The Pro183Thr/His variants showed additional dots around the ER, which could not be seen for emerin wild type.

Further, for the TMD lacking Trp226* variant, the frame-shift mutant Leu225Arg-FS and variant with a partially deleted TMD $\triangle$ Val236-Phe241 no nuclear envelope localization was observed using Triton X-100 permeabilization. These three mutants were distributed inside and outside the nucleus, with no clear localization to a distinct cellular compartment (Figure 33).

Surprisingly, the frame shift variant Phe240His-FS, which bears the mutation at the very Cterminal part of the protein, clearly showed a membrane localization with both permeabilization methods. With Triton X-100 permeabilization a more distinct nuclear rim localization and less ER could be observed (Figure 33, most bottom panel). Taken together, compared to the NE-rim localization of emerin wild type, also the emerin variants Pro183Thr, Pro183His, Gln228His and Phe240His-FS seemed to localize to the inner nuclear membrane, indicated by a nuclear rim. Against expectations from the membrane insertion assay, the Phe240His-FS was able to localize to the NE (INM) even though a weak insertion to the ER was demonstrated. Considering the results of the differential permeabilization assays, it can be concluded that certain emerin mutations, which affect the membrane integration at the ER, can also have a strong influence on proper targeting to the INM. 


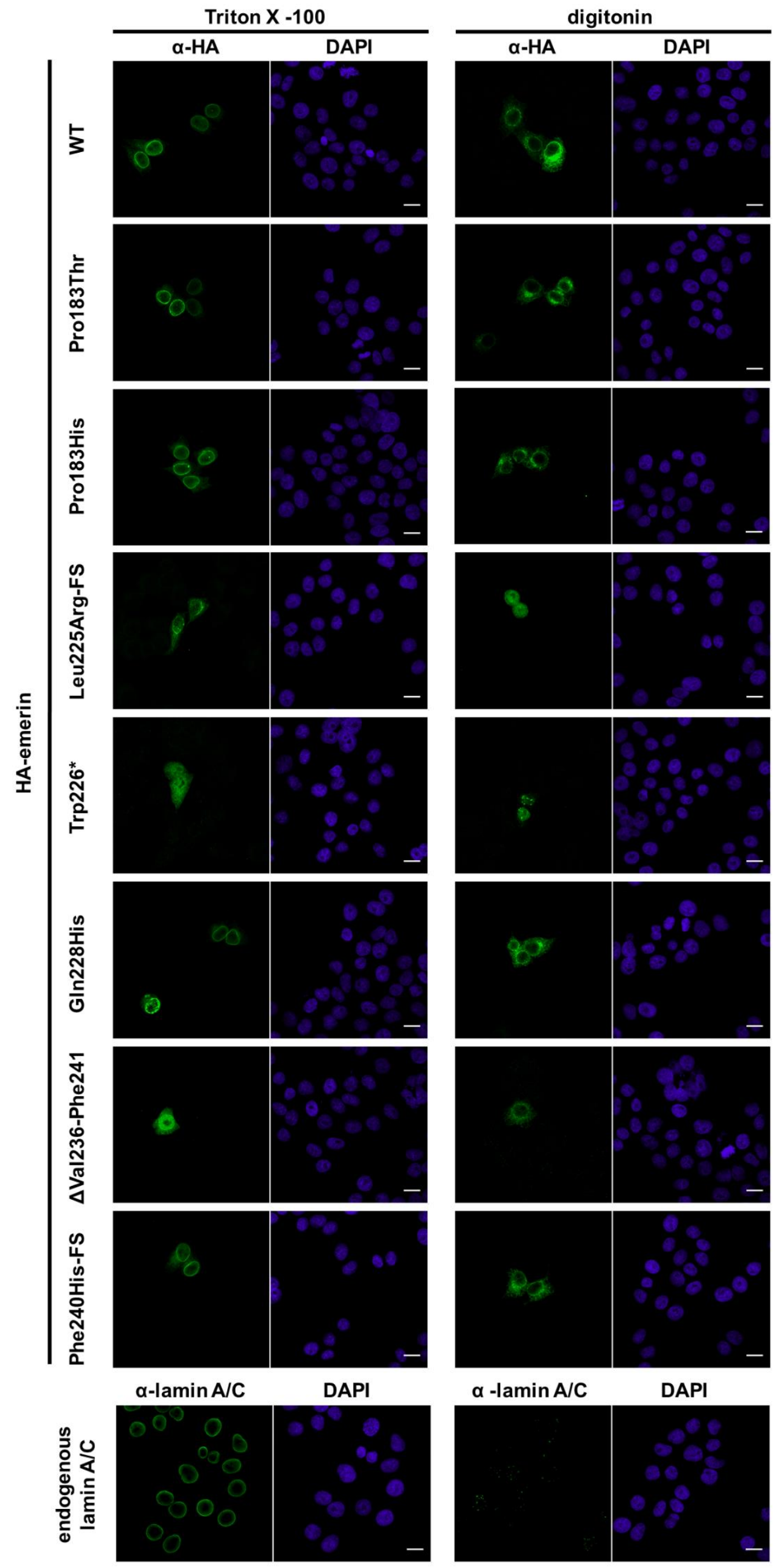


Figure 33: Subcellular localization of emerin mutants. HeLa P4 cells were transfected with plasmids coding for HA-emerin variants for $24 \mathrm{~h}$. Cells were differentially permeabilized with Triton X-100 or digitonin as indicated and subjected to indirect immunofluorescence. An anti-HA antibody was used for detection of the emerin variants. As a marker for the nuclear interior, endogenous lamin $A / C$ was used. Scale bars: $15 \mu \mathrm{m}$.

\subsection{Mutations of emerin affect targeting to the INM}

In the previous chapter, the emerin mutants were analyzed for their subcellular distributions using a differential permeabilization approach. To substantiate the results obtained for a possible INM localization of several emerin mutants, the newly established in vitro rapamycin assay (section 3.2.2.1) was used. For other putative TA-INM proteins, this assay already provided valuable information about the localization at the INM. Consequently, the in vitro rapamycin assay was performed to test for an INM localization and to allow for differentiation of a possible ONM-rim. Emerin versions were cloned into the mCherry-FRB expression vector background. Cells were transfected with mCherry-FRB-"emerin mutant" together with the EGFP2-GST-NLSFKBP12 reporter protein. After the proteins were expressed, the rapamycin assay was performed in permeabilized HeLa cells.

Indeed, it could be shown, that emerin point mutation variants (Pro183Thr, Pro183His, Gln228His) and the emerin Phe240His-FS mutant localize to the INM (Figure 34). This was observed by a shift of the GFP-FKBP12 reporter protein from a homogenous distribution (Figure $34,-$ rap) to a concentrated "nuclear rim" localization upon rapamycin addition. Knowing that the rapamycin assay only allows qualitative statements, for the purpose of comparing the emerin wild type with the mutants for its efficiency in GFP-FKBP12 INM- "rim" formation, a semiquantitative analysis of nuceli positive for "rim"-formation was performed (Table 4). The Phe240His-FS protein only showed a slight GFP-reporter "rim" in some cells. This indicates a reduced efficiency of INM-targeting compared to emerin wild type. In opposition to the previous mentioned mutants, the deletion mutations $\Delta$ Val236-Phe241, Trp226* and the frame-shift version Leu225Arg-FS showed no change in GFP-FKBP12 localization (Figure 34). The $\Delta$ Val236Phe241 mutant was found in aggregates throughout the cell and according to this, no recruitment of FKBP12 to the INM upon rapamycin treatment was anticipated.

As expected from the distribution of Leu225Arg-FS all over the cell with a pronounced nucleoplasmic localization in the differential permeabilization (section 3.3.3.3.1), the absence of this mutant at the INM was not surprising. Localization inside the nucleus for constructs lacking the TMD has previously been reported by Tsuchiya et al. (1999).

Studying the EDMD-associated emerin mutants with the in vitro rapamycin assay, the targeting of several mutants (Pro183Thr, Pro183His, GIn228His, Phe240His-FS) to the INM as already observed in the differential permeabilization assay could be confirmed. Nevertheless, the efficiency of INM-targeting varied a lot between the examined mutants. This assay clearly showed, that the final INM-targeting is impaired for example in the Phe240His-FS mutant (Table $4,+$ ), even though a prominent nuclear rim staining was observed in the differential permeabilization assay with both detergents (Figure 33). Therefore, it is important to discriminate between an observed "nuclear rim" staining and correct targeting to the INM, which can be monitored by the rapamycin assay. 
Taken together, the investigation of emerin mutants in comparison with the wild type protein provides valuable insights for the targeting process of emerin to the INM. Differences in the efficiency of INM-targeting might rely on the C-terminal part of emerin and most probably distinct regions within the TMD. The reduced INM-targeting efficiency revealed by several mutants might therefore be connected to a defective transport process or a reduced retention of emerin at the INM. 

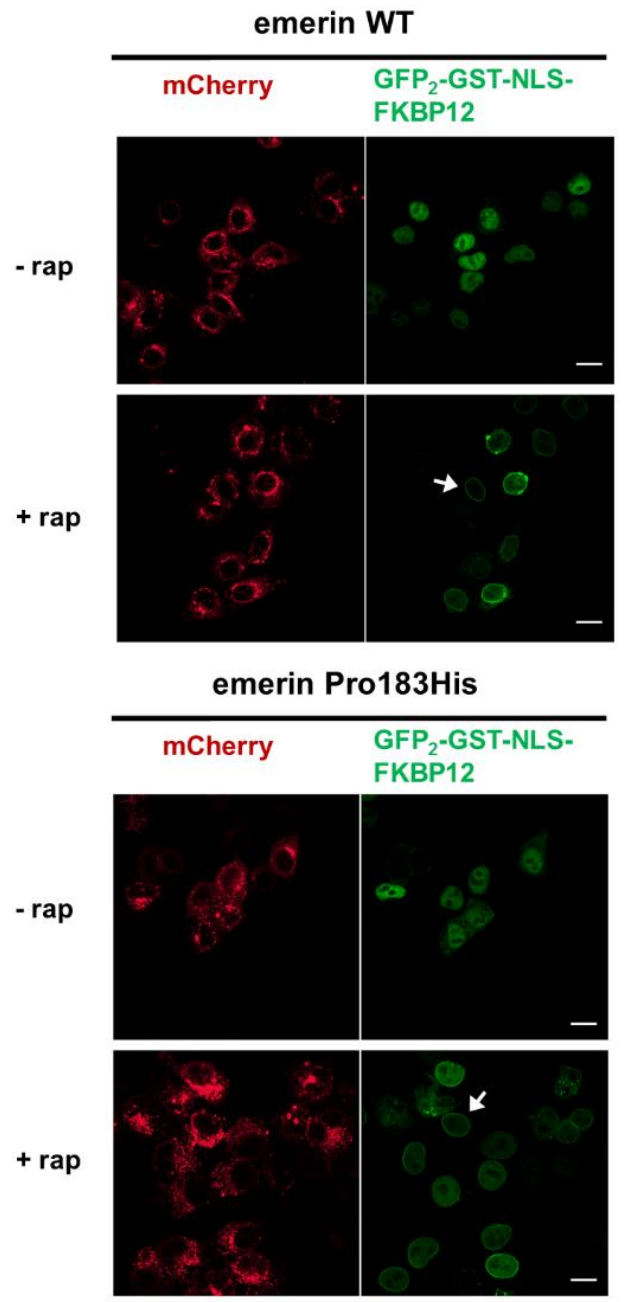

emerin Trp226*
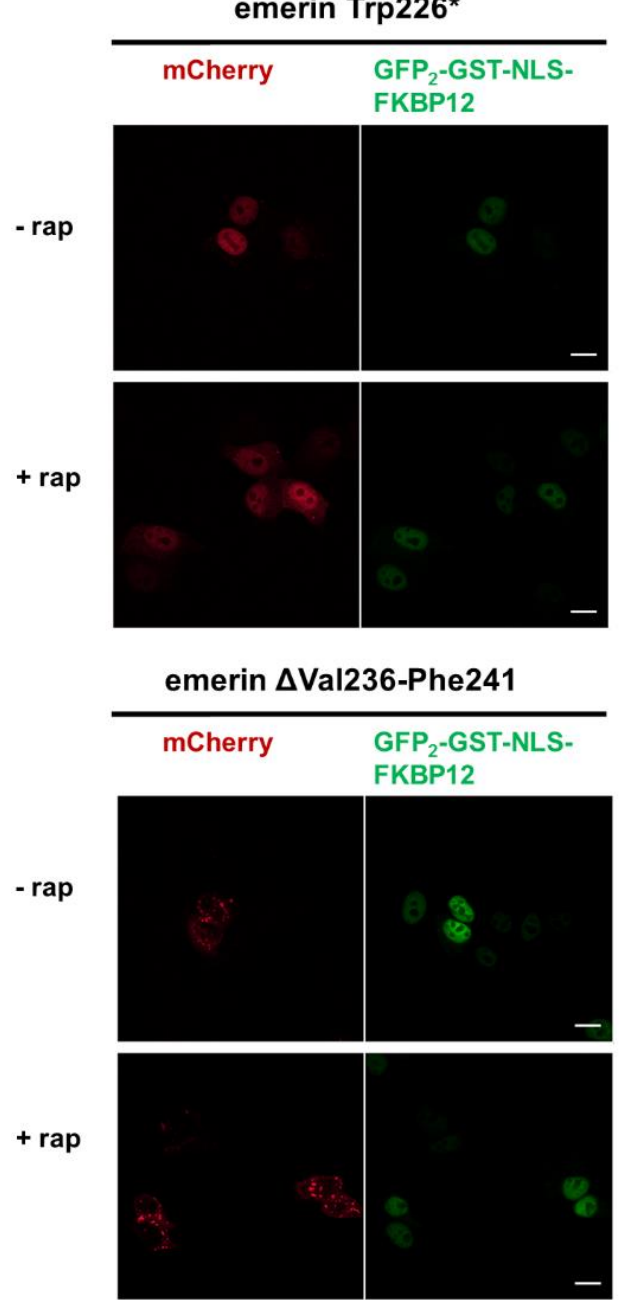
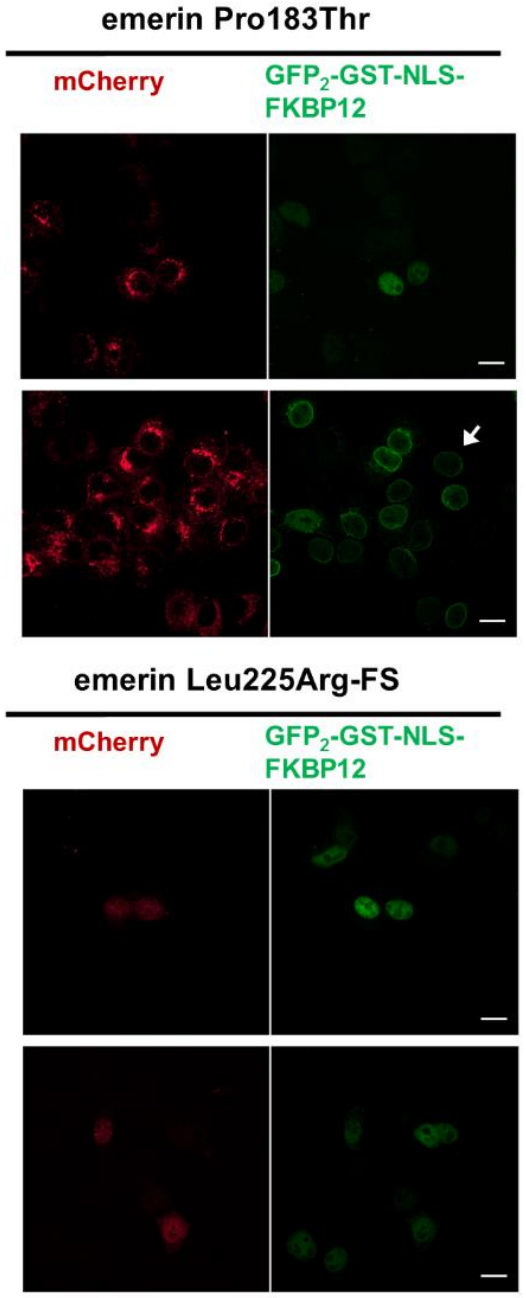

emerin Gln228His

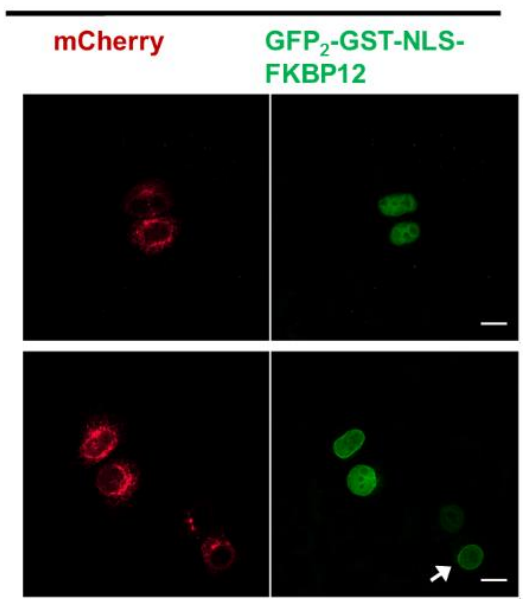

emerin Phe240His-FS

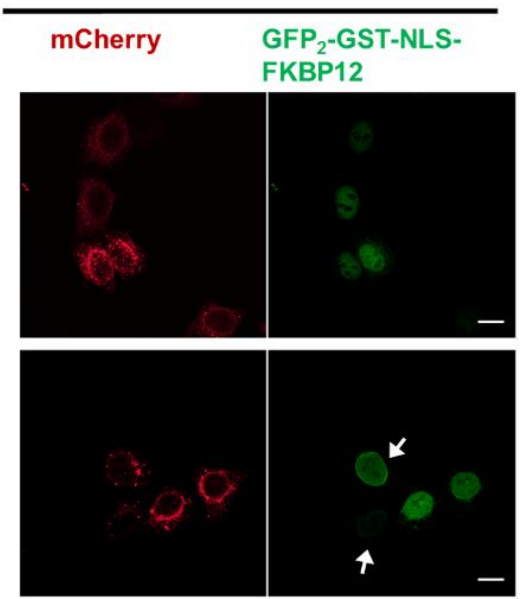


Figure 34: Localization of emerin mutants revealed by in vitro rapamycin assay. HeLa P4 cells were transfected with emerin wild type or Pro183Thr, Pro183His, Leu235Arg-FS, Trp226*, GIn228His, $\triangle$ Val236-Phe241 and Phe240His-FS emerin mutants together with the EGFP 2 -GST-NLS-FKBP12 reporter. The cells were treated according to the in vitro rapamycin assay protocol (2.2.4.2.2). A change in localization of the GFP-reporter inside the nucleus can be observed, when cells are treated with rapamycin (+rap) compared to non-treated cells (- rap) and the particular mutant is present at the INM. Arrows indicate nuclei of cells, which showed the typical altered GFP-reporter distribution. Scale bars: $15 \mu \mathrm{m}$.

Table 4: Semi-quantitative analysis of the rapamycin-effect on EGFP - GST-NLS-FKBP12. +++ , clear rim in essentially all cells; ++ , visible rim in most cells but residual nuclear signal; +, visible rim in some cells, signal mostly nuclear; and -, no nuclear rim). Between 20 (Trp226*) to 100 cells (WT, Phe240His-FS) from separate in vitro rapamycin experiments were scored.

\begin{tabular}{|c|c|}
\hline \multicolumn{2}{|c|}{ “Rapamycin Effect” } \\
\cline { 2 - 2 } mCherry-FRB & $\begin{array}{c}\text { EGFP } \text {-GST-NLS-FKBP12 }_{\text {localized at the INM }} \\
\text { WT }\end{array}$ \\
\hline Pro183Thr & ++ \\
\hline Pro183His & ++ \\
\hline Leu225Arg-FS & ++ \\
\hline Trp226* & - \\
\hline GIn228His & - \\
\hline$\Delta$ Val236-Phe241 & ++ \\
\hline Phe240His-FS & - \\
\hline
\end{tabular}




\section{Discussion}

The transport of proteins destined for the INM was studied in this work and the group of tailanchored proteins was depicted to examine the initial process of membrane insertion at the ER membrane. Furthermore, with emerin, a proposed TA-protein of the INM, as a model protein the targeting to the INM was characterized. On the basis of assays established for investigation of INM targeting of emerin, other putative TA-proteins of the INM were analyzed the same way.

\subsection{Membrane insertion mechanisms of putative INM-proteins}

In this work, a set of integral membrane proteins was studied with respect to their localization at the inner nuclear membrane. The first part of this study dealt with the insertion mechanism of a set of membrane proteins, which were chosen because of their single TMD close to the Cterminus.

Their role as putative tail-anchored proteins of the INM was investigated, using robust techniques for the analysis of post-translational membrane insertion of single-pass integral membrane proteins at the ER (Favaloro et al., 2010; Vilardi et al., 2011).

As a general established place for insertion of membrane proteins into a lipid bilayer, the ER membrane plays an important role. For either mono-or multi-topic transmembrane proteins, the ER provides a first entry site into cellular membranes via co-or post-translational integration mechanisms (Rapoport, 1992; Kutay et al., 1993).

To test the ability of a protein to integrate into an ER-derived membrane either rough microsomes or semi-permeabilized cells were used in combination with bacterially produced and purified protein complexes (see section 3.1.2).

Alternatively, in vitro translated proteins were combined together with the ER-derived membranes for a membrane insertion reaction. The bacterial expression of TRC40-TA-protein complexes compared to the in vitro translated version has the advantage of producing much larger amounts of the integral membrane protein and therefore proteins could also be used for binding studies, where high amounts of protein are required. Furthermore, knowing the exact concentration of protein, as well as the ratio of TRC40 to TA-protein, allows for using standardized amounts for each integration reaction. By using the in vitro translated protein instead, the exact amount of protein translated in the reticulocyte lysate and further used for membrane integration is not known and can vary between different reactions.

Another advantage of the pre-formed TA-protein-TRC40 complex is that the risk of aggregation, which membrane proteins are prone to, is reduced due to the binding and chaperone function of TRC40. On the other hand, due to this pre-formed co-purification together with TRC40, the examined protein is in a way forced to use the TRC40-pathway, which might not happen for some substrates in vivo. In contrast to this, the in vitro translated protein, together with rough microsomes offers a less biased approach to study the specific kind of post-translational insertion (TRC40-, chaperone or unassisted pathway).

The membrane proteins emerin, LAP2 $\beta$, VAPB and PTP1B were tested for their insertion potential in this work and in general were shown to follow a post-translational insertion mechanism, whereas differences were observed regarding their post-translational insertion mode. 
Previous tail-anchored protein studies, which dealt with the possible post-translational insertion mechanisms of different proteins, showed that the hydrophobicity of the transmembrane segment of a protein can be a crucial feature in determining the mode of insertion. With decreasing hydrophobicity of the TMD, a protein would more likely insert via an unassisted or chaperone-mediated pathway (Johnson et al., 2013; Rabu et al., 2008; Rabu et al., 2009). To determine the hydrophobicity of the investigated proteins the Membrane Protein Explorer (MPEX) tool was used for calculation by using the difference in the apparent Gibbs free energy $(\Delta G)$ (Hessa et al., 2007). The more negative a $\Delta G$ value is, the more hydrophobic a TMD of a protein of interest is predicted to be (Table 1 ).

For emerin, a well-studied protein of the INM, an in vitro transcription/translation system using rabbit reticulocyte lysate was utilized. Emerin was observed to be integrated into rough microsomes. The integration was indicated by a shift in higher molecular weight due to glycosylation of the small opsin-tag attached to the carboxy-terminus of the protein. Furthermore, the membrane integration process of emerin seemed to be an energy- requiring step (Figure 10), which was reported to be crucial for other TA-proteins like synaptobrevin as well (Kutay et al., 1995). In addition, a bacterially co-expressed emerin construct in complex with TRC40 was shown to integrate in both rough microsomes and ER-membranes of semipermeabilized HeLa cells (Figure 14, Figure 15). Using degylcosylation by PNGaseF, we could verify that the shifted, higher molecular weight band of emerin was indeed based on an ERspecific $\mathrm{N}$-glycosylation (Figure 16). HZZ-Emerin-opsin was shown by the above-described assays to use a post-translational mechanism for insertion into the ER and it was strongly indicated to belong to the class of TA-proteins. Specifically, the TRC40-mediated pathway is involved in membrane-integration of emerin, because the short, inhibitory fragments of the ER-receptors WRB and CAML (WRBCC and CAML-N) (Vilardi et al., 2011; Yamamoto and Sakisaka, 2012) affected the membrane insertion of bacterially produced as well as in vitro translated emerin (Figure 15, Figure 10). The inhibition of membrane insertion of emerin was more efficient using the CAML-N fragment compared to WRBcc. This might be explained by the finding that the CAML to WRB ratio was found to be $5: 1$ in mammalian cells (Colombo et al., 2016). With respect to the different amounts of CAML and WRB, less of the CAML-N fragment might be required to severely affect the membrane integration or binding of the TRC40-emerin-complex to the receptor subunit. Concerning the hydrophobicity of the TMD, emerin is predicted to be even more hydrophobic than RAMP4, an established TRC40-substrate. Following the argumentation by Johnson et al. (2013), this would be another indication that emerin takes the TRC40-route for membrane insertion.

LAP2 $\beta$, a known INM-protein, was used due to its characteristic TMD and investigated as well. In vitro synthesized LAP $2 \beta$ could be integrated into rough microsomes, which was detected by a shift in MW (glycosylation of the opsin-tag) by using an anti-opsin antibody (Figure 11). The membrane integration of LAP $2 \beta$ into the ER occurs by a post-translational mode. LAP $2 \beta$ most probably uses the TRC40-pathway, because the hydrophobicity of the transmembrane segment is still moderately high compared to the TMD of the ER-TA-protein RAMP4 (Table 1).

The protein VAPB is known to localize mainly to the ER and is proposed to be a TA-protein, because of its 20 amino acid stretch of hydrophobic aa directly at its C-terminal end. In vitro 
translated VAPB was shown to integrate post-translationally into rough microsomal membranes (Figure 11, C \& D). In this study, two different plasmids coding for VAPB were used for in vitro translation assays and subsequent insertion into RM. One was HZZ-VAPB-opsin and the other was VAPB-ops28, which has a longer, 19 aa opsin tag (Fasana et al., 2010; Brambillasca et al., 2005), whereas the opsin-tag of HZZ-VAPB-opsin includes only 13 aa.

The HZZ-VAPB-opsin translated in vitro, but after membrane insertion into RM, only a very faint band (red asterisk) of the higher MW and glycosylated form of VAPB could be detected (Figure $11, \mathrm{C})$. Thus, VAPB-ops28 was used in insertion assays in parallel and surprisingly, a visible amount of integrated (shifted) VAPB-ops28 was detectable with the $\alpha$-opsin antibody (ops28G, red asterisk). An explanation for the low efficiency in integration, indicated by glycosylation of the HZZ-VAPB-op construct, could be a conformational hindrance, which might not be given in the ops 28 construct due to the six additional amino acids. To test whether the post-translational integration into RM is facilitated by the TRC40-pathway, VAPB-ops 28 was translated in vitro and in addition to the standard insertion protocol in RM, different amounts of the short inhibitory fragments of the TRC40-pathway receptors, WRB and CAML, were added (Figure 10).

Even when using high inhibitor concentrations of $10 \mu \mathrm{M}$ MBP-WRBcc, no reduction of the glycosylated and therefore membrane-integrated VAPB-ops 28 was observed. VAPB-ops 28 seems to be unaffected by the TRC40-mediated integration of proteins. In agreement with this, Fasana et al. (2010) already had shown that VAPB is not able to insert into pure liposomes but instead into rat liver microsomes post-translationally.

Taking the hydrophobicity of the TMD of VAPB into account, it was reported by Fasana et al. (2010) that VAPB has a moderately hydrophobic region and thus an ER integration via an assisted pathway was suggested. In conformity with this, VAPB harbors a less hydrophobic TMD compared to the segment of emerin (Table 1).

The experiment with the short ER- membrane-receptor fragments VAPB-ops28 membrane integration showed an integration into the ER membrane independently of the TRC40mechanism (Figure 10). Further experiments, addressing a chaperone-mediated mode of integration like the $\mathrm{Hsc70/Hsp40} \mathrm{route,} \mathrm{would} \mathrm{be} \mathrm{needed} \mathrm{to} \mathrm{confirm} \mathrm{an} \mathrm{alternative} \mathrm{assisted}$ insertion mechanism for VAPB. Another fact pointing against a TRC40-involvement of the membrane insertion of VAPB is a structural feature of VAPB, the Major Sperm Protein (MSP) domain.

At the amino-terminus of VAPB the 125 amino acids long MSP domain is located. It is named after an abundant $C$. elegans MSP protein and was reported to be cleaved in neuronal cells having a function in signaling (Deidda et al., 2014; Tsuda et al., 2008). This domain was reported to interact with proteins containing FFAT-motifs like oxysterol-binding proteins. Concomitantly, it was shown that VAPB can bind an FFAT-like motif of TRC40 via its MSP domain, but not its C-terminal TMD, even though it is a TA-protein (Baron et al., 2014). The binding of TRC40 to VAPB seems to be independent of a function in ER-membrane insertion and presumably fulfills another not yet identified function of a TRC40-VAPB complex. In the same study, the TRC40-VAPB complex localized to the perinuclear space. In theory, the MSP domain (14 kDa) could be proteolytically cleaved and a shortened version of VAPB (only about half of the size of the full-length protein) might be found at the ER membrane, if insertion is carried out by another assisted membrane insertion mechanism (e.g. Hsc70/Hsp40). With respect to these findings, several populations of TRC40 are proposed to exist, either functioning in the established delivery of TA-proteins to the 
ER membrane or perhaps in a chaperone function to shield the bound protein (e.g. VAPB) from the cytosolic environment or retain it there. In context to this, TRC40 already has been implicated in quality control mechanisms

For the yeast homolog of TRC40 (Get3) it has been reported, that in situations, where energy is depleted (e.g. oxidative stress), TRC40 does not deliver TA-protein to the ER membrane anymore, but instead is able to serve as a chaperone. It can shield unfolded proteins, prevent aggregation and protect proteins from oxidative stress (Powis et al., 2013; Voth et al., 2014). The involvement of TRC40 in a quality control mechanism could very well be an explanation for the presence of a TRC40-VAPB complex.

PTP1B was also examined in membrane integration studies and could be found inserted into rough microsomal membranes when the protein was synthesized in vitro (Figure 11, B).

Generally, for membrane integration of HZZ-PTP1B-opsin either in vitro or bacterially expressed proteins were used, but in all cases the membrane integrated protein bands observed for PTP1B were blurry and not distinct. It has been reported that PTP1B is highly modified depending on the signal pathway or process it is involved in and thus perhaps this observation could be explained (Bakke and Haj, 2015).

PTP1B was reported to exist in a non-transmembrane state with catalytical function and as an integral membrane protein at the ER (Chernoff et al., 1990; Brown-Shimer et al., 1990; Guan et al., 1990). The hydrophobic region or TMD of PTP1B was identified at the C-terminus with a length of 35 aa (Frangioni et al., 1992). Latest studies about the C-terminal anchor segment revealed that the TMD cannot be defined by a fixed sequence, but instead is moveable within several amino acids and furthermore the TMD length as well as its hydropathy is crucial for localization at the mitochondrial outer membrane (Anderie et al., 2007; Fueller et al., 2015). The predicted 35 amino acids TMD is compared to emerin notably less hydrophobic (Table 1 ). This property of the TMD of PTP1B supports the idea of an unassisted insertion mechanism into membranes like seen for cytochrome b5, which has a similarly low hydrophobic TMD (Table 1).

Brambillasca et al. (2006) already showed in an in vitro approach that PTP1B inserts into liposomes via an unassisted mode and that its integration was strongly dependent on the cholesterol amount in the membrane. With increasing amounts of cholesterol used, insertion into membranes was inhibited as seen for the TA-protein cytochrome b5 with similar hydrophobicity. Furthermore, Brambillasca et al. (2006) did show that a nucleotide-independent insertion for PTP1B is possible. It has been proposed that proteins shedding the TMD in the cytoplasm before the spontaneous insertion can occur and that cytosolic proteins most probably would not need much energy to keep PTP1B in the steady-state. In addition to the unassisted pathway suggested for PTP1B, it was shown that it can exploit the Hsp40/Hsc70-mediated membrane insertion route when a high amount of these chaperones is present. In the same experiment, also the basal levels of insertion were quite high and pointed again to a spontaneous ER integration mode. Especially for the unassisted pathway, which PTP1B most probably uses, the lipid composition of a membrane as well as cytosolic factors are important. To further analyze the non-assisted ER membrane insertion mode, cytosolic factors need to be identified, which would be able to control the spontaneous insertion process of PTP1B and to recognize the correct target membrane (e.g. ER, mitochondrion) (Colombo et al., 2009). 
For LEMD1, which has a typical LEM-domain like emerin, membrane integration was not investigated so far. By virtue of the calculated hydrophobicity of the TMD of LEMD1, it possesses a slightly more hydrophobic TMD than LAP2 $\beta$ (Table 1 ). Based on this it could be sorted into the group of moderate hydrophobic TMDs, which might very well be inserted into the ER via an assisted pathway.

LRRC59 was not addressed for its membrane insertion mechanism in this study, but unpublished data from C. Jamieson, K. Rajanala and M. Blensky support a post-translational membrane insertion. Regarding to the characteristics of LRRC59 it could be a borderline TA-protein, because its TMD is found about 42 aa upstream of the C-terminal end and has a moderately hydrophobic TMD (Table 1). A threshold of about 30 aa following the TMD was proposed to define a protein as a TA-protein which uses a post-translational ER insertion mechanism (Borgese et al., 2003). Due to the fact that about 39 aa of the nascent protein are protected inside the large ribosomal subunit during translation (Blobel and Sabatini, 1970), the TMD cannot be more than 30 aa apart from the carboxy-terminus depending on the length of the TMD itself. In future, an involvement of the translocon and SRP-dependent pathway therefore needs to be elucidated for LRRC59.

\subsection{Verification of localization of proteins to the inner nuclear membrane protein using a rapamycin-based dimerization assay}

\subsubsection{Applications of a newly developed rapamycin-induced dimerization assay}

In chapter 3.2.2.1, the rapamycin-based INM localization assay was introduced. Previously, the rapamycin system was utilized in several approaches connected to research concerning the nucleus, but so far not for studying the targeting and localization of INM-proteins. Studies have been performed dealing for example with the characterization of nuclear export of the protein Tap (Schmitt and Gerace, 2001), trapping of reporter proteins at the nuclear lamina (Ohba et al., 2004) or in yeast, the system was utilized for depletion of a protein from the nucleus with an anchor-away approach (Haruki et al., 2008).

The two-component rapamycin system, which is used in this work consists of mCherry-FRB-TAprotein and an $\mathrm{EGFP}_{2}$-GST-NLS-FKBP12 reporter protein. For the specific experimental setup, it means that in presence of rapamycin, the soluble FKBP12 reporter binds to the FRB cassette of the protein of interest at the INM. Concerning the parameters used for this assay, the concentration of $200 \mathrm{nM}$ rapamycin used for this assay for 10 minutes at the longest can be seen as a moderate concentration, which was used also for an approach, where proteins were inactivated by rapamycin treatment (Robinson et al., 2010). Due to the speed of action that can be seen for shifting of the homogenously distributed nucleoplasmic FKBP12-reporter to the nuclear periphery (depending on the FRB-TA-protein within 20 seconds) upon rapamycin addition in vitro, the risk of side effects induced by rapamycin can be considered as relatively low (Putyrski and Schultz, 2012).

Another observation made for the rapamycin assay was, that the responsiveness of the cells upon rapamycin treatment varied a lot between different constructs, but also for the same FRB-protein transfected. This seemed to be independent of the transfection level of the FRB- protein inside the individual cells. 
A reason that often some residual GFP-staining is found inside the nucleus, could be the expression rate of the GFP-reporter. If a highly GFP-reporter protein expressing cell is treated with rapamycin, an incomplete shift in localization can be observed maybe because binding sites at the INM are limited.

Furthermore, there could be differences in the efficiency of binding between the FRB and FKBP12 reporter hypothetically caused by interactions of FKBP12 and endogenous MTOR. mTOR is reported to reside at different compartments of the cell like the cytoplasm or the nucleus (Malik et al., 2013; Betz and Hall, 2013). Levels of mTOR could of course differ depending on the cell cycle stage and a competitive situation between FRB-TA-proteins constructs at the INM and soluble endogenous mTOR cannot be completely excluded.

Especially in malignant cells, mTOR is found inside the nucleus (Zhang et al., 2002) applying to the cell lines used in this work. By contrast, endogenous mTOR was detected equally distributed between nucleus and cytoplasm for the HeLa P4 and U2OS cells used in this study (data not shown). Therefore, it is very unlikely that endogenous mTOR inhibited the binding to FRB-TAproteins at the INM.

Rapamycin was primarily known for its immunosuppressive properties and it became important for basic research with respect to its use in FRB-FKBP12-dimerization experiments to address various cellular processes in the last years. Due to its influence on cellular processes like regulation of mTOR mediated cell growth and proliferation or upregulation of autophagy (Tanemura et al., 2012), cells cannot be used in an unbiased manner. Thus, alternative modified chemical inducers for dimerization (CIDs) were developed, which are called rapalogs. The advantage of these new rapamycin analogs is that they can be very useful in approaches, where an influence on endogenous mTOR and other downstream pathways need to be excluded.

Taken together, the rapamycin-based dimerization assay established in this work represents a reliable and solid approach to monitor localization of a protein of interest to the INM. It allows to make a qualitative statement about the localization of a protein, however a quantitative analysis and comparison between different proteins is only possible to a limited extent because the transfection efficiency and expression levels of both FRB and FKBP12 constructs on the single cell level cannot be controlled.

\subsubsection{Localization of emerin, LAP2 $\beta$, VAPB, PTP1B, LEMD1 and LRRC59 at the INM}

After the post-translational membrane integration of the subset of proteins was analyzed, the proteins should be confirmed to exist not only at the ER membrane, but also at the INM. By using either a differential permeabilization assay (see chapter 3.2.1) and the rapamycin-based dimerization assay (see chapter 3.2.2.2), the subcellular localization of the proteins emerin, LAP2 $\beta$, VAPB, PTP1B, LEMD1 and LRRC59 was examined. Some of the investigated proteins could only be referred to as localized to the nuclear envelope and for others like LAP2 $\beta$ instead EM studies (Furukawa et al., 1995) revealed it to be clearly localized to the INM.

The membrane integration assays showed that emerin uses the TRC40-pathway for membrane integration as a bona fide TA-protein, but localization to the INM was not investigated in this work so far. By virtue of a differential permeabilization experiment, emerin was shown to be present at the INM seen by a predominant localization at the "nuclear rim" compared to digitonin treated samples (Figure 33). Further support for the INM as a primary destination of emerin was 
given by the rapamycin assay using. mCherry-FRB-emerin (Figure 24). As a well-studied INMprotein (Manilal et al., 1996; Nagano et al., 1996), emerin was shown to mainly localize to the INM by immuno-gold labeling EM (Yorifuji et al., 1997; Tsuchiya et al., 1999), but also a pool at the ER and ONM could be observed, which was also seen by Salpingidou et al. (2007).

LAP2 $\beta$ was tested for its insertion ability into the ER membrane (see section 3.1.2) and shown to be integrated post-translational at the ER membrane. Early studies have demonstrated LAP2 $\beta$ to be a protein of the nuclear envelope and especially the INM shown by EM studies (Foisner and Gerace, 1993; Furukawa et al., 1995; Senior and Gerace, 1988). The subcellular localization assay confirmed LAP2 $\beta$ to localize at the nuclear envelope with a prominent "nuclear rim" staining compared to cells only permeabilized with digitonin (Figure 23). In the rapamycin-assay LAP2 $\beta$ was as well found to be localized at the INM with nearly all of the GFP-FKBP12 reporter shifted to the INM after applying rapamycin (Figure 23). The extent, to which the dimerization reaction occurred, is comparable with the well-established protein emerin. Because of reports dealing with an interaction of LAP2 $\beta$ and lamins (Furukawa et al., 1998; Senior and Gerace, 1988), the influence of a lamin A/C downregulation for 48 hours on the localization of LAP2 $\beta$ at the NE was examined, because a lamin $A / C$ knockdown resulted in a severe reduction of emerin at the NE (Supplementary figure 3). No influence on LAP2 $\beta$ NE localization was observed (Appendix, Supplementary figure 3), confirming that LAP2 $\beta$ INM localization is not depending on lamin A/C. Instead it has been reported to be retained at the INM by B-type lamins, which were not tested in this work (Foisner and Gerace, 1993). Moreover, other properties of LAP2 $\beta$, like its chromosome-binding domain have been reported to play a role in retention of LAP $2 \beta$ at the INM.

The vesicle-associated membrane protein (VAMP)-associated protein B (VAPB) was demonstrated to localize at the ER shown by EM (Stoica et al., 2014), the ERGIC (Tran et. al., 2012) and to endosomes (Soussan et al., 1999; Skehel et al., 2000). For overexpressed mCherryFRB-VAPB a localization at a reticular structure around the nucleus, most probably the ER and a nuclear envelope "rim" staining was observed (Figure 9 and Figure 23). So far, VAPB has been reported to influence the targeting of NE components emerin and the nucleoporin Nup214 and a mutant version of VAPB causing amyotrophic lateral sclerosis has been shown to influence spacing of INM and ONM (Tran et al., 2012). This indicates an effect of VAPB on the INM. In the same study, it was demonstrated to localize to the ER and the nuclear envelope for wild type and a VAPB mutant. Indeed, in the rapamycin-assay the FKBP12 reporter was detected as a faint "rim" at the nuclear periphery upon rapamycin treatment. The change in distribution of GFP-FKBP12 is an indirect evidence for the localization of mCherry-FRB-VAPB at the INM. Compared to the FKBP12-reporter translocation of emerin or LAP2 $\beta$, no complete translocation of FKBP12 to the INM was observed and for most of the cells residual GFP-fluorescence could be seen. It can be concluded that exogenous VAPB can be found at the INM in vivo. Due to previous reports about an influence of VAPB on INM-protein and nucleoporin targeting, the presence of VAPB at the INM might be explainable by functioning in this context.

A long variant of the phosphatase PTP1B containing a transmembrane domain is investigated in the localization assay. According to immunofluorescence and subcellular fractionation experiments it was reported to localize mainly at the outer leaflet of the ER. Furthermore, EM studies revealed myc-tagged PTP1B to localize at the ER (Eden et al., 2010). The localization 
pattern reported for PTP1B did not only include reticular structures but also a nuclear membrane distribution was observed (Frangioni et al., 1992).

For the overexpression of mCherry-FRB-PTP1B per se, an ER-staining and a nuclear envelope "rim" was observed similar to the pattern of mCherry-FRB-emerin (Figure 9). In presence of rapamycin, the transfected EGFP2-GST-NLS-FKBP12 was shifted from the nucleoplasm to the periphery, but not to the same extent in all cells. For most of the cells expressing the mCherryFRB-PTP1B recombinant protein at a low or moderate level, the co-transfected GFP-FKBP12 reporter translocated almost entirely to the INM (Figure 23). By contrast, in cells strongly expressing PTP1B, a large fraction was observed at the ER and relatively low levels of nuclear "rim" staining could be monitored upon rapamycin treatment. Interestingly, PTP1B was found to bind to emerin and to regulate its tyrosine phosphorylation at the INM. This was analyzed by colocalization studies with lamins and biochemically in fractionation experiments (Yip et al., 2012). The INM pool of PTP1B was observed to be sumoylated and thus proposed to be in its enzymatically inactive state. PTP1B as a TA-protein is able to bind to and regulate emerin being as well another TA-protein of the INM.

Yip et al. (2012) indicated PTP1B to have a function at the INM, where it was confirmed to be localized at in the rapamycin experiments (Figure 23). PTP1B was indeed proven to exist at the INM and can use a post-translational pathway (Figure 11, D), most probably an unassisted mode, for membrane insertion. Therefore, it is classified as a tail-anchored protein of the INM, no matter if the INM could be only an intermediate destination for PTP1B in contrast to emerin, which is retained there.

LEMD1 was investigated as an INM-protein owing to its characteristic LEM-domain, which it has in common with emerin. Due to its structural properties being a C-terminal single pass transmembrane protein, it was proposed to belong to the group of TA-proteins. Yuki et al. (2004) first identified this protein and reported it to play a role in cancer. Furthermore, LEMD1 was found as a testis-specific expressed protein and overexpressed LEMD1F, a short isoform of LEMD1, could be found localized at the nuclear membrane together with the DNA-binding protein BAF. Since no further localization studies of LEMD1 were available, this was the only information about the distribution at the nuclear envelope. Like for other proteins, the in vitro kinetics/time course rapamycin assay was performed directly at the microscope in permeabilized cells. Transfected mCherry-FRB-LEMD1 itself could be clearly found at the NE and at reticular structures, probably ER, around the nucleus. The assay revealed that mCherry-FRB-LEMD1 is present at the INM, because a distribution of the GFP-FKBP12 reporter at the nuclear periphery was observed after rapamycin addition (Figure 23). For LEMD1 a complete shift of the GFPreporter from the nucleoplasm to the INM was never observed to the extent as seen for emerin. This could indicate a lower amount of the protein at the INM compared to emerin. On the other hand, a low amount of LEMD1 at the INM could as well be caused by the possibility that the construct design itself is not the best choice for investigating LEMD1. By far, LEMD1 had the lowest transfection efficiency compared to all other mCherry-FRB constructs. The protein has a molecular weight of $20 \mathrm{kDa}$ and thus the mCherry-tag with a size of $27 \mathrm{kDa}$ would be larger than the protein itself. For all other constructs, the tag was never larger than the protein size itself. Another explanation for a reduced amount of LEMD1 at the INM might be that the size of the cytoplasmic portion was reported to be critical for correct targeting to the INM via a peripheral 
channel of the NPC (Holmer and Worman, 2001; Ohba et al., 2004). The N-terminal portion of mCherry-FRB-LEMD1 would be about ( $55 \mathrm{kDa}$ ) and close to the threshold reported to be at $60 \mathrm{kDa}$. In line with this, LEMD1 with a smaller N-terminal portion could be designed and tested in rapamycin assays. Nevertheless, using the rapamycin dimerization system, LEMD1 was shown to localize to the INM.

LRRC59 was studied as a putative TA-protein, because first experiments about the topology of the protein using $\mathrm{RM}$, indicated it to have a very C-terminal TMD and no signal sequence throughout the N-terminal part (Ohsumi et al., 1993). Furthermore, Skjerpen et al. (2002) and Zhen et al. (2012) showed the protein to localize to the ER and the nuclear envelope in U2OS cells, but it has not been examined by immunoelectron microscopy. Using an mCherry-FRBLRRC59 for the rapamycin experiment, as well a localization at the ER and nuclear rim was detected. After rapamycin treatment, the GFP-FKBP12 reporter shifted to the periphery of the nucleus, strongly indicating the presence of LRRC59 at the INM (Figure 23). Again, as observed for LEMD1, not all the cells showed a strong translocation of the GFP-reporter to the INM. This was also correlated to the expression levels of exogenous LRRC59 in individual cells. Concerning the function of LRRC59 at the INM to our knowledge not much is known so far, except its involvement in shuttling the growth factor FGF1 to the nuclear interior (Zhen et al., 2012).

Due to the use of the rapamycin-dimerization assay all investigated mCherry-FRB-tagged proteins were demonstrated to localize to the inner nuclear membrane in HeLa cells under in vivo conditions.

\subsection{Targeting of emerin from the ER to the INM}

This work focused on the characterization of membrane insertion and transport of tail-anchored proteins to the INM. Along these lines, emerin was investigated in detail as a model protein because there is plenty of information interaction partners. In the following, the outcome of a TRC40-dependent membrane integration at the ER and the localization of wild type emerin as well as emerin mutants related to Emery-Dreifuss muscular dystrophy are discussed with respect to possible INM-targeting models.

\section{Emerin is a substrate of post-translational membrane insertion machinery involving TRC40}

Emerin is a C-terminal, monotopic transmembrane protein belonging to the class of TA-proteins. Even though several post-translational modes of membrane insertion at the ER were reported for TA-proteins (section 1.2.2.2), the most recently identified TRC40- or Get3-mediated pathway is supposed to be a prominent route. To elucidate whether emerin is using the TRC40-pathway, emerin was expressed together with TRC40 and could be co-purified as a stable TA-proteinTRC40-complex (see Figure 12). This complex would resemble the proposed in vivo situation in mammalian cells except of the pre-targeting complex factors Bag6, TRC35 and Ubl4A, when TRC40 captures and shields the TMD of emerin as soon as it exits from the ribosomal tunnel after translation. After having the protein produced in way that it could use the TRC40-pathway, emerin was tested for its ability to integrate into ER-derived membranes. Accordingly, either dog pancreas derived rough microsomes or semi-permeabilized HeLa cells were used to test the membrane insertion competence of the recombinant HZZ-emerin-opsin. For both membrane 
types, a detection of emerin as a higher molecular weight band (integrated into membranes), caused by ER-luminal N-glycosylation of the C-terminal opsin-tag of the HZZ-emerin-opsin, was possible (Figure 14, Figure 15, Figure 16). Moreover, the insertion of emerin could be inhibited at these membranes, when short fragments of the TRC40-pathway receptors WRB and CAML were added (Figure 15), which also supported the requirement of TRC40 for membrane insertion of emerin. To not merely use a pre-determined TRC40-emerin complex, emerin was translated in rabbit reticulocyte lysate in vitro and HZZ-emerin-opsin could be membrane integrated in RM (Figure 10). For TRC40-depleted reticulocyte lysate a reduced membrane insertion of emerin was observed (Figure 17). With TRC40 depleted reticulocyte lysates the membrane insertion capacity of emerin was lowered. By contrast Hsc70 depletion left the membrane integration of emerin unaffected compared to control treated lysates. This corroborates the dependency of emerin on TRC40 regarding its membrane insertion mode under the present conditions.

Presuming the nature of binding between TRC40 and its substrate TA-protein (e.g. emerin) to be a transient and rapid process, conventional co-immunoprecipitation studies are rather difficult to carry out. Therefore, an in situ approach was used to confirm the most likely transient interactions between exogenous TRC40 and emerin (Pfaff et al., 2016). By using a proximity ligation assay, the interaction of overexpressed TRC40-myc with endogenous emerin was monitored in comparison to the TRC40-independent substrate STT3B. STT3B is supposed to use a co-translational SRP-dependent membrane insertion mode instead. As a positive control, Seb61 $\beta$, a well-established TRC40-substrate, was used (Figure 29). Areas, where emerin and TRC40 were present in close proximity, could be visualized and for TRC40-myc-emerin 12 interactions in a cell and for TRC40-myc- Sec61ß 56 interactions per cell were scored. Unfortunately, a direct comparison of interactions between emerin-TRC40 and Sec61 $\beta$-TRC40 is not possible, because factors like the abundance of the proteins inside the cell or the quality of the antibodies used cannot be taken into account for a quantitative statement. A general advantage of this method was, that it is possible to see directly, in which compartment or at which site emerin and TRC40 interact, meaning that the PLA probes of both proteins are present in a range of $40 \mathrm{~nm}$. For both TA-proteins together with TRC40, signals occurred almost entirely in the cytoplasm close to the ER membrane as it was expected for the TA-protein delivery to the ER via the TRC40-pathway.

\section{Effects of TRC40 and WRB depletion on the localization of emerin at the NE}

Beyond the in vitro membrane integration experiments, the influence of the TRC40-pathway as a post-translational ER membrane integration mechanism on emerin was examined in living cells. The siRNA-mediated knockdown of two components of the TRC40-pathway, TRC40 and WRB, resulted in reduced emerin levels at the nuclear envelope, detected by indirect immunofluorescence (Figure 27). In contrast to the reduction of emerin seen by microscopic analysis, the total protein levels were found to be unaffected by the depletion of both TRC40 and WRB (Figure 28). The reduction of emerin specifically at the NE (Figure 27) observed with downregulation of TRC40 and WRB together with the finding that the total protein levels of emerin remained stable, could be explained by a dilution effect for emerin and a localization to other compartments like the ER. Furthermore, a cause for the overall unchanged protein levels could be the capacity of emerin to use alternative membrane insertion pathways. It most likely can be excluded that alternative membrane insertion pathways (Borgese and Fasana, 2010; 
Leznicki et al., 2011) used by emerin, could be the reason for the overall unaffected emerin protein levels. Supportive for this is, that in membrane insertion assays using semi-permeabilized cells or RM it was specifically displayed that emerin depends on the TRC40-mechanism, when short inhibitory fragments of the membrane receptors WRB and CAML were added and interfered in the membrane insertion of emerin (Figure 15, Figure 10).

Recently, the role of both endogenous receptors CAML and WRB as well as their concentration and stoichiometry in mammalian cells was investigated (Colombo et al., 2016). The authors of this study found that with an up-or downregulation of one receptor subunit, the other was affected as well in a mutual manner.

In the light of this study and the possibility of a mutual influence of components of the TRC40machinery, the finding that TRC40 total protein levels are reduced itself, when WRB is depleted (Figure 28), is not as surprising.

According to this TRC40 reduction, indirect immunofluorescence showed an almost entirely lack of TRC40, similar to a TRC40 knockdown (Figure 27). As mentioned in section 3.3.1, this reduction could be caused by a possible feedback-mechanism regulating the expression and controlling the ratio of the membrane-bound components WRB and CAML to the TRC40 pool in the cytoplasm. In contrast to this, it has not been reported so far that depletion of TRC40 itself influences the protein levels of WRB and CAML. In this context, a possible role of CAML, the second ERmembrane receptor of the TRC40-pathway, in sensing downstream signals and controlling TAprotein biogenesis has been proposed (Yamamoto and Sakisaka, 2015). With respect to this potential new function of CAML, WRB together with CAML could be seen as a functional unit and perhaps a signaling effect initiated by this unit explains the regulation of TRC40. A further possibility to explain, why overall TRC40 levels are found to be reduced, could be that not only the expression of the protein is modulated and less protein is translated, but certain degradation processes e.g. via the proteasome could be initiated to remove not required protein from the TRC40 pool.

\section{Possible INM trafficking pathways for INM-proteins and emerin}

After insertion of emerin as a TA-protein via the post-translational TRC40-mediated pathway into the ER membrane, it still has not reached its final destination, the INM. As described in section 1.2.4 (Figure 7) several models for transport to the INM have been proposed. One of the most discussed models for INM-transport is the diffusion-retention mechanism (Powell and Burke, 1990; Smith and Blobel, 1993; Soullam and Worman, 1993). An INM-protein is proposed to travel after insertion into the ER membrane in a membrane-bound mode to the INM. From the ER membrane, which is continuous with the ONM, it reaches the ONM and uses peripheral channels of the NPC (Maimon et al., 2012) to insert into the INM. There, the INM-protein is retained by its interaction partners e.g. lamins (Haraguchi et al., 2001; Lee et al., 2001). So far, no exclusive mode of trafficking to the INM was studied for INM-proteins belonging to the group of TAproteins. For emerin, being a very well-characterized INM-protein (Berk et al., 2013b; Bengtsson and Wilson, 2004), its mobility inside membranes was investigated by microscopic approaches using fluorescence recovery after photobleaching (FRAP) and fluorescence loss in photobleaching (FLIP) (Östlund et al., 1999). A clear reduction in mobility was found for the fraction of emerin residing at the NE (INM) compared to the ER and plasma membrane fraction. The authors found emerin to be able to laterally diffuse into the ER and INM. At the NE, a very slow lateral 
movement was observed, which was faster than that of rather immobile lamins. Further studies addressing the mobility of other INM-proteins (e.g. LBR, MAN1) at the distinct locations inside the cells showed a distinct behavior in their mobility due to distinct interaction partners at the INM (Soullam and Worman, 1993; Ellenberg et al., 1997; Östlund et al., 2006; Zuleger et al., 2011).

The studies of Östlund et al. (1999) and Ungricht et al. (2015) used C-terminally tagged INMprotein versions for the bona fide tail-anchored proteins emerin and LAP $2 \beta$, which due to the tags should not use a post-translational membrane insertion mechanism anymore. Whether the general membrane targeting mode or at least the mobility and movement is influenced by the mechanism of insertion into the ER-membrane due to the positioning of the fluorescent tag of the protein, would be interesting to test. In addition, general information about the possible changes caused by tagging of proteins at different positions in relation to their distribution and localization could be obtained.

According to the above reports, as well with a knockdown of lamin A/C, the localization of emerin to the NE was disrupted (Supplementary figure 3) and proper localization of emerin at the INM seemed to rely on binding to its interaction partner lamin $A$, which was shown for lamin knockout mice and fibroblasts treated with shRNA for lamin A/C (Sullivan et al., 1999; Östlund et al., 2006; Moiseeva et al., 2011). Furthermore, for emerin an interaction with chromatin was shown and could be seen besides lamin as another "retention factor" at the INM (Shumaker et al., 2001; Lee et al., 2001).

Recently, two reports about the requirements of diffusion-retention based INM-protein targeting taking protein mobility and nuclear architecture like NPC number, permeability as well as the existence of nuclear binding sites into account, supported this targeting model (Ungricht and Kutay, 2015; Boni et al., 2015).

For some INM-proteins, energy requirement and temperature-dependency was reported to be crucial for transport to the INM (Ohba et al., 2004). With respect to this, the mobility of emerin was shown to be affected by ATP depletion. Not the translocation step to the INM, but instead a process of maintaining the ER structure could be energy-requiring and a limiting step (Ungricht et al., 2015). Further, ATP-depletion was shown to influence emerin and its mobility in the ER. Sequences required for the ATP-dependent step were allocated to the nucleoplasmic region of emerin (Zuleger et al., 2011). Related to this, all membrane insertion steps performed throughout the work were shown to be dependent on ATP as an energy source (Figure 15 and Figure 10) and even the membrane association shown for emerin in the in vitro transport assays was shown to require an ATP-regenerating system (Figure 18).

Another feature regulating and influencing transport to the INM, is the existence of an INMsorting motif (see section 1.2.4). It was found to be able to promote targeting to the INM e.g. for LBR (Katta et al., 2014; Saksena et al., 2006; Braunagel et al., 2007), but no experimental data testing the predicted INM-sorting motif of emerin (Katta et al., 2014) are available.

Another structural feature critical for targeting to the INM can be the existence of intrinsic FGrepeats (Zuleger et al., 2011). According to this, FG-repeats were found to be present and enriched in NE transmembrane proteins (Schirmer et al., 2003), but especially for INM-trafficking of emerin, FG-repeats are not present and therefore this path does not play a role at all. 
When a protein like emerin inserts post-translational via the TRC40-pathway, the question arises whether emerin could conceivably be integrated directly at the INM from the inside of the nucleus. To address this, emerin would need to be transported by means of its predicted, nonclassical NLS (Katta et al., 2014) as a soluble protein. The insertion step into the INM from within the nucleus would probably need to occur in an assisted process mediated by a membrane receptor. This membrane receptor might probably be an unidentified protein, because the ERreceptor WRB, which is crucial for membrane integration from the cytoplasmic side, is indicated to be present only at the ER or ONM (Figure 24). According to results of the rapamycin assay for WRB, a shift of the GFP-FKBP12 reporter to the nuclear periphery was not observed. This suggested that overexpressed WRB is not present at the INM or at least in such low amounts that a change in localization for GFP-FKBP12 could not be monitored in this microscopic approach (Figure 24). Speaking against a soluble mode of targeting from the nucleoplasmic side is the observation that TRC40-myc alone was found to localize predominantly cytoplasmic, not nucleoplasmic. Also, TRC40 together with endogenous emerin was found to be mainly localized in the cytoplasm near the nucleus, not many interaction signals could be seen inside the nuclei in situ (Figure 29).

The transport-factor mediated pathway results in translocation to the INM by passing the central channel of the NPC with assistance of NLS-recognizing classical transport receptors and was indicated to apply for the INM-protein SUN2 and the yeast proteins Heh1 and Heh2 (Turgay et al., 2010; Theerthagiri et al., 2010; King et al., 2006; Meinema et al., 2011).

Other than that, INM-protein transport can be facilitated via the diffusion-retention mechanism, which was suggested to be the most probable route for LAP2 $\beta$ INM-transport. In general, targeting to the INM by the diffusion-retention model was found to depend on the maintenance of an elaborate ER network, translocation through a peripheral channel of the NPCs and the presence of retention partners at the INM (Ungricht et al., 2015).

Considering the different possibilities of trafficking of emerin from the ER to the INM, in light of the dependency of emerin on A-type lamins for proper localization at the NE, the diffusionretention model is favored. For emerin, the retention and localization at the INM was shown to be directly affected by a lamin A/C knockdown (Supplementary figure 3) (Sullivan et al., 1999). As well, with emerin being found at the ER-membrane and revealing differences in mobility between emerin at the ER and NE (Östlund et al., 1999), the diffusion process along the ER is very likely to happen.

Overall, targeting of INM-proteins was shown to require distinct factors like temperature and energy, proteins as-co-factors or to depend on harboring specialized internal sequences. Different types of INM-proteins might utilize distinct routes for trafficking from the ERmembrane as initial point of membrane insertion and a single, uniform route to enrich at the INM is very unlikely to exist (Antonin et al., 2011). So far, the initial membrane integration process of proteins was studied intensively, but whether this step can be critical in determining the transport route of an INM-protein remains unclear. 


\subsection{Disease-related emerin mutants exhibit decreased targeting efficiency to the inner nuclear membrane}

Apart from wild type emerin, a subset of X-linked Emery-Dreifuss muscular dystrophy mutations in emerin were examined with respect to their membrane integration and their targeting to the INM.

Because it was reported that the features of the TMD of TA-proteins and its adjacent regions might have a particular role in post-translational membrane insertion (Beilharz et al., 2003; Borgese et al., 2001)), emerin mutants with different TMDs and C-termini were investigated.

The emerin mutants showing a frame-shift occurring in the TMD (Leu225Arg-FS, Phe240-His-FS) or partially ( $\triangle$ Val236-Phe241) and completely (Trp226*) lacking the TMD, all showed a reduced binding to TRC40, when they were co-expressed together with TRC40 in bacteria compared to the wild type protein (Figure 31). Related to this, an impaired membrane insertion into RM (Figure 32) was observed as well. For Leu225Arg-FS, Trp226* and $\Delta$ Val236-Phe241 no nuclear localization at the NE could be detected when using a differential permeabilization approach. Instead a more nucleoplasmic, as well as cytoplasmic distribution for emerin was monitored. The localization of these mutants to the nucleoplasm can perhaps be explained by the finding that amin acids 110-147 might be crucial for import into the nucleus. Either a non-canonical NLS can be found at aa position 110-147 of emerin, which could be bound by a transport receptor or this region could associate with an NLS-bearing partner (Östlund et al., 1999; Berk et al., 2013a).

An unexpected observation was made for the Phe240His-FS mutant. Even though a lowered membrane insertion and decreased protein purification efficiency with TRC40 was shown, it was obviously able to localize to the NE and membranes in the differential permeabilization assays (Figure 32) and the hydrophobicity of the TMD was definitely reduced (Figure 30). Additionally, the rapamycin assay showed that the protein can be found at the INM (Figure 34), albeit the extent of translocation of the GFP-FKBP12 reporter was reduced compared to wild type emerin. The discrepancy between the low efficiency in membrane insertion of Phe240His-FS using bacterially expressed protein in a complex with TRC40 and the ultimate localization of this mutant version at the NE, raises the question whether Phe240His-FS might use an alternative pathway for membrane insertion than the TRC40 mode. As mentioned above, the hydrophobicity is highly reduced for this mutant and an assisted pathway for tail-anchored protein insertion like the Hsc70/Hsp40-based pathway could be used like it was reported above for the tail-anchored protein PTP1B (Brambillasca et al., 2006). To address the potential role of the chaperone-assisted pathway in the ER insertion of the emerin mutant Phe240His-FS, reticulocyte lysates could be depleted for Hsc70/Hsp40 and tested for post-translational membrane insertion compared to control, TRC40- and SRP-depleted lysates. Alternatively, co-localization studies or proximity ligation assays for Hsc70/Hsp40 and emerin could be performed.

Furthermore, the Pro183Thr and Pro183His point mutations of emerin revealed a reduced membrane integration capability, as opposed to this a localization at the NE, meaning the INM, was confirmed for these mutants by differential permeabilization and a change in FKBP12-GFP reporter protein distribution in the rapamycin assay (Figure 34).

Moreover, for both mutants in some cells additionally to the membrane distribution, a punctate pattern was observed. After transient expression of these mutants, a partial co-localization of these dots with the autophagy and lysosomal marker Lamp2, could be seen (data not shown). The referred dots could potentially be places, to which mutated emerin mislocalize. 
Regarding the hydrophobicity of both mutants compared to the wild type protein, it can be said that they are equally hydrophobic. In fact, even a single amino acid change upstream the TMD can obviously affect the membrane integration capacity and localization of emerin. With regard to the aggregates observed in some cells, a recent study reported both mutations being responsible for oligomerization, aggregation and mitochondrial localization of emerin (Herrada et al., 2015).

Additionally, Lee et al. (2001) showed the capacity of emerin to bind lamin A and the DNA-binding factor BAF to be unaffected by this mutation. Further, it was proposed that the disease-relevance for these mutants might be explained by the disruption of a binding domain in the last third of emerin to a yet unidentified binding partner.

Another analyzed emerin mutant had a point mutation (Gln228His) inside the TMD. This substitution of only one aa resulted in a significantly reduced membrane integration capacity (Figure 32). Targeting to the INM was still possible, even though the rapamycin-assay revealed an incomplete shift of the GFP-FKBP12 reporter to the INM. Thus, the mutant can reach the INM but compared to the wild type maybe not to the same extent, which could be seen by the number of cells responding to the rapamycin treatment (Table 4). Moreover, a specific localization of the mutant to one side of the nucleus was often seen for mCherry- or HA-emerin Gln228His. Due to the pattern observed, it was tested for a possible co-localization with the Golgi-marker GM 130, which is known to cycle between ERGIC and cis-Golgi (Barr et al., 1998). Indeed, a considerable fraction of the protein co-localized with the Golgi apparatus (data not shown). Perhaps mutant emerin is localized at the ERGIC/Golgi compartment and modified or processed there until an unknown co-factor mediates the transport to the INM. Hypothetically, the TA-protein VAPB could play a role in transport of this mutant emerin from ERGIC to the NE, because VAPB has been implicated in the retrograde membrane protein transport of wild type emerin and Nup214 from ERGIC to the NE (Tran et al., 2012).

Having analyzed these different emerin mutants for membrane insertion and final targeting to the INM, especially the mutant with a single aa change inside the TMD (Gln228His) or a shortened version of emerin (Phe240His-FS) were still able to localize to the INM, although results of the performed TRC40-based protein expression showed the amount of mutant emerin Phe240His-FS to be in complex with TRC40 much lower than for wild type emerin. The membrane insertion experiments for Phe240His-FS showed only a little amount of integrated protein. For emerin GIn228His a complex with TRC40 could be obtained and the membrane integration was only slightly reduced compared to wild type emerin. Therefore, it was not surprising to find emerin GIn228His localizing to the INM, but the presence at the INM was less than expected. Probably somehow the region around residue 228 could be crucial for the efficiency of targeting. Thus, concluded from the observations of the differential permeabilization assay and the rapamycinINM targeting experiments possibly the mode of membrane protein integration at the ER could affect the efficiency with which the protein is targeted to the INM.

Emerin, as an inner nuclear membrane protein, was implied in several cellular functions like gene expression regulation, mRNA splicing, signaling, mechanosensing via an indirect connection to the cytoskeleton, nuclear architecture as well as regulating autophagy (Demmerle et al., 2013; Holaska and Wilson, 2007; Deroyer et al., 2014). It was also proposed to have a general function in anchoring protein complexes at the INM (Bengtsson and Wilson, 2004) and reported to have self-interacting properties (Berk et al., 2014). How crucial the correct targeting of INM-proteins and especially emerin is, can be seen for the described emerin mutations, where differences in 
localization can result in a neuromuscular disease like X-linked EDMD. In general, the stability of emerin at the INM could be altered in different mutants compared to the wild type. The stability of course is strongly affected by the interaction of emerin with several binding partners at the INM. As a consequence, emerin could be found more abundant at the ONM and the ER. A loss of emerin at the INM, disrupted or at least reduced binding of emerin to its interaction partners at the INM and mislocalization of emerin variants to other organelles or aggregate formation could contribute to the pathologic phenotypes of EDMD. As emerin has been characterized as a tailanchored protein, it is important to know that TA-proteins can mislocalize to the outer mitochondrial membrane (Schuldiner et al., 2008). TA-proteins localized to mitochondria were shown to have highly toxic potential and special AAA-ATPases were reported to be required for maintenance of mitochondrial integrity (Okreglak and Walter, 2014; Chen et al., 2014b). All possible reasons for the outcome of diseases connected to emerin like the loss of protein, mislocalization or the lack of interactions with binding partners at the INM need to be considered when elucidating the targeting of emerin to the INM for wild type as well as for EDMD mutants.

Altogether, the membrane insertion mechanism of emerin was shown to depend on the TRC40mediated post-translational pathway. It was possible to target emerin to the INM and verify its localization specifically at the INM by establishing a rapamycin-based localization assay. Concomitantly, emerin mutants implied in EDMD were analyzed for their membrane integration properties and targeting to the INM. According to the results obtained from these experiments, there are indications that the efficiency of ER membrane insertion might have an influence on proper targeting to the INM and in turn a weak binding of mutated emerin to TRC40 not necessarily results in abrogated localization to the nuclear envelope. Besides emerin, which was the model protein this work focused on, other putative TA-INM proteins like Lap2 $\beta$, LEMD1, PTP1B, VAPB or LRRC59 were characterized along these lines and all have been shown to localize to the INM. 


\subsection{Outlook}

This study provided information about the targeting of proteins to the INM focusing on the important aspect of membrane integration and the relevance of the TRC40-pathway for emerin as a tail-anchored protein.

Membrane insertion assays for emerin were performed in RM and semi-permeabilized cells. Using digitonin-permeabilized cells can be of advantage for investigating the mode of posttranslational insertion of a protein, because knockdown experiments for several pathway components can be performed and a possible influence on membrane integration can be examined directly. Accordingly, it might be helpful to gain detailed insight in the dynamics of membrane insertion in terms of spatial and temporal resolution for the substrate binding, delivery and ER-membrane integration steps.

In addition, it would be very interesting to examine in detail, how the mode and efficiency of insertion into the ER membrane would affect the targeting and localization of a TA-protein to the inner nuclear membrane. This seems especially interesting because a discrepancy between membrane integration and final localization at the INM was observed for some mutants of the TA-protein emerin.

Furthermore, the dynamics of the trafficking process of emerin and selected putative TA-INMproteins might be addressed by microscopic approaches as described by Theerthagiri et al. (2010) or Ungricht and Kutay (2015) using fluorescently tagged proteins with a protease cleavage site and a controlled cleavage process by a NusA-tagged TEV protease.

During this study, the established rapamycin-based INM-localization assay turned out to be a solid and relatively quick microscopy based method, therefore it might be used for different aspects of nuclear transport in future as well. In this work, the rapamycin assay was carried out at a low concentration with a short incubation time, nevertheless it cannot be excluded completely that other cellular pathways are affected by the rapamycin treatment. Thus, alternative modified chemical inducers for dimerization (CIDs) were developed, which are called rapalogs. The advantage of these new rapamycin analogs is, that an influence on the endogenous mTOR and other downstream pathways can be excluded. For future applications, the current rapamycin assay could be modified and photoactivatable rapalogs should be tested (Putyrski and Schultz, 2012). These compounds would allow to only activate and dimerize proteins in specific areas of the cell, which would be helpful in investigating the INM-protein trafficking.

Moreover, a combination of the in vitro import and the rapamycin assays using bacterially expressed proteins containing the FRB-portion in combination with the NLS-containing FKBP12reporter would allow to target a protein to the NE and confirm its localization at the INM. So far, mCherry-FRB-emerin in complex with TRC40 was produced in bacteria and shown to associate with membranes, most probably the ER and NE, of semi-permeabilized cells in vitro (Figure 18). Additionally, the approach would provide a possibility to reconstitute the requirements of transport to the INM for individual proteins.

With regard to the question, which model for INM-targeting emerin and the selected set of proteins favor, the TRC40 localization would need to be examined in further detail. Along these lines, it would be interesting to see, whether TRC40 would be found inside the nucleus. It would be important to analyze, whether the ER-membrane receptors WRB and CAML can be detected at the INM, as this would indicate a possible way for TA-proteins to integrate into the INM from 
within the nucleus. In this context, PLA interaction studies for various TA-INM-proteins and TRC40-pathway receptors WRB and CAML could be performed and first insights of the cellular distribution of the interaction might be gained. Potentially, a yet unidentified receptor, which can facilitate INM-protein integration, could exist at the INM. Microinjection experiments could be performed to address this possibility. For that, one option would be blocking of nuclear import by using the lectin wheat germ agglutinin (WGA) or inhibit transport through the NPCs. A fluorescently tagged TA-INM-protein of interest could then be microinjected into the nucleus and monitored for its localization in vivo.

Accordingly, the temporal and spatial aspects of trafficking to the INM could be analyzed by performing for example FRAP (fluorescence recovery after photobleaching) experiments. This would give insight into whether membrane integration occurs prior to translocation to the INM or the protein in its "soluble" state translocates and integrates directly into the INM.

INM-proteins described in this study, which were reported to be involved in very dynamic processes (e.g. VAPB, PTP1B, LRRC59), might localize at the INM "transiently". These proteins need to be further characterized in terms of trafficking to the INM. In detail, requirements for transport like dependency on soluble factors, energy or structural components of the NPC could be addressed using in vitro import assays. Furthermore, RNAi experiments of nucleoporins associated with the central or peripheral channel of the NPC or overexpression studies could be performed to also gain insights into the mechanism the protein uses for translocation to the INM. Besides the investigated proteins, other putative TA-INM proteins, which have been reported at the NE like otefin, bocksbeutel or ORP8 could be studied with the established assays.

Focusing in this study on the specific group of TA-proteins of INM-protein, which shared the common feature of a post-translational membrane insertion, was a good way to explore possible targeting pathways to the INM. Based on reports of the selected proteins being implicated in various cellular functions, a possibility for investigating proteins using different kinds of transport mechanisms was given. In long-term, the transport of multi-spanning INM-proteins like LBR or MAN1 would need to be compared to the transport of single-pass INM-proteins to identify possible preferences of each group for one of the insertion and targeting mechanisms or to establish differences in the specific requirements for both types of INM-proteins.

Gaining more insight into the molecular mechanisms of protein targeting to the INM would help to complete the picture of the INM as an important entity of the nuclear envelope. It was not only reported to have a structural function but also shown to provide a place for sequestration of transcription factors due to direct binding of INM-proteins and can therefore influence gene expression considerably (Heessen and Fornerod, 2007). Consequently, the availability of a protein at INM would control sequestering of distinct transcription factors at the INM. In case an INM-protein is lacking or mutated as described for Emery-Dreifuss muscular dystrophy (EDMD), the outcome could be an aberrant gene expression perhaps contributing to the pathology of the disease.

Overall, elucidating the transport of INM-proteins would help to get a better understanding of the complex pathologic phenotypes of laminopathies like EDMD. 


\section{REFERENCES}

Abell, B.M., Rabu, C., Leznicki, P., Young, J.C. and High, S. (2007), "Post-translational integration of tail-anchored proteins is facilitated by defined molecular chaperones", J Cell Sci, Vol. 120 No. 10, pp. 1743-1751.

Adam, S.A., Marr, R.S. and Gerace, L. (1990), "Nuclear protein import in permeabilized mammalian cells requires soluble cytoplasmic factors", J Cell Biol, Vol. 111 No. 3, pp. 807816.

Adamus, G., Arendt, A. and Hargrave, P.A. (1991), "Genetic control of antibody response to bovine rhodopsin in mice: epitope mapping of rhodopsin structure", J Neuroimmunol, Vol. 34 No. 2-3, pp. 89-97.

Aebi, M. (2013), "N-linked protein glycosylation in the ER", Biochim Biophys Acta, Vol. 1833 No. 11, pp. 2430-2437.

Akey, C.W. and Radermacher, M. (1993), "Architecture of the Xenopus nuclear pore complex revealed by three-dimensional cryo-electron microscopy", J Cell Biol, Vol. 122 No. 1, pp. 119.

Alber, F., Dokudovskaya, S., Veenhoff, L.M., Zhang, W., Kipper, J., Devos, D., Suprapto, A., KarniSchmidt, O., Williams, R., Chait, B.T., Sali, A. and Rout, M.P. (2007), "The molecular architecture of the nuclear pore complex", Nature, Vol. 450 No. 7170, pp. 695-701.

Anderie, I., Schulz, I. and Schmid, A. (2007), "Characterization of the C-terminal ER membrane anchor of PTP1B", Exp Cell Res, Vol. 313 No. 15, pp. 3189-3197.

Anderson, D.J. and Hetzer, M.W. (2008), "Reshaping of the endoplasmic reticulum limits the rate for nuclear envelope formation", The Journal of Cell Biology, Vol. 182 No. 5, pp. 911-924.

Anderson, D.J., Vargas, J.D., Hsiao, J.P. and Hetzer, M.W. (2009), "Recruitment of functionally distinct membrane proteins to chromatin mediates nuclear envelope formation in vivo", J Cell Biol, Vol. 186 No. 2, pp. 183-191.

Antonin, W., Ungricht, R. and Kutay, U. (2011), "Traversing the NPC along the pore membrane: Targeting of membrane proteins to the INM", Nucleus, Vol. 2 No. 2, pp. 87-91.

Appen, A. von, Kosinski, J., Sparks, L., Ori, A., DiGuilio, A.L., Vollmer, B., Mackmull, M.-T., Banterle, N., Parca, L., Kastritis, P., Buczak, K., Mosalaganti, S., Hagen, W., Andres-Pons, A., Lemke, E.A., Bork, P., Antonin, W., Glavy, J.S., Bui, K.H. and Beck, M. (2015), "In situ structural analysis of the human nuclear pore complex", Nature, Vol. 526 No. 7571, pp. 140-143.

Baake, M., Bauerle, M., Doenecke, D. and Albig, W. (2001), "Core histones and linker histones are imported into the nucleus by different pathways", Eur J Cell Biol, Vol. 80 No. 11, pp. 669677.

Bakke, J. and Haj, F.G. (2015), "Protein-tyrosine phosphatase 1B substrates and metabolic regulation", Semin Cell Dev Biol, Vol. 37, pp. 58-65.

Baron, Y., Pedrioli, P.G., Tyagi, K., Johnson, C., Wood, N.T., Fountaine, D., Wightman, M. and Alexandru, G. (2014), "VAPB/ALS8 interacts with FFAT-like proteins including the p97 cofactor FAF1 and the ASNA1 ATPase", BMC Biol, Vol. 12, p. 39.

Barr, F.A., Nakamura, N. and Warren, G. (1998), "Mapping the interaction between GRASP65 and GM130, components of a protein complex involved in the stacking of Golgi cisternae", EMBO J, Vol. 17 No. 12, pp. 3258-3268. 
Barton, L.J., Soshnev, A.A. and Geyer, P.K. (2015), "Networking in the nucleus: a spotlight on LEM-domain proteins", Curr Opin Cell Biol, Vol. 34, pp. 1-8.

Bauerle, M., Doenecke, D. and Albig, W. (2002), "The requirement of H1 histones for a heterodimeric nuclear import receptor", J Biol Chem, Vol. 277 No. 36, pp. 32480-32489.

Beck, M., Lucic, V., Forster, F., Baumeister, W. and Medalia, O. (2007), "Snapshots of nuclear pore complexes in action captured by cryo-electron tomography", Nature, Vol. 449 No. 7162, pp. 611-615.

Beck, M., Schmidt, A., Malmstroem, J., Claassen, M., Ori, A., Szymborska, A., Herzog, F., Rinner, O., Ellenberg, J. and Aebersold, R. (2011), "The quantitative proteome of a human cell line", Mol Syst Biol, Vol. 7, p. 549.

Beilharz, T., Egan, B., Silver, P.A., Hofmann, K. and Lithgow, T. (2003), "Bipartite signals mediate subcellular targeting of tail-anchored membrane proteins in Saccharomyces cerevisiae", J Biol Chem, Vol. 278 No. 10, pp. 8219-8223.

Bengtsson, L. and Otto, H. (2008), "LUMA interacts with emerin and influences its distribution at the inner nuclear membrane", J Cell Sci, Vol. 121 No. 4, pp. 536-548.

Bengtsson, L. and Wilson, K.L. (2004), "Multiple and surprising new functions for emerin, a nuclear membrane protein", Curr Opin Cell Biol, Vol. 16 No. 1, pp. 73-79.

Berk, J.M., Maitra, S., Dawdy, A.W., Shabanowitz, J., Hunt, D.F. and Wilson, K.L. (2013a), “OLinked $\beta-N$-acetylglucosamine (O-GlcNAc) regulates emerin binding to barrier to autointegration factor (BAF) in a chromatin- and lamin B-enriched "niche"”, J Biol Chem, Vol. 288 No. 42, pp. 30192-30209.

Berk, J.M., Simon, D.N., Jenkins-Houk, C.R., Westerbeck, J.W., Gronning-Wang, L.M., Carlson, C.R. and Wilson, K.L. (2014), "The molecular basis of emerin-emerin and emerin-BAF interactions", J Cell Sci, Vol. 127 No. 18, pp. 3956-3969.

Berk, J.M., Tifft, K.E. and Wilson, K.L. (2013b), "The nuclear envelope LEM-domain protein emerin", Nucleus, Vol. 4 No. 4, pp. 298-314.

Betz, C. and Hall, M.N. (2013), "Where is mTOR and what is it doing there?", J Cell Biol, Vol. 203 No. 4, pp. 563-574.

Bischoff, F.R. and Ponstingl, H. (1991), "Catalysis of guanine nucleotide exchange on Ran by the mitotic regulator RCC1", Nature, Vol. 354 No. 6348, pp. 80-82.

Blobel, G. and Sabatini, D.D. (1970), "Controlled proteolysis of nascent polypeptides in rat liver cell fractions. I. Location of the polypeptides within ribosomes", J Cell Biol, Vol. 45 No. 1, pp. 130-145.

Boni, A., Politi, A.Z., Strnad, P., Xiang, W., Hossain, M.J. and Ellenberg, J. (2015), "Live imaging and modeling of inner nuclear membrane targeting reveals its molecular requirements in mammalian cells", J Cell Biol, Vol. 209 No. 5, pp. 705-720.

Borgese, N., Gazzoni, I., Barberi, M., Colombo, S. and Pedrazzini, E. (2001), "Targeting of a tailanchored protein to endoplasmic reticulum and mitochondrial outer membrane by independent but competing pathways", Mol Biol Cell, Vol. 12 No. 8, pp. 2482-2496.

Borgese, N., Colombo, S. and Pedrazzini, E. (2003), "The tale of tail-anchored proteins: coming from the cytosol and looking for a membrane", J Cell Biol, Vol. 161 No. 6, pp. 1013-1019.

Borgese, N. and Fasana, E. (2011), "Targeting pathways of C-tail-anchored proteins", Biochim Biophys Acta, Vol. 1808 No. 3, pp. 937-946. 
Borgese, N. and Righi, M. (2010), "Remote origins of tail-anchored proteins", Traffic, Vol. 11 No. 7, pp. 877-885.

Brambillasca, S., Yabal, M., Makarow, M. and Borgese, N. (2006), "Unassisted translocation of large polypeptide domains across phospholipid bilayers", J Cell Biol, Vol. 175 No. 5, pp. 767777.

Brambillasca, S., Yabal, M., Soffientini, P., Stefanovic, S., Makarow, M., Hegde, R.S. and Borgese, N. (2005), "Transmembrane topogenesis of a tail-anchored protein is modulated by membrane lipid composition", EMBO J, Vol. 24 No. 14, pp. 2533-2542.

Braunagel, S.C., Williamson, S.T., Ding, Q., Wu, X. and Summers, M.D. (2007), "Early sorting of inner nuclear membrane proteins is conserved", Proc Natl Acad Sci USA, Vol. 104 No. 22, pp. 9307-9312.

Brobeil, A., Viard, M., Petri, M.K., Steger, K., Tag, C. and Wimmer, M. (2015), "Memory and PTPIP51 - A new protein in hippocampus and cerebellum", Mol Cell Neurosci, Vol. 64, pp. 61-73.

Brown-Shimer, S., Johnson, K.A., Lawrence, J.B., Johnson, C., Bruskin, A., Green, N.R. and Hill, D.E. (1990), "Molecular cloning and chromosome mapping of the human gene encoding protein phosphotyrosyl phosphatase 1B", Proc Natl Acad Sci USA, Vol. 87 No. 13, pp. 5148 5152.

Buch, C., Lindberg, R., Figueroa, R., Gudise, S., Onischenko, E. and Hallberg, E. (2009), "An integral protein of the inner nuclear membrane localizes to the mitotic spindle in mammalian cells", J Cell Sci, Vol. 122 Pt 12, pp. 2100-2107.

Burke, B. and Stewart, C.L. (2013), "The nuclear lamins: flexibility in function", Nat Rev Mol Cell Biol, Vol. 14 No. 1, pp. 13-24.

Burns, L.T. and Wente, S.R. (2012), "Trafficking to uncharted territory of the nuclear envelope", Curr Opin Cell Biol, Vol. 24 No. 3, pp. 341-349.

Buszard, B.J., Johnson, T.K., Meng, T.-C., Burke, R., Warr, C.G. and Tiganis, T. (2013), "The nucleus- and endoplasmic reticulum-targeted forms of protein tyrosine phosphatase $61 \mathrm{~F}$ regulate Drosophila growth, life span, and fecundity", Mol Cell Biol, Vol. 33 No. 7, pp. 13451356.

Cartegni, L., Di Barletta, Barresi, R., Squarzoni, S., Sabatelli, P., Maraldi, N., Mora, M., Di Blasi, C., Cornelio, F., Merlini, L., Villa, A., Cobianchi, F. and Toniolo, D. (1997), "Heart-specific localization of emerin: new insights into Emery-Dreifuss muscular dystrophy", Hum Mol Genet, Vol. 6 No. 13, pp. 2257-2264.

Charneau, P., Mirambeau, G., Roux, P., Paulous, S., Buc, H. and Clavel, F. (1994), "HIV-1 reverse transcription. A termination step at the center of the genome", J Mol Biol, Vol. 241 No. 5, pp. 651-662.

Chen, C. and Okayama, H. (1987), "High-efficiency transformation of mammalian cells by plasmid DNA", Mol Cell Biol, Vol. 7 No. 8, pp. 2745-2752.

Chen, J., Zheng, X.F., Brown, E.J. and Schreiber, S.L. (1995), "Identification of an 11-kDa FKBP12rapamycin-binding domain within the 289-kDa FKBP12-rapamycin-associated protein and characterization of a critical serine residue", Proc Natl Acad Sci USA, Vol. 92 No. 11, pp. 4947-4951.

Chen, Y., Sanchez, A., Rubio, M.E., Kohl, T., Pardo, L.A. and Stuhmer, W. (2011), "Functional K(v)10.1 channels localize to the inner nuclear membrane", PLoS One, Vol. 6 No. 5, e19257. 
Chen, Y., Pieuchot, L., Loh, R.A., Yang, J., Kari, Teuku Mahfuzh Aufar, Wong, J.Y. and Jedd, G. (2014a), "Hydrophobic handoff for direct delivery of peroxisome tail-anchored proteins", Nat Commun, Vol. 5, p. 5790.

Chen, Y.C., Umanah, G.K., Dephoure, N., Andrabi, S.A., Gygi, S.P., Dawson, T.M., Dawson, V.L. and Rutter, J. (2014b), "Msp1/ATAD1 maintains mitochondrial function by facilitating the degradation of mislocalized tail-anchored proteins", EMBO J, Vol. 33 No. 14, pp. 1548-1564.

Chernoff, J., Schievella, A.R., Jost, C.A., Erikson, R.L. and Neel, B.G. (1990), "Cloning of a cDNA for a major human protein-tyrosine-phosphatase", Proc Natl Acad Sci USA, Vol. 87 No. 7 , pp. 2735-2739.

Chi, N.C., Adam, E.J. and Adam, S.A. (1995), "Sequence and characterization of cytoplasmic nuclear protein import factor p97", J Cell Biol, Vol. 130 No. 2, pp. 265-274.

Chiu, M.I., Katz, H. and Berlin, V. (1994), "RAPT1, a mammalian homolog of yeast Tor, interacts with the FKBP12/rapamycin complex", Proc Natl Acad Sci USA, Vol. 91 No. 26, pp. 1257412578.

Cho, I., Jackson, M.R. and Swift, J. (2016), "Roles of Cross-Membrane Transport and Signaling in the Maintenance of Cellular Homeostasis", Cell Mol Bioeng, Vol. 9, pp. 234-246.

Choi, J., Chen, J., Schreiber, S.L. and Clardy, J. (1996), "Structure of the FKBP12-rapamycin complex interacting with the binding domain of human FRAP", Science, Vol. 273 No. 5272, pp. 239-242.

Colombo, S.F., Cardani, S., Maroli, A., Vitiello, A., Soffientini, P., Crespi, A., Bram, R.F., Benfante, R. and Borgese, N. (2016), "Tail-anchored Protein Insertion in Mammals: Function and reciprocal interactions of the two subunits of the TRC40 receptor", J Biol Chem, Vol. 291 No. 29, pp. 15292-15306.

Colombo, S.F., Longhi, R. and Borgese, N. (2009), "The role of cytosolic proteins in the insertion of tail-anchored proteins into phospholipid bilayers", J Cell Sci, Vol. 122 No. 14, pp. 23832392.

Cooper, G.M. (2000), The cell: A molecular approach, 2nd ed, ASM Press, Sunderland Mass., The nucleolus.

Crisp, M., Liu, Q., Roux, K., Rattner, J.B., Shanahan, C., Burke, B., Stahl, P.D. and Hodzic, D. (2006), "Coupling of the nucleus and cytoplasm: role of the LINC complex", J Cell Biol, Vol. 172 No. 1, pp. 41-53.

Cronshaw, J.M., Krutchinsky, A.N., Zhang, W., Chait, B.T. and Matunis, M.J. (2002), "Proteomic analysis of the mammalian nuclear pore complex", J Cell Biol, Vol. 158 No. 5, pp. 915-927.

Daneholt, B. (2001), "Assembly and transport of a premessenger RNP particle", Proc Natl Acad Sci USA, Vol. 98 No. 13, pp. 7012-7017.

Dauer, W.T. and Worman, H.J. (2009), "The nuclear envelope as a signaling node in development and disease", Dev Cell, Vol. 17 No. 5, pp. 626-638.

de Las Heras, Jose I, Meinke, P., Batrakou, D.G., Srsen, V., Zuleger, N., Kerr, A.R. and Schirmer, E.C. (2013), "Tissue specificity in the nuclear envelope supports its functional complexity", Nucleus, Vol. 4 No. 6, pp. 460-477.

Dechat, T., Vlcek, S. and Foisner, R. (2000), "Review: lamina-associated polypeptide 2 isoforms and related proteins in cell cycle-dependent nuclear structure dynamics", J Struct Biol, Vol. 129 No. 2-3, pp. 335-345. 
Deidda, I., Galizzi, G., Passantino, R., Cascio, C., Russo, D., Colletti, T., La Bella, V. and Guarneri, P. (2014), "Expression of vesicle-associated membrane-protein-associated protein B cleavage products in peripheral blood leukocytes and cerebrospinal fluid of patients with sporadic amyotrophic lateral sclerosis", Eur J Neurol, Vol. 21 No. 3, pp. 478-485.

Demmerle, J., Koch, A.J. and Holaska, J.M. (2013), "Emerin and histone deacetylase 3 (HDAC3) cooperatively regulate expression and nuclear positions of MyoD, Myf5, and Pax7 genes during myogenesis", Chromosome Res, Vol. 21 No. 8, pp. 765-779.

Deroyer, C., Rénert, A.-F., Merville, M.-P. and Fillet, M. (2014), "New role for EMD (emerin), a key inner nuclear membrane protein, as an enhancer of autophagosome formation in the C16ceramide autophagy pathway", Autophagy, Vol. 10 No. 7, pp. 1229-1240.

Doenecke, D. and Tonjes, R. (1986), "Differential distribution of lysine and arginine residues in the closely related histones $\mathrm{H} 1$ and H5. Analysis of a human $\mathrm{H} 1$ gene", J Mol Biol, Vol. 187 No. 3, pp. 461-464.

Dreger, M., Bengtsson, L., Schoneberg, T., Otto, H. and Hucho, F. (2001), “Nuclear envelope proteomics: novel integral membrane proteins of the inner nuclear membrane", Proc Natl Acad Sci USA, Vol. 98 No. 21, pp. 11943-11948.

Eden, E.R., White, I.J., Tsapara, A. and Futter, C.E. (2010), “Membrane contacts between endosomes and ER provide sites for PTP1B-epidermal growth factor receptor interaction", Nat Cell Biol, Vol. 12 No. 3, pp. 267-272.

Ellenberg, J., Siggia, E.D., Moreira, J.E., Smith, C.L., Presley, J.F., Worman, H.J. and LippincottSchwartz, J. (1997), "Nuclear membrane dynamics and reassembly in living cells: targeting of an inner nuclear membrane protein in interphase and mitosis", J Cell Biol, Vol. 138 No. 6, pp. 1193-1206.

Ellis, J.A., Yates, JR, Kendrick-Jones, J. and Brown, C.A. (1999), "Changes at P183 of emerin weaken its protein-protein interactions resulting in X-linked Emery-Dreifuss muscular dystrophy", Hum Genet, Vol. 104 No. 3, pp. 262-268.

Emery, A.E. and Dreifuss, F.E. (1966), "Unusual type of benign X-linked muscular dystrophy", J Neurol Neurosurg Psychiatry, Vol. 29 No. 4, pp. 338-342.

Emery, A.E.H. (1989), "Emery-Dreifuss syndrome”, J Med Genet., Vol. 26 No. 10, pp. 637-641. Fasana, E., Fossati, M., Ruggiano, A., Brambillasca, S., Hoogenraad, C.C., Navone, F., Francolini, M. and Borgese, N. (2010), "A VAPB mutant linked to amyotrophic lateral sclerosis generates a novel form of organized smooth endoplasmic reticulum", FASEB J, Vol. 24 No. 5, pp. 14191430.

Favaloro, V., Spasic, M., Schwappach, B. and Dobberstein, B. (2008), "Distinct targeting pathways for the membrane insertion of tail-anchored (TA) proteins", J Cell Sci, Vol. 121 No. 11, pp. 1832-1840.

Favaloro, V., Vilardi, F., Schlecht, R., Mayer, M.P. and Dobberstein, B. (2010), "Asna1/TRC40mediated membrane insertion of tail-anchored proteins", J Cell Sci, Vol. 123 No. 9, pp. 15221530.

Feldherr, C.M., Kallenbach, E. and Schultz, N. (1984), "Movement of a karyophilic protein through the nuclear pores of oocytes", J Cell Biol, Vol. 99 No. 6, pp. 2216-2222. 
Flint, A.J., Gebbink, M.F., Franza, B.R., JR, Hill, D.E. and Tonks, N.K. (1993), "Multi-site phosphorylation of the protein tyrosine phosphatase, PTP1B: identification of cell cycle regulated and phorbol ester stimulated sites of phosphorylation", EMBO J, Vol. 12 No. 5, pp. 19371946.

Foisner, R. and Gerace, L. (1993), "Integral membrane proteins of the nuclear envelope interact with lamins and chromosomes, and binding is modulated by mitotic phosphorylation", Cell, Vol. 73 No. 7, pp. 1267-1279.

Fornerod, M., Ohno, M., Yoshida, M. and Mattaj, I.W. (1997), "CRM1 is an export receptor for leucine-rich nuclear export signals", Cell, Vol. 90 No. 6, pp. 1051-1060.

Frangioni, J.V., Beahm, P.H., Shifrin, V., Jost, C.A. and Neel, B.G. (1992), "The nontransmembrane tyrosine phosphatase PTP-1B localizes to the endoplasmic reticulum via its 35 amino acid Cterminal sequence", Cell, Vol. 68 No. 3, pp. 545-560.

Franke, W.W., Scheer, U., Krohne, G. and Jarasch, E.D. (1981), "The nuclear envelope and the architecture of the nuclear periphery", J Cell Biol, Vol. 91 No.3 Pt 2, pp. 39s-50s.

Fredriksson, S., Gullberg, M., Jarvius, J., Olsson, C., Pietras, K., Gustafsdottir, S.M., Ostman, A. and Landegren, U. (2002), "Protein detection using proximity-dependent DNA ligation assays", Nat Biotechnol, Vol. 20 No. 5, pp. 473-477.

Fueller, J., Egorov, M.V., Walther, K.A., Sabet, O., Mallah, J., Grabenbauer, M. and Kinkhabwala, A. (2015), "Subcellular Partitioning of Protein Tyrosine Phosphatase 1B to the Endoplasmic Reticulum and Mitochondria Depends Sensitively on the Composition of Its Tail Anchor", PLoS One, Vol. 10 No. 10, e0139429.

Fujiki, Y., Hubbard, A.L., Fowler, S. and Lazarow, P.B. (1982), "Isolation of intracellular membranes by means of sodium carbonate treatment: application to endoplasmic reticulum", JCell Biol, Vol. 93 No. 1, pp. 97-102.

Furukawa, K. (1998), "The Major Nuclear Envelope Targeting Domain of LAP2 Coincides with Its Lamin Binding Region but Is Distinct from Its Chromatin Interaction Domain", J Biol Chem, Vol. 273 No. 7, pp. 4213-4219.

Furukawa, K. (1999), "LAP2 binding protein 1 (L2BP1/BAF) is a candidate mediator of LAP2chromatin interaction", J Cell Sci, Vol. 112 No.15, pp. 2485-2492.

Furukawa, K., Fritze, C.E. and Gerace, L. (1998), "The major nuclear envelope targeting domain of LAP2 coincides with its lamin binding region but is distinct from its chromatin interaction domain", J Biol Chem, Vol. 273 No. 7, pp. 4213-4219.

Furukawa, K., Glass, C. and Kondo, T. (1997), "Characterization of the chromatin binding activity of lamina-associated polypeptide (LAP) 2", Biochem Biophys Res Commun, Vol. 238 No. 1, pp. 240-246.

Furukawa, K., Panté, N., Aebi, U. and Gerace, L. (1995), "Cloning of a cDNA for lamina-associated polypeptide 2 (LAP2) and identification of regions that specify targeting to the nuclear envelope", EMBO J, Vol. 14 No. 8, pp. 1626-1636.

Gant, T.M., Harris, C.A. and Wilson, K.L. (1999), "Roles of LAP2 proteins in nuclear assembly and DNA replication: truncated LAP2beta proteins alter lamina assembly, envelope formation, nuclear size, and DNA replication efficiency in Xenopus laevis extracts", J Cell Biol, Vol. 144 No. 6, pp. 1083-1096. 
Gerace, L., Blum, A. and Blobel, G. (1978), "Immunocytochemical localization of the major polypeptides of the nuclear pore complex-lamina fraction. Interphase and mitotic distribution", J Cell Biol, Vol. 79 No.2 Pt 1, pp. 546-566.

Gerace, L. and Burke, B. (1988), "Functional organization of the nuclear envelope", Annu Rev Cell Biol, Vol. 4, pp. 335-374.

Ghafouri-Fard, S., Ousati Ashtiani, Z., Sabah Golian, B., Hasheminasab, S.-M. and Modarressi, M.H. (2010), "Expression of two testis-specific genes, SPATA19 and LEMD1, in prostate cancer", Arch Med Res, Vol. 41 No. 3, pp. 195-200.

Gkogkas, C., Wardrope, C., Hannah, M. and Skehel, P. (2011), "The ALS8-associated mutant VAPBP56S is resistant to proteolysis in neurons", J Neurochem, Vol. 117 No. 2, pp. 286-294.

Gomez-Cavazos, J.S. and Hetzer, M.W. (2012), "Outfits for different occasions: tissue-specific roles of Nuclear Envelope proteins", Curr Opin Cell Biol, Vol. 24 No. 6, pp. 775-783.

Gonzalez, J.M. and Andres, V. (2011), "Synthesis, transport and incorporation into the nuclear envelope of A-type lamins and inner nuclear membrane proteins", Biochem Soc Trans, Vol. 39 No. 6, pp. 1758-1763.

Görlich, D., Kostka, S., Kraft, R., Dingwall, C., Laskey, R.A., Hartmann, E. and Prehn, S. (1995), "Two different subunits of importin cooperate to recognize nuclear localization signals and bind them to the nuclear envelope", Curr Biol, Vol. 5 No. 4, pp. 383-392.

Görlich, D., Pante, N., Kutay, U., Aebi, U. and Bischoff, F.R. (1996), "Identification of different roles for RanGDP and RanGTP in nuclear protein import”, EMBO J, Vol. 15 No. 20, pp. 55845594.

Görlich, D. and Rapoport, T.A. (1993), "Protein translocation into proteoliposomes reconstituted from purified components of the endoplasmic reticulum membrane", Cell, Vol. 75 No. 4, pp. 615-630.

Guan, K.L., Haun, R.S., Watson, S.J., Geahlen, R.L. and Dixon, J.E. (1990), “Cloning and expression of a protein-tyrosine-phosphatase", Proc Natl Acad Sci USA, Vol. 87 No. 4, pp. 1501-1505.

Haque, F., Lloyd, D.J., Smallwood, D.T., Dent, C.L., Shanahan, C.M., Fry, A.M., Trembath, R.C. and Shackleton, S. (2006), "SUN1 interacts with nuclear lamin A and cytoplasmic nesprins to provide a physical connection between the nuclear lamina and the cytoskeleton", Mol Cell Biol, Vol. 26 No. 10, pp. 3738-3751.

Haque, F., Mazzeo, D., Patel, J.T., Smallwood, D.T., Ellis, J.A., Shanahan, C.M. and Shackleton, S. (2010), "Mammalian SUN protein interaction networks at the inner nuclear membrane and their role in laminopathy disease processes", J Biol Chem, Vol. 285 No. 5, pp. 3487-3498.

Haraguchi, T., Holaska, J.M., Yamane, M., Koujin, T., Hashiguchi, N., Mori, C., Wilson, K.L. and Hiraoka, Y. (2004), "Emerin binding to Btf, a death-promoting transcriptional repressor, is disrupted by a missense mutation that causes Emery-Dreifuss muscular dystrophy", Eur J Biochem, Vol. 271 No. 5, pp. 1035-1045.

Haraguchi, T., Koujin, T., Hayakawa, T., Kaneda, T., Tsutsumi, C., Imamoto, N., Akazawa, C., Sukegawa, J., Yoneda, Y. and Hiraoka, Y. (2000), "Live fluorescence imaging reveals early recruitment of emerin, LBR, RanBP2, and Nup153 to reforming functional nuclear envelopes", J Cell Sci, 113 No. 5, pp. 779-794.

Haraguchi, T., Koujin, T., Segura-Totten, M., Lee, K.K., Matsuoka, Y., Yoneda, Y., Wilson, K.L. and Hiraoka, Y. (2001), "BAF is required for emerin assembly into the reforming nuclear envelope", J Cell Sci, Vol. 114 No. 24, pp. 4575-4585. 
Haruki, H., Nishikawa, J. and Laemmli, U.K. (2008), "The anchor-away technique: rapid, conditional establishment of yeast mutant phenotypes", Mol Cell, Vol. 31 No. 6, pp. 925-932.

Heessen, S. and Fornerod, M. (2007), "The inner nuclear envelope as a transcription factor resting place", EMBO Rep, Vol. 8 No. 10, pp. 914-919.

Herrada, I., Samson, C., Velours, C., Renault, L., Ostlund, C., Chervy, P., Puchkov, D., Worman, H.J., Buendia, B. and Zinn-Justin, S. (2015), "Muscular Dystrophy Mutations Impair the Nuclear Envelope Emerin Self-assembly Properties", ACS Chem Biol, Vol. 10 No. 12, pp. 27332742.

Hessa, T., Meindl-Beinker, N.M., Bernsel, A., Kim, H., Sato, Y., Lerch-Bader, M., Nilsson, I., White, S.H. and Heijne, G. von (2007), "Molecular code for transmembrane-helix recognition by the Sec61 translocon", Nature, Vol. 450 No. 7172, pp. 1026-1030.

Hessa, T., Sharma, A., Mariappan, M., Eshleman, H.D., Gutierrez, E. and Hegde, R.S. (2011), "Protein targeting and degradation are coupled for elimination of mislocalized proteins", Nature, Vol. 475 No. 7356, pp. 394-397.

Hinshaw, J.E., Carragher, B.O. and Milligan, R.A. (1992), "Architecture and design of the nuclear pore complex", Cell, Vol. 69 No. 7, pp. 1133-1141.

Holaska, J.M. and Wilson, K.L. (2007), "An emerin "proteome": purification of distinct emerincontaining complexes from HeLa cells suggests molecular basis for diverse roles including gene regulation, mRNA splicing, signaling, mechanosensing, and nuclear architecture", Biochemistry, Vol. 46 No. 30, pp. 8897-8908.

Holaska, J.M., Wilson, K.L. and Mansharamani, M. (2002), "The nuclear envelope, lamins and nuclear assembly", Curr Opin Cell Biol, Vol. 14 No. 3, pp. 357-364.

Holmer, L. and Worman, H.J. (2001), "Inner nuclear membrane proteins: functions and targeting", Cell Mol Life Sci, Vol. 58 No.12-13, pp. 1741-1747.

Hu, J., Li, J., Qian, X., Denic, V. and Sha, B. (2009), "The crystal structures of yeast Get3 suggest a mechanism for tail-anchored protein membrane insertion", PLoS One, Vol. 4 No. 11, e8061.

Hülsmann, B.B., Labokha, A.A. and Gorlich, D. (2012), "The permeability of reconstituted nuclear pores provides direct evidence for the selective phase model", Cell, Vol. 150 No. 4, pp. 738751.

Ichimura, T., Shindo, Y., Uda, Y., Ohsumi, T., Omata, S. and Sugano, H. (1993), “Anti-(p34 protein) antibodies inhibit ribosome binding to and protein translocation across the rough microsomal membrane", FEBS Lett, Vol. 326 No. 1-3, pp. 241-245.

Imamoto, N., Shimamoto, T., Takao, T., Tachibana, T., Kose, S., Matsubae, M., Sekimoto, T., Shimonishi, Y. and Yoneda, Y. (1995), "In vivo evidence for involvement of a 58 kDa component of nuclear pore-targeting complex in nuclear protein import", EMBO J, Vol. 14 No. 15, pp. 3617-3626.

Jadhav, B., McKenna, M., Johnson, N., High, S., Sinning, I. and Pool, M.R. (2015), "Mammalian SRP receptor switches the Sec61 translocase from Sec62 to SRP-dependent translocation", Nat Commun, Vol. 6, p. 10133.

Johnson, A.W., Lund, E. and Dahlberg, J. (2002), "Nuclear export of ribosomal subunits", Trends Biochem Sci., Vol. 27 No. 11, pp. 580-585.

Johnson, N., Powis, K. and High, S. (2013), "Post-translational translocation into the endoplasmic reticulum", Biochim Biophys Acta, Vol. 1833 No. 11, pp. 2403-2409. 
Kabachinski, G. and Schwartz, T.U. (2015), "The nuclear pore complex - structure and function at a glance", J Cell Sci, Vol. 128 No. 3, pp. 423-429.

Kalbfleisch, T., Cambon, A. and Wattenberg, B.W. (2007), "A bioinformatics approach to identifying tail-anchored proteins in the human genome", Traffic, Vol. 8 No. 12, pp. 16871694.

Katta, S.S., Smoyer, C.J. and Jaspersen, S.L. (2014), "Destination: inner nuclear membrane", Trends Cell Biol, Vol. 24 No. 4, pp. 221-229.

Keenan, R.J., Freymann, D.M., Stroud, R.M. and Walter, P. (2001), "The signal recognition particle", Annu Rev Biochem, Vol. 70, pp. 755-775.

Kehlenbach, R.H., Dickmanns, A. and Gerace, L. (1998), "Nucleocytoplasmic shuttling factors including Ran and CRM1 mediate nuclear export of NFAT In vitro", J Cell Biol, Vol. 141 No. 4, pp. 863-874.

Kim, H.-J., Hwang, S.-H., Han, M.-E., Baek, S., Sim, H.-E., Yoon, S., Baek, S.-Y., Kim, B.-S., Kim, J.-H., Kim, S.-Y. and Oh, S.-O. (2012), "LAP2 Is Widely Overexpressed in Diverse Digestive Tract Cancers and Regulates Motility of Cancer Cells", PLoS One, Vol. 7 No. 6, e39482.

King, M.C., Lusk, C.P. and Blobel, G. (2006), "Karyopherin-mediated import of integral inner nuclear membrane proteins", Nature, Vol. 442 No. 7106, pp. 1003-1007.

Köhler, A. and Hurt, E. (2007), "Exporting RNA from the nucleus to the cytoplasm", Nat Rev Mol Cell Biol, Vol. 8 No. 10, pp. 761-773.

Korfali, N., Wilkie, G.S., Swanson, S.K., Srsen, V., Las Heras, J. de, Batrakou, D.G., Malik, P., Zuleger, N., Kerr, A.R.W., Florens, L. and Schirmer, E.C. (2012), "The nuclear envelope proteome differs notably between tissues", Nucleus, Vol. 3 No. 6, pp. 552-564.

Kriechbaumer, V., Shaw, R., Mukherjee, J., Bowsher, C.G., Harrison, A.-M. and Abell, B.M. (2009), "Subcellular distribution of tail-anchored proteins in Arabidopsis", Traffic, Vol. 10 No. 12, pp. 1753-1764.

Kuchay, S.M., Kim, N., Grunz, E.A., Fay, W.P. and Chishti, A.H. (2007), "Double knockouts reveal that protein tyrosine phosphatase $1 \mathrm{~B}$ is a physiological target of calpain-1 in platelets", Mol Cell Biol, Vol. 27 No. 17, pp. 6038-6052.

Kutay, U., Ahnert-Hilger, G., Hartmann, E., Wiedenmann, B. and Rapoport, T.A. (1995), "Transport route for synaptobrevin via a novel pathway of insertion into the endoplasmic reticulum membrane", EMBO J, Vol. 14 No. 2, pp. 217-223.

Kutay, U., Hartmann, E. and RAPOPORT, T. (1993), "A class of membrane proteins with a Cterminal anchor", Trends Cell Biol, Vol. 3 No. 3, pp. 72-75.

Kutay, U., Lipowsky, G., Izaurralde, E., Bischoff, F.R., Schwarzmaier, P., Hartmann, E. and Gorlich, D. (1998), "Identification of a tRNA-specific nuclear export receptor", Mol Cell, Vol. 1 No. 3, pp. 359-369.

La Banaszynski, Liu, C.W. and Wandless, T.J. (2005), "Characterization of the FKBP.rapamycin.FRB ternary complex", J Am Chem Soc, Vol. 127 No. 13, pp. 4715-4721.

La Cour, T., Gupta, R., Rapacki, K., Skriver, K., Poulsen, F.M. and Brunak, S. (2003), "NESbase version 1.0: a database of nuclear export signals", Nucleic Acids Res, Vol. 31 No. 1, pp. 393396.

Laba, J.K., Steen, A., Popken, P., Chernova, A., Poolman, B. and Veenhoff, L.M. (2015), "Active Nuclear Import of Membrane Proteins Revisited", Cells, Vol. 4 No. 4, pp. 653-673. 
Laba, J.K., Steen, A. and Veenhoff, L.M. (2014), "Traffic to the inner membrane of the nuclear envelope", Curr Opin Cell Biol, Vol. 28, pp. 36-45.

Laemmli, U.K. (1970), "Cleavage of structural proteins during the assembly of the head of bacteriophage T4", Nature, Vol. 227 No. 5259, pp. 680-685.

Lange, A., Mills, R.E., Lange, C.J., Stewart, M., Devine, S.E. and Corbett, A.H. (2007), "Classical nuclear localization signals: definition, function, and interaction with importin alpha", J Biol Chem, Vol. 282 No. 8, pp. 5101-5105.

Lee, K.K., Haraguchi, T., Lee, R.S., Koujin, T., Hiraoka, Y. and Wilson, K.L. (2001), "Distinct functional domains in emerin bind lamin A and DNA-bridging protein BAF", J Cell Sci, Vol. 114 No. 24, pp. 4567-4573.

Lev, S., Halevy, D.B., Peretti, D. and Dahan, N. (2008), "The VAP protein family: from cellular functions to motor neuron disease", Trends in Cell Biology, Vol. 18 No. 6, pp. 282-290.

Leznicki, P., Warwicker, J. and High, S. (2011), "A biochemical analysis of the constraints of tailanchored protein biogenesis", Biochem J, Vol. 436 No. 3, pp. 719-727.

Liang, J., Choi, J. and Clardy, J. (1999), "Refined structure of the FKBP12-rapamycin-FRB ternary complex at 2.2 A resolution", Acta Crystallogr D Biol Crystallogr, Vol. 55 No. 4, pp. 736-744.

Lin, F., Blake, D. L., Callebaut, I., Skerjanc, I. S., Holmer, L., McBurney, M. W., Paulin-Levasseur, M. and Worman, H. J. (2000), "MAN1, an inner nuclear membrane protein that shares the LEM domain with lamina-associated polypeptide 2 and emerin.", J. Biol. Chem, Vol. 275, pp.48404847.

Lusk, C.P., Blobel, G. and King, M.C. (2007), "Highway to the inner nuclear membrane: rules for the road", Nat Rev Mol Cell Biol, Vol. 8 No. 5, pp. 414-420.

Macara, I.G. (2001), "Transport into and out of the nucleus", Microbiol Mol Biol Rev., Vol. 65 No. 4, pp. 570-594.

Maimon, T., Elad, N., Dahan, I. and Medalia, O. (2012), "The human nuclear pore complex as revealed by cryo-electron tomography", Structure, Vol. 20 No. 6, pp. 998-1006.

Malik, A.R., Urbanska, M., Macias, M., Skalecka, A. and Jaworski, J. (2013), "Beyond control of protein translation: What we have learned about the non-canonical regulation and function of mammalian target of rapamycin (mTOR)", Biochim Biophys Acta, Vol. 1834 No. 7, pp. 1434-1448.

Malik, P., Korfali, N., Srsen, V., Lazou, V., Batrakou, D.G., Zuleger, N., Kavanagh, D.M., Wilkie, G.S., Goldberg, M.W. and Schirmer, E.C. (2010), "Cell-specific and lamin-dependent targeting of novel transmembrane proteins in the nuclear envelope", Cell Mol Life Sci, Vol. 67 No. 8, pp. 1353-1369.

Manilal, S. (1996), "The Emery-Dreifuss muscular dystrophy protein, emerin, is a nuclear membrane protein", Hum Mol Genet, Vol. 5 No. 6, pp. 801-808.

Manilal, S. (1999), "Distribution of emerin and lamins in the heart and implications for EmeryDreifuss muscular dystrophy", Hum Mol Genet, Vol. 8 No. 2, pp. 353-359.

Manilal, S., Nguyen, T.M., Sewry, C.A. and Morris, G.E. (1996), "The Emery-Dreifuss muscular dystrophy protein, emerin, is a nuclear membrane protein", Hum Mol Genet, Vol. 5 No. 6, pp. 801-808. 
Manilal, S., Recan, D., Sewry, C.A., Hoeltzenbein, M., Llense, S., Leturcq, F., Deburgrave, N., Barbot, J., Man, N., Muntoni, F., Wehnert, M., Kaplan, J. and Morris, G.E. (1998), "Mutations in Emery-Dreifuss muscular dystrophy and their effects on emerin protein expression", Hum Mol Genet, Vol. 7 No. 5, pp. 855-864.

Mariappan, M., Li, X., Stefanovic, S., Sharma, A., Mateja, A., Keenan, R.J. and Hegde, R.S. (2010), "A ribosome-associating factor chaperones tail-anchored membrane proteins", Nature, Vol. 466 No. 7310, pp. 1120-1124.

Markiewicz, E., Tilgner, K., Barker, N., van de Wetering, M., Clevers, H., Dorobek, M., Hausmanowa-Petrusewicz, I., Ramaekers, F.C., Broers, J.L., Blankesteijn, W.M., Salpingidou, G., Wilson, R.G., Ellis, J.A. and Hutchison, C.J. (2006), "The inner nuclear membrane protein emerin regulates beta-catenin activity by restricting its accumulation in the nucleus", EMBO J, Vol. 25 No. 14, pp. 3275-3285.

Marrero-Rodriguez, D., Taniguchi-Ponciano, K., Lopez-Sleman, J., Romero-Morelos, P., MendozaRodriguez, M., Garcia, I., Huerta-Padilla, V., Mantilla, A., Duarte, A., Pina, P., RodriguezEsquivel, M., Lopez-Romero, R., Parrazal-Romero, J., Tobias-Alonso, S., Jimenez-Vega, F., Alvarez-Blanco, M. and Salcedo, M. (2015), "Thymopoietin Beta and Gamma Isoforms as a Potential Diagnostic Molecular Marker for Breast Cancer: Preliminary Data", Pathol Oncol Res, Vol. 21 No. 4, pp. 1045-1050.

Mateja, A., Paduch, M., Chang, H.-Y., Szydlowska, A., Kossiakoff, A.A., Hegde, R.S. and Keenan, R.J. (2015), "Protein targeting. Structure of the Get3 targeting factor in complex with its membrane protein cargo", Science, Vol. 347 No. 6226, pp. 1152-1155.

Mateja, A., Szlachcic, A., Downing, M.E., Dobosz, M., Mariappan, M., Hegde, R.S. and Keenan, R.J. (2009), "The structural basis of tail-anchored membrane protein recognition by Get3", Nature, Vol. 461 No. 7262, pp. 361-366.

Maul, G.G. and Deaven, L. (1977), "Quantitative determination of nuclear pore complexes in cycling cells with differing DNA content", J Cell Biol, Vol. 73 No. 3, pp. 748-760.

Meinema, A.C., Laba, J.K., Hapsari, R.A., Otten, R., Mulder, Frans A A, Kralt, A., van den Bogaart, Geert, Lusk, C.P., Poolman, B. and Veenhoff, L.M. (2011), "Long unfolded linkers facilitate membrane protein import through the nuclear pore complex", Science, Vol. 333 No. 6038, pp. 90-93.

Mejat, A. and Misteli, T. (2010), "LINC complexes in health and disease", Nucleus, Vol. 1 No. 1, pp. 40-52.

Melchior, F., Paschal, B., Evans, J. and Gerace, L. (1993), "Inhibition of nuclear protein import by nonhydrolyzable analogues of GTP and identification of the small GTPase Ran/TC4 as an essential transport factor", JCell Biol, Vol. 123 No. 6, pp. 1649-1659.

Melchior, F., Sweet, D.J. and Gerace, L. (1995), "Analysis of Ran/TC4 function in nuclear protein import", Methods Enzymol, Vol. 257, pp. 279-291.

Mingot, J.M., Kostka, S., Kraft, R., Hartmann, E. and Gorlich, D. (2001), "Importin 13: a novel mediator of nuclear import and export", EMBO J, Vol. 20 No. 14, pp. 3685-3694.

Moiseeva, O., Bourdeau, V., Vernier, M., Dabauvalle, M. and Ferbeyre, G. (2011), "Retinoblastoma-independent regulation of cell proliferation and senescence by the p53-p21 axis in lamin A/C-depleted cells", Aging Cell, Vol. 10 No. 5, pp. 789-797. 
Mora, M., Cartegni, L., Di Blasi, C., Barresi, R., Bione, S., Di Raffaele, B.M., Morandi, L., Merlini, L., Nigro, V., Politano, L., Donati, M.A., Cornelio, F., Cobianchi, F. and Toniolo, D. (1997), “Xlinked Emery-Dreifuss muscular dystrophy can be diagnosed from skin biopsy or blood sample", Ann Neurol, Vol. 42 No. 2, pp. 249-253.

Morla, A.O., Draetta, G., Beach, D. and Wang, J.Y. (1989), "Reversible tyrosine phosphorylation of cdc2: Dephosphorylation accompanies activation during entry into mitosis", Cell, Vol. 58 No. 1, pp. 193-203.

Muhlhausser, P., Muller, E.C., Otto, A. and Kutay, U. (2001), "Multiple pathways contribute to nuclear import of core histones", EMBO Rep, Vol. 2 No. 8, pp. 690-696.

Nagano, A., Koga, R., Ogawa, M., Kurano, Y., Kawada, J., Okada, R., Hayashi, Y.K., Tsukahara, T. and Arahata, K. (1996), "Emerin deficiency at the nuclear membrane in patients with EmeryDreifuss muscular dystrophy", Nat Genet, Vol. 12 No. 3, pp. 254-259.

Neumann, N., Lundin, D. and Poole, A.M. (2010), "Comparative genomic evidence for a complete nuclear pore complex in the last eukaryotic common ancestor", PLoS One, Vol. 5 No. 10, e13241.

Nigro, V., Bruni, P., Ciccodicola, A., Politano, L., Nigro, G., Piluso, G., Cappa, V., Covone, A.E., Romeo, G. and D'Urso, M. (1995), "SSCP detection of novel mutations in patients with EmeryDreifuss muscular dystrophy: definition of a small C-terminal region required for emerin function", Hum Mol Genet, Vol. 4 No. 10, pp. 2003-2004.

Nili, E., Cojocaru, G.S., Kalma, Y., Ginsberg, D., Copeland, N.G., Gilbert, D.J., Jenkins, N.A., Berger, R., Shaklai, S., Amariglio, N., Brok-Simoni, F., Simon, A.J. and Rechavi, G. (2001), "Nuclear membrane protein LAP2beta mediates transcriptional repression alone and together with its binding partner GCL (germ-cell-less)", J Cell Sci, Vol. 114 No. 18, pp. 3297-3307.

Nishikawa, M., Nojima, S., Akiyama, T., Sankawa, U. and Inoue, K. (1984), "Interaction of digitonin and its analogs with membrane cholesterol", J Biochem, Vol. 96 No. 4, pp. 12311239.

Nishimura, A.L., Mitne-Neto, M., Silva, H.C., Richieri-Costa, A., Middleton, S., Cascio, D., Kok, F., Oliveira, JR, Gillingwater, T., Webb, J., Skehel, P. and Zatz, M. (2004), "A mutation in the vesicle-trafficking protein VAPB causes late-onset spinal muscular atrophy and amyotrophic lateral sclerosis", Am J Hum Genet, Vol. 75 No. 5, pp. 822-831.

Ognibene, A., Sabatelli, P., Petrini, S., Squarzoni, S., Riccio, M., Santi, S., Villanova, M., Palmeri, S., Merlini, L. and Maraldi, N.M. (1999), "Nuclear changes in a case of X-linked Emery-Dreifuss muscular dystrophy", Muscle Nerve, Vol. 22 No. 7, pp. 864-869.

Ohba, T., Schirmer, E.C., Nishimoto, T. and Gerace, L. (2004), "Energy- and temperaturedependent transport of integral proteins to the inner nuclear membrane via the nuclear pore", J Cell Biol, Vol. 167 No. 6, pp. 1051-1062.

Ohsumi, T., Ichimura, T., Sugano, H., Omata, S., Isobe, T. and Kuwano, R. (1993), "Ribosomebinding protein p34 is a member of the leucine-rich-repeat-protein superfamily", Biochem J, Vol. 294 No. 2, pp. 465-472.

Okreglak, V. and Walter, P. (2014), "The conserved AAA-ATPase Msp1 confers organelle specificity to tail-anchored proteins", Proc Natl Acad Sci USA, Vol. 111 No. 22, pp. 80198024. 
Östlund, C., Ellenberg, J., Hallberg, E., Lippincott-Schwartz, J. and Worman, H.J. (1999), "Intracellular trafficking of emerin, the Emery-Dreifuss muscular dystrophy protein", J Cell Sci, Vol. 112 No. 11, pp. 1709-1719.

Östlund, C., Sullivan, T., Stewart, C.L. and Worman, H.J. (2006), "Dependence of diffusional mobility of integral inner nuclear membrane proteins on A-type lamins", Biochemistry, Vol. 45 No. 5, pp. 1374-1382.

Ott, C.M. and Lingappa, V.R. (2002), "Integral membrane protein biosynthesis: why topology is hard to predict", J Cell Sci, Vol. 115 No. 10, pp. 2003-2009.

Ott, M., Tascher, G., Hassdenteufel, S., Zimmermann, R., Haas, J. and Bailer, S.M. (2011), "Functional characterization of the essential tail anchor of the herpes simplex virus type 1 nuclear egress protein pUL34", J Gen Virol, Vol. 92 No. 12, pp. 2734-2745.

Paine, P.L., Moore, L.C. and Horowitz, S.B. (1975), "Nuclear envelope permeability", Nature, Vol. 254 No. 5496, pp. 109-114.

Pallai, R., Bhaskar, A., Barnett-Bernodat, N., Gallo-Ebert, C., Pusey, M., Nickels, J.T., JR and Rice, L.M. (2015), "Leucine-rich repeat-containing protein 59 mediates nuclear import of cancerous inhibitor of PP2A in prostate cancer cells", Tumour Biol, Vol. 36 No. 8, pp. 63836390.

Pante, N. and Kann, M. (2002), "Nuclear pore complex is able to transport macromolecules with diameters of about 39 nm", Mol Biol Cell, Vol. 13 No. 2, pp. 425-434.

Park, E. and Rapoport, T.A. (2012), "Mechanisms of Sec61/SecY-mediated protein translocation across membranes", Annu Rev Biophys, Vol. 41, pp. 21-40.

Pemberton, L.F. and Paschal, B.M. (2005), "Mechanisms of receptor-mediated nuclear import and nuclear export", Traffic, Vol. 6 No. 3, pp. 187-198.

Pfaff, J., Rivera, M.J., Jamieson, C., Rajanala, K., Vilardi, F., Schwappach, B. and Kehlenbach, R.H. (2016), "Emery-Dreifuss muscular dystrophy mutations impair TRC40-mediated targeting of emerin to the inner nuclear membrane", J Cell Sci, Vol. 129 No. 3, pp. 502-516.

Pollard, V.W., Michael, W.M., Nakielny, S., Siomi, M.C., Wang, F. and Dreyfuss, G. (1996), "A novel receptor-mediated nuclear protein import pathway", Cell, Vol. 86 No. 6, pp. 985-994.

Powell, L. and Burke, B. (1990), "Internuclear exchange of an inner nuclear membrane protein (p55) in heterokaryons: in vivo evidence for the interaction of p55 with the nuclear lamina", J Cell Biol, Vol. 111 No. 6 Pt 1, pp. 2225-2234.

Powis, K., Schrul, B., Tienson, H., Gostimskaya, I., Breker, M., High, S., Schuldiner, M., Jakob, U. and Schwappach, B. (2013), "Get3 is a holdase chaperone and moves to deposition sites for aggregated proteins when membrane targeting is blocked", J Cell Sci, Vol. 126 No. 2, pp. 473483.

Ptak, C., Aitchison, J.D. and Wozniak, R.W. (2014), "The multifunctional nuclear pore complex: a platform for controlling gene expression", Curr Opin Cell Biol, Vol. 28, pp. 46-53.

Putyrski, M. and Schultz, C. (2012), "Protein translocation as a tool: The current rapamycin story", FEBS Lett, Vol. 586 No. 15, pp. 2097-2105.

Rabu, C., Schmid, V., Schwappach, B. and High, S. (2009), "Biogenesis of tail-anchored proteins: the beginning for the end?", J Cell Sci, Vol. 122 No. 20, pp. 3605-3612.

Rabu, C., Wipf, P., Brodsky, J.L. and High, S. (2008), "A precursor-specific role for Hsp40/Hsc70 during tail-anchored protein integration at the endoplasmic reticulum", J Biol Chem, Vol. 283 No. 41, pp. 27504-27513. 
Radu, A., Blobel, G. and Moore, M.S. (1995), "Identification of a protein complex that is required for nuclear protein import and mediates docking of import substrate to distinct nucleoporins", Proc Natl Acad Sci USA, Vol. 92 No. 5, pp. 1769-1773.

Rapoport, T.A. (1992), "Transport of proteins across the endoplasmic reticulum membrane", Science, Vol. 258 No. 5084, pp. 931-936.

Reichelt, R., Holzenburg, A., Buhle, E.L., JR, Jarnik, M., Engel, A. and Aebi, U. (1990), "Correlation between structure and mass distribution of the nuclear pore complex and of distinct pore complex components", J Cell Biol, Vol. 110 No. 4, pp. 883-894.

Ribbeck, K. and Görlich, D. (2001), "Kinetic analysis of translocation through nuclear pore complexes”, EMBO J, Vol. 20 No. 6, pp. 1320-1330.

Ribbeck, K. and Görlich, D. (2002), "The permeability barrier of nuclear pore complexes appears to operate via hydrophobic exclusion", EMBO J, Vol. 21 No. 11, pp. 2664-2671.

Robinson, M.S., Sahlender, D.A. and Foster, S.D. (2010), "Rapid inactivation of proteins by rapamycin-induced rerouting to mitochondria", Dev Cell, Vol. 18 No. 2, pp. 324-331.

Rout, M.P., Aitchison, J.D., Suprapto, A., Hjertaas, K., Zhao, Y. and Chait, B.T. (2000), "The yeast nuclear pore complex: composition, architecture, and transport mechanism", J Cell Biol, Vol. 148 No. 4, pp. 635-651.

Rout, M.P., Aitchison, J.D., Magnasco, M.O. and Chait, B.T. (2003), "Virtual gating and nuclear transport: the hole picture", Trends Cell Biol, Vol. 13 No. 12, pp. 622-628.

Sakaki, M., Koike, H., Takahashi, N., Sasagawa, N., Tomioka, S., Arahata, K. and Ishiura, S. (2001), "Interaction between emerin and nuclear lamins", J Biochem, Vol. 129 No. 2, pp. 321-327.

Saksena, S., Summers, M.D., Burks, J.K., Johnson, A.E. and Braunagel, S.C. (2006), "Importinalpha-16 is a translocon-associated protein involved in sorting membrane proteins to the nuclear envelope", Nat Struct Mol Biol, Vol. 13 No. 6, pp. 500-508.

Salpingidou, G., Smertenko, A., Hausmanowa-Petrucewicz, I., Hussey, P.J. and Hutchison, C.J. (2007), "A novel role for the nuclear membrane protein emerin in association of the centrosome to the outer nuclear membrane", J Cell Biol, Vol. 178 No. 6, pp. 897-904.

Sasahira, T., Kurihara, M., Nakashima, C., Kirita, T. and Kuniyasu, H. (2016), "LEM domain containing 1 promotes oral squamous cell carcinoma invasion and endothelial transmigration", Br J Cancer, Vol. 115 No. 1, pp. 52-58.

Schirmer, E.C., Florens, L., Guan, T., Yates, J.R.3. and Gerace, L. (2003), "Nuclear membrane proteins with potential disease links found by subtractive proteomics", Science, Vol. 301 No. 5638, pp. 1380-1382.

Schirmer, E.C. and Gerace, L. (2005), "The nuclear membrane proteome: extending the envelope", Trends Biochem Sci, Vol. 30 No. 10, pp. 551-558.

Schmidt, H.B. and Görlich, D. (2016), "Transport Selectivity of Nuclear Pores, Phase Separation, and Membraneless Organelles", Trends Biochem Sci, Vol. 41 No. 1, pp. 46-61.

Schmitt, I. and Gerace, L. (2001), "In vitro analysis of nuclear transport mediated by the Cterminal shuttle domain of Tap", J Biol Chem, Vol. 276 No. 45, pp. 42355-42363.

Schuldiner, M., Metz, J., Schmid, V., Denic, V., Rakwalska, M., Schmitt, H.D., Schwappach, B. and Weissman, J.S. (2008), "The GET complex mediates insertion of tail-anchored proteins into the ER membrane", Cell, Vol. 134 No. 4, pp. 634-645. 
Schulz, O., Pieper, C., Clever, M., Pfaff, J., Ruhlandt, A., Kehlenbach, R.H., Wouters, F.S., Grosshans, J., Bunt, G. and Enderlein, J. (2013), "Resolution doubling in fluorescence microscopy with confocal spinning-disk image scanning microscopy", Proc Natl Acad Sci USA, Vol. 110 No. 52, pp. 21000-21005.

Senior, A. and Gerace, L. (1988), "Integral membrane proteins specific to the inner nuclear membrane and associated with the nuclear lamina", J Cell Biol, Vol. 1076 No. 1, pp. 20292036.

Shao, S. and Hegde, R.S. (2011), "Membrane protein insertion at the endoplasmic reticulum", Annu Rev Cell Dev Biol, Vol. 27, pp. 25-56.

Shumaker, D.K., Lee, K.K., Tanhehco, Y.C., Craigie, R. and Wilson, K.L. (2001), "LAP2 binds to BAF.DNA complexes: requirement for the LEM domain and modulation by variable regions", EMBO J, Vol. 20 No. 7, pp. 1754-1764.

Singh, K., Sun, S. and Vezina, C. (1979), "Rapamycin (AY-22,989), a new antifungal antibiotic. IV. Mechanism of action", J Antibiot, Vol. 32 No. 6, pp. 630-645.

Skehel, P.A., Fabian-Fine, R. and Kandel, E.R. (2000), "Mouse VAP33 is associated with the endoplasmic reticulum and microtubules", Proc Natl Acad Sci USA, Vol. 97 No. 3, pp. 11011106.

Skjerpen, C.S., Wesche, J. and Olsnes, S. (2002), "Identification of Ribosome-binding Protein p34 as an Intracellular Protein That Binds Acidic Fibroblast Growth Factor", J Bioll Chem, Vol. 277 No. 26, pp. 23864-23871.

Smith, S. and Blobel, G. (1993), "The first membrane spanning region of the lamin B receptor is sufficient for sorting to the inner nuclear membrane", J Cell Biol, Vol. 120 No. 3, pp. 631-637.

Snider, C., Jayasinghe, S., Hristova, K. and White, S.H. (2009), "MPEx: a tool for exploring membrane proteins", Protein Sci, Vol. 18 No. 12, pp. 2624-2628.

Soullam, B. and Worman, H.J. (1993), "The amino-terminal domain of the lamin B receptor is a nuclear envelope targeting signal", J Cell Biol, Vol. 120 No. 5, pp. 1093-1100.

Soussan, L., Burakov, D., Daniels, M.P., Toister-Achituv, M., Porat, A., Yarden, Y. and Elazar, Z. (1999), "ERG30, a VAP-33-related protein, functions in protein transport mediated by COPI vesicles", J Cell Biol, Vol. 146 No. 2, pp. 301-311.

Speese, S.D., Ashley, J., Jokhi, V., Nunnari, J., Barria, R., Li, Y., Ataman, B., Koon, A., Chang, Y.-T., Li, Q., Moore, M.J. and Budnik, V. (2012), "Nuclear envelope budding enables large ribonucleoprotein particle export during synaptic Wnt signaling", Cell, Vol. 149 No. 4, pp. 832-846.

Stan, R., McLaughlin, M.M., Cafferkey, R., Johnson, R.K., Rosenberg, M. and Livi, G.P. (1994), "Interaction between FKBP12-rapamycin and TOR involves a conserved serine residue", J Biol Chem, Vol. 269 No. 51, pp. 32027-32030.

Stefanovic, S. and Hegde, R.S. (2007), "Identification of a Targeting Factor for Posttranslational Membrane Protein Insertion into the ER", Cell, Vol. 128 No. 6, pp. 1147-1159.

Stoica, R., Vos, K.J. de, Paillusson, S., Mueller, S., Sancho, R.M., Lau, K.-F., Vizcay-Barrena, G., Lin, W.-L., Xu, Y.-F., Lewis, J., Dickson, D.W., Petrucelli, L., Mitchell, J.C., Shaw, C.E. and Miller, C.C.J. (2014), "ER-mitochondria associations are regulated by the VAPB-PTPIP51 interaction and are disrupted by ALS/FTD-associated TDP-43", Nat Commun, Vol. 5, p. 3996. 
Sullivan, T., Escalante-Alcalde, D., Bhatt, H., Anver, M., Bhat, N., Nagashima, K., Stewart, C.L. and Burke, B. (1999), "Loss of A-type lamin expression compromises nuclear envelope integrity leading to muscular dystrophy", J Cell Biol, Vol. 147 No. 5, pp. 913-920.

Takahashi, N. (1977), "Demonstration of a new amidase acting on glycopeptides", Biochem Biophys Res Commun, Vol. 76 No. 4, pp. 1194-1201.

Tanemura, M., Ohmura, Y., Deguchi, T., Machida, T., Tsukamoto, R., Wada, H., Kobayashi, S., Marubashi, S., Eguchi, H., Ito, T., Nagano, H., Mori, M. and Doki, Y. (2012), "Rapamycin causes upregulation of autophagy and impairs islets function both in vitro and in vivo", Am J Transplant, Vol. 12 No. 1, pp. 102-114.

Tarpey, P.S., Smith, R., Pleasance, E., Whibley, A., Edkins, S., Hardy, C., O'Meara, S., Latimer, C., Dicks, E., Menzies, A., Stephens, P., Blow, M., Greenman, C., Xue, Y., Tyler-Smith, C., Thompson, D., Gray, K., Andrews, J., Barthorpe, S., Buck, G., Cole, J., Dunmore, R., Jones, D., Maddison, M., Mironenko, T., Turner, R., Turrell, K., Varian, J., West, S., Widaa, S., Wray, P., Teague, J., Butler, A., Jenkinson, A., Jia, M., Richardson, D., Shepherd, R., Wooster, R., Tejada, M.I., Martinez, F., Carvill, G., Goliath, R., Brouwer, A.P. de, van Bokhoven, H., van Esch, H., Chelly, J., Raynaud, M., Ropers, H.H., Abidi, F.E., Srivastava, A.K., Cox, J., Luo, Y., Mallya, U., Moon, J., Parnau, J., Mohammed, S., Tolmie, J.L., Shoubridge, C., Corbett, M., Gardner, A., Haan, E., Rujirabanjerd, S., Shaw, M., Vandeleur, L., Fullston, T., Easton, D.F., Boyle, J., Partington, M., Hackett, A., Field, M., Skinner, C., Stevenson, R.E., Bobrow, M., Turner, G., Schwartz, C.E., Gecz, J., Raymond, F.L., Futreal, P.A. and Stratton (2009), "A systematic, largescale resequencing screen of X-chromosome coding exons in mental retardation", Nat Genet, Vol. 41 No. 5, pp. 535-543.

Tatematsu, M., Funami, K., Ishii, N., Seya, T., Obuse, C. and Matsumoto, M. (2015), "LRRC59 Regulates Trafficking of Nucleic Acid-Sensing TLRs from the Endoplasmic Reticulum via Association with UNC93B1", J Immunol, Vol. 195 No. 10, pp. 4933-4942.

Terry, L.J. and Wente, S.R. (2009), "Flexible Gates: Dynamic Topologies and Functions for FG Nucleoporins in Nucleocytoplasmic Transport", Eukaryot Cell, Vol. 8 No. 12, pp. 1814-1827.

Theerthagiri, G., Eisenhardt, N., Schwarz, H. and Antonin, W. (2010), "The nucleoporin Nup188 controls passage of membrane proteins across the nuclear pore complex", J Cell Biol, Vol. 189 No. 7, pp. 1129-1142.

Tonks, N.K., Diltz, C.D. and Fischer, E.H. (1988a), "Characterization of the major protein-tyrosinephosphatases of human placenta", J Biol Chem, Vol. 263 No. 14, pp. 6731-6737.

Tonks, N.K., Diltz, C.D. and Fischer, E.H. (1988b), "Purification of the major protein-tyrosinephosphatases of human placenta", J Biol Chem, Vol. 263 No. 14, pp. 6722-6730.

Torrisi, Lotti, L.V., Pavan, A., Migliaccio, G. and Bonatti, S. (1987), "Free diffusion to and from the inner nuclear membrane of newly synthesized plasma membrane glycoproteins", J Cell Biol, Vol. 104 No. 3, pp. 733-737.

Tran, D., Chalhoub, A., Schooley, A., Zhang, W. and Ngsee, J.K. (2012), "A mutation in VAPB that causes amyotrophic lateral sclerosis also causes a nuclear envelope defect", J Cell Sci, Vol. 125 No. 12, pp. 2831-2836.

Tsuchiya, Y., Hase, A., Ogawa, M., Yorifuji, H. and Arahata, K. (1999), "Distinct regions specify the nuclear membrane targeting of emerin, the responsible protein for Emery-Dreifuss muscular dystrophy", Eur J Biochem, Vol. 259 No. 3, pp. 859-865. 
Tsuda, H., Han, S.M., Yang, Y., Tong, C., Lin, Y.Q., Mohan, K., Haueter, C., Zoghbi, A., Harati, Y., Kwan, J., Miller, M.A. and Bellen, H.J. (2008), "The amyotrophic lateral sclerosis 8 protein VAPB is cleaved, secreted, and acts as a ligand for Eph receptors", Cell, Vol. 133 No. 6, pp. 963-977.

Turgay, Y., Ungricht, R., Rothballer, A., Kiss, A., Csucs, G., Horvath, P. and Kutay, U. (2010), “A classical NLS and the SUN domain contribute to the targeting of SUN2 to the inner nuclear membrane", EMBO J, Vol. 29 No. 14, pp. 2262-2275.

Tuschl, T. (2001), "RNA interference and small interfering RNAs", Chembiochem, Vol. 2 No. 4, pp. 239-245.

Ungricht, R., Klann, M., Horvath, P. and Kutay, U. (2015), "Diffusion and retention are major determinants of protein targeting to the inner nuclear membrane", J Cell Biol, Vol. 209 No. 5, pp. 687-704.

Ungricht, R. and Kutay, U. (2015), "Establishment of NE asymmetry-targeting of membrane proteins to the inner nuclear membrane", Curr Opin Cell Biol, Vol. 34, pp. 135-141.

van Geest, M. and Lolkema, J.S. (2000), "Membrane Topology and Insertion of Membrane Proteins. Search for Topogenic Signals", Microbiol Mol Biol Rev, Vol. 64 No. 1, pp. 13-33.

Vaughan, A., Alvarez-Reyes, M., Bridger, J.M., Broers, J.L., Ramaekers, F.C., Wehnert, M., Morris, G.E., Whitfield, W.G. and Hutchison, C.J. (2001), "Both emerin and lamin C depend on lamin A for localization at the nuclear envelope", J Cell Sci, Vol. 114 Pt 14, pp. 2577-2590.

Vilardi, F., Lorenz, H. and Dobberstein, B. (2011), "WRB is the receptor for TRC40/Asna1mediated insertion of tail-anchored proteins into the ER membrane", J Cell Sci, Vol. 124 Pt 8, pp. 1301-1307.

Vilardi, F., Stephan, M., Clancy, A., Janshoff, A. and Schwappach, B. (2014), "WRB and CAML are necessary and sufficient to mediate tail-anchored protein targeting to the ER membrane", PLoS One, Vol. 9 No. 1, pp. e85033.

Vohanka, S., Vytopil, M., Bednarik, J., Lukas, Z., Kadanka, Z., Schildberger, J., Ricotti, R., Bione, S. and Toniolo, D. (2001), "A mutation in the X-linked Emery-Dreifuss muscular dystrophy gene in a patient affected with conduction cardiomyopathy", Neuromuscul Disord, Vol. 11 No. 4, pp. 411-413.

Voth, W., Schick, M., Gates, S., Li, S., Vilardi, F., Gostimskaya, I., Southworth, Schwappach, B. and Jakob, U. (2014), "The protein targeting factor Get3 functions as ATP-independent chaperone under oxidative stress conditions", Mol Cell, Vol. 56 No. 1, pp. 116-127.

Walter, P. and Blobel, G. (1980), "Purification of a membrane-associated protein complex required for protein translocation across the endoplasmic reticulum", Proc Natl Acad Sci USA, Vol. 77 No. 12, pp. 7112-7116.

Walter, P. and Blobel, G. (1982), "Signal recognition particle contains a 7S RNA essential for protein translocation across the endoplasmic reticulum", Nature, Vol. 299 No. 5885, pp. 691698.

Walter, P. and Blobel, G. (1983), "Preparation of microsomal membranes for cotranslational protein translocation", Methods Enzymol, Vol. 96, pp. 84-93.

Walton, K.M. and Dixon, J.E. (1993), "Protein tyrosine phosphatases", Annu Rev Biochem, Vol. 62, pp. 101-120.

Weis, K. (2007), "The Nuclear Pore Complex: Oily Spaghetti or Gummy Bear?”, Cell, Vol. 130 No. 3, pp. 405-407. 
Wickner, W. and Schekman, R. (2005), "Protein translocation across biological membranes", Science, Vol. 310 No. 5753, pp. 1452-1456.

Wilkie, G.S., Korfali, N., Swanson, S.K., Malik, P., Srsen, V., Batrakou, D.G., Las Heras, J. de, Zuleger, N., Kerr, A.R.W., Florens, L. and Schirmer, E.C. (2011), "Several novel nuclear envelope transmembrane proteins identified in skeletal muscle have cytoskeletal associations", Mol Cell Proteomics, Vol. 10 No. 1, M110.003129.

Worman, H.J., Evans, C.D. and Blobel, G. (1990), "The lamin B receptor of the nuclear envelope inner membrane: a polytopic protein with eight potential transmembrane domains", J Cell Biol, Vol. 111 No. 4, pp. 1535-1542.

Wu, W., Lin, F. and Worman, H.J. (2002), "Intracellular trafficking of MAN1, an integral protein of the nuclear envelope inner membrane", J Cell Sci, Vol. 115 Pt 7, pp. 1361-1371.

Yabal, M., Brambillasca, S., Soffientini, P., Pedrazzini, E., Borgese, N. and Makarow, M. (2003), "Translocation of the $C$ terminus of a tail-anchored protein across the endoplasmic reticulum membrane in yeast mutants defective in signal peptide-driven translocation", J Biol Chem, Vol. 278 No. 5, pp. 3489-3496.

Yamada, J., Phillips, J.L., Patel, S., Goldfien, G., Calestagne-Morelli, A., Huang, H., Reza, R., Acheson, J., Krishnan, V.V., Newsam, S., Gopinathan, A., Lau, E.Y., Colvin, M.E., Uversky, V.N. and Rexach, M.F. (2010), "A bimodal distribution of two distinct categories of intrinsically disordered structures with separate functions in FG nucleoporins", Mol Cell Proteomics, Vol. 9 No. 10, pp. 2205-2224.

Yamagata, A., Mimura, H., Sato, Y., Yamashita, M., Yoshikawa, A. and Fukai, S. (2009), "Structural insight into the membrane insertion of tail-anchored proteins by Get3", Genes Cells, Vol. 15 No. 1, pp. 29-41.

Yamamoto, Y. and Sakisaka, T. (2012), "Molecular machinery for insertion of tail-anchored membrane proteins into the endoplasmic reticulum membrane in mammalian cells", Mol Cell, Vol. 48 No. 3, pp. 387-397.

Yamamoto, Y. and Sakisaka, T. (2015), "The emerging role of calcium-modulating cyclophilin ligand in posttranslational insertion of tail-anchored proteins into the endoplasmic reticulum membrane", J Biochem, Vol. 157 No.6, pp.419-429.

Yang, L., Guan, T. and Gerace, L. (1997), "Integral Membrane Proteins of the Nuclear Envelope Are Dispersed throughout the Endoplasmic Reticulum during Mitosis", J Cell Biol, Vol. 137 No. 6, pp. 1199-1210.

Yates, JR, Bagshaw, J., Aksmanovic, V.M., Coomber, E., McMahon, R., Whittaker, J.L., Morrison, P.J., Kendrick-Jones, J. and Ellis, J.A. (1999), "Genotype-phenotype analysis in X-linked EmeryDreifuss muscular dystrophy and identification of a missense mutation associated with a milder phenotype", Neuromuscul Disord, Vol. 9 No. 3, pp. 159-165.

Yip, S.-C., Cotteret, S. and Chernoff, J. (2012), "Sumoylated protein tyrosine phosphatase 1B localizes to the inner nuclear membrane and regulates the tyrosine phosphorylation of emerin", J Cell Sci, Vol. 125 No. 2, pp. 310-316.

Yorifuji, H., Tadano, Y., Tsuchiya, Y., Ogawa, M., Goto, K., Umetani, A., Asaka, Y. and Arahata, K. (1997), "Emerin, deficiency of which causes Emery-Dreifuss muscular dystrophy, is localized at the inner nuclear membrane", Neurogenetics, Vol. 1 No. 2, pp. 135-140. 
Yuki, D., Lin, Y.M., Fujii, Y., Nakamura, Y. and Furukawa, Y. (2004), "Isolation of LEM domaincontaining 1, a novel testis-specific gene expressed in colorectal cancers", Oncol Rep, Vol. 12 No. 2, pp. 275-280.

Zhang, X., Shu, L., Hosoi, H., Murti, K.G. and Houghton, P.J. (2002), "Predominant Nuclear Localization of Mammalian Target of Rapamycin in Normal and Malignant Cells in Culture", J Biol Chem, Vol. 277 No. 31, pp. 28127-28134.

Zhen, Y., Sorensen, V., Skjerpen, C.S., Haugsten, E.M., Jin, Y., Walchli, S., Olsnes, S. and Wiedlocha, A. (2012), "Nuclear import of exogenous FGF1 requires the ER-protein LRRC59 and the importins Kpnalpha1 and Kpnbeta1", Traffic, Vol. 13 No. 5, pp. 650-664.

Zheng, R., Ghirlando, R., Lee, M.S., Mizuuchi, K., Krause, M. and Craigie, R. (2000), "Barrier-toautointegration factor (BAF) bridges DNA in a discrete, higher-order nucleoprotein complex", Proc Natl Acad Sci USA, Vol. 97 No. 16, pp. 8997-9002.

Zheng, X.-F., Fiorentino, D., Chen, J., Crabtree, G.R. and Schreiber, S.L. (1995), "TOR kinase domains are required for two distinct functions, only one of which is inhibited by rapamycin", Cell, Vol. 82 No. 1, pp. 121-130.

Zuleger, N., Kelly, D.A., Richardson, A.C., Kerr, A.R.W., Goldberg, M.W., Goryachev, A.B. and Schirmer, E.C. (2011), "System analysis shows distinct mechanisms and common principles of nuclear envelope protein dynamics", J Cell Biol, Vol. 193 No. 1, pp. 109-123.

Zuleger, N., Kerr, A.R.W. and Schirmer, E.C. (2012), "Many mechanisms, one entrance: membrane protein translocation into the nucleus", Cell Mol Life Sci, Vol. 69 No. 13, pp. 22052216.

Zwerger, M., Kolb, T., Richter, K., Karakesisoglou, I. and Herrmann, H. (2010), "Induction of a massive endoplasmic reticulum and perinuclear space expansion by expression of lamin $B$ receptor mutants and the related sterol reductases TM7SF2 and DHCR7", Mol Biol Cell, Vol. 21 No. 2, pp. 354-368. 


\section{LIST OF FIGURES}

Figure 1: The nucleus and the nuclear envelope composition. 9

Figure 2: Schematic view on the nuclear pore complex architecture. 11

Figure 3: Nucleocytoplasmic transport. 12

Figure 4: Scheme of co-translational membrane protein insertion. 15

Figure 5: Post-translational membrane insertion of TA-proteins via the TRC40-pathway. 17

Figure 6: Schematic view of prominent INM-proteins and their unique features. 19

Figure 7: Major models of membrane protein trafficking to the INM. 21

Figure 8: Endogenous localization of investigated putative TA-INM-proteins in HeLa P4 cells. 60

Figure 9: Localization of overexpressed putative INM-proteins. 61

Figure 10: Membrane integration of in vitro translated HZZ-emerin-opsin and VAPB-ops28. 63

Figure 11: Membrane integration of in vitro translated HZZ-VAPB-op (A), VAB-ops28 (B), LAP2 $\beta$ (C) and PTP1B (D) into RMs.

Figure 12: Co-expression and -purification of emerin in a complex with TRC40. 67

Figure 13: Schematic view of a protein complex consisting of HZZ-emerin-op and MBP-TRC40. 69

Figure 14: HZZ-emerin-opsin is able to insert into rough microsomal membranes. 69

Figure 15: Membrane insertion of HZZ-emerin-opsin into semi-permeabilized cell membranes. 70

Figure 16: Deglycosylation of HZZ-emerin-opsin integrated into semi-permeabilized cells. 71

Figure 17: Membrane insertion of HZZ-emerin-op with immunodepleted reticulocyte lysate. 72

Figure 18: In vitro transport assay to the NE using different emerin variants. 76

Figure 19: In vitro transport assay to the ER and NE using VAPB, PTP1B expressed in a complex with TRC40. 78

Figure 20: Subcellular localization of membrane proteins. 80

Figure 21: Schematic view of the rapamycin-based dimerization of FKBP12- and FRB-containing-proteins at the INM.

Figure 22: Time course of rapamycin-induced change in localization of the GFP-FKBP12 reporter in emerin transfected cells.

Figure 23: Emerin, LAP2 $\beta$, PTP1B, LRRC59, VAPB and LEMD1 can be found at the INM using an in vitro- kinetics rapamycin assay.

Figure 24: In vitro rapamycin-based INM-localization assay for emerin and WRB.

Figure 25: A short, soluble FKBP12 reporter is functional in other compartments than the nucleus and can bind the ERfraction of mCherry-FRB-emerin.

Figure 26: Alternative FKBP12-GFP reporter proteins are functional in the rapamycin-assay. 93

Figure 27: Downregulation of TRC40 and WRB affect the localization of emerin at the NE. 94

Figure 28: Emerin protein levels are unaffected by downregulation of TRC40 or WRB. 95

Figure 29: Emerin interacts with TRC40-myc in situ. 97

Figure 30: Schematic view of emerin mutant variants and the predicted hydrophobicity of their C-terminal region. 99

Figure 31: Co-purification of emerin mutants with TRC40. 100

Figure 32: Emerin mutants show a reduced an altered membrane integration competence. 101

Figure 33: Subcellular localization of emerin mutants. 104

Supplementary figure 1: U2OS cells stably expressing the EGFP2-GST-NLS-FKBP12 reporter were selected. 148

Supplementary figure 2: In vivo rapamycin-based INM-localization assay for emerin in U2OS cells stably expressing the long version of the GFP-FKBP12 reporter. 148

Supplementary figure 3: Lamin A/C knockdown affects the localization of emerin at the INM. 149

Supplementary figure 4: Characterization of a custom specific anti-emerin antibody (Genosphere) by immunofluorescence. 


\section{LIST OF TABLES}

Table 1: Integral membrane proteins studied throughout this work including properties of their transmembrane domain (TMD).

Table 2: Overview of expression constructs used for rapamycin assays

Table 3: List of the investigated integral membrane proteins including characteristics and possible functions.

Table 4: Semi-quantitative analysis of the rapamycin-effect on EGFP2-GST-NLS-FKBP12. 


\section{APPENDIX}

\section{Development of a stable cell line expressing the FKBP12-reporter protein}

As a rapamycin-based INM-localization assay was established in this work and transient transfection of both, the FKBP12- and FRB-containing reporter proteins were performed. In prospect of a more homogenous FKBP12-expression level than observed by transient transfection methods, stable expressing FKBP12 cells were selected. As described in section 2.2.3.7, U2OS cells were chosen due to their large and flat cell morphology and selected for cells expressing the EGFP2-GST-NLS-FKBP12 reporter, which is needed to detect an INM-localization with the rapamycin assay. After selection of several G418-resistant U2OS cells colonies, a mixture of cells expressing the FKBP12 was obtained. To enrich the GFP-positive and G418-resistant fraction of cells, the cells have been sorted at the Cell Sorting Facility of the UMG. The initial fraction of GFP-positive cells (expressing the FKBP12 reporter) was shown to be about $20 \%$ of the cell mixture (Supplementary figure 1, A). The localization of the sorted U2OS cell population was analyzed by using fluorescence microscopy. In U2OS cells, the GFP-reporter seemed to localize predominantly to the nucleus (Supplementary figure $1, \mathrm{~B}$ ).

Furthermore, these stable cell lines were used in an in vivo rapamycin assay and the model protein emerin was transfected in the U2OS stable "cell line". Upon rapamycin addition, the reporter localized to the nuclear periphery (Supplementary figure 2), but overall compared to experiments in HeLa cells, it was only very little FKBP12 reporter localizing to the INM. Another drawback was that a considerable fraction of the reporter localized to the cytoplasm and therefore could provide false information about an INM localization. The U2OS cells, even though their flat morphology, which is very useful for microscopy- based approaches, do not provide a very efficient system for being used in future rapamycin assays compared to HeLa cells. 
A

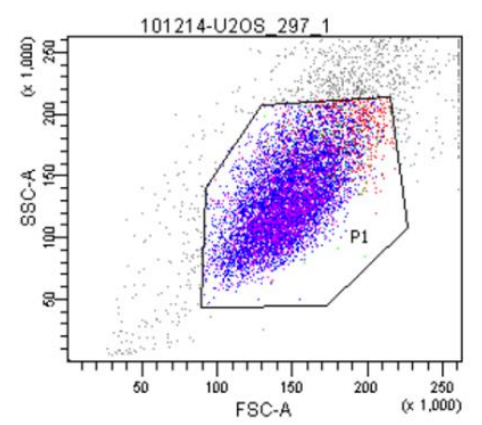

Cellsorting UMG

Tube: U20S_297_1
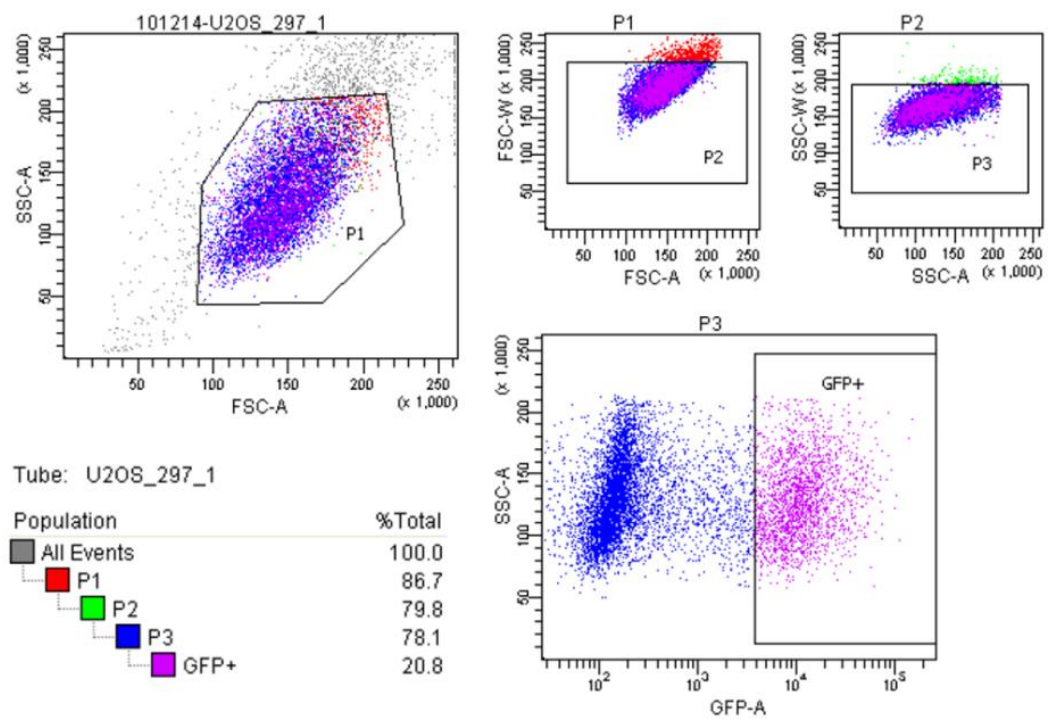

B

U2OS- stably expressing EGFP 2 -GST-NLS-FKBP12

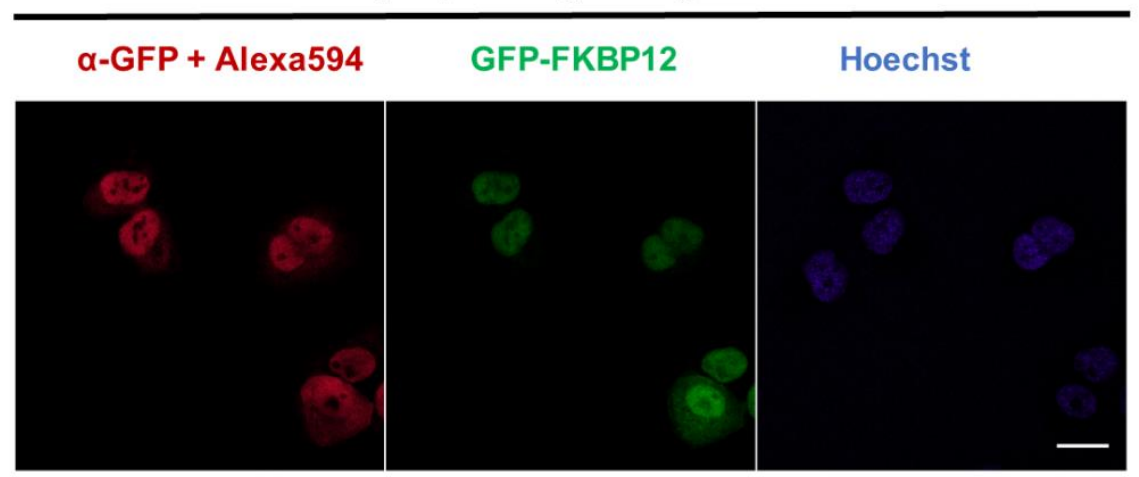

Supplementary figure 1: U2OS cells stably expressing the EGFP2-GST-NLS-FKBP12 reporter were selected. U2OS cells stable cells were obtained by the protocol described in section 2.2.3.7. They were selected with the antibiotic gentamycin (G418) and the cells were sorted for GFP-positive and G418 resistant cells. (A) Analysis of the U2OS cell sorting process. (B) Localization of the GFP-FKBP12 reporter inside U2OS cells. Scale bar: $20 \mu \mathrm{m}$.

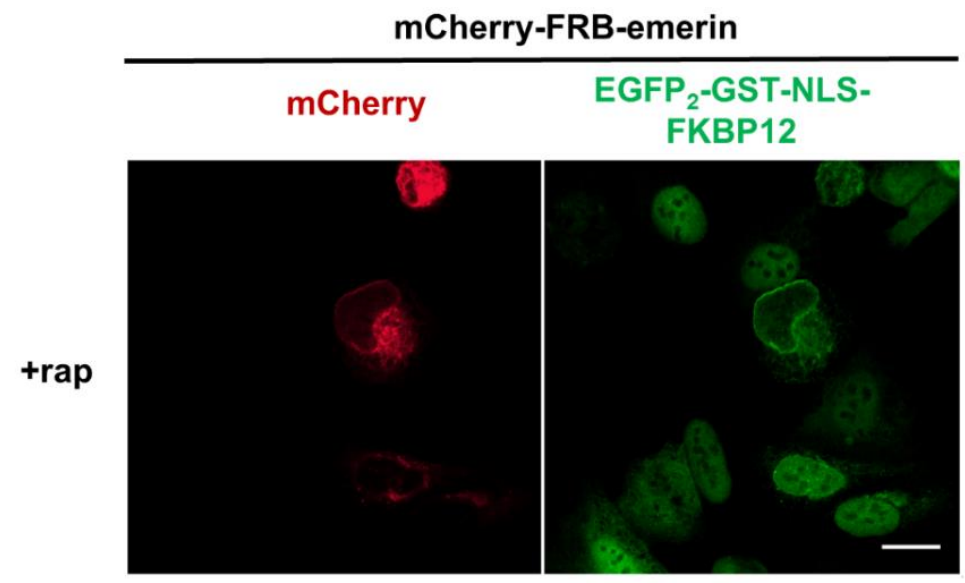

Supplementary figure 2: In vivo rapamycin-based INM-localization assay for emerin in U2OS cells stably expressing the long version of the GFP-FKBP12 reporter. U2OS cells were transfected with mCherry-FRBemerin and the rapamycin assay was carried out for 10 minutes at $37^{\circ} \mathrm{C}$ in living cells. Images reflecting the situation after rapamycin treatment (+rap). Scale bar: $20 \mu \mathrm{m}$. 


\section{Knockdown of lamin $\mathrm{A} / \mathrm{C}$ influences the localization of emerin at the NE}

Besides studying the effect of the TRC40-machinery on targeting on emerin to the NE, as well the effect of lamin A/C downregulation was studied by RNAi. Lamin A/C was reported to be one of the interaction partners of emerin at the INM and supposed to have a role in retention of emerin at the INM (Vaughan et al., 2001). This knockdown experiment confirmed a downregulation of emerin at the nuclear envelope (Supplementary figure 3). At the same time LAP2 $\beta$ did not show any change in localization, which was to be expected because only an interaction of LAP2 with lamin B has been shown (Furukawa, 1998) and was used as a control for this experiment. This result supports that the enrichment of emerin at the INM most likely requires a retention process at the INM.

\section{Lamin A/C RNAi}

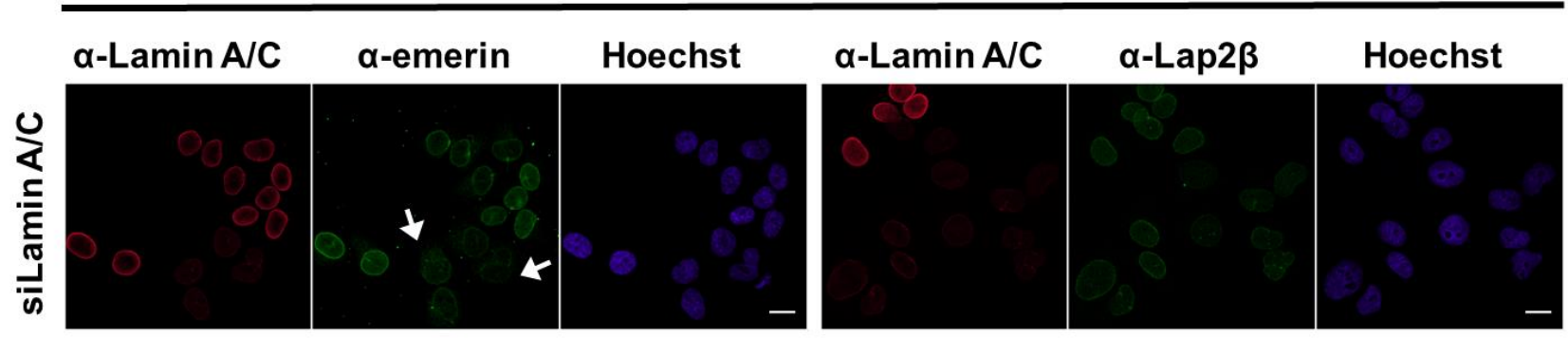

Supplementary figure 3: Lamin A/C knockdown affects the localization of emerin at the INM. HeLa P4 cells were transfected with an siLaminA/C $(20 \mathrm{nM})$ with Lipofectamine for $48 \mathrm{~h}$. Endogenous protein localization of laminA/C, emerin and LAP $2 \beta$ was detected immunostaining with the respective antibodies. 


\section{Characterization of a custom-specific emerin antibody}
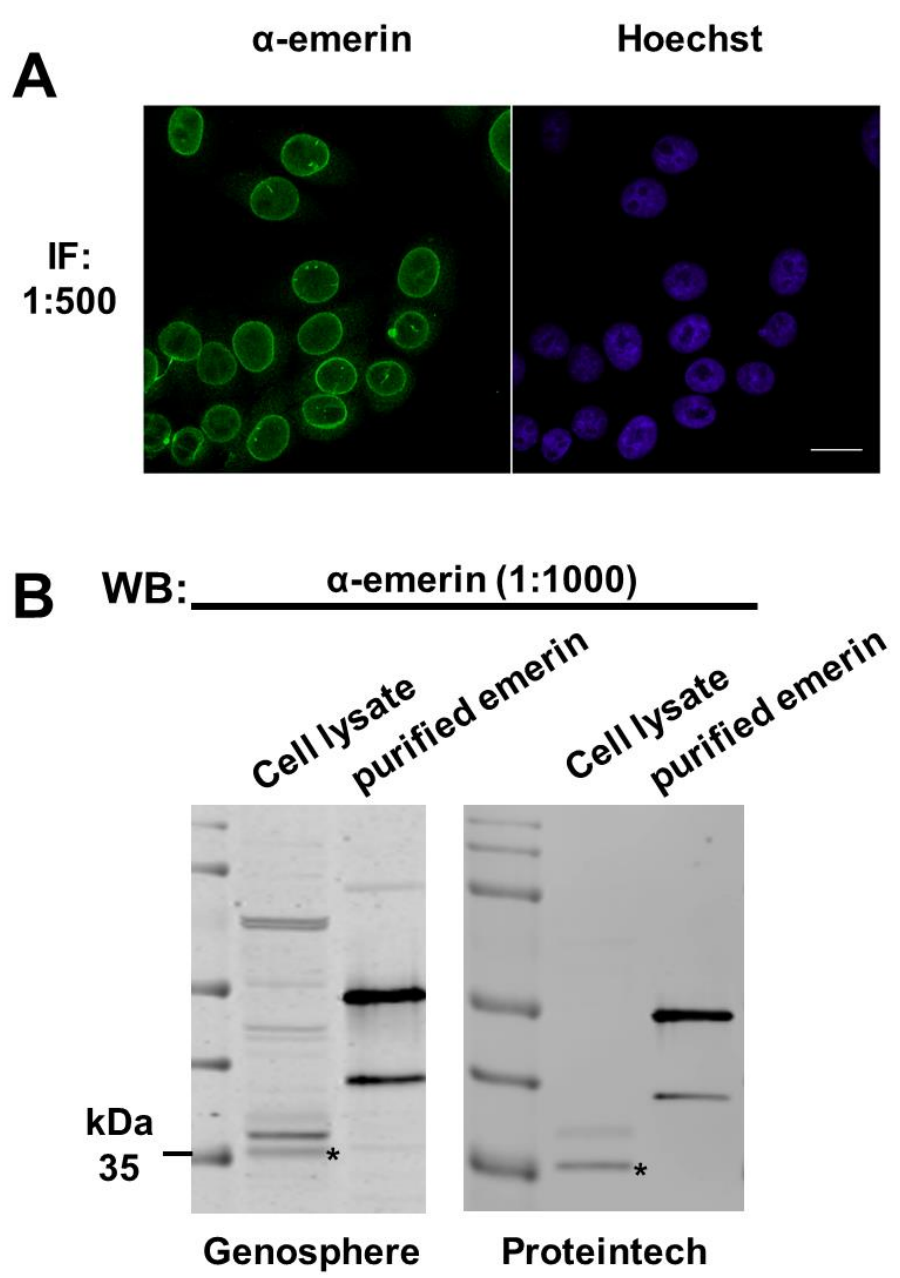

Supplementary figure 4: Characterization of a custom specific anti-emerin antibody (Genosphere) by immunofluorescence. A custom-specific emerin antibody was ordered from Genosphere Biotechnologies. As a peptide for immunization following sequence was used: ' $N$ '-CFPDADAFHHQVHDDDLL (18 aa). (A) Endogenous emerin can be detected in HeLa P4 cells using the anti-emerin antibody at a dilution of 1:500. Emerin localizes at the nuclear envelope, which is displayed by a prominent nuclear rim. (B) The emerin antibody is compared to a well-established anti-emerin antibody from Proteintech for specificity on protein level. Both antibodies recognize endogenous as well as recombinant emerin protein, but for the Genosphere antibody additional bands appear. The band which is indicated by an asterisk is recognized by both antibodies at the predicted size ( $35 \mathrm{kDa})$, at which emerin can usually be detected by western blotting. For immunoblotting the anti-emerin antibody detects compared to the Proteintech antibody many unspecific bands therefore further testing and optimization of the immunofluorescence protocol might be required for the Genosphere anti-emerin antibody. 


\section{Abbreviations}

${ }^{\circ} \mathrm{C}$

$\alpha$

$\beta$

$\Delta$

$\Delta \mathrm{G}$

$\mu \mathrm{m}$

$\mu \mathrm{M}$

aa

Arg

ATP

bp

BSA

Ca-P

CAML

C-terminus

DNA

DMEM

dNTPs

DTT

E. coli

EDMD

ER

EtOH

FG

FRB

FKBP12 degree Celsius

alpha (in case of antibodies: anti-)

beta

delta

change in Gibbs free energy (free enthalpy)

micrometer

micromolar

amino acid

arginine

adenosine-5-triphosphate

base pair

bovine serum albumin

Calciu phosphate

Calcium modulating ligand

carboxy

Desoxyribonucleic acid

Dulbecco's modified eagles medium

2'-desoxynucleoside-5'-triphosphate

dithiothreitol

Escherichia coli

Emery-Dreifuss muscular dystrophy

endoplasmic reticulum

ethanol

Phenylalanine glycin

FKBP12-rapamycin-binding

FK-506 binding proteins $12 \mathrm{kDa}$ 
FS

g

G418

GAPDH

GFP

Gln

GST

GTP

h

H1

HA

His

HRP

IF

INM

$\mathrm{kDa}$

LAP2 $\beta$

LBR

LEM

LEMD1

Leu

LRRC59

$\mathrm{mA}$

$\mathrm{mg}$

$\mathrm{ml}$

$\mathrm{mM}$

M9

MBP

mock
Frame shift

G-force

gentamycin

Glyceraldehyde 3-phosphate dehydrogenase

green fluorescent protein

glutamine

Glutathione S-transferase

Guanosine triphosphate

hour

Histone1

hemagglutinin

histidine tag

horseraddish peroxidase

immunofluorescence

inner nuclear membrane

kilo dalton

Lamina-associated polypeptide 2 beta

Lamin B receptor

LAP2-emerin-MAN1 (domain)

LEMD domain containing 1

leucine

Leucine rich repeat containing 59

milliampere

milligram

milliliter

millimolar

non-classical nuclear localization signal

maltose binding protein

control treated sample 


\begin{tabular}{|c|c|}
\hline $\min$ & minute \\
\hline $\mathrm{N}$-terminus & amino terminus \\
\hline NE & nuclear envelope \\
\hline NLS & nuclear localization signal \\
\hline $\mathrm{nm}$ & nanometer \\
\hline $\mathrm{nM}$ & nanomolar \\
\hline NPC & nuclear pore complex \\
\hline nt & non targeting \\
\hline Nup & nucleoporin \\
\hline ONM & outer nuclear membrane \\
\hline opsin & opsin-tag (13 aa) \\
\hline PAGE & polyacrylamide gel electrophoresis \\
\hline Phe & phenylalanine \\
\hline PNGase F & Peptide:N-Glycosidase F \\
\hline Pro & proline \\
\hline PCR & polymerase chain reaction \\
\hline PBS & Phosphate buffered saline \\
\hline PLA & proximity ligation assay \\
\hline Pro & proline \\
\hline PTP1B & Protein tyrosine phosphatase $1 \mathrm{~B}$ \\
\hline RM & rough microsomes \\
\hline RNA & Ribonucleic acid \\
\hline RNAi & RNA interference \\
\hline rpm & rotations per minute \\
\hline s & Second(s) \\
\hline SDS & sodium dodecyl sulphate \\
\hline SiRNA & small interfering RNA \\
\hline SRP & Signal recognition particel \\
\hline SPCS & semi-permeabilized cells \\
\hline
\end{tabular}


tev

TA

Thr

TMD

TRC40

UV

V

$\mathrm{v} / \mathrm{v}$

VAPB

Val

$w / v$

WB

WRB

WT

ZZ
TEV-protease cleavage site

tail-anchored

threonine

transmembrane domain

transmembrane domain recognition complex of $40 \mathrm{kDa}$ (ASNA1)

ultraviolet

volt

volume per volume

VAMP-associated protein B

valine

weight per volume

western blot

tryptophan rich basic protein

wild type

protein tag (S. aureus protein A IgG-binding domain) 


\section{Acknowledgements}

Ein sehr großes "DANKESCHÖN" an all die Menschen, die mich im Laufe der letzten Jahre unterstützt haben und an mich geglaubt haben.

Ganz zu Beginn möchte ich mich bei Prof. Dr. Ralph Kehlenbach für die Bereitstellung des sehr spannenden und interessanten Projekts bedanken und im Zuge dessen auch für die vielen produktiven Ideen und Ansätze, welche für das Projekt von entscheidender Bedeutung waren. Für die Möglichkeit im Rahmen meiner Arbeit an Kursen, Seminaren und Konferenzen teilgenommen haben zu dürfen bin ich sehr dankbar.

Ebenso gilt ein besonderer Dank Prof. Blanche Schwappach, die im Zuge meines Thesis Committees und auch durch die bestehende Kooperation bedeutenden Einfluss auf das Projekt hatte.

Des Weiteren bedanke ich mich bei Prof. Mikael Simons als ein Mitglied meines Thesis Committees für seine konstruktiven Vorschläge.

Natürlich nicht zu vergessen sind die spannenden Diskussionen und auch der Austausch von Ideen mit Fabio Vilardi und Jhon Rivera, danke für eine so konstruktive, problemlose und tolle Kooperation!

Im Anschluss daran möchte ich mich auch ganz herzlich bei all meinen Kollegen für ein stetig gutes und produktives „Wohlfühl-Arbeitsklima“ bedanken, ich weiß dieses sehr zu schätzen, denn lange Versuchstage wären allein nur halb so schön gewesen. Im Zuge dessen, danke an Imke Baade, Sarah Port, Christiane Spillner, Cara Jamieson, Cornelia Frohnert, Marina Blensky, Marrett Müller, Kalpana Rajanala und Sarina Norell.

Vielen Dank an Annegret Nath, die mich in der Anfangsphase mit vollem Einsatz unterstützt hat und bereit war ihr fundiertes Wissen mit mir zu teilen und mit mir zusammen über den verschwundenen „emerin-rim“ im Importassay gegrübelt hat.

Ebenso einen großen Dank an Christiane Spillner, die jegliche Sorgen und Probleme ihrer Kollegen erkennt und immer ein paar aufmunternde Worte für mich bereit hatte! Danke für deine Unterstützung in der letzten Phase meiner Arbeit.

Des Weiteren gilt mein Dank der ganzen Abteilung im Hinblick auf ein sehr gutes Miteinander und eine große Hilfsbereitschaft unter den einzelnen Arbeitsgruppen.

Nicht zu vergessen gilt der größte Dank natürlich meinen Freunden und vor allem meiner Familie, gleichwohl ob zwei- oder vierbeinig. Danke, dass ihr mich ununterbrochen und in jeglicher Hinsicht unterstützt habt!!!

Schließlich, vielen Dank allen Korrekturlesern! 


\section{Curriculum Vitae}

\section{Personal data}

Name

Janine Pfaff

Date of Birth

June 5th, 1987

Place of Birth

Bad Hersfeld, Germany

\section{Education}

10/2012 - 09/2016: $\quad$ PhD student at Georg-August Universiät Göttingen

GGNB doctoral program "Molecular Biology of Cells"

Doctoral studies in the laboratory of Prof. Ralph Kehlenbach

10/2006 - 06/2012: $\quad$ Graduate and Undergraduate Studies:

Biology (Diploma) at Goethe-University in Frankfurt/ Main

Major subjects: Genetics, Cell-and Developmental Biology, Forensic Biology

Secondary subject: Virology

07/2010 - 08/2010:

Summer School at University of California Irvine

Subjects: Virology, Brain and Dysfunction

09/2011 - 06/2012:

Diploma thesis in the Department of "Experimental Neurology" (Group of Prof. Dr. Georg Auburger) at Goethe-University Medical School, Frankfurt/Main entitled

"Charakterisierung des mitochondrialen Teilungsfaktors MTP18"

09/2003 - 06/2006: Abitur - Gymnasiale Oberstufe at Modellschule Obersberg in Bad Hersfeld

09/1997-07/2003: $\quad$ Gymansialzweig at Gesamtschule Geistal in Bad Hersfeld

09/1993 - 07/1997: $\quad$ Basic school at Grundschule Friedlos/Ludwigsau

\section{Publications}

Pfaff, J. * , Rivera, M.J. *, Jamieson, C., Rajanala, K., Vilardi, F., Schwappach, B. and Kehlenbach, R.H. (2016), "Emery-Dreifuss muscular dystrophy mutations impair TRC40-mediated targeting of emerin to the inner nuclear membrane", J Cell Sci, Vol. 129 No. 3, pp. 502-516.

Schulz, O., Pieper, C., Clever, M., Pfaff, J., Ruhlandt, A., Kehlenbach, R.H., Wouters, F.S., Grosshans, J., Bunt, G. and Enderlein, J. (2013), "Resolution doubling in fluorescence microscopy with confocal spinning-disk image scanning microscopy", Proc Natl Acad Sci USA, Vol. 110 No. 52, pp. 21000-21005.

\footnotetext{
* The authors contributed equally to this work.
} 